\title{
Cardiac and Mitochondrial Impacts of Acute Pulmonary Xenobiotic Exposure
}

Cody Edward Nichols

Follow this and additional works at: https://researchrepository.wvu.edu/etd

\section{Recommended Citation}

Nichols, Cody Edward, "Cardiac and Mitochondrial Impacts of Acute Pulmonary Xenobiotic Exposure" (2016). Graduate Theses, Dissertations, and Problem Reports. 6313.

https://researchrepository.wvu.edu/etd/6313

This Dissertation is protected by copyright and/or related rights. It has been brought to you by the The Research Repository @ WVU with permission from the rights-holder(s). You are free to use this Dissertation in any way that is permitted by the copyright and related rights legislation that applies to your use. For other uses you must obtain permission from the rights-holder(s) directly, unless additional rights are indicated by a Creative Commons license in the record and/ or on the work itself. This Dissertation has been accepted for inclusion in WVU Graduate Theses, Dissertations, and Problem Reports collection by an authorized administrator of The Research Repository @ WVU.

For more information, please contact researchrepository@mail.wvu.edu. 


\title{
Cardiac and Mitochondrial Impacts of Acute Pulmonary Xenobiotic Exposure
}

\author{
Cody Edward Nichols \\ Dissertation submitted to the \\ School of Medicine \\ at West Virginia University
}

in partial fulfillment of the requirements for the degree of

Doctor of Philosophy

in

Exercise Physiology

John M. Hollander, Ph.D., Chair

Stephen E. Alway, Ph.D.

Aaron Erdely, Ph.D.

Timothy R. Nurkiewicz, Ph.D.

I. Mark Olfert, Ph.D.

Emidio E. Pistilli, Ph.D.

Division of Exercise Physiology

Morgantown, West Virginia

2016

Key Words: Particulate, Particulate Matter, Engineered Nanomaterial, Mitochondria, Oxidative Stress, Antioxidant 


\section{ABSTRACT \\ Cardiac and Mitochondrial Impacts of Acute Pulmonary Xenobiotic Exposure}

\section{Cody Edward Nichols}

With every breath, we breathe in foreign materials, xenobiotic particles, which once inside these particles can interact with our tissues and influence the systems within. Airborne xenobiotic particles classically refer to ambient particulate matter (PM), but with technological advancement and the flourishing of nanotechnology, engineered nanomaterials (ENMs) have become entwined in the definition. Because the term xenobiotic particles encompasses particles with a broad range of size, shapes and chemical composition, definition of the properties that induce toxicity can be difficult, yet crucial to understand and predicting which of these characteristics is capable of inducing toxicity. This concept is crucial as nanotechnology moves forward and continues to introduce particles with new, unique properties. Beginning to identify the health impacts of xenobiotic particles it is important to consider ambient air pollution and the solid fraction of this mixture, particulate matter (PM). PM itself is a non-uniform, composite particle containing particles ranging in size and chemical composition. Further, PM composition can vary throughout the US and has been shown to differentially affect cardiovascular susceptibilities and outcomes. Within the Appalachian region, coal is a multi-billion dollar industry and comes in two forms: underground and surface mining. Surface mining is growing throughout the region due to its less labor-intensive methods, which employs large machinery to remove the soil and rock from on top of mineral deposits. One form of surface mining utilizes explosives to remove this overburden, mountaintop removal mining (MTM). Even though the mining companies attempt to abate fugitive dust, the populations surrounding these mining operations have a higher incidence of chronic cardiovascular disease mortality rates. This suggests that the PM created by MTM ( $\left.\mathrm{PM}_{\mathrm{MTM}}\right)$ may induce cardiac stress leading to cardiovascular disease. Nanotechnology is rapidly growing into a multi-billion dollar industry and is already incorporated into consumer products including everything from sporting equipment and food storage to personal care products and biomedical applications. With the rapid growth of nanotechnology, the toxicological impact of the ENMs driving expansion cannot keep pace with the advancement. Nano-sized particles differ in their physicochemical properties as compared to their micron-sized counterparts and while these properties imbue them with the novel applications driving nanotechnology, they may also be driving toxicological impacts. ENMs are carefully and methodically produced in particles of varying size, shape and chemical composition to accomplish different consumer-based end-products. Multi-walled carbon nanotubes (MWCNT) are a rapidly growing ENM with uniquely strong and electrical properties making it useful in everything from sporting equipment to electronics. Titanium dioxide $\left(\right.$ nano- $\left.\mathrm{TiO}_{2}\right)$ is a relatively inert ENM widely used as a photocatalyst and pigment in paints and personal care products. Exposure to these materials has shown adverse pulmonary and cardiovascular effects but the cardiac functional impacts following exposure have not been well characterized. Further, the subcellular cardiac mechanisms impacted by xenobiotic exposure have not been well defined. The mitochondrion may be a target of xenobiotic exposure propagating toxicity. Within the cardiomyocyte, mitochondrial analyses are further complicated by the presence of spatially and biochemically distinct subpopulations of mitochondria: the subsarcolemmal (SSM) and interfibrillar (IFM) mitochondria. The SSM sit below the sarcolemma while the IFM reside within the contractile apparatus. The goal of the current studies was to investigate the cardiac and mitochondrial impacts following an acute pulmonary xenobiotic exposure. To complete this goal, we utilized pulmonary exposure techniques, state of the art echocardiographic assessment, and mitochondrial functional analyses following xenobiotic exposure. Following a pulmonary exposure to

$\mathrm{PM}_{\mathrm{MTM}}$, we identified a significant decrease in cardiac ejection fraction and fractional shortening 
concomitant with an increase in cardiac apoptosis. Investigation into the source of apoptotic signaling suggested the mitochondria as central into apoptotic initiation and leads to both SSM and IFM respiratory dysfunction. Similarly, when we exposed animals to MWCNT we identified cardiac dysfunction developing after SSM and IFM respiratory dysfunction. Yet, further investigation into the mitochondrial affects identified that the IFM produced more reactive oxygen species (ROS) following exposure. Finally, following exposure to nano- $\mathrm{TiO}_{2}$ cardiac diastolic dysfunction was observed indicative of restrictive filling during diastole. Following exposure, there was a significant decrease in mitochondrial respiratory function and an increase in ROS production and damage in the IFM. To attenuate the mitochondrial ROS production and damage leading to cardiac dysfunction, we utilized a novel transgenic animal overexpressing the antioxidant mitochondrial phospholipid hydroperoxide glutathione peroxidase (mPHGPx). MPHGPx has been previously shown to be efficient in protecting the inner mitochondrial membrane (IMM) from ROS damage and preserve the mitochondrion's function and proteome. The IMM is essential to protect as the complexes within the mitochondrial electron transport chain (ETC) reside within the locale. Overexpressing $\mathrm{MPHGPx}$ attenuated mitochondrial ROS production and damage as well as the cardiac diastolic dysfunction observed following exposure to nano- $\mathrm{TiO}_{2}$. These findings support that acute xenobiotic exposure can negatively impact cardiac and mitochondrial function. Overall, this data also suggests that the xenobiotic particles with different sizes and chemical composition can differentially impact these extrapulmonary effects. Further, these studies suggest that ROS plays a significant role in the induction of mitochondrial dysfunction following exposure to xenobiotic exposure. Better understanding the physicochemical properties that induce cardiac and mitochondrial dysfunction is vital in preserving and protecting the heart from xenobiotic induced damage. 


\section{ACKNOWLEDGEMENTS}

Thank you to everyone that has contributed to my education and graduate work throughout my tenure at WVU. I would like to first acknowledge my advisor and mentor, Dr. John Hollander. Thank you for your support and guidance that helped me to grow as a research scientist. The white board discussions and time spent crafting ideas into research that develops into complete scientific stories has helped to prepare me for an excitingly challenging career ahead. Additionally, I would like to thank Dr. Tim Nurkiewicz not only as a scientific advisor and supporter of my research and development scientifically, but also as an adoptive mentor at scientific meetings for introducing me to other scientists and helping me become more involved regionally and nationally within the Society of Toxicology. I would also like to thank Dr. Aaron Erdely for the extensive discussions and research support. Finally, I would like to thank my committee members Dr. Steve Alway, Dr. Mark Olfert and Dr. Emidio Pistilli for their guidance, critical input and suggestions pertaining to my research and academic progression.

Next I would like to thank my colleagues within WVU. First, I would like to thank the past and present members of the Hollander lab: Dr. Walter Baseler, Dr. Tara Croston, Dr. Rajaganapathi Jagannathan, Sara Lewis and Quincy Hathaway. Additionally, I would like to thank Janelle Sticker and Gerald Audet for their support and encouragement. I would like to also thank the members of the Nurkiewicz and Erdely laboratories for their assistance throughout my studies: Dr. Valerie Minarchick, Dr. Jinghai Yi, Carroll McBride, Dr. Travis Knuckles, Rebecca Salmen and Lindsey Bishop. In addition, I would like to thank the staff of the Graduate and Research Education office and the Division of Exercise Physiology for their support. To my longstanding scientific friend, Dr. Phoebe Stapleton, from undergraduate and on I have always known that I can come to you for advice or to simply escape, so thank you for everything. To Dr. Dharendra Thapa, even after you moved on you have been one of my greatest supporters and friends. Thank you for everything that you have taught me and helped me with throughout my time at WVU. Finally, I am forever grateful for my labmate, roommate, lab wife and friend Danielle Shepherd. We have spent more time together than most people can believe and constantly supported each other throughout this process. Graduate school would not have been the same without you, so thank goodness you were here.

I would like to thank my family for their unparalleled support. Without the support, belief and sacrifices of my mother and father, Kendel and Jo Nichols I would not have been able to get as far as I have. My sisters, Mallory Bilodeau and Kaitlyn Johnson, their husbands, and my niece and nephew, Addisyn and Myles, have helped to support me throughout my career and lighten the emotional burden in the tough times. Dr. Jennie Ivey (you'll always be Zambito to me) you are family to me and have helped scientifically and emotionally to help me throughout this process in every way possible. I would not have enjoyed graduate school nearly as much as I have if you were not in it. Finally, to my other half, Dr. Andrew Hazelwood, thank you for your support and understanding throughout this process. I would not have made it through this without you and your encouragement, support, and emotional strength. You have always been my rock and driving force and I am eternally grateful for you. 


\section{DEDICATION}

To My Parents: Kendel and Jo Nichols

Thank you for your unwavering support throughout my entire education. Even though it probably seemed like I was making up words when I talk about my work, you unconditionally supported me throughout this entire academic process. 


\section{LIST OF ABBREVIATIONS}

\begin{tabular}{|c|c|}
\hline ADP & Adenosine Diphosphate \\
\hline AIF & Apoptosis-inducing factor \\
\hline ANT & Adenine Nucleotide Transporter \\
\hline ATP & Adenosine Triphosphate \\
\hline APAF1 & Apoptotic protease activating factor 1 \\
\hline Cyto C & Cytochrome C \\
\hline cox & Cytochrome c Oxidase \\
\hline CypD & Cyclophilin D \\
\hline DNA & Deoxyribo Nucleic Acid \\
\hline EDV & End Diastolic Volume \\
\hline EF & Ejection Fraction \\
\hline EM & Electron Microscopy \\
\hline ENMs & Engineered Nanomaterials \\
\hline ETC & Electron Transport Chain \\
\hline ESV & End Systolic Volume \\
\hline FS & Fractional Shortening \\
\hline FSC & Forward Scatter \\
\hline GPx & Glutathione Peroxidase \\
\hline GSH & Glutathione reduced \\
\hline GSSG & Glutathione oxidized \\
\hline HAE & Hydroxyalkenals \\
\hline IFM & Interfibrillar Mitochondria \\
\hline IMM & Inner Mitochondrial Membrane \\
\hline LPO & Lipid Peroxidation \\
\hline LV & Left Ventricle \\
\hline
\end{tabular}




\begin{tabular}{|c|c|}
\hline MDA & Malondialdehyde \\
\hline MPTP & Mitochondrial Permeability Transition Pore \\
\hline MPHGPx & Mitochondrial Phospholipid Hydroperoxide Glutathione Peroxidase \\
\hline MTM & Mountaintop Removal Mining \\
\hline MWCNT & Multi-walled Carbon Nanotube \\
\hline $\mathrm{NADH}$ & Nicotinamide adenine dinucleotide \\
\hline OM & Outer Membrane \\
\hline OXPHOS & Oxidative Phosphorylation \\
\hline PAGE & Polyacyrlamide Gel Electrophoresis \\
\hline PBS & Phosphate Buffered Saline \\
\hline PM & Particulate Matter \\
\hline PM & Mountaintop Removal Mining Particulate Matter \\
\hline $\mathrm{PM}_{10}$ & Particulate Matter $\leq 10 \mu \mathrm{m}$ \\
\hline $\mathrm{PM}_{2.5}$ & Particulate Matter $\leq 2.5 \mu \mathrm{m}$ \\
\hline PHGPx & Phospholipid Hydroperoxide Glutathione Peroxidase \\
\hline Prdx & Peroxiredoxin \\
\hline ROS & Reactive Oxygen Species \\
\hline RT-PCR & Real Time Polymerase Chain Reaction \\
\hline $\mathrm{SeOH}$ & Selenium Hydroxide \\
\hline SOD & Superoxide Dismutase \\
\hline SSC & Side Scatter \\
\hline SSM & Subsarcolemmal Mitochondria \\
\hline $\mathrm{TiO}_{2}$ & Titanium Dioxide \\
\hline UFP & Ultrafine Particles \\
\hline US & United States of America \\
\hline VDAC & Voltage Dependent Anion Channel \\
\hline
\end{tabular}




\section{TABLE OF CONTENTS}

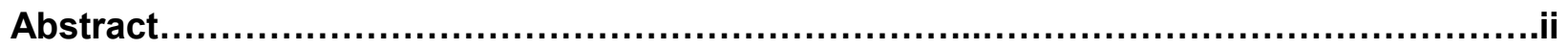

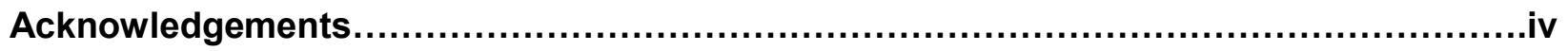

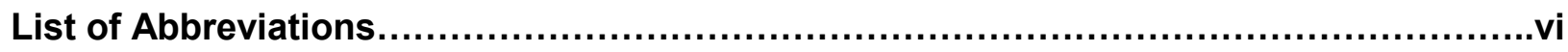

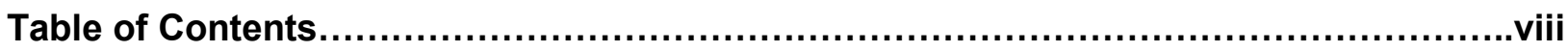

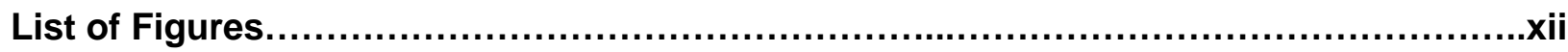

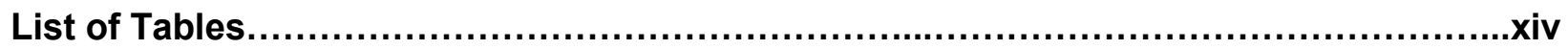

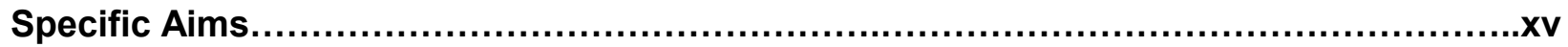

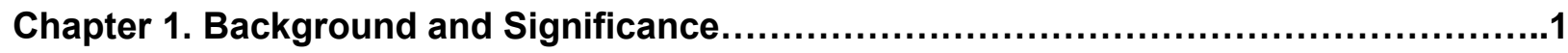

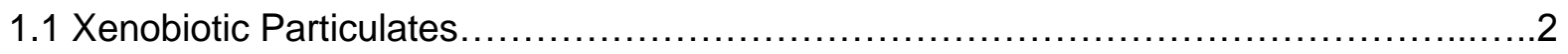

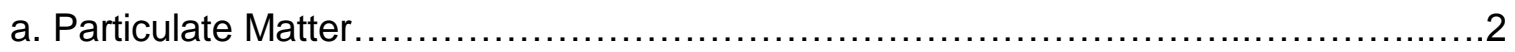

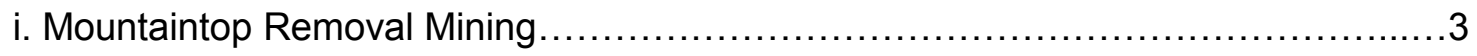

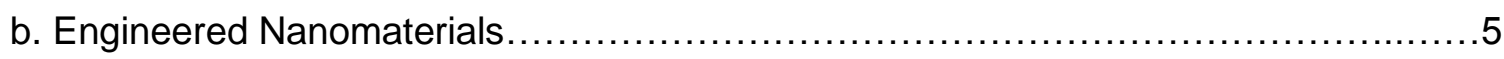

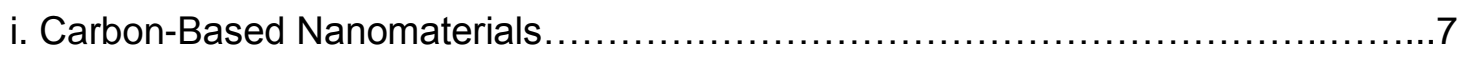

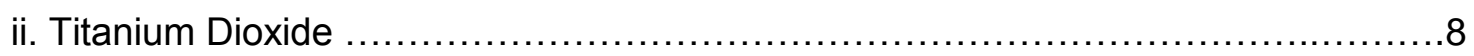

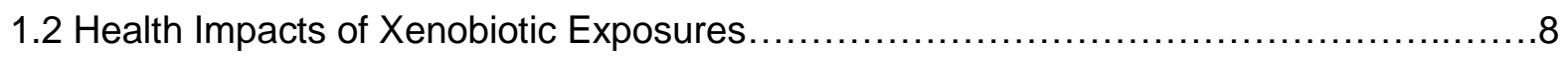

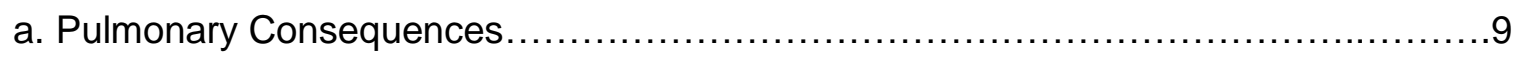

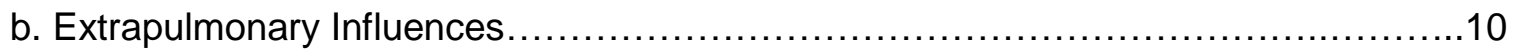

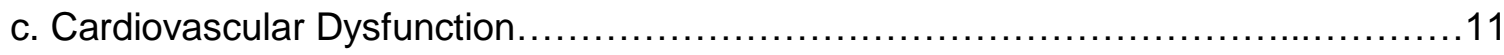

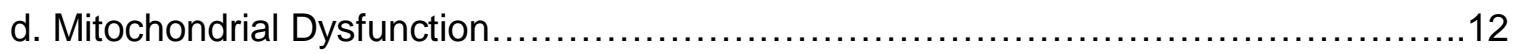

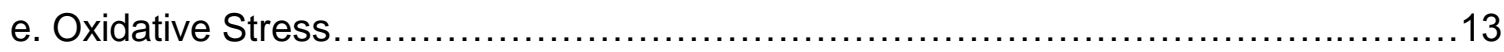

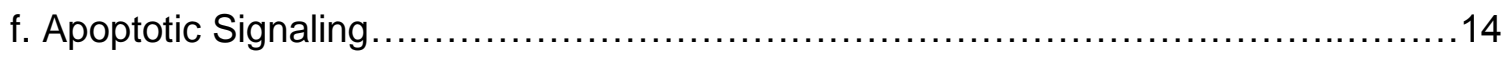

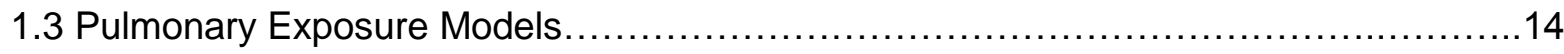

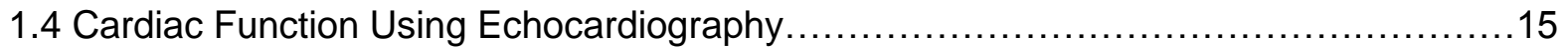




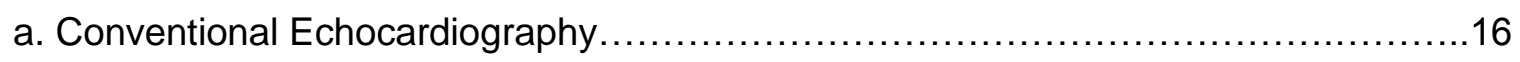

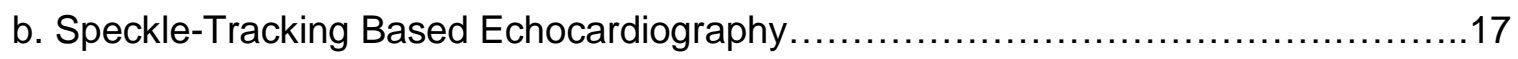

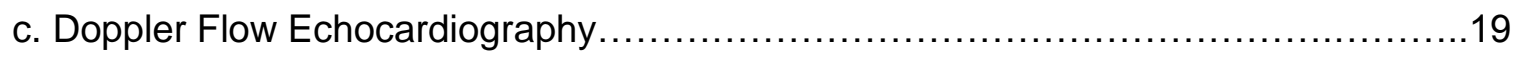

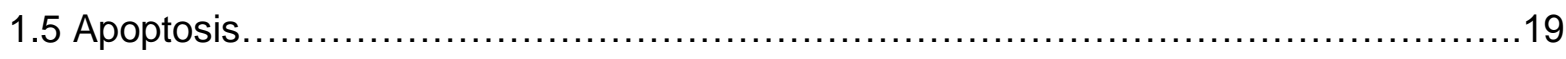

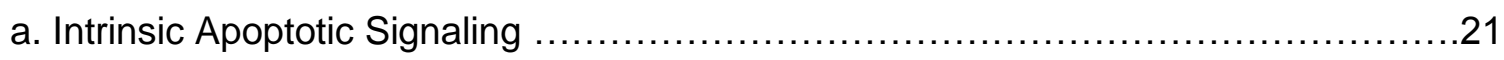

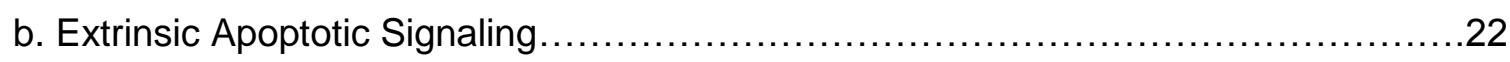

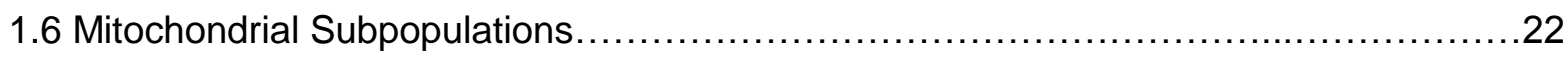

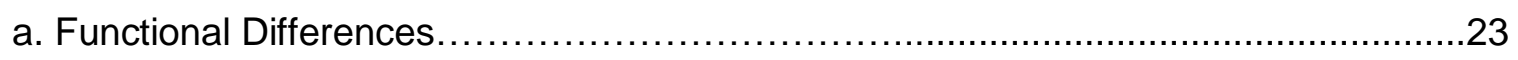

b. Communication Between Subpopulations...................................24

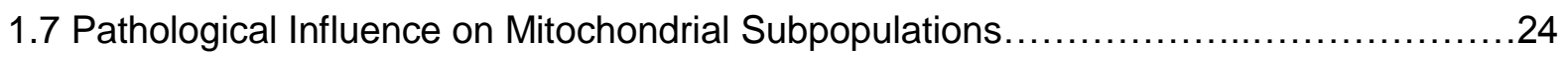

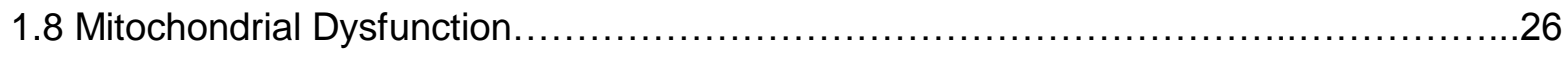

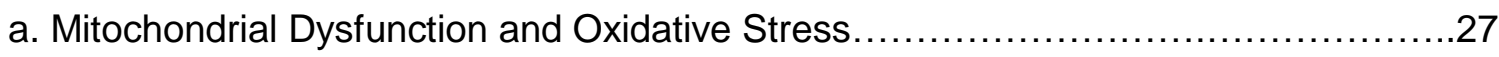

b. Mitochondrial Dysfunction and Apoptotic Signaling .............................28

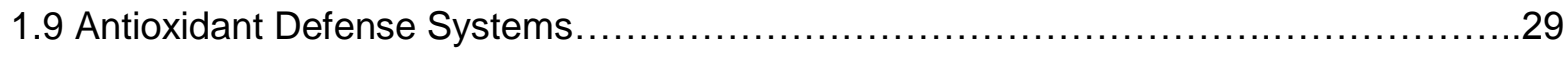

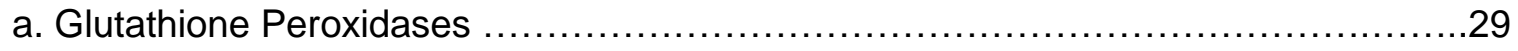

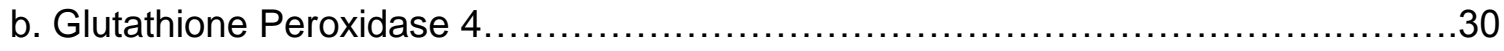

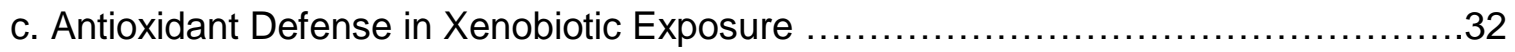

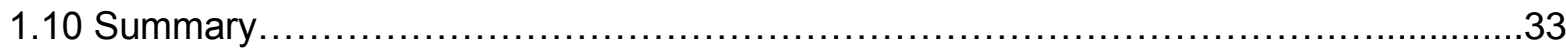

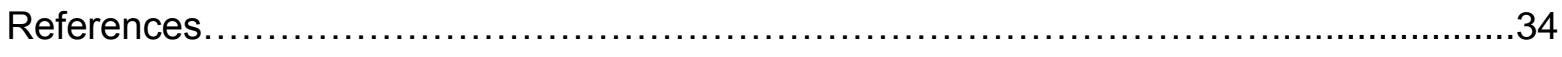

Chapter 2. Cardiac and Mitochondrial Dysfunction Following Acute Pulmonary Exposure

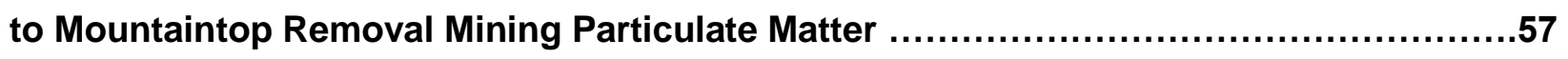

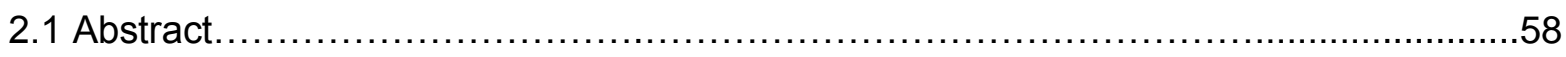

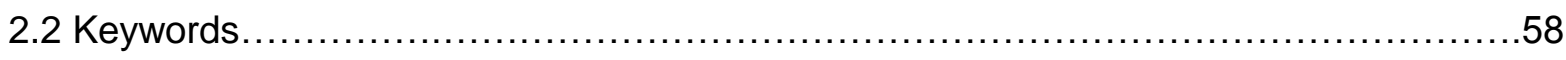

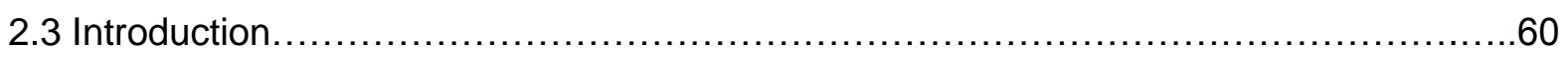




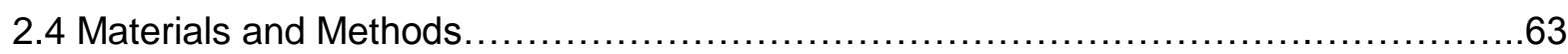

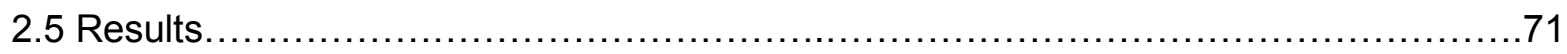

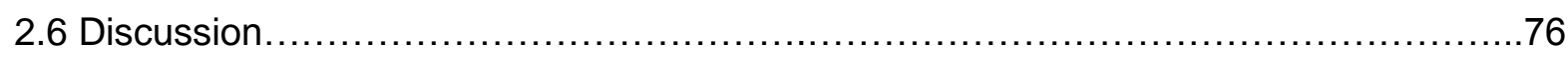

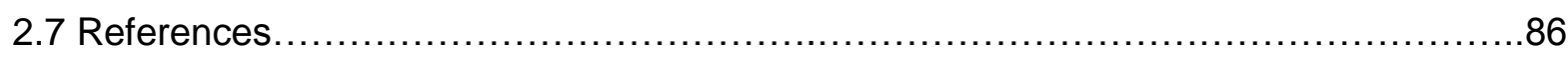

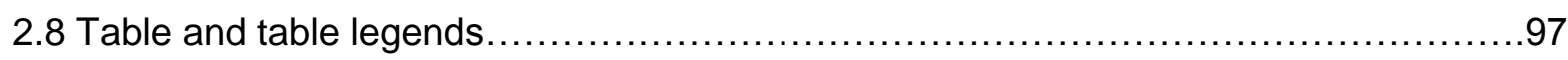

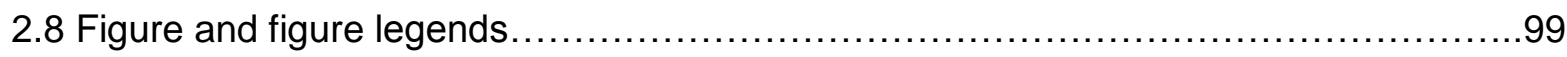

Chapter 3. Differential Cardiac Mitochondrial Dose Responses Following Pulmonary Exposure to Multi-Walled Carbon Nanotubes..........................................115

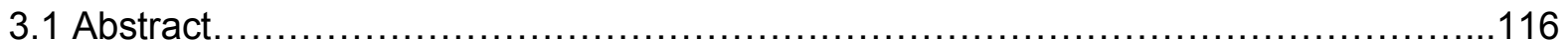

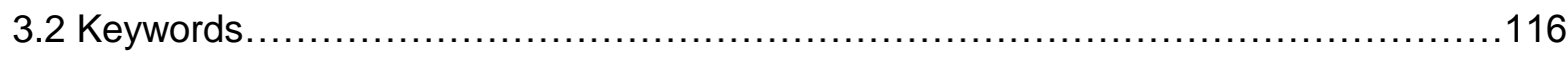

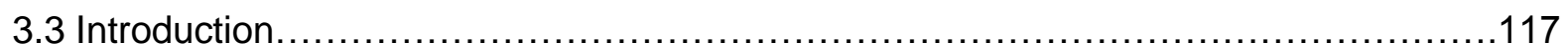

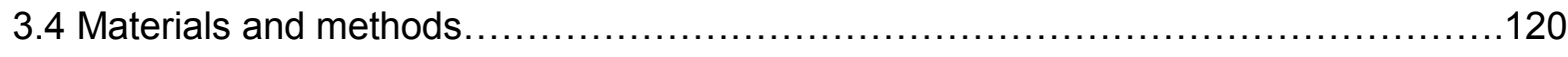

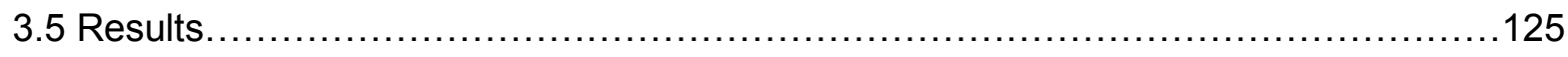

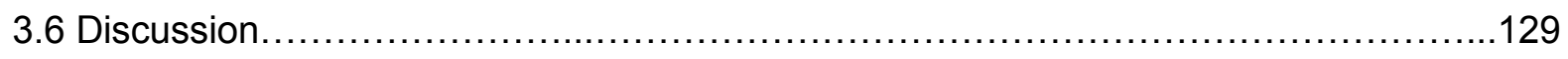

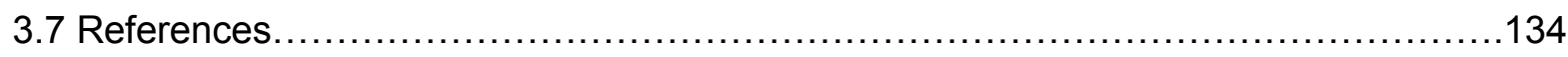

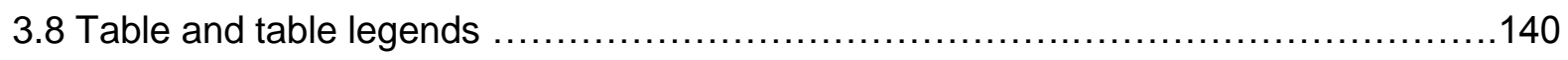

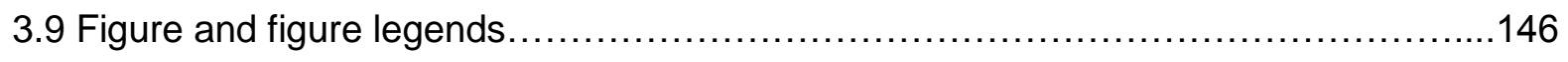

Chapter 4. Reactive Oxygen Species Damage Drives Cardiac and Mitochondrial Dysfunction Following Acute Nano-Titanium Dioxide Inhalation Exposure................156

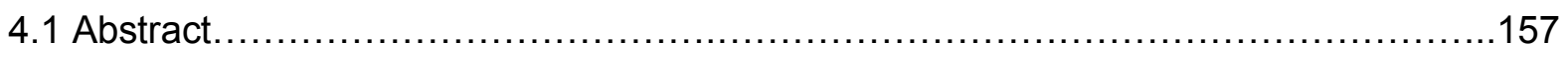

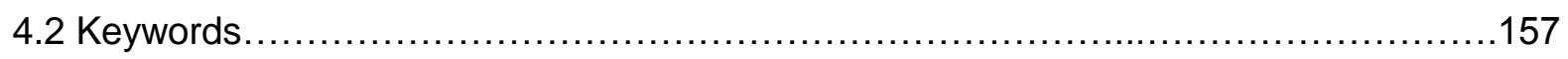

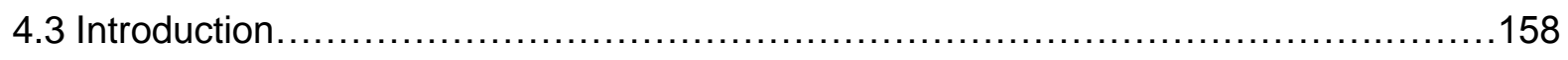

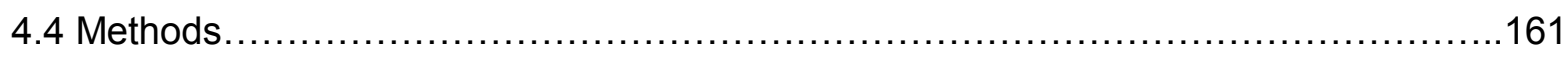

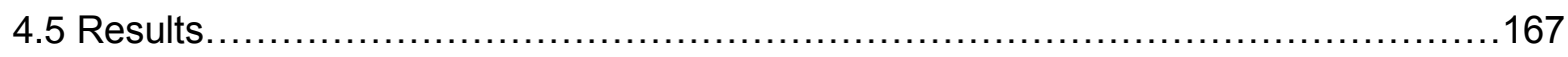




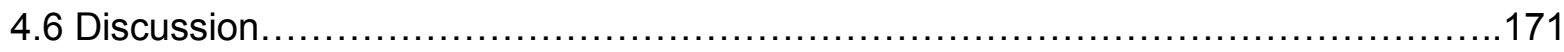

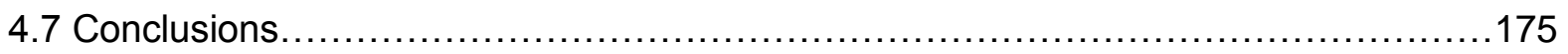

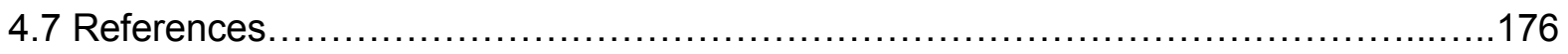

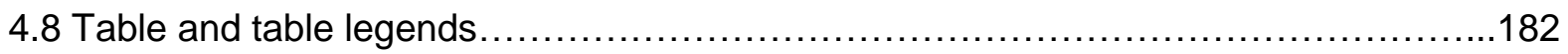

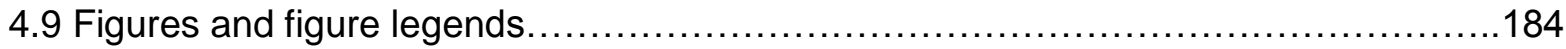

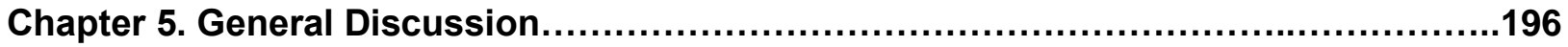

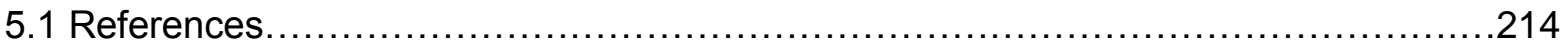

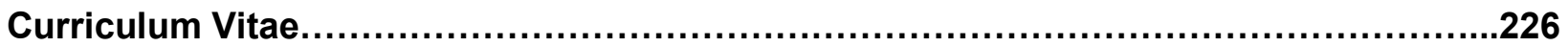




\section{LIST OF FIGURES}

\section{Chapter 1}

1.1 Nanomaterial Size Comparisons and Health Consequences.......................6

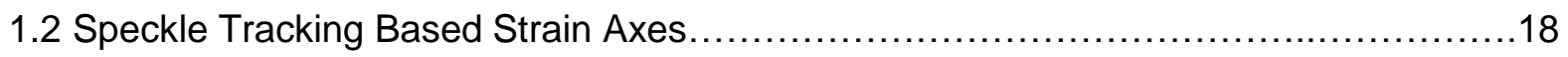

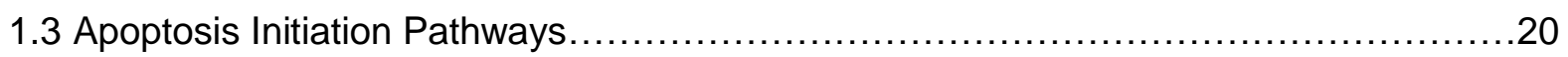

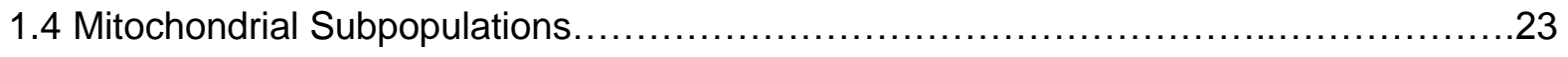

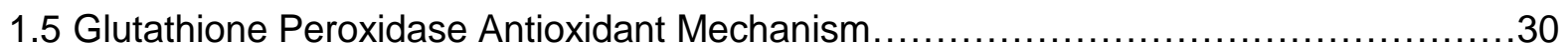

\section{Chapter 2}

2.1 Cardiac Apoptotic Index Following $\mathrm{PM}_{\mathrm{MTM}}$ Exposure $\ldots \ldots \ldots \ldots \ldots \ldots \ldots \ldots \ldots \ldots \ldots \ldots \ldots \ldots$

2.2 Cardiac Caspase Activities and Content Following PMMTM Exposure.................101

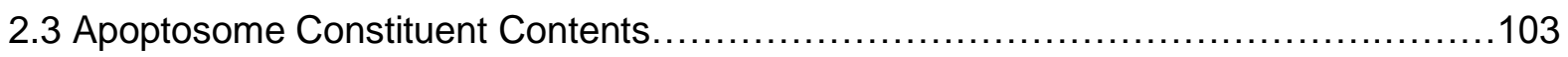

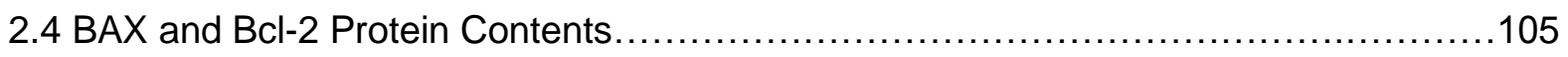

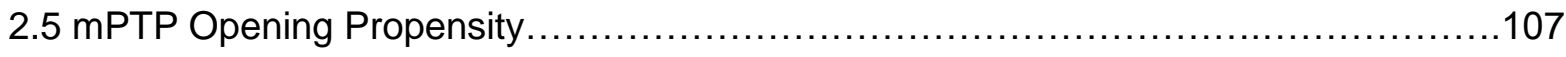

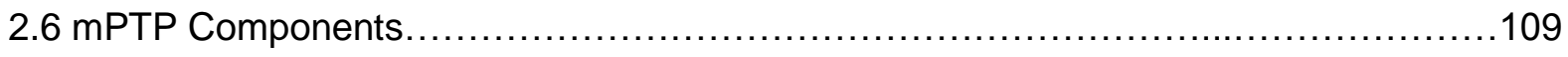

2.7 Mitochondrial Morphological Assessment.....................................111

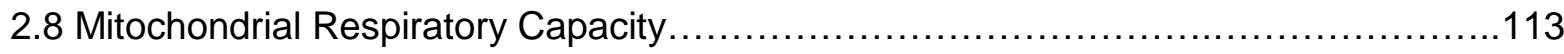

\section{Chapter 3}

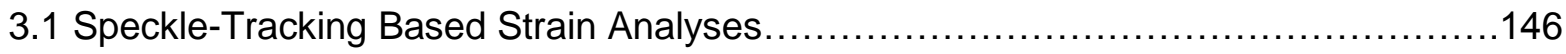

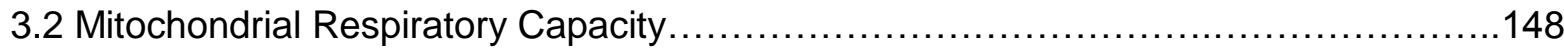

3.3 Mitochondrial Reactive Oxygen Species Production.............................150

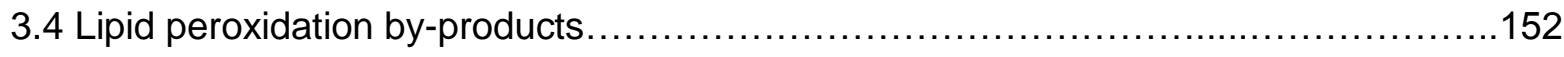

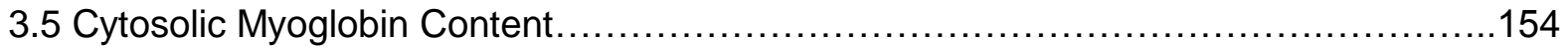




\section{Chapter 4}

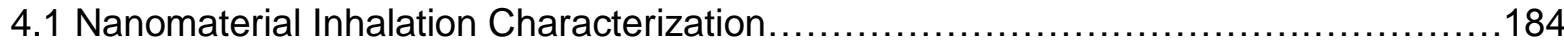

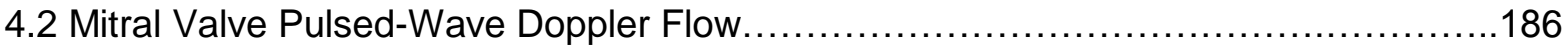

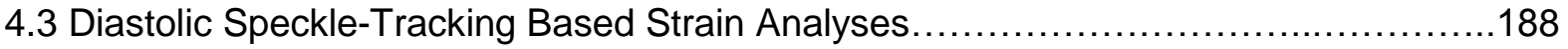

4.4 Mitochondrial Respiratory Capacity and ATP Synthase Function.....................190

4.5 Mitochondrial Reactive Oxygen Species Production and Lipid peroxidation by-

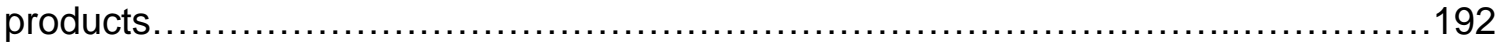

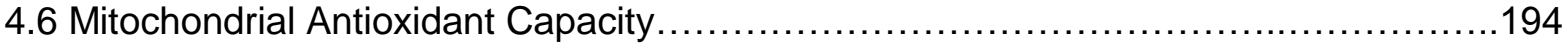




\section{LIST OF TABLES}

\section{Chapter 2}

2.1 M-Mode Echocardiographic Measurements.

\section{Chapter 3}

3.1 M-Mode Echocardiographic Measurements

3.2 Mitochondrial Electron Transport Chain Assessment Four Hours Following MWCNT

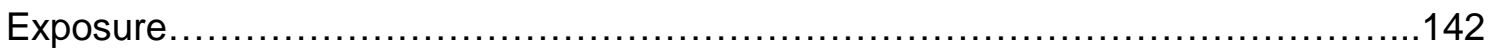

3.3 Mitochondrial Electron Transport Chain Assessment 24 Hours Following MWCNT Exposure.

\section{Chapter 4}

4.1 M-Mode Echocardiographic Measurements. 


\section{SPECIFIC AIMS}

Inhalation of xenobiotic particles, foreign particles that gain access to our bodies, is universal, yet differences in particle size, shape and composition exist between different environments. Particulate matter exposures, which occur within our everyday environment, are a non-specific agglomerate of particles making investigation into effects translationally relevant yet the broad range of constituent size, shape and chemical composition makes causality of each of these characteristics on human health difficult. Distilling this particulate into particles with uniform characteristics allows us to better elucidate the impact of each characteristic on health. Realizing impacts of particle characteristics is important to diminish the impact these exposures have on human health and expedite the process of toxicological assessment when new materials are introduced. One rapidly expanding area of material research and production is in engineered nanomaterials. These materials, while all less than one-hundred nanometers in at least one dimension, have different shapes and chemical composition making predictions into the human health effects difficult without first realizing the impacts these characteristics themselves have on health.

Inhalation exposure to particulates of varying size, shape and composition has shown adverse health effects throughout the body with the cardiopulmonary system being specifically targeted (1). While cardiovascular effects have been well recognized $(3,7,10)$, the attributing mechanisms and influence of subcellular locales have not been well characterized. Due to its central role in energy production and the formation of reactive oxygen species (ROS), the mitochondrion has been identified as central in the etiology of many cardiovascular pathologies and may be a target of environmental toxicants $(4,6)$. Studies investigating the impacts of environmental toxicants on mitochondrial function are limited but have highlighted the mitochondrion's role in ROS production and systemic ROS damage as central to the toxicity of various particulates $(5,9,11)$. Because the mitochondrion is a primary source of ROS, its 
proteins, lipids and DNA are targets of damage from excess ROS (2). Increased ROS damage can lead to mitochondrial dysfunction and the induction of apoptosis through the mitochondrion (8). Yet, no studies have attempted to elucidate the role of mitochondrial ROS production and function within the heart following a pulmonary xenobiotic exposure. Within the cardiomyocyte, mitochondrial analyses are further complicated by the presence of two spatially and biochemically distinct subpopulations: the subsarcolemmal mitochondria (SSM), present beneath the sarcolemma, and the interfibrillar mitochondria (IFM), found between the contractile apparatus. Currently a gap in knowledge exists regarding our understanding of cardiac impacts following pulmonary exposures to particulates of varying size, shape and composition and the role of ROS in these cardiovascular effects.

My long-term goal is to identify and alleviate mechanisms contributing to adverse cardiac effects associated with a pulmonary xenobiotic exposure. By identifying mechanisms in a composite xenobiotic particulate and then moving to particles of uniform size, shape and chemical composition I will be able to better elucidate the role physiochemical properties contribute to the adverse cardiac effects associated with a pulmonary exposure. My objectives are: [1] to elucidate the impact a regionally-specific composite particulate matter xenobiotic pulmonary exposure has on cardiac apoptosis and mitochondrial dysfunction [2] to investigate the influence of a pulmonary exposure to carbon-based engineered nanomaterials on mitochondrial oxidative stress and [3] to evaluate the impact ROS damage plays in cardiac and mitochondrial dysfunction following a pulmonary exposure to an engineered nanomaterial using a mitochondrial therapy (mitochondrial phospholipid hydroperoxide glutathione peroxidase; mPHGPx). My central hypothesis is that acute pulmonary exposure to particulates of varying size, shape and chemical composition differentially elicits increased cardiac oxidative stress triggering apoptosis and eliciting cardiac mitochondrial dysfunction, which is subject to spatial influence, contributing to cardiac dysfunction following 
exposure. My rationale for the proposed research is based on the finding that particulate matter increases cardiac susceptibility and increased mortality from chronic cardiovascular disease. Also, this research is based on the findings that mitochondria may be targets of engineered nanomaterial exposure. My central hypothesis is based on preliminary data showing cardiac and mitochondrial dysfunction following pulmonary xenobiotic exposures. I will test my central hypothesis by pursuing the following Specific Aims:

\section{Specific Aim l: Elucidate the impact of a pulmonary exposure of mountaintop mining} particulate matter on cardiac mitochondrial ROS production leading to apoptosis and mitochondrial dysfunction.

To address Specific aim I, I will utilize a translationally relevant particulate collected around an active mountaintop mine, immunostaining and mitochondrial functional assessments in isolated subsarcolemmal (SSM) and interfibrillar (IFM) subpopulations. I will test my working hypothesis that acute mountaintop mining particulate matter pulmonary exposure increases mitochondrial apoptosis and decreases mitochondrial function in spatially-distinct cardiac mitochondria, with effects most pronounced in the SSM.

Specific Aim II: Investigate the impact of acute pulmonary exposure to carbon-based engineered nanomaterials on cardiac and mitochondrial function.

In order to address Specific aim II, I will utilize isolated cardiac mitochondrial SSM and IFM subpopulations for fluorescent and spectrophotometric assays for ROS production and mitochondrial function. I will test my working hypothesis that carbon-based engineered nanomaterial dose will differentially elicit mitochondrial ROS production negatively impacting the function of spatially-distinct mitochondria, with effects most pronounced in the IFM. 
Specific Aim III: Evaluate the cardioprotective efficacy of a mitochondrial-targeted antioxidant therapeutic (mitochondrial phospholipid hydroperoxide glutathione peroxidase; mPHGPx) following engineered nanomaterial exposure.

To address Specific aim III, I will utilize WVU's unique inhalation chamber, a commercially available titanium dioxide and a novel antioxidant overexpressing transgenic mouse. I will test my working hypothesis that overexpression of a mitochondrially-targeted antioxidant, mPHGPx, will protect the heart from increased oxidative stress contributing to spatiallydistinct mitochondrial dysfunction following nano-Titanium dioxide exposure, that is most pronounced in the IFM.

This work is innovative because it is the first in vivo study to suggest a mitochondrial mechanism, with a spatial element, to be central in the cardiac dysfunction presented by pulmonary xenobiotic exposure. The expected outcomes will provide insight into the role of ROS in mitochondrial mechanisms impacting the cardiovascular system following an acute pulmonary xenobiotic exposure. Using particles of different size, shape and chemical composition I expect to better understand how these various properties impact the mechanisms of ROS production and damage following exposure. Also by utilizing a mitochondrially-targeted antioxidant I expect to attenuate oxidative damage and better understand the impacts of ROS on cardiac function following acute pulmonary xenobiotic exposures. To improve cardiovascular health of all Americans and decrease deaths from cardiovascular disease we need to understand the mechanisms surrounding xenobiotic pulmonary exposures. 


\section{REFERENCES}

1. Buzea C, Pacheco, II, and Robbie K. Nanomaterials and nanoparticles: sources and toxicity. Biointerphases 2: MR17-71, 2007.

2. Imai $\mathbf{H}$ and Nakagawa Y. Biological significance of phospholipid hydroperoxide glutathione peroxidase (PHGPx, GPx4) in mammalian cells. Free Radic Biol Med 34: 145-169, 2003.

3. Knuckles TL, Yi J, Frazer DG, Leonard HD, Chen BT, Castranova V, and Nurkiewicz TR. Nanoparticle inhalation alters systemic arteriolar vasoreactivity through sympathetic and cyclooxygenase-mediated pathways. Nanotoxicology 6: 724-735, 2012.

4. Li N, Sioutas C, Cho A, Schmitz D, Misra C, Sempf J, Wang M, Oberley T, Froines J, and Nel A. Ultrafine particulate pollutants induce oxidative stress and mitochondrial damage. Environ Health Perspect 111: 455-460, 2003.

5. Magnani ND, Marchini T, Vanasco V, Tasat DR, Alvarez S, and Evelson P. Reactive oxygen species produced by NADPH oxidase and mitochondrial dysfunction in lung after an acute exposure to residual oil fly ashes. Toxicol Appl Pharmacol 270: 31-38, 2013.

6. Marchini T, Magnani N, D'Annunzio V, Tasat D, Gelpi RJ, Alvarez S, and Evelson P. Impaired cardiac mitochondrial function and contractile reserve following an acute exposure to environmental particulate matter. Biochim Biophys Acta 1830: 2545-2552, 2013.

7. Stapleton PA, Minarchick VC, Cumpston AM, McKinney W, Chen BT, Sager TM, Frazer DG, Mercer RR, Scabilloni J, Andrew ME, Castranova V, and Nurkiewicz TR. Impairment of coronary arteriolar endothelium-dependent dilation after multi-walled carbon nanotube inhalation: a time-course study. Int J Mol Sci 13: 13781-13803, 2012.

8. Wu CC and Bratton SB. Regulation of the intrinsic apoptosis pathway by reactive oxygen species. Antioxid Redox Signal 19: 546-558, 2013. 
9. Xu Z, Xu X, Zhong M, Hotchkiss IP, Lewandowski RP, Wagner JG, Bramble LA, Yang Y, Wang A, Harkema JR, Lippmann M, Rajagopalan S, Chen LC, and Sun Q. Ambient particulate air pollution induces oxidative stress and alterations of mitochondria and gene expression in brown and white adipose tissues. Part Fibre Toxicol 8: 20, 2011.

10. Zanobetti A and Schwartz J. The effect of fine and coarse particulate air pollution on mortality: a national analysis. Environ Health Perspect 117: 898-903, 2009.

11. Zhao H, Ma JK, Barger MW, Mercer RR, Millecchia L, Schwegler-Berry D, Castranova V, and Ma JY. Reactive oxygen species- and nitric oxide-mediated lung inflammation and mitochondrial dysfunction in wild-type and iNOS-deficient mice exposed to diesel exhaust particles. J Toxicol Environ Health A 72: 560-570, 2009. 


\section{Chapter 1: \\ Literature Review}




\subsection{Xenobiotic Particulates}

Every day humans are exposed to xenobiotic compounds either intentionally or unintentional as xenobiotic is broadly defined as anything not naturally produced by or expected to be present within that organism. Most of these materials are food and drugs that we knowingly and willingly expose ourselves to, but with each breath we breathe in millions of particles unintentionally. This group of environmental xenobiotic particles includes air pollution particulate matter (PM) and other well-established environmental toxicants. Yet, as nanotechnology continues to flourish the group has expanded to encompass not only PM but also anthropogenic particles, such as engineered nanomaterials (ENM) (163). While these exposures are nearly ubiquitous the human health impacts may vary between the particles and require further investigation.

\section{1a. Particulate Matter}

Ambient air pollution is a mixture of solid and gases in the air produced by vehicle and industrial emissions and dust, pollen and other small molecules that can be suspended within the air. In general, the non-soluble solid fraction of air pollution is termed particulate matter which is a non-specific term in itself. PM is a complex mixture of components of varying chemical composition and size. PM can be separated by its aerodynamic diameter into four size ranges: $\mathrm{PM}_{10},<10 \mu \mathrm{m}$; coarse particles, $10 \mu \mathrm{m}$ to $2.5 \mu \mathrm{m} ; \mathrm{PM}_{2.5},<2.5 \mu \mathrm{m}$; and Ultra-Fine Particles (UFP), $<100 \mathrm{~nm}$. The size of the particle within the PM is directly linked to the adverse health outcomes associated with exposure (18). Once inhaled, particle size dictates pulmonary deposition and retention directing particle toxicity.

Throughout the United States the Environmental Protection Agency (EPA) regulates the concentration of two different PM sizes: $\mathrm{PM}_{10}$ and $\mathrm{PM}_{2.5}$. Historically, the EPA began to regulate 
total PM concentration in the 1970s without size distinctions. This ruling continued until 1997 when the EPA detailed that particle size dictates toxicological response as indicated by increased toxicity associated with $\mathrm{PM}_{2.5}$ exposure as compared to $\mathrm{PM}_{10}(9)$. Thus regulations on both $\mathrm{PM}_{10}$ and $\mathrm{PM}_{2.5}$ were set: with $\mathrm{PM}_{2.5}$ set lower to attempt to alleviate negative health impacts.

The World Health Organization estimates that ambient air pollution contributes to 3.7 million premature deaths a year (184). Epidemiologically, exposure to PM contributes to acute cardiovascular morbidity and mortality (17). Further, $\mathrm{PM}_{2.5}$ exposure increases the risk for cardiovascular events such as myocardial infarction, stroke, arrhythmia and exacerbation of heart failure within hours of exposure $(137,156)$. While long-term exposure can reduce life expectancy by a few years, short-term increases in $\mathrm{PM}_{2.5}$ exposure can lead to increased early mortality in thousands of individuals within the United States (US) (17, 137). Although PM exposure is widespread, the makeup of this material varies considerably based on origin and geographical region (47). This further suggests that particle composition differentially contributes to the adverse health impacts following exposure (38).

\section{1a.i. Mountaintop Removal Mining}

One regionally-specific PM that is known to impact cardiovascular health is produced as a by-product of coal mining throughout the Appalachian region of the US. Coal mining can be accomplished through two main methods: underground and surface mining. Underground mining is the more conventional type of mining where the miners dig into the soil and rock through shafts and tunnels to remove the mineral deposit. In contrast, during surface mining miners remove the overburden, soil and rock, from on top of the deposit so they can then

remove the coal. Surface mining relies on the use of heavy machinery; thus, is less labor 
intensive than underground mining. A decreased labor force is attractive to mining companies and has led to an approximately $30 \%$ increase in surface mining throughout the US (45). Surface mining is a broad category of mining and includes strip, open-pit and mountaintop removal mining (MTM).

Mountaintop removal mining is common throughout the Appalachian region: primarily Kentucky, Virginia, Tennessee and West Virginia. In West Virginia alone, MTM accounts for approximately $30 \%$ of the mining operations throughout the state (45). During MTM, explosives are utilized to remove the mountain summit to expose the underlying coal seam. Then using diesel-fueled machinery, the remaining overburden is dumped into the adjacent valleys leveling the mountain. While the economic and ecological impacts of this mining technique are well realized; the human health impacts are not fully realized.

Broadly, the health effects of coal mining have been outlined $(186,198)$, but the differential impacts of mining type had not been defined. Governmental regulations require fugitive dust abatement to protect the individuals working and living in areas surrounding active MTM sites. Yet epidemiologically in the areas surrounding active MTM sites there is an increase in chronic cardiovascular disease mortality rates (49). Interestingly, this study compared individuals surrounding active MTM sites and underground mining sites and was able to suggest that the increased mortality rates could be attributed to the PM in the air. Comparing the PM concentrations in these areas surrounding different surface mining sites confirmed that $\mathrm{PM}_{10}$ and $\mathrm{PM}_{2.5} \mathrm{PM}$ concentration was increased (94) and have a high crustal affinity and primarily aluminosilicate composition (93). Investigation in to the mechanisms contributing to the increased cardiovascular mortality rate observed is limited. Animals exposed to the PM collected in areas surrounding MTM sites $\left(\mathrm{PM}_{\text {MTM }}\right)$ have decreased microvascular function (89) but the cardiac impacts have not been identified. 


\section{1b. Engineered Nanomaterials}

The incorporation of nanotechnology into consumer-based products helps to propel this area into a billion dollar market and at the heart of the market are engineered nanomaterials (ENMs). ENMs are anthropogenic materials with at least one dimension smaller than 100 nanometers. Naturally humans are exposed to materials within this size range, yet these particles are commonly classified as ultrafine particles. The difference between these particles is the intention: ENMs are created intentionally while ultrafine particles are unintentional. As technology has progressed and we began to manipulate matter at the nanoscale; soon it was realized nano-sized particles behave differently than their micro-sized counterparts.

Moving from the micron- to nano-sized particles many physicochemical properties can change. Most notably there is an increase in surface area and mass to charge ratios with the significant change in size in nanomaterials. Figure 1.1A illustrates how the change in particle size can affect mass and surface area. One carbon microparticle with a diameter of $60 \mu \mathrm{m}$ has a mass of $0.3 \mu \mathrm{g}$ and a surface area of $0.01 \mathrm{~mm}^{2}$, yet the same mass of carbon in nanoparticulate form, with each particle having a diameter of $60 \mathrm{~nm}$, has a surface area of $11.3 \mathrm{~mm}^{2}$ and consists of 1 billion nanoparticles (20). These changes in physicochemical properties are essential to their incorporation into consumer products as they can be used in ways different than their micron sized counterpart. Yet this change in properties can also make them unpredictable when interacting with biological materials. In Figure 1.1B, a size comparison of a macrophage and the organelles within the cell compared to particulates of different sizes helps to illustrate how nanomaterial size may create novel interactions in biology. 

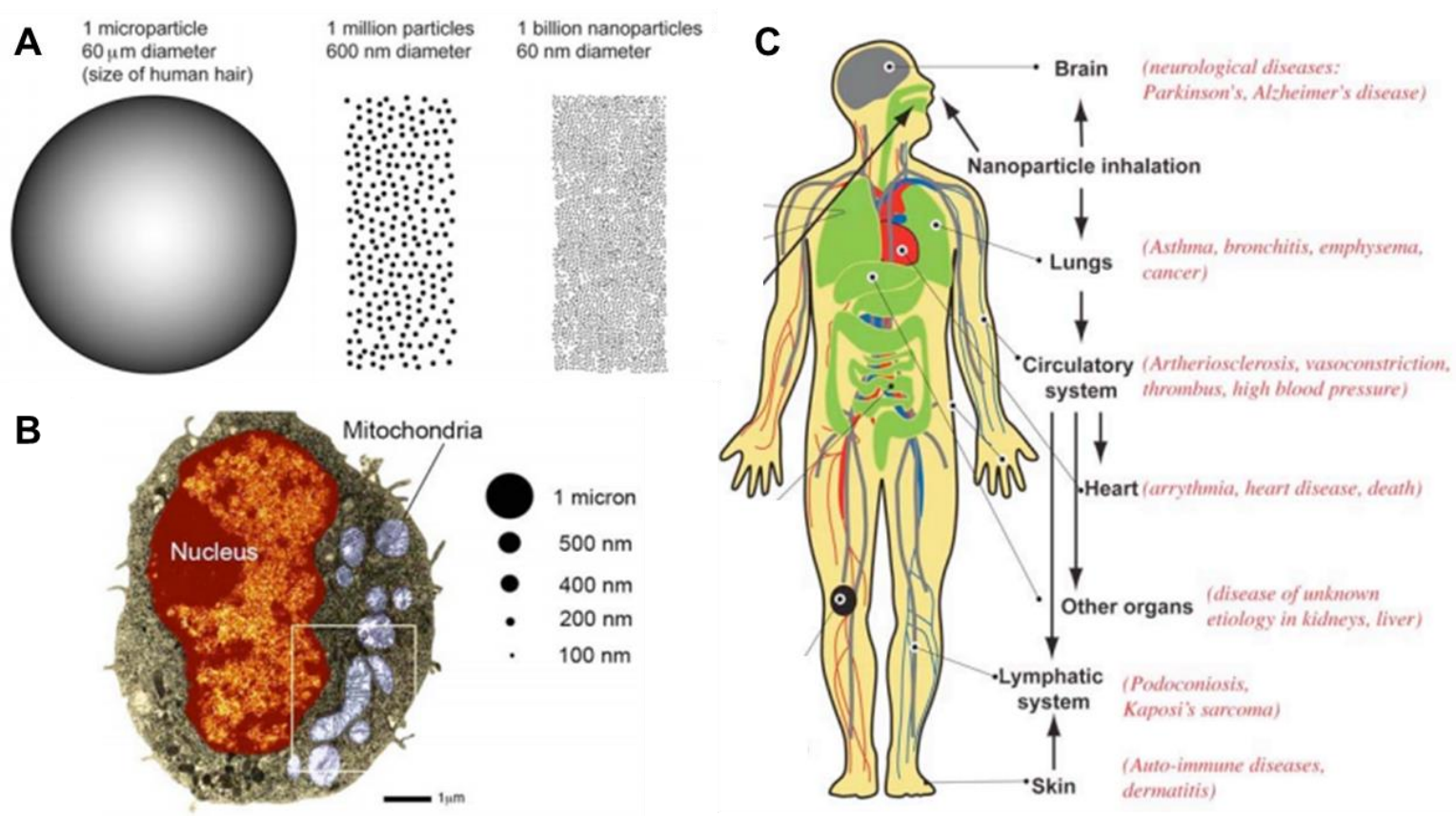

Figure 1.1 Nanomaterial Size Comparisons and Health Consequences. (A) Schematics illustrating a microparticle of $60 \mu \mathrm{m}$ diameter, and the number of nanoparticles with diameter of $600 \mathrm{~nm}$ and $60 \mathrm{~nm}$ having the same mass as one microparticle of $60 \mu \mathrm{m}$ diameter. (B) Comparison of rat macrophage cells size to nanoparticles size using TEM images (at scale). Human macrophages are up to two times larger than rat macrophages. TEM image (C) Illustration of human body with pathways of exposure to nanoparticles, affected organs, and associated diseases from epidemiological, in vivo and in vitro studies. (20)

Nanomaterials have been shown to influence nearly all systems, yet these effects are not consistent between particles. The inhalation of nanomaterials alone can have negative impacts from the brain to the skin and everything in-between (Figure 1.1C). Some nanomaterials seem to be toxic, some non-toxic and others may have beneficial health effects (13). The ENM nomenclature is a broad category and is made up of particles of varying size and shape. While to technically be a nanomaterial one dimension must be less than $100 \mathrm{~nm}$, the other dimensions are not defined and can be micrometers in length. Considering individual nanomaterials, we are modeling only a few atoms and even though different ENM may be formed from the same material; the configuration of its atoms can be different resulting in different physical and toxicological outcomes. 


\section{1b.i. Carbon-Based Nanomaterials}

The global market for carbon nanomaterials was $\$ 158.6$ million in 2014 and is projected to reach $\$ 670.6$ million in 2019 (126). Due to their varied size and shape, carbon-based nanomaterials have a wide range of end-consumer products and is the most quickly growing class of nanomaterials with a compound growth rate of $33.4 \%$ (126). Carbon-based nanomaterials are a distinct class formed entirely out of carbon but with a wide variety of size and shapes: ranging from 2-dimensional graphene sheets to 3-dimensional fullerene spheres and carbon nanotubes (CNT). These shapes imbue them with unique properties like the high electrical conductance found in a graphene sheet or tensile strength of a multi-walled carbon nanotube (MWCNT). While they are widely useful in technology and consumer applications considerable concern has been raised in reference to their human health effects (121). Health hazards are most obvious with manufacture/workplace exposure, but general exposures from use, degradation or disposal of commercial products as well as direct exposure through biomedical applications are a growing concern $(39,168)$.

CNT are especially interesting due to their physicochemical properties: 10-fold stronger than steel, 1.2-fold harder than diamond, light and heat resistant and exhibit unique electrical properties (44). These unique physicochemical properties lend to increased durability, which from an engineering perspective is attractive, but this durability remains in exposure scenarios and increases biopersistence in the lung (95). In fact, some studies suggest MWCNT may be analogous to asbestos in the induction of mesothelioma (136). Yet, cardiac impacts are not defined following pulmonary exposure to CNT. 


\section{1b.ii. Titanium Dioxide}

While the use of carbon-based nanomaterials is rapidly growing, titanium dioxide $\left(\mathrm{TiO}_{2}\right)$ use is one of the most commonly used materials and is one of the top 5 nanoparticles produced annually (149). $\mathrm{TiO}_{2}$ is a white pigment commonly used in paints, coatings, plastics, paper, inks, medicines, food products and personal care products to enhance the color and brightness of the product; it is also found in sunscreen to provide protection from the sun's ultraviolet rays. Traditionally, micron- $\mathrm{TiO}_{2}$ has been considered a poorly soluble and low toxicity particle (81). To this end, micron- $\mathrm{TiO}_{2}$ was used as a "negative control" in many in vitro and in vivo toxicological studies (195). While $\mathrm{TiO}_{2}$ is a relatively inert nanomaterial, compared to its micron-sized counterpart, nano- $\mathrm{TiO}_{2}$ was as much as 41 -fold more potent in causing lung inflammation, lung damage, inflammatory cytokine/chemokine production and oxidant generation (146). While inhalation of ENMs may primarily occur through occupational production and degradation, new consumer products that utilize ENMs can contribute to consumer exposure and fugitive materials may seep into the environment expanding the exposure risk beyond apparent contact.

\subsection{Health Impacts of Xenobiotic Exposures}

As stated previously, humans are constantly subjected to xenobiotic particles and in numerous exposure models. Yet inhalation and pulmonary exposures are the most common route of exposure. In human models inhalation of PM has proven to have negative health impacts and more specifically negative cardiovascular effects $(17,18)$. ENM production has become more prevalent within the last ten years, preventing long-term health effects and retrospective studies to be well established. Thus while human results indicative of nanomaterial toxicity are not documented, significant injury and the contributing mechanisms are well characterized in animal models of exposure. 


\section{2a. Pulmonary Consequences}

Thorough evaluation of pulmonary impacts following xenobiotic exposure have identified effects specific to the exposure particulate. Decreased pulmonary function in healthy models is not commonly identified following particulate exposure, but because the lung is the primary site of exposure, molecular mechanisms are affected. Between micro- and nanoparticles pulmonary deposition varies greatly. In simulations of human pulmonary deposition nanoparticle deposition was more uniform and more likely in the deeper, gaseous-exchange regions of the lung (194). Observations in animal models support the simulations identifying increased pulmonary deposition of nanoparticles as compared to micro-particles (52). Thus size not only dictates response but can also impact pulmonary deposition. In an adult human, this model suggests that particles 10 microns in size will have a high total deposition, but the bulk of this deposition will be within the extrathoracic portion of the respiratory tract. Yet, smaller nano-sized particles have decreased deposition efficiency, but when deposited these materials will deposit into the gaseous exchange region of the respiratory tract (1). Therefore even though nanomaterials more specifically deposit in the alveoli, larger particles can still get into this region, but clearance between these particles varies.

Pulmonary clearance can impact the total deposition but also can be central in the toxicity identified following exposure. Comparing micron and nano-sized particle macrophage clearance by observing nanoparticles within bronchoalveolar lavage macrophage populations more than two-fold higher in the animals exposed to micron-sized particles (58). Following exposure, the percentage of nanoparticles associated with macrophages increases over time (90).Further, pulmonary evaluation of the impacts of CNT suggests not only biopersistence but also an associated inflammatory response following exposure $(48,105)$. Increased macrophage recruitment suggest an attempt at removal of the particle but surrounding tissue is damaged (52). 
$\mathrm{TiO}_{2}$ inhalation exposure shows a dose-dependent deposition of titanium in the pulmonary tissue and an associated increase inflammatory response as signified by an increase in neutrophils in the bronchioalveolar lavage fluid (10). Nano- $\mathrm{TiO}_{2}$ pulmonary effects of a pulmonary exposure are well characterized and extrapulmonary effects are identified with investigation into how these remote effects manifest (12). Systemic inflammatory spillover from the lung following nano- $\mathrm{TiO}_{2}$ pulmonary exposure is suggested to be one of the pathways contributing to the extrapulmonary impacts (80). Specifically, this inflammatory response is great enough to decrease the in vivo vascular reactivity showing that the cardiovascular system is affected following nano- $\mathrm{TiO}_{2}$ exposure (119). Yet the mechanisms eliciting extrapulmonary effects are not well understood and of considerable controversy.

\section{2b. Extrapulmonary Influences}

While extrapulmonary toxicological effects are well-documented, the mechanisms of toxicity are still under considerable debate. Three potential hypotheses have been advanced to explain extrapulmonary effects: [1] a systemic inflammatory response that is initiated in the lung; [2] translocation of the particles to extrapulmonary tissue; and [3] neural effects $(18,40)$. Studies in both murine and human models have identified pro-inflammatory markers in the circulation of exposed subjects, providing evidence that a pulmonary insult may stimulate a systemic inflammatory response $(7,69,131,139,145,170,179,181)$ which may contribute to downstream cardiovascular effects $(115,120)$. Data also exists suggesting particulate translocation from the lung to the affected tissues $(46,91,123,124,164)$. Pulmonary exposure damages lung epithelium, increasing permeability and enabling particle penetration from the gaseous exchange region leading to escape into the circulation with subsequent impact on extrapulmonary tissues $(117,152)$. Finally, exposure may interfere with neuronal signaling and 
cardiac autonomic dysfunction following exposure $(22,23,132)$. While the hypotheses are scientifically independent, the mechanisms are not mutually exclusive and may overlap, propagating activation of additional mechanisms.

\section{2c. Cardiovascular Dysfunction}

While the pulmonary tissue is the primary site of injury, the link between particulate exposure and cardiovascular disease is not new. The cardiovascular system is commonly identified as one of the affected organ systems following exposure, yet the mechanisms supporting this association are not fully examined. Sufficient evidence supports that after exposure to both PM and ENM systemic vascular dysfunction underline cardiovascular dysfunction $(89,112,165)$. In different exposures the mechanisms contributing to this dysfunction differ as inflammation is culpable in some (120) and particle translocation is suspected in others (147) suggesting that different particles stimulate distinctive pathological stimuli. This vascular dysfunction is typically related to peripheral vascular disease and hypertension but dysfunction of the coronary microcirculation suggests the heart is affected following exposure and could lead to increased cardiovascular disease mortality $(32,164)$.

Cardiac function is not a typical endpoint of inhalation toxicology evaluation, but evidence supports that particulate exposure can interrupt both relaxation and contraction of the heart. Investigating the effect of diesel exhaust particle inhalation on cardiac function identified decreases in fractional shortening due to diastolic effects with an increase in end-diastolic diameter (191). Similarly, decreased fractional shortening following PM exposure was identified in senescent mice (172). Prenatal PM exposure reduced fractional shortening (61) and a chronic model of PM exposure decreased ejection fraction (185), demonstrating the detrimental role PM exposure plays in the progression of heart disease. Cardiac effects are not well 
documented following CNT exposure but data suggests the tissue is at least sensitized by exposure $(101,177)$. In vitro exposure to nano- $\mathrm{TiO}_{2}$ induced impairment of sarcomere shortening and decreased stability of resting membrane potential (147). In vivo nano- $\mathrm{TiO}_{2}$ pulmonary exposure increases tissue excitability enhancing the propensity for arrhythmias (147). Also, inhalation exposure to nano- $\mathrm{TiO}_{2}$ can depress diastolic function in animal stimulated with isoproterenol suggesting decreased capacity for cardiac response following ENM exposure (85). Following particulate exposure, overt cardiac dysfunction is not commonly observed in humans; however, cardiac remodeling occurs indicating cardiac stress (180). Ex vivo assessment of cardiac contractile reserve following PM exposure highlighted deficient cardiac contractility and correlated this effect with impaired myocardial metabolism suggesting mitochondrial dysfunction associated with xenobiotic exposure (107).

\section{2d. Mitochondrial Dysfunction}

The mitochondrion supplies the cell with the energy necessary to maintain homeostasis, yet following xenobiotic exposure the mitochondrion may become a target. Intentional xenobiotic targeting to the mitochondria can be used for imaging (50) but unintentional exposure may stimulate the organelle and propagate toxicity. For example, PM produces changes in pulmonary mitochondrial morphology and the expression of mitochondrial fission/fusion markers (100). In vitro, PM induces opening of the mitochondrial permeability transition pore (mPTP), decreases membrane potential and generates mitochondrial dysfunction in RAW 264.7 cells (188). Further, silver nanomaterials were also able to induce mPTP opening and decrease mitochondrial respiration associated with increased reactive oxygen species (ROS) production (41). Pulmonary exposure to single-walled CNT was accompanied by aortic mitochondrial DNA 
damage and changes in mitochondrial glutathione and protein carbonyls levels suggesting the cardiovascular mitochondria can be impacted by xenobiotic exposure (101).

Within the heart, mitochondrial swelling following PM exposure was correlated with cristae disorder and increased oxidative stress (99) then mitochondrial functional deficits (60). Nano- $\mathrm{TiO}_{2}$ exposure can induce cardiac mitochondrial damage in different exposure models: after oral administration mitochondrial swelling arose (19) and inhalation induced mitochondrial dysfunction in both the heart and uterus of pregnant rats (166). Mitochondrial dysfunction observed following PM exposure was correlated to impaired cardiac oxygen consumption and decreased contractility (107) indicative of impaired metabolism and could represent an early cardiovascular alteration induced by xenobiotic exposure.

\section{2e. Oxidative Stress}

Oxidative stress is defined as the imbalance of ROS generation and antioxidant defense. Oxygen-derived free radicals such as superoxide and hydroxyl radicals, as well as non-radical derivatives such as hydrogen peroxide and peroxynitrite, are the key drivers of oxidative stress that can impair cellular and organelle function. Following xenobiotic exposure an increase in systemic oxidative stress is well characterized and oxidative potential has been used as an effective exposure metric in identifying toxicity within diverse xenobiotic particle exposures (87). In vitro studies demonstrate a clear link between particulates and ROS generation (41, 111, 135), and in vivo studies consistently support increased levels of oxidative stress in xenobiotic exposure $(101,119)$. Vascular impairments observed can be attenuated by pretreatment or coadministration of free radical scavengers and other antioxidant compounds suggesting ROS is an important mechanism in cardiovascular dysfunction induced by xenobiotic exposure (28, 
116). Further, while there are different intracellular sources of ROS, due to its high respiratory capacity the mitochondrion is central in ROS production.

\section{2f. Apoptotic Signaling}

Apoptosis, or programmed cell death, is an evolutionarily conserved process involved in distinct physiological processes, yet deregulation of the process is central in the etiology of several diseases. Xenobiotic exposures can induce apoptotic cell death and contribute to the collection of pathological conditions observed. In vitro PM exposure induces significant oxidative stress leading to DNA damage triggering apoptosis in alveolar epithelial cells (176). Other pulmonary cell lines exposed to ENMs corroborate the induction of apoptosis through ROS mediated pathways and additionally suggest a mitochondrial role in the initiation (183, 189, 190). Extrapulmonary cellular death investigation following exposure is limited but in vitro analyses suggest ENMs induce apoptosis in the liver but mechanisms initiating death are absent $(150,155)$. Finally, in a rat cardiac cell line (H9C2 cells) PM exposure initiated apoptosis

through ROS mediated pathways and mitochondrial associated proteins (21), yet in vivo analyses of extrapulmonary apoptosis and the contributing mechanisms following xenobiotic exposure are lacking.

\subsection{Pulmonary Exposure Models}

The evaluation of airborne xenobiotic materials extrapulmonary impacts begins with exposing the animal's lung and there are many ways to accomplish this exposure. Inhalation exposure is considered the gold standard as this provides a natural route of entry, but there are many obstacles that can prevent the use of this technique. Inhalation, especially nanomaterial inhalation, can require special equipment and expertise not available at many institutions or if 
available are too expensive to maintain. Even when inhalation facilities are available, other factors may make inhalation unfeasible: limited test material, highly reactive/toxic material or hazards associated with material handling that preclude atmospheric generation (42).

Alternative methods, intratracheal instillation and pharyngeal aspiration, are much simpler and limit the risks to the investigator. Further, these methods can be utilized to assure the actual dose delivered to the lungs of the animal as inhalation relies heavily on estimations. During intratracheal instillation, a ball needle is attached to a tuberculin syringe and inserted under the glottis into the trachea releasing the particulate solution into the lungs (14). Yet in the mouse, there can be significant trauma associated with the intratracheal instillation method alone; decreasing the method's translational relevance and making conclusion into the xenobiotic impacts difficult. Pharyngeal aspiration is able to decrease exposure associated trauma as there is no needle insertion. Exposure using pharyngeal aspiration introduces the exposure solution to the base of the tongue and the animal brings the solution into its lungs with normal respiration. When utilized with ENM exposures, pharyngeal aspiration deposits the material into the deep lung and with an even lung distribution correlated to the administered dose (141). Between exposure models, pulmonary deposition was found to be similar at 24 hours suggesting comparisons of effects are due to particle differences and not exposure technique $(42,96,122)$. Each method is a well validated model of pulmonary exposure with advantages and disadvantages, but can be utilized to investigate extrapulmonary effects of xenobiotic exposure.

\subsection{Cardiac Function Using Echocardiography}

Echocardiography is one of the most widely utilized diagnostic tests in cardiology; being routinely used in the diagnosis, management and follow-up of patients with suspected or known 
heart disease. Echocardiography uses standard two-dimensional and Doppler ultrasound to produce quick, non-invasive, cost-effective, and highly accurate images of the heart that can be analyzed for cardiac functional analyses. In animal models, echocardiography is commonly used to assess cardiac function in disease and the therapeutic potential of treatments. In both humans and animals, systolic and diastolic echocardiographic analyses can involve the use of conventional, speckle-tracking based and pulsed wave Doppler echocardiography to thoroughly assess disturbances to cardiac function.

\section{4a. Conventional Echocardiography}

One of the earliest forms of cardiac ultrasound is Motion or "M"-mode echocardiography and due to its precedent it's now a member of the class of ultrasound affectionately termed conventional echocardiography. M-mode is widely accepted to measure volumetric and diametric cardiac functional indices across multiple cardiac cycles. This technique is used to provide a right parasternal short axis view of the left ventricle, and by placing a gate through this two dimensional image we can evaluate the motion of the ventricular walls across one dimension. This one dimensional view allows for fine measurements increasing temporal and spatial acuity because the focus is narrowed from the two dimensional trace. By tracing the motion of the ventricular walls, end-systolic and diastolic volume and diameter quantification allows for the calculation of ejection fraction and stroke volume of the left ventricle, which can then be used to calculate cardiac output. While M-mode is reliable enough to identify overt cardiac dysfunction, it is being considered obsolete by some clinicians (51) as more sensitive indicators are available. 


\section{4b. Speckle-Tracking Based Echocardiography}

During recent years, velocity, displacement, and deformation analyses have emerged as a valuable system for comprehensive and reliable echocardiographic assessment. In order to perform these analyses, speckle-tracking based echocardiography utilizes natural acoustic reflections throughout the left ventricular wall and follows these "speckles" throughout the cardiac cycle to assess wall motion and deformation (59). These speckles move in along the direction of the wall, and not along the ultrasound beam, thus the technique is angle independent (133). Two-dimensional echocardiographic images are used in both the right parasternal short and long axes to fully delineate the movement of the heart throughout the cardiac cycle. While the technique itself is relatively straightforward, the differences between wall velocity, deformation, and the relationship of these indices to conventional cardiac function can be more difficult.

Speckle-tracking based echocardiography measures wall motion with velocity and displacement as indices, and deformation in the context of strain and strain rate. Velocity and displacement are uncomplicated: like the basic physics terms, they quantify the movement of the speckle and the velocity with which it moves. Yet strain and strain rate are more complex. The term "strain" in everyday language means "to exert" yet in echocardiography is used to describe deformation. Cardiac deformation and strain values correlate to the thickening and thinning in the radial parameter and elongating and shortening of the cardiomyocyte in the longitudinal and circumferential parameters. During contraction, as the wall shortens it also thickens; thus, radial thickening (positive strain), circumferential shortening (negative strain) and longitudinal shortening (negative strain) thoroughly evaluate systolic function (Figure 1.2). By taking into account the time it takes to reach peak deformation (strain) we can calculate the strain rate augmenting the deformation analysis. 

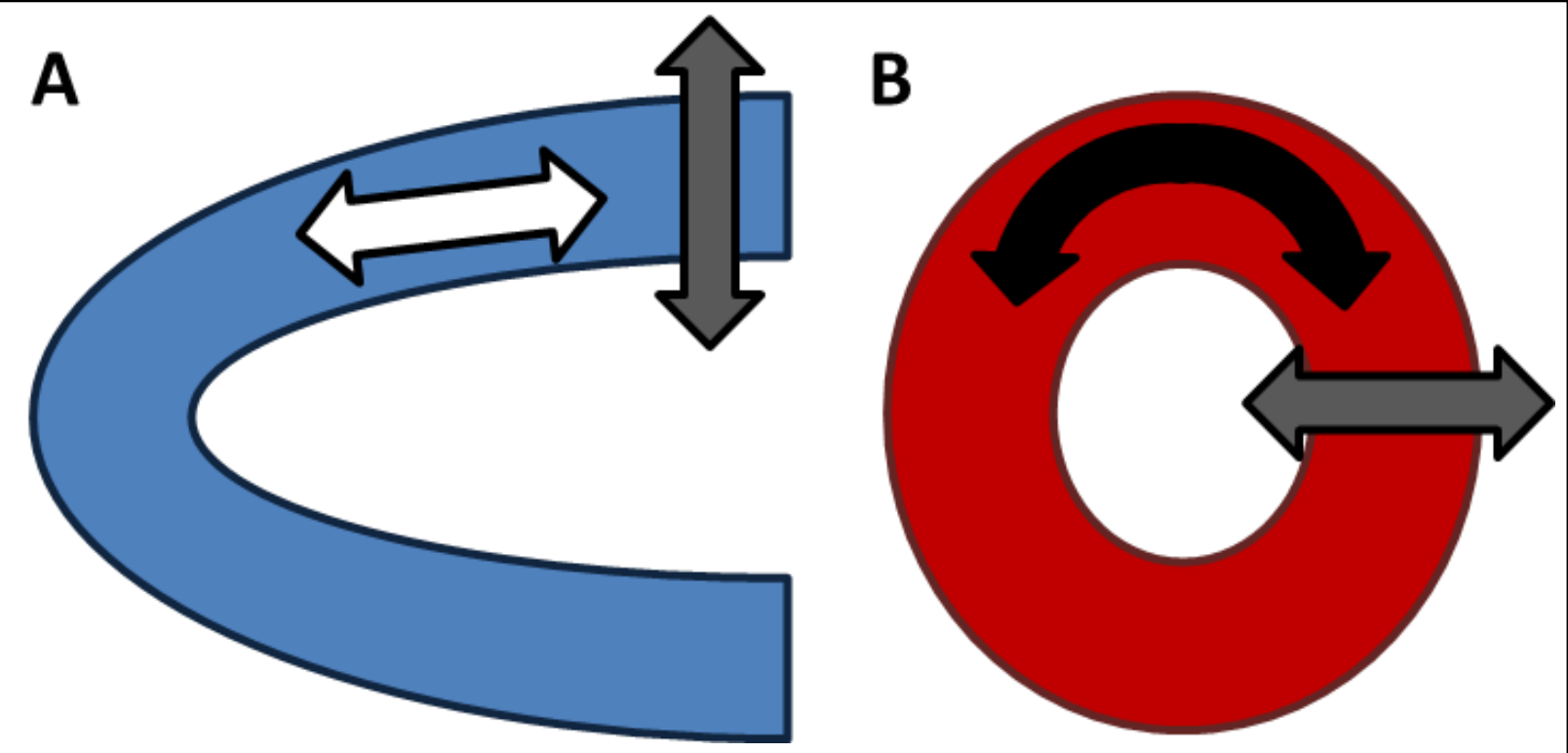

Figure 1.2 Speckle Tracking Based Strain Axes. Normal cardiac function involves myocardial deformation along the longitudinal (white arrow), radial (grey arrow), and circumferential (black arrow) axes of the ventricular wall. Long (A) and short (B) axes view of the ventricular wall illustrate the strain analyses.

Strain and strain rate measurements are sensitive indicators of sub-clinical diseases including diabetes (151), myocardial ischemia (182), and non-ischemic cardiomyopathies (103) and prediction of patient outcomes with heart failure (68). The use of strain and strain rate analyses in diastole are less abundant but also show high predictive values for the outcome of patients with idiopathic dilated cardiomyopathy (82). In patients with heart failure with preserved ejection fraction increased diastolic wall strain correlated with diastolic stiffness, cardiac remodeling and a higher rate of cardiovascular events (125). Further, by combining strain analyses with pulsed wave Doppler flow analyses the predictive capabilities are augmented (27). 


\section{4c. Doppler Flow Echocardiography}

Doppler flow echocardiography uses the Doppler principle to estimate blood velocity through the heart. Blood-flow velocity estimation is accomplished by comparing the frequency change between the transmitted and reflected sound waves. Doppler flow echocardiography can come in two approaches: continuous and pulsed wave flow. Continuous wave uses a constant ultrasound beam to detect the Doppler shift of very high velocities but is not capable of well localizing where the shift is occurring. Pulsed wave Doppler uses short bursts of ultrasound alternating with pauses to detect shifts in Doppler flow and estimates not only the blood velocity but also allows for the localization of the movement. Thus, the technique can be used to measure flow through the mitral valve in order to assess cardiac diastolic function.

When flow across the mitral valve is assessed with pulsed wave Doppler flow, two characteristic waves are observed. These distinct waves represent the early passive filling of the ventricle, known as the $\mathrm{E}$ wave, and the active filling with atrial systole, designated the $\mathrm{A}$ wave. Classically, the velocity of the $E$ wave is slightly greater than that of the $A$ wave, and the relationship of these velocities acts on a spectrum to predict diastolic function. A simple ratio (E/A ratio) between the wave velocities indicates either normal function ( 1.5$)$, pseudonormal $(\sim 1.5)$, impaired relaxation $(<1.0)$, and restrictive filling $(>2.0)$. Further, from the pulsed wave Doppler flow imaging we can estimate the deceleration and deceleration time of the mitral valve, by measuring the peak E velocity to the beginning of the A wave, which correlates to ventricular stiffness (113).

\subsection{Apoptosis}

Apoptosis, or programmed cell death, is a highly regulated and organized process characterized by the systematic activation of mechanisms leading to precise biochemical and 
morphological alterations. Initially, apoptotic mechanisms are indicated by initiator caspase activation, alterations in cellular redox potential, cell shrinkage, loss of membrane asymmetry, and chromatin condensation. Progressively, the execution phase of apoptosis is characterized by the activation of execution caspases and endonucleases, apoptotic body formation and cell fragmentation (72). While the endpoints are similar, the signaling cascades that regulate the progression of apoptosis can come through two distinct initiator pathways: the intrinsic and extrinsic pathways (Figure 1.3).

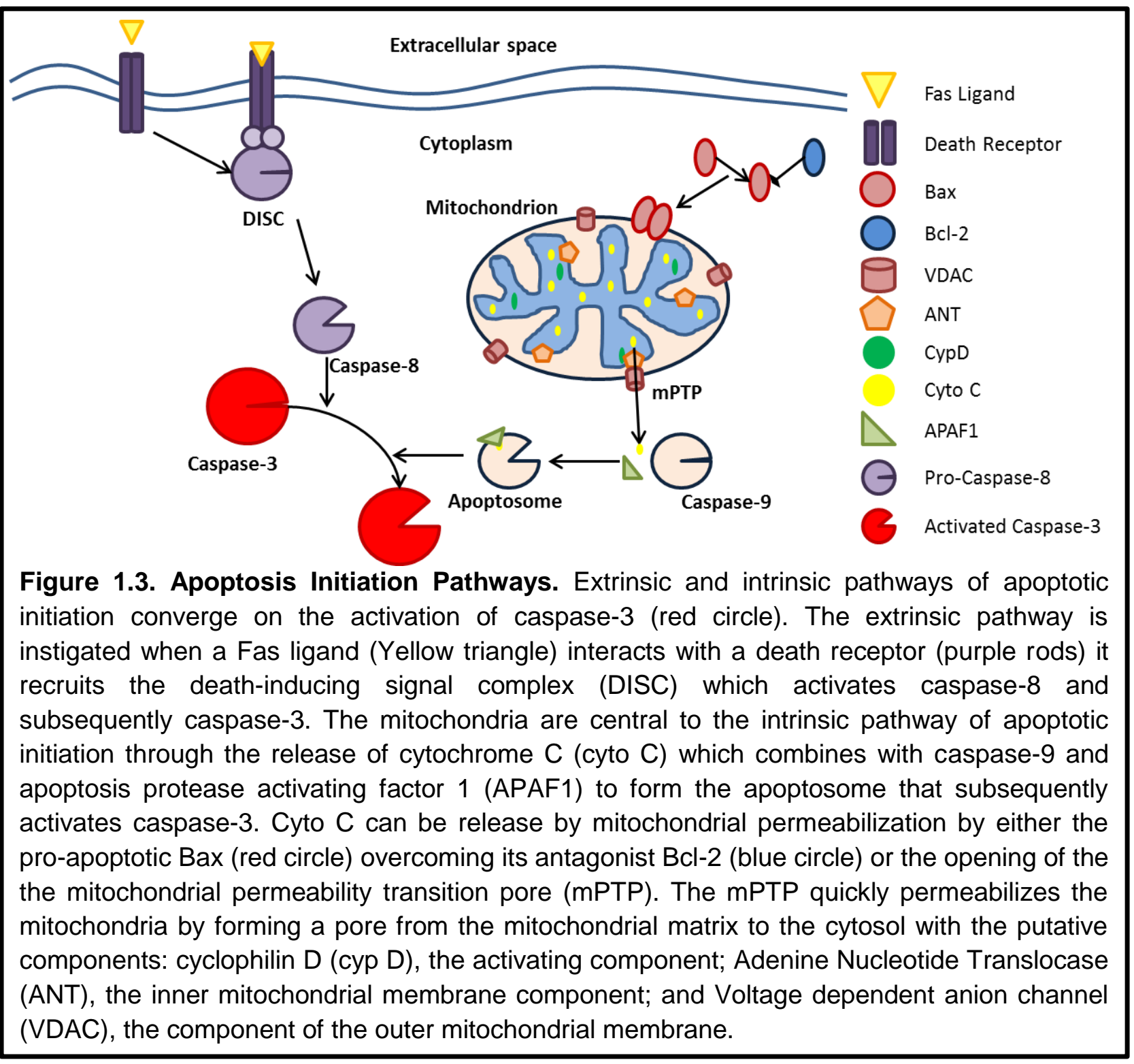




\section{5a. Intrinsic Apoptotic Signaling}

The intrinsic pathway of apoptosis, also known as the mitochondrial pathway, is activated by a variety of stimuli, such as environmental stressors. The pathway refers to the mitochondria due to its role in the apoptotic progression associated with the release of proapoptotic proteins from the organelle. Mitochondrial components and released proteins such as cytochrome C (cyto C), apoptosis-inducing factor, the adenine-nucleotide translocator (ANT), cyclophilin D (cypD), p53, and Smac/Diablo contribute to mitochondrial apoptotic propagation. The release of cyto $\mathrm{C}$ into the cytosol commonly correlates to the induction of apoptosis through the mitochondrial pathway. Once in the cytosol, cyto $\mathrm{C}$ forms a complex with apoptotic protease activating factor 1 (APAF1) and caspase- 9 to stimulate the autocatalysis of caspase-9 and activation of the complex, the apoptosome (Figure 1.3) (143). Once the apoptosome is activated this stimulates the activation of execution caspases, such as caspase3 , that will then carry out the structural and genetic disruptions observed during apoptosis. Thus the apoptotic process is propagated by mitochondrial permeabilization and the release of cyto $\mathrm{C}$ which can occur through multiple mechanisms.

Mitochondrial permeabilization can be accomplished through two main processes: the opening of the mPTP and dysregulated members of the Bcl-2 family of proteins. While the members of the MPTP are not definitive; putative members of the pore consist of voltagedependent anion-channel (VDAC), ANT, and CypD. CypD is believed to be the activator component of the pore (4): when it interacts with ANT it recruits VDAC creating a pore from the mitochondrial matrix to the cytosol through which cyto $\mathrm{C}$ can be released (Figure 1.3). The Bcl-2 family of proteins is made up of both pro and antiapoptotic proteins that counteract each other to control apoptotic initiation. Antiapoptotic $\mathrm{Bcl}-2$ proteins $(\mathrm{Bcl}-2$ and $\mathrm{Bcl}-\mathrm{xl})$ regulate the proapoptotic proteins Bad, Bid, Bim, NOXA, and PUMA (members of the Bcl-2 family of proteins) to prevent apoptosis. Bax forms a homodimer and moves to the outer mitochondrial 
membrane to create a pore through which cyto $\mathrm{C}$ can escape (64). Yet, Bax can also form a heterodimer with Bcl-2 which prevents the formation of the pore and permeabilization of the mitochondria (Figure 1.3).

\section{5b. Extrinsic Apoptotic Signaling}

Induction of apoptosis via the extrinsic pathway is triggered by the activation of death receptors such as those activated by Fas ligand or FasL (Fas (CD95/Apo-1); by the TNF-related apoptosis-inducing ligand or TRAIL (DR4, DR5); and by tumor necrosis factor receptor (TNFR1). Death receptor activation leads to the formation of the death-inducing signaling complex (DISC) formed by the recruitment of the Fas-associated death domain (FADD), caspase 8 and the cellular FLICE-inhibitory protein (FLIP). The initiator caspase, caspase-8, is then processed and activated which further amplifies the apoptotic cascade by activation of execution caspases, such as caspase-3 (Figure 1.3). Upon death receptor activation, cells have lower levels of DISC formation and active caspase-8, the progression of the cell death program relies on an amplification loop created by the cleavage of Bid, a Bcl-2-family protein, by caspase 8 and the resultant release of cytochrome $\mathrm{c}$ from mitochondria (88). Suggesting there is a role for the mitochondria even in the extrinsic pathway of apoptosis initiation.

\subsection{Mitochondrial Subpopulations}

Localization within the cell is critical to function. We know that proteins and organelles are positioned near their site of use. Sufficient evidence suggests that the mitochondria, especially of neural and muscle cells, are functionally heterogeneous within different cellular locations. Dendritic, somatic, axonal, and presynaptic neural segments require different energy 
and calcium dynamics which are associated with structural and biochemical differences in the neural regions (86). Within the cardiomyocyte, there are also spatially and biochemically distinct subpopulations of mitochondria: the subsarcolemmal mitochondria (SSM) which reside below the sarcolemma and the interfibrillar mitochondria (IFM) that sit between the myofibril contractile apparatus (Figure 1.4). This feature has been substantiated in numerous mammalian species including mouse, rat, muskrat, guinea pig, hamster, rabbit, dog, pig, monkey, cow and human $(36,54,73,98,110,153,159,175)$. Furthermore, another specific population of mitochondria populating the perinuclear region within the cardiomyocyte exist and are commonly isolated with the IFM. Ultimately, the heterogeneity of these subpopulations leads to a differential mitochondrial response under physiological and pathological stimuli $(66,83,86,92,109,171)$.
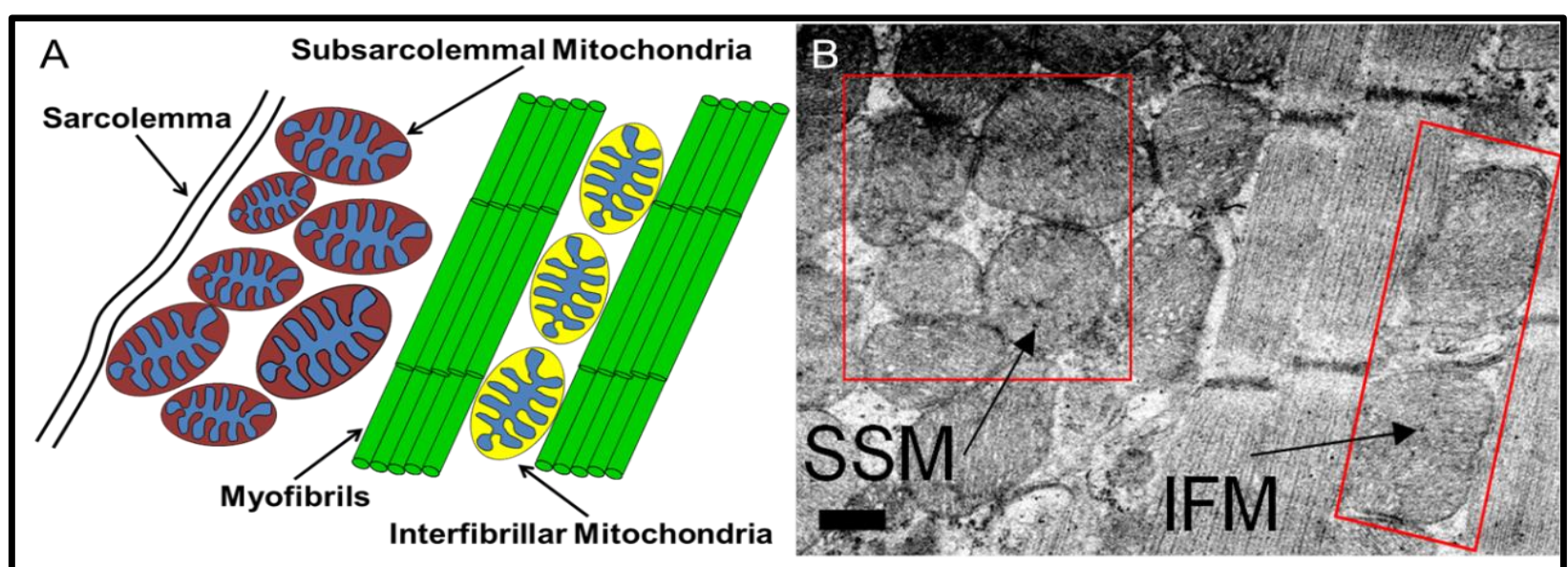

Figure 1.4. Mitochondrial Subpopulations. A graphic representation (A) and electron micrograph image (B) of the mitochondrial subpopulations found within myocytes. The subsarcolemmal mitochondria (SSM), which sit below the sarcolemma, and the interfibrillar mitochondria (IFM), residing between the myofibrils (75).

\section{6a. Functional Differences}

Not only are the mitochondrial subpopulations within the cardiomyocyte spatially distinct, but they are also biochemically distinct with numerous studies reporting distinct functional role for the SSM and IFM. It is hypothesized that the SSM primarily provide the ATP needed for 
active transport of electrolytes and metabolites through the sarcolemma, in contrast the IFM supply the myofibrils with the necessary ATP for cardiac contraction $(114,129,144)$. While these hypotheses have not been determined experimentally, they are consistent with the concept that the location of the mitochondrion is related to the process that it fuels with ATP.

Biochemical functional differences have been outlined between the SSM and IFM supporting distinct metabolic roles for each subpopulation within the cell (129). In the IFM, higher respiratory rates as well as succinate dehydrogenase and citrate synthase activities compared to the SSM. Additionally, higher complex I, II and III oxidation rates (128) and increased ATP synthase (complex V) activities (6) have been reported in the IFM compared to the SSM. These biochemical differences may also suggest that the mitochondrial subpopulations will react differentially to pathological stimuli.

\section{6b. Communication between Subpopulations}

It has been indicated that mitochondrial subpopulations may be able to communicate across the cell, providing a platform for mitochondrial synchronization (196). The degree of interaction between these two subpopulations is of debate but one hypothesis indicates that the innermost SSM and the outermost IFM are connected through mitochondrial filaments enabling metabolic coupling (157)

\subsection{Pathological Influence on Mitochondrial Subpopulations}

With the development of mitochondrial isolation techniques, utilizing both mechanical and enzymatic procedures to sequentially fraction the spatially-distinct mitochondrial subpopulations (129), efforts to define their differential reactions to pathological stimuli have 
been pursued. Mitochondrial subpopulations are differentially influenced during ischemia, ischemia/reperfusion, hypoxia, myocardial infraction, preconditioning, postconditioning, heart failure, exercise, and diabetes mellitus (75). Ischemia alone led to an increase in ROS production (26) and decreased mitochondrial function (154) in the SSM. Yet, when the ischemic event is followed by reperfusion of the blood, both the SSM and IFM were impacted $(36,43)$. After chronic hypoxia, both SSM and IFM were functionally impacted but the dysfunction of the SSM was suggested to be compensatory to decrease ROS production (71). During myocardial infarction the heart loses blood perfusion leading to ischemia and necrosis within that region. Following models of myocardial infarction both the SSM and IFM respiratory rates were decreased and ROS production increased (70). Pre- and postconditioning of the heart use ischemia to protect the heart against a greater ischemic insult. Following preconditioning, the SSM are primarily protected and this may be a function of initial ischemic condition and calcium overload $(25,97)$. Cardiac ischemic postconditioning decreased cardiac injury and helped to maintain the inner mitochondrial membrane potential reducing the oxidative stress of both mitochondrial subpopulations (127).

When the heart is unable to sufficiently supply oxygenated blood to the systemic circulation and enters heart failure the mitochondrion is implicated due to the metabolic imbalance. Heart failure is induced through either pressure or volume overload and the mitochondrial subpopulations are differentially impacted based on the stimulus. Pressure overload induces dysfunction in the IFM (77) while the SSM are primarily impacted by volume overload induced heart failure (108). Exercise training is associated with mitochondrial biogenesis (76) and increased mitochondrial enzyme proteins and activities (162). Exercise training has shown to be effective in decreasing ROS production in both subpopulations of mitochondria, yet the SSM have increased ROS damage due to decreased antioxidant capacity (84). 
Finally, mitochondrial dysfunction has been shown to be central in the pathogenesis of diabetic cardiomyopathy. Diabetes mellitus, which is characterized by lack of insulin (type 1 diabetes mellitus) or insulin resistance (type 2 diabetes mellitus), has shown differential subpopulation effects. In type 1 diabetes the IFM are most impacted exhibiting decreased respiratory capacity (35), morphology (173) and dysregulated proteome (5). In contrast, the SSM from animals with type 2 diabetes have decreased respiratory rates, complex activities and increased ROS damage (34). This data was echoed in the atrial tissue of diabetic patients suggesting that mitochondrial subpopulations are differentially impacted by pathology in humans (33). Ultimately, these studies help to illustrate that mitochondrial subpopulations can be differentially impacted by pathological stimuli, and that similar stimuli may differentially affect these mitochondria.

\subsection{Mitochondrial Dysfunction}

Mitochondria are essential organelles present in all but a few mammalian cell types, where they perform multiple functions in homeostatic mechanisms. Not only through the production of ATP from oxidative phosphorylation utilizing the electrochemical gradient generated across the inner membranes by the electron transport chain (ETC) but also due to its oxidative and apoptotic potential. Thus, mitochondrial dysfunction is central in the etiology of many cardiovascular diseases. Further, the mitochondrion may not only be susceptible to external damage but may be capable of additionally damaging its own membranes, proteins and DNA exacerbating disease. 


\section{8a. Mitochondrial Dysfunction and Oxidative Stress}

A number of studies demonstrate that an altered level of oxidative stress in the cardiovascular environment is crucial to the development of cardiovascular disease. Diatomic oxygen, despite being a radical species, is the most important oxidant in all aerobic organisms. Oxygen is sparingly reactive in its basal state, and while $\mathrm{O}_{2}$ can accept two electrons, it rarely does so at one time. As a result, $\mathrm{O}_{2}$ is usually serially reduced through enzyme-catalyzed oneelectron reductions in vivo and the required enzymes generally contain iron within their active sites. The ROS term encompasses the superoxide radical, $\mathrm{O}_{2}{ }^{\circ}$, hydrogen peroxide, $\mathrm{H}_{2} \mathrm{O}_{2}$, and the hydroxyl radical, $\mathrm{OH}^{*}$. At physiologic $\mathrm{pH}$, the superoxide radical dismutates or is catalyzed by superoxide dismutase (SOD) to form $\mathrm{H}_{2} \mathrm{O}_{2}$ (53). Cellular sources of ROS include: xanthine oxidase, NADPH oxidase, arachidonic acid metabolism, microsomal P-450 enzymes, and the mitochondrial ETC (8).

Within the cell there are multiple sources of ROS generation but the mitochondrion accounts for about $90 \%$ of basal cellular ROS production (30). The respiratory chain is the major source of ROS production: due to electron leakage from complexes I and III of the ETC $(15,160)$. Through the Fenton reaction, superoxide can generate the hydroxyl radical in the

presence of redox metals (i.e. iron, copper). The proteins of the ETC are iron-sulfur centered proteins, thus they can increase the formation of hydroxyl radicals. Of course the ETC isn't the only site of mitochondrial ROS generation: $\alpha$-ketoglutarate and aconitase generate hydroxyl radicals from superoxide but this leads to enzyme inactivation $(55,56)$.

The three main classes of biological materials are susceptible to free radical attack and suffer oxidative damage in vivo. Oxidation of lipids was the earliest research on the destruction of biological materials (67). Peroxidative chain reactions occur when a lipid hydroperoxyl radical extricates a hydrogen from the neighboring unsaturated lipid, forming a hydroperoxide and an 
alkyl radical which then combines with $\mathrm{O}_{2}$ and regenerates a lipid hydroperoxyl radical beginning a new round. Ultimately, cyclic endoperoxides and unsaturated aldehydes are formed inactivating enzymes (169), operating as endogenous fixatives with proteins and nucleic acids forming heterogeneous cross-links (29), but primarily decreasing membrane fluidity altering membrane properties and disrupting membrane-bound proteins $(24,174)$. The oxidation of proteins is less well characterized, but classes of damage have been identified: oxidation of sulfhydryl groups, reduction of disulfides, oxidative adduction of amino acid residues close to metal-binding sites via metal-catalyzed oxidation, reactions with aldehydes, protein-protein cross-linking, and peptide fragmentation $(161,167)$. Even though proteins represent a very diverse target for oxidative damage, there has been little scrutiny of differences between proteins in their sensitivities. Yet due to proximity, mitochondrial ROS can oxidize the mitochondrial lipids and proteins found within the inner mitochondrial membrane (IMM), most importantly the proteins of the ETC.

\section{8b. Mitochondrial Dysfunction and Apoptotic Signaling}

The mitochondrion plays a major role in the apoptotic signaling in the intrinsic pathway of apoptosis initiation. One of the key nodal points in mediating cell death and cardiac function is the opening of the mPTP. While mPTP opening releases pro-apoptotic proteins such as cyto C and AIF, it also leads to membrane depolarization $(78,193)$, cessation of ATP production (142), release of mitochondrial calcium (11), and decreased mitochondrial efficiency leading to increased ROS generation (197). Demonstratively, mitochondrial dysfunction precedes apoptosis following in vitro pharmacological induction (63). In animals with a dysfunctional chaperone protein, $\alpha$-B-crystallin, mitochondrial dysfunction precedes apoptosis and heart 
failure (106) further suggesting mitochondrial dysfunction and apoptotic initiation can lead to cardiac dysfunction.

\subsection{Antioxidant Defense Systems}

Oxidative stress is the balance between ROS and the antioxidant defense systems of the cell. The high respiratory capacity of the mitochondrion leads to high ROS production and have developed an evolutionarily beneficial defense system. The antioxidant defense within the mitochondria has several mechanisms of defense against enhanced oxidative stress (62). One mechanism of reducing ROS generation is the uncoupling of the mitochondria by decreasing mitochondrial membrane potential (158). Yet this results in the decline of oxidative phosphorylation and ATP production. Thus, the mitochondria more frequently rely on enzymes to diminish oxidative stress and preserve metabolic function. These enzymatic reactions include: superoxide dismutation to $\mathrm{H}_{2} \mathrm{O}_{2}$ by manganese $\mathrm{SOD}$ and $\mathrm{H}_{2} \mathrm{O}_{2}$ scavenging by catalase, peroxiredoxins, or glutathione peroxidases (GPx) (62).

\section{9a. Glutathione Peroxidases}

Glutathione peroxidases comprise a phylogenetically related family of enzymes whose main biological role is to diminish the oxidative stress and oxidative damage within the cell. There are several GPx isozymes with similar functions, but are encoded by different genes and vary in cellular locations. Mammalian GPx1-4 are selenoproteins with a selenocysteine in the catalytic center, and GPx6 is a selenoprotein only found in humans. It is well established that GPxs catalyze the reduction of $\mathrm{H}_{2} \mathrm{O}_{2}$ to water, or the corresponding alcohol, using glutathione (GSH) as a reductant (Figure 1.5) (178). The presence of selenium in the active site is 


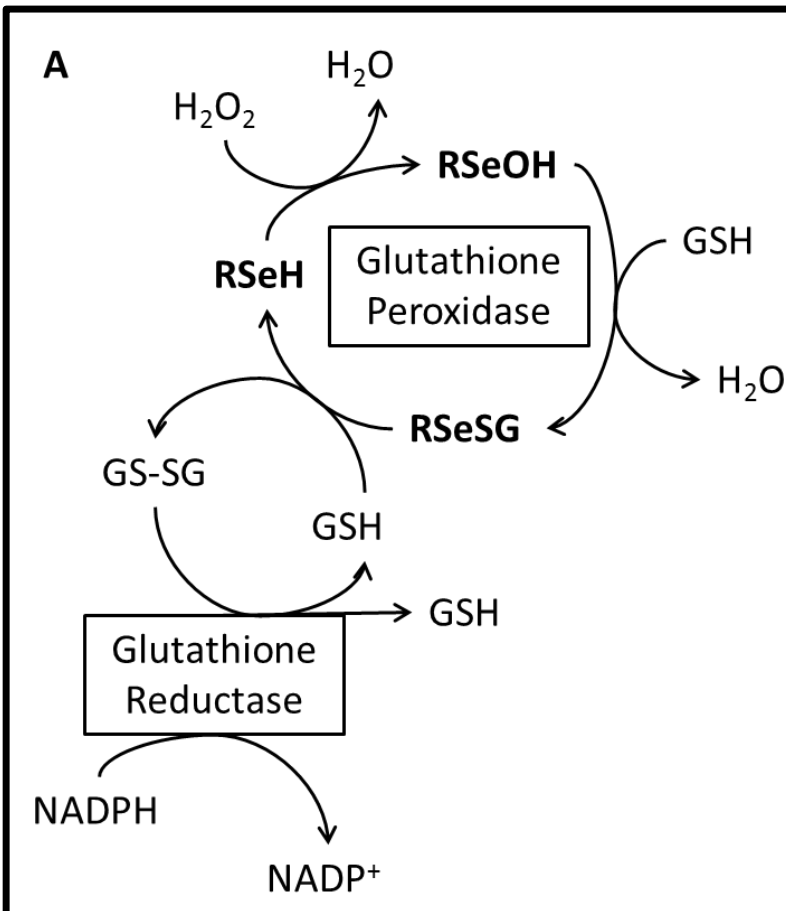

B

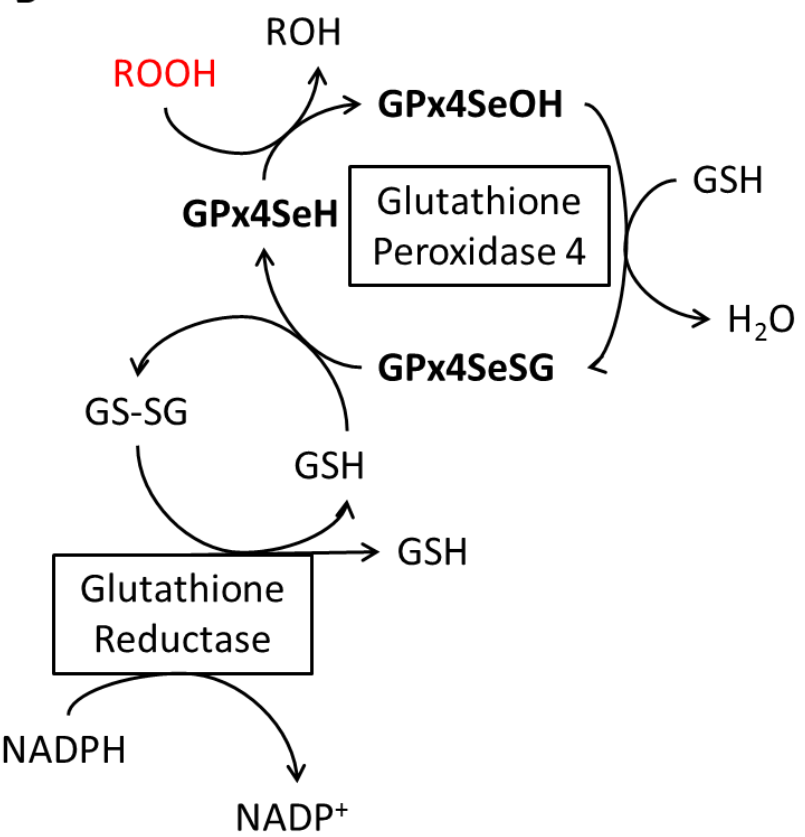

Figure 1.5. Glutathione Peroxidase Antioxidant Mechanism. The selenocysteine site of glutathione peroxidase $(A)$ reduces hydrogen peroxide $\left(\mathrm{H}_{2} \mathrm{O}_{2}\right)$ or lipid peroxides by glutathione peroxidase 4 (B). Recycling of the glutathione necessary for proper enzyme function is accomplished by glutathione reductase in both enzymes.

necessary for the antioxidant properties of GPx. At its resting state the selenocysteine site of these selenoproteins is in a Se (-) form. This site is oxidized by a peroxide to form a selenic acid group $(\mathrm{RSeOH})$ which is then ensnared by a reduced GSH molecule to form GS-SeR. Another GSH molecule reduces this to Se (-) again, releasing a GS-SG by-product. The functions of these enzymes are similar, yet their structures differ. GPx1-3 are homotetrameric proteins, and catalyze the reduction of hydrogen peroxide and organic hydroperoxides, whereas GPx4 has a monomeric structure and directly reduces phospholipid and cholesterol hydroperoxides.

\section{9b. Glutathione Peroxidase 4}

Glutathione peroxidase 4, also referred to as phospholipid hydroperoxide glutathione peroxidase (PHGPx), is expressed in all cell types and is a unique GPx due to its affinity for lipid 
hydroxides. PHGPx is exceptional as the only antioxidant capable of reducing lipid hydroperoxides to alcohols and still reducing free $\mathrm{H}_{2} \mathrm{O}_{2}(104,178)$. Similar to other GPxs, the Se (-) site is oxidized by a hydroperoxide to a selenenic acid group and then reduced with two GSH molecules, yet this reaction can incorporate a selenadisulfide step. Normally, GS-SG (oxidized GSH) is recycled by glutathione reductase (GR) at the expense of $\mathrm{NADPH} / \mathrm{H}+(178)$. Though, at low GSH levels, PHGPx converts into a protein thiol peroxidase and creates disulfide bridges in proteins. If free thiols aren't available, PHGPx may become cross-linked through selenenylsulfide bridges or disulfide bridges to other proteins.

Within the cell PHGPx has several isoforms: cytoplasmic, nuclear, and mitochondrial. Full length PHGPx contains seven exons and differential transcription drives isoform localization due to divergent targeting sequences. PHGPx RNA is synthesized as a long and short form owing to two initiation sites within exon la of the PHGPx genomic DNA $(3,138)$. Transfection of cells with DNA of the short form overexpressed PHGPx in the cytosol but not in the mitochondria suggesting the short form is cytosolic PHGPx (2). Addition of the long form leader sequence to the $\mathrm{N}$-terminus of green fluorescent protein results in the localization of the protein to the mitochondria (2). Thus, the long form is the mitochondrial PHGPx (mPHGPx) with the signal peptide for mitochondrial transport. In the PHGPx DNA a different first exon in lb exists between exon la and II containing a nuclear targeting signal (134). This transcript creates the nuclear isoform of PHGPx, the most unique version of GPx4.

Genetic manipulation of PHGPx in animals has helped to elucidate its importance in development and role in the response to pathological stimuli. PHGPx knockout mice die at E7.5 in the embryonic stage indicating an essential role for the selenoprotein during development $(79,192)$. Lung fibroblasts from heterozygous knockout of GPx4 (GPx4 +/-) were more susceptible to $\mathrm{H}_{2} \mathrm{O}_{2}$, cadmium and cumene hydroperoxide (57). Utilizing PHGPx inactivation in mice, Seiler et al. identified PHGPx can protect from neurodegeneration through attenuation of 
AlF-mediated apoptosis (148). Corroboratingly, transgenic overexpression provided protection against oxidative-stress induced apoptosis $(65,140)$. Numerous in vitro studies agree with these in vivo reports: PHGPx can protect against oxidants, apoptosis, and DNA damage $(16,31,102)$.

While these reports highlight the importance of PHGPx, they do not focus on the differential importance of GPx4 isoforms in response to various stimuli. In order to direct our focus on the mitochondrial form's protective ability, our lab developed a mouse line in which PHGPx is targeted to the mitochondria at higher expression levels (36). Utilizing this novel animal model, mPHGPx was able to preserve cardiac contractile following Ischemia/repercussion (36). Within the mitochondrion, overexpression of mPHGPx was able to diminish lipid peroxidation and preserved mitochondrial function in both the SSM and IFM following Ischemialrepercussion. Animals overexpressing mPHGPx were also able to maintain mitochondrial function and proteomic composition of the IFM during type 1 diabetes mellitus (5). MPHGPX is specific to the inner membrane space where it interfaces with the IMM and scavenges phospholipid hydroperoxides to preserve IMM integrity $(74,118)$. Phospholipids within the IMM interact with the proteins of the ETC and mitochondrial protein import machinery essential to the function of the organelle. Therefore, preserving mitochondrial IMM phospholipids is essential to maintaining mitochondrial function.

\section{9c. Antioxidant Defense in Xenobiotic Exposure}

Antioxidant defense mechanisms are not commonly investigated but differential expression of key enzymes involved in attenuating oxidative stress have been identified following xenobiotic exposure. In humans, circulating SOD and GPx1 levels were increased by relocating to an area with higher PM concentration (187). In animal models of PM exposure, decreased expression of SOD, GPx, and catalase are correlated to pulmonary and systemic 
responses to exposure $(37,130)$. Further, a single exposure to PM can elicit a decrease in mitochondrial SOD activity in the lung (100). In vitro analysis corroborate these findings, identifying mitochondrial dysfunction, ROS production and decreased antioxidant capacity following treatment with ENMs (183). Finally, one recent study suggests that antioxidant pretreatment can protect the heart from particulate-induced ROS-mediated dysfunction (37).

\subsection{Summary}

Nearly every individual in the industrial world is exposed to xenobiotic particles either in the form of ambient particulate matter or the emergent class of particles, ENMs. As nanotechnology has grown into a multi-billion dollar industry, due to their incorporation into consumer based products, investigation into the toxicological impacts of these materials has not met the pace of the industrial growth. ROS are heavily implicated in the etiology of adverse pulmonary and extrapulmonary impacts of exposure. Xenobiotic exposure is also associated with mitochondrial dysfunction and apoptotic signaling in extrapulmonary tissues. Hence, the goal of this dissertation was to examine the impacts of xenobiotic exposure on cardiac and mitochondrial function. Further, a transgenic mouse model overexpressing mPHGPx was utilized to determine the role of mitochondrial ROS in the initiation of dysfunction. 


\section{References}

1. Human respiratory tract model for radiological protection. A report of a Task Group of the International Commission on Radiological Protection. Ann ICRP 24: 1-482, 1994.

2. Arai M, Imai H, Koumura T, Yoshida M, Emoto K, Umeda M, Chiba N, and Nakagawa Y. Mitochondrial phospholipid hydroperoxide glutathione peroxidase plays a major role in preventing oxidative injury to cells. J Biol Chem 274: 4924-4933, 1999.

3. Arai M, Imai H, Sumi D, Imanaka T, Takano T, Chiba N, and Nakagawa Y. Import into mitochondria of phospholipid hydroperoxide glutathione peroxidase requires a leader sequence. Biochem Biophys Res Commun 227: 433-439, 1996.

4. Baines CP, Kaiser RA, Purcell NH, Blair NS, Osinska H, Hambleton MA, Brunskill EW, Sayen MR, Gottlieb RA, Dorn GW, Robbins J, and Molkentin JD. Loss of cyclophilin D reveals a critical role for mitochondrial permeability transition in cell death. Nature 434: 658-662, 2005.

5. Baseler WA, Dabkowski ER, Jagannathan R, Thapa D, Nichols CE, Shepherd DL, Croston TL, Powell M, Razunguzwa TT, Lewis SE, Schnell DM, and Hollander JM. Reversal of mitochondrial proteomic loss in Type 1 diabetic heart with overexpression of phospholipid hydroperoxide glutathione peroxidase. Am J Physiol Regul Integr Comp Physiol 304: R553-565, 2013.

6. Baseler WA, Thapa D, Jagannathan R, Dabkowski ER, Croston TL, and Hollander JM. miR-141 as a regulator of the mitochondrial phosphate carrier (Slc25a3) in the type 1 diabetic heart. Am J Physiol Cell Physiol 303: C1244-1251, 2012.

7. Becher R, Bucht A, Ovrevik J, Hongslo JK, DahIman HJ, Samuelsen JT, and Schwarze PE. Involvement of NADPH oxidase and iNOS in rodent pulmonary cytokine responses to urban air and mineral particles. Inhal Toxicol 19: 645-655, 2007.

8. Beckman KB and Ames BN. The free radical theory of aging matures. Physiol Rev 78: 547-581, 1998. 
9. Bell ML, Ebisu K, Peng RD, Samet JM, and Dominici F. Hospital admissions and chemical composition of fine particle air pollution. Am J Respir Crit Care Med 179: 1115-1120, 2009.

10. Bermudez E, Mangum JB, Wong BA, Asgharian B, Hext PM, Warheit DB, and

Everitt Jl. Pulmonary responses of mice, rats, and hamsters to subchronic inhalation of ultrafine titanium dioxide particles. Toxicol Sci 77: 347-357, 2004.

11. Bernardi P and von Stockum S. The permeability transition pore as a $\mathrm{Ca}(2+)$ release channel: new answers to an old question. Cell Calcium 52: 22-27, 2012.

12. Boland S, Hussain S, and Baeza-Squiban A. Carbon black and titanium dioxide nanoparticles induce distinct molecular mechanisms of toxicity. Wiley Interdiscip Rev Nanomed Nanobiotechnol 6: 641-652, 2014.

13. Bosi S, Da Ros T, Spalluto G, and Prato M. Fullerene derivatives: an attractive tool for biological applications. Eur J Med Chem 38: 913-923, 2003.

14. Brain JD, Knudson DE, Sorokin SP, and Davis MA. Pulmonary distribution of particles given by intratracheal instillation or by aerosol inhalation. Environ Res 11: 13-33, 1976.

15. Brand MD, Affourtit C, Esteves TC, Green K, Lambert AJ, Miwa S, Pakay JL, and Parker N. Mitochondrial superoxide: production, biological effects, and activation of uncoupling proteins. Free Radic Biol Med 37: 755-767, 2004.

16. Brielmeier M, Bechet JM, Suppmann S, Conrad M, Laux G, and Bornkamm GW. Cloning of phospholipid hydroperoxide glutathione peroxidase (PHGPx) as an anti-apoptotic and growth promoting gene of Burkitt lymphoma cells. Biofactors 14: 179-190, 2001.

17. Brook RD, Franklin B, Cascio W, Hong Y, Howard G, Lipsett M, Luepker R, Mittleman M, Samet J, Smith SC, Jr., Tager I, Expert Panel on P, and Prevention Science of the American Heart A. Air pollution and cardiovascular disease: a statement for healthcare professionals from the Expert Panel on Population and Prevention Science of the American Heart Association. Circulation 109: 2655-2671, 2004. 
18. Brook RD, Rajagopalan S, Pope CA, 3rd, Brook JR, Bhatnagar A, Diez-Roux AV, Holguin F, Hong Y, Luepker RV, Mittleman MA, Peters A, Siscovick D, Smith SC, Jr., Whitsel L, Kaufman JD, American Heart Association Council on E, Prevention CotKiCD, Council on Nutrition PA, and Metabolism. Particulate matter air pollution and cardiovascular disease: An update to the scientific statement from the American Heart Association. Circulation 121: 2331-2378, 2010.

19. Bu Q, Yan G, Deng P, Peng F, Lin H, Xu Y, Cao Z, Zhou T, Xue A, Wang Y, Cen X, and Zhao YL. NMR-based metabonomic study of the sub-acute toxicity of titanium dioxide nanoparticles in rats after oral administration. Nanotechnology 21: 125105, 2010.

20. Buzea C, Pacheco, II, and Robbie K. Nanomaterials and nanoparticles: sources and toxicity. Biointerphases 2: MR17-71, 2007.

21. Cao J, Qin G, Shi R, Bai F, Yang G, Zhang M, and Lv J. Overproduction of reactive oxygen species and activation of MAPKs are involved in apoptosis induced by PM2.5 in rat cardiac H9c2 cells. J Appl Toxicol 36: 609-617, 2016.

22. Carll AP, Haykal-Coates N, Winsett DW, Hazari MS, Ledbetter AD, Richards JH, Cascio WE, Costa DL, and Farraj AK. Cardiomyopathy confers susceptibility to particulate matter-induced oxidative stress, vagal dominance, arrhythmia and pulmonary inflammation in heart failure-prone rats. Inhal Toxicol 27: 100-112, 2015.

23. Carll AP, Hazari MS, Perez CM, Krantz QT, King CJ, Haykal-Coates N, Cascio WE, Costa DL, and Farraj AK. An autonomic link between inhaled diesel exhaust and impaired cardiac performance: insight from treadmill and dobutamine challenges in heart failure-prone rats. Toxicological sciences : an official journal of the Society of Toxicology 135: 425-436, 2013. 24. Chen JJ and Yu BP. Alterations in mitochondrial membrane fluidity by lipid peroxidation products. Free Radic Biol Med 17: 411-418, 1994. 
25. Chen Q and Lesnefsky EJ. Blockade of electron transport during ischemia preserves bcl-2 and inhibits opening of the mitochondrial permeability transition pore. FEBS Lett 585: 921926, 2011.

26. Chen Q, Moghaddas S, Hoppel CL, and Lesnefsky EJ. Ischemic defects in the electron transport chain increase the production of reactive oxygen species from isolated rat heart mitochondria. Am J Physiol Cell Physiol 294: C460-466, 2008.

27. Chen S, Yuan J, Qiao S, Duan F, Zhang J, and Wang H. Evaluation of left ventricular diastolic function by global strain rate imaging in patients with obstructive hypertrophic cardiomyopathy: a simultaneous speckle tracking echocardiography and cardiac catheterization study. Echocardiography 31: 615-622, 2014.

28. Cherng TW, Paffett ML, Jackson-Weaver O, Campen MJ, Walker BR, and Kanagy NL. Mechanisms of diesel-induced endothelial nitric oxide synthase dysfunction in coronary arterioles. Environ Health Perspect 119: 98-103, 2011.

29. Chio KS and Tappel AL. Synthesis and characterization of the fluorescent products derived from malonaldehyde and amino acids. Biochemistry 8: 2821-2826, 1969.

30. Conn PM. Handbook of models for human aging. Amsterdam ; Boston: Elsevier Academic Press, 2006.

31. Conrad M, Schneider M, Seiler A, and Bornkamm GW. Physiological role of phospholipid hydroperoxide glutathione peroxidase in mammals. Biol Chem 388: 1019-1025, 2007.

32. Crea F, Camici PG, and Bairey Merz CN. Coronary microvascular dysfunction: an update. Eur Heart J 35: 1101-1111, 2014.

33. Croston TL, Thapa D, Holden AA, Tveter KJ, Lewis SE, Shepherd DL, Nichols CE, Long DM, Olfert IM, Jagannathan R, and Hollander JM. Functional deficiencies of subsarcolemmal mitochondria in the type 2 diabetic human heart. Am J Physiol Heart Circ Physiol 307: H54-65, 2014. 
34. Dabkowski ER, Baseler WA, Williamson CL, Powell M, Razunguzwa TT, Frisbee

JC, and Hollander JM. Mitochondrial dysfunction in the type 2 diabetic heart is associated with alterations in spatially distinct mitochondrial proteomes. Am J Physiol Heart Circ Physiol 299: H529-540, 2010.

35. Dabkowski ER, Williamson CL, Bukowski VC, Chapman RS, Leonard SS, Peer CJ, Callery PS, and Hollander JM. Diabetic cardiomyopathy-associated dysfunction in spatially distinct mitochondrial subpopulations. Am J Physiol Heart Circ Physiol 296: H359-369, 2009.

36. Dabkowski ER, Williamson CL, and Hollander JM. Mitochondria-specific transgenic overexpression of phospholipid hydroperoxide glutathione peroxidase (GPx4) attenuates ischemia/reperfusion-associated cardiac dysfunction. Free Radic Biol Med 45: 855-865, 2008.

37. Dianat M, Radmanesh E, Badavi M, Mard SA, and Goudarzi G. Disturbance effects of PM on iNOS and eNOS mRNA expression levels and antioxidant activity induced by ischemiareperfusion injury in isolated rat heart: protective role of vanillic acid. Environ Sci Pollut Res Int, 2015.

38. Dominici F, McDermott A, Zeger SL, and Samet JM. National maps of the effects of particulate matter on mortality: exploring geographical variation. Environmental health perspectives 111: 39-44, 2003.

39. Donaldson K, Aitken R, Tran L, Stone V, Duffin R, Forrest G, and Alexander A. Carbon nanotubes: a review of their properties in relation to pulmonary toxicology and workplace safety. Toxicol Sci 92: 5-22, 2006.

40. Donaldson K and Stone V. Current hypotheses on the mechanisms of toxicity of ultrafine particles. Ann Ist Super Sanita 39: 405-410, 2003.

41. Dong P, Li JH, Xu SP, Wu XJ, Xiang X, Yang QQ, Jin JC, Liu Y, and Jiang FL. Mitochondrial dysfunction induced by ultra-small silver nanoclusters with a distinct toxic mechanism. J Hazard Mater 308: 139-148, 2016. 
42. Driscoll KE, Costa DL, Hatch G, Henderson R, Oberdorster G, Salem H, and Schlesinger RB. Intratracheal instillation as an exposure technique for the evaluation of respiratory tract toxicity: uses and limitations. Toxicol Sci 55: 24-35, 2000.

43. Duan $\mathbf{J}$ and Karmazyn M. Relationship between oxidative phosphorylation and adenine nucleotide translocase activity of two populations of cardiac mitochondria and mechanical recovery of ischemic hearts following reperfusion. Can J Physiol Pharmacol 67: 704-709, 1989.

44. Ebbesen TW, Lezec HJ, Hiura H, Bennett JW, Ghaemi HF, and Thio T. Electrical conductivity of individual carbon nanotubes. Nature 382: 54-56, 1996.

45. EIA. US. Annual coal report 2013, edited by Administration USEI. Washington, DC, 2015.

46. Elder A and Oberdorster G. Translocation and effects of ultrafine particles outside of the lung. Clin Occup Environ Med 5: 785-796, 2006.

47. EPA. US. Air Quality Criteria for Particulate Matter (Final Report, Oct 2004). edited by Agency USEP. Washington, DC, 2004.

48. Erdely A, Dahm M, Chen BT, Zeidler-Erdely PC, Fernback JE, Birch ME, Evans DE, Kashon ML, Deddens JA, Hulderman T, Bilgesu SA, Battelli L, Schwegler-Berry D, Leonard HD, McKinney W, Frazer DG, Antonini JM, Porter DW, Castranova V, and Schubauer-Berigan MK. Carbon nanotube dosimetry: from workplace exposure assessment to inhalation toxicology. Part Fibre Toxicol 10: 53, 2013.

49. Esch L and Hendryx M. Chronic cardiovascular disease mortality in mountaintop mining areas of central Appalachian states. J Rural Health 27: 350-357, 2011.

50. Fanizza E, lacobazzi RM, Laquintana V, Valente G, Caliandro G, Striccoli M, Agostiano A, Cutrignelli A, Lopedota A, Curri ML, Franco M, Depalo N, and Denora N. Highly selective luminescent nanostructures for mitochondrial imaging and targeting. Nanoscale 8: 3350-3361, 2016. 
51. Feigenbaum H. Role of M-mode technique in today's echocardiography. J Am Soc Echocardiogr 23: 240-257; 335-247, 2010.

52. Ferin J, Oberdorster G, and Penney DP. Pulmonary retention of ultrafine and fine particles in rats. Am J Respir Cell Mol Biol 6: 535-542, 1992.

53. Fridovich I. Superoxide anion radical (O2-.), superoxide dismutases, and related matters. J Biol Chem 272: 18515-18517, 1997.

54. Galvao TF, Brown BH, Hecker PA, O'Connell KA, O'Shea KM, Sabbah HN, Rastogi S, Daneault C, Des Rosiers C, and Stanley WC. High intake of saturated fat, but not polyunsaturated fat, improves survival in heart failure despite persistent mitochondrial defects. Cardiovasc Res 93: 24-32, 2012.

55. Gardner PR. Superoxide-driven aconitase FE-S center cycling. Biosci Rep 17: 33-42, 1997.

56. Gardner PR, Raineri I, Epstein LB, and White CW. Superoxide radical and iron modulate aconitase activity in mammalian cells. J Biol Chem 270: 13399-13405, 1995.

57. Garry MR, Kavanagh TJ, Faustman EM, Sidhu JS, Liao R, Ware C, Vliet PA, and Deeb SS. Sensitivity of mouse lung fibroblasts heterozygous for GPx4 to oxidative stress. Free Radic Biol Med 44: 1075-1087, 2008.

58. Geiser M, Baumann M, Cruz-Orive LM, Im Hof V, Waber U, and Gehr P. The effect of particle inhalation on macrophage number and phagocytic activity in the intrapulmonary conducting airways of hamsters. Am J Respir Cell Mol Biol 10: 594-603, 1994.

59. Geyer H, Caracciolo G, Abe H, Wilansky S, Carerj S, Gentile F, Nesser HJ, Khandheria B, Narula J, and Sengupta PP. Assessment of myocardial mechanics using speckle tracking echocardiography: fundamentals and clinical applications. J Am Soc Echocardiogr 23: 351-369; quiz 453-355, 2010. 
60. Golomb E, Matza D, Cummings CA, Schwalb H, Kodavanti UP, Schneider A, Houminer E, Korach A, Nyska A, and Shapira OM. Myocardial mitochondrial injury induced by pulmonary exposure to particulate matter in rats. Toxicol Pathol 40: 779-788, 2012.

61. Gorr MW, Velten M, Nelin TD, Youtz DJ, Sun Q, and Wold LE. Early life exposure to air pollution induces adult cardiac dysfunction. Am J Physiol Heart Circ Physiol 307: H13531360, 2014.

62. Green K, Brand MD, and Murphy MP. Prevention of mitochondrial oxidative damage as a therapeutic strategy in diabetes. Diabetes 53 Suppl 1: S110-118, 2004.

63. Green PS and Leeuwenburgh C. Mitochondrial dysfunction is an early indicator of doxorubicin-induced apoptosis. Biochim Biophys Acta 1588: 94-101, 2002.

64. Gross A, Jockel J, Wei MC, and Korsmeyer SJ. Enforced dimerization of BAX results in its translocation, mitochondrial dysfunction and apoptosis. EMBO J 17: 3878-3885, 1998.

65. Guo Z, Ran Q, Roberts LJ, 2nd, Zhou L, Richardson A, Sharan C, Wu D, and Yang H. Suppression of atherogenesis by overexpression of glutathione peroxidase-4 in apolipoprotein E-deficient mice. Free Radic Biol Med 44: 343-352, 2008.

66. Gustafsson R, Tata JR, Lindberg O, and Ernster L. The relationship between the structure and activity of rat skeletal muscle mitochondria after thyroidectomy and thyroid hormone treatment. J Cell Biol 26: 555-578, 1965.

67. Gutteridge JM and Halliwell B. The measurement and mechanism of lipid peroxidation in biological systems. Trends Biochem Sci 15: 129-135, 1990.

68. Hare JL, Brown JK, and Marwick TH. Association of myocardial strain with left ventricular geometry and progression of hypertensive heart disease. Am J Cardiol 102: 87-91, 2008.

69. Hartz AM, Bauer B, Block ML, Hong JS, and Miller DS. Diesel exhaust particles induce oxidative stress, proinflammatory signaling, and P-glycoprotein up-regulation at the blood-brain barrier. FASEB J 22: 2723-2733, 2008. 
70. Heather LC, Carr CA, Stuckey DJ, Pope S, Morten KJ, Carter EE, Edwards LM, and Clarke K. Critical role of complex III in the early metabolic changes following myocardial infarction. Cardiovasc Res 85: 127-136, 2010.

71. Heather LC, Cole MA, Tan JJ, Ambrose LJ, Pope S, Abd-Jamil AH, Carter EE, Dodd MS, Yeoh KK, Schofield CJ, and Clarke K. Metabolic adaptation to chronic hypoxia in cardiac mitochondria. Basic Res Cardiol 107: 268, 2012.

72. Hengartner MO. The biochemistry of apoptosis. Nature 407: 770-776, 2000.

73. Herpin P and Barre H. Loose-coupled subsarcolemmal mitochondria from muscle Rhomboideus in cold-acclimated piglets. Comp Biochem Physiol B 92: 59-65, 1989.

74. Hollander JM, Lin KM, Scott BT, and Dillmann WH. Overexpression of PHGPx and HSP60/10 protects against ischemia/reoxygenation injury. Free Radic Biol Med 35: 742-751, 2003.

75. Hollander JM, Thapa D, and Shepherd DL. Physiological and structural differences in spatially distinct subpopulations of cardiac mitochondria: influence of cardiac pathologies. Am J Physiol Heart Circ Physiol 307: H1-14, 2014.

76. Holloszy JO. Biochemical adaptations in muscle. Effects of exercise on mitochondrial oxygen uptake and respiratory enzyme activity in skeletal muscle. J Biol Chem 242: 2278-2282, 1967.

77. Hoppel CL, Tandler B, Parland W, Turkaly JS, and Albers LD. Hamster cardiomyopathy. A defect in oxidative phosphorylation in the cardiac interfibrillar mitochondria. $J$ Biol Chem 257: 1540-1548, 1982.

78. Huser $\mathbf{J}$ and Blatter LA. Fluctuations in mitochondrial membrane potential caused by repetitive gating of the permeability transition pore. Biochem J 343 Pt 2: 311-317, 1999.

79. Imai H and Nakagawa Y. Biological significance of phospholipid hydroperoxide glutathione peroxidase (PHGPx, GPx4) in mammalian cells. Free Radic Biol Med 34: 145-169, 2003. 
80. Inoue K, Takano H, Ohnuki M, Yanagisawa R, Sakurai M, Shimada A, Mizushima K, and Yoshikawa T. Size effects of nanomaterials on lung inflammation and coagulatory disturbance. Int J Immunopathol Pharmacol 21: 197-206, 2008.

81. Institute IRS. The relevance of the rat lung response to particle overload for human risk assessment: a workshop consensus report. Inhal Toxicol 12: 1-17, 2000.

82. Jasaityte R, Dandel M, Lehmkuhl H, and Hetzer R. Prediction of short-term outcomes in patients with idiopathic dilated cardiomyopathy referred for transplantation using standard echocardiography and strain imaging. Transplant Proc 41: 277-280, 2009.

83. Jones M, Ferrans VJ, Morrow AG, and Roberts WC. Ultrastructure of crista supraventricularis muscle in patients with congenital heart diseases associated with right ventricular outflow tract obstruction. Circulation 51: 39-67, 1975.

\section{Judge S, Jang YM, Smith A, Selman C, Phillips T, Speakman JR, Hagen T, and}

Leeuwenburgh $\mathbf{C}$. Exercise by lifelong voluntary wheel running reduces subsarcolemmal and interfibrillar mitochondrial hydrogen peroxide production in the heart. Am J Physiol Regul Integr Comp Physiol 289: R1564-1572, 2005.

85. Kan H, Wu Z, Lin YC, Chen TH, Cumpston JL, Kashon ML, Leonard S, Munson AE, and Castranova $\mathbf{V}$. The role of nodose ganglia in the regulation of cardiovascular function following pulmonary exposure to ultrafine titanium dioxide. Nanotoxicology 8: 447-454, 2014. 86. Kann $\mathbf{O}$ and Kovacs R. Mitochondria and neuronal activity. Am J Physiol Cell Physiol 292: C641-657, 2007.

87. Kelly FJ and Fussell JC. Linking ambient particulate matter pollution effects with oxidative biology and immune responses. Ann N Y Acad Sci 1340: 84-94, 2015.

88. Khosravi-Far R and Esposti MD. Death receptor signals to mitochondria. Cancer Biol Ther 3: 1051-1057, 2004. 
89. Knuckles TL, Stapleton PA, Minarchick VC, Esch L, McCawley M, Hendryx M, and Nurkiewicz TR. Air pollution particulate matter collected from an Appalachian mountaintop mining site induces microvascular dysfunction. Microcirculation 20: 158-169, 2013.

90. Kreyling WG and Geiser M. Dosimetry of Inhaled Nanoparticles. In: Nanoparticles in medicine and environment: Inhalation and health effects, edited by Marijnissen JC and Gradon L. Dordrecht: Springer Netherlands, 2010, p. 145-171.

91. Kreyling WG, Semmler-Behnke M, and Moller W. Ultrafine particle-lung interactions: does size matter? J Aerosol Med 19: 74-83, 2006.

92. Kubista V, Kubistova J, and Pette D. Thyroid hormone induced changes in the enzyme activity pattern of energy-supplying metabolism of fast (white), slow (red), and heart muscle of the rat. Eur J Biochem 18: 553-560, 1971.

93. Kurth L, Kolker A, Engle M, Geboy N, Hendryx M, Orem W, McCawley M, Crosby L, Tatu C, Varonka M, and DeVera C. Atmospheric particulate matter in proximity to mountaintop coal mines: sources and potential environmental and human health impacts. Environ Geochem Health 37: 529-544, 2015.

94. Kurth LM, McCawley M, Hendryx M, and Lusk S. Atmospheric particulate matter size distribution and concentration in West Virginia coal mining and non-mining areas. J Expo Sci Environ Epidemiol 24: 405-411, 2014.

95. Lam CW, James JT, McCluskey R, and Hunter RL. Pulmonary toxicity of single-wall carbon nanotubes in mice 7 and 90 days after intratracheal instillation. Toxicol Sci 77: 126-134, 2004.

96. Leong BK, Coombs JK, Sabaitis CP, Rop DA, and Aaron CS. Quantitative morphometric analysis of pulmonary deposition of aerosol particles inhaled via intratracheal nebulization, intratracheal instillation or nose-only inhalation in rats. J Appl Toxicol 18: 149-160, 1998. 
97. Lesnefsky EJ, Chen Q, Moghaddas S, Hassan MO, Tandler B, and Hoppel CL.

Blockade of electron transport during ischemia protects cardiac mitochondria. J Biol Chem 279: 47961-47967, 2004.

98. Lesnefsky EJ, Slabe TJ, Stoll MS, Minkler PE, and Hoppel CL. Myocardial ischemia selectively depletes cardiolipin in rabbit heart subsarcolemmal mitochondria. Am J Physiol Heart Circ Physiol 280: H2770-2778, 2001.

99. Li R, Kou X, Geng H, Xie J, Tian J, Cai Z, and Dong C. Mitochondrial damage: an important mechanism of ambient PM2.5 exposure-induced acute heart injury in rats. $J$ Hazard Mater 287: 392-401, 2015.

100. Li R, Kou X, Geng H, Xie J, Yang Z, Zhang Y, Cai Z, and Dong C. Effect of ambient $\mathrm{PM}(2.5)$ on lung mitochondrial damage and fusion/fission gene expression in rats. Chem Res Toxicol 28: 408-418, 2015.

101. Li Z, Hulderman T, Salmen R, Chapman R, Leonard SS, Young SH, Shvedova A, Luster MI, and Simeonova PP. Cardiovascular effects of pulmonary exposure to single-wall carbon nanotubes. Environ Health Perspect 115: 377-382, 2007.

102. Liang H, Ran Q, Jang YC, Holstein D, Lechleiter J, McDonald-Marsh T, Musatov A, Song W, Van Remmen H, and Richardson A. Glutathione peroxidase 4 differentially regulates the release of apoptogenic proteins from mitochondria. Free Radic Biol Med 47: 312-320, 2009. 103. Liang HY, Cauduro S, Pellikka P, Wang J, Urheim S, Yang EH, Rihal C, Belohlavek M, Khandheria B, Miller FA, and Abraham TP. Usefulness of two-dimensional speckle strain for evaluation of left ventricular diastolic deformation in patients with coronary artery disease. Am J Cardiol 98: 1581-1586, 2006.

104. Lu J and Holmgren A. Selenoproteins. J Biol Chem 284: 723-727, 2009.

105. Ma-Hock L, Strauss V, Treumann S, Kuttler K, Wohlleben W, Hofmann T, Groters S, Wiench K, van Ravenzwaay B, and Landsiedel R. Comparative inhalation toxicity of multi- 
wall carbon nanotubes, graphene, graphite nanoplatelets and low surface carbon black. Part Fibre Toxicol 10: 23, 2013.

106. Maloyan A, Sanbe A, Osinska H, Westfall M, Robinson D, Imahashi K, Murphy E, and Robbins J. Mitochondrial dysfunction and apoptosis underlie the pathogenic process in alpha-B-crystallin desmin-related cardiomyopathy. Circulation 112: 3451-3461, 2005.

107. Marchini T, Magnani N, D'Annunzio V, Tasat D, Gelpi RJ, Alvarez S, and Evelson P. Impaired cardiac mitochondrial function and contractile reserve following an acute exposure to environmental particulate matter. Biochim Biophys Acta 1830: 2545-2552, 2013.

108. Mayer LR, Bonner HW, and Farrar RP. Myocardial mitochondrial synthesis in response to various workloads. Res Commun Chem Pathol Pharmacol 34: 157-160, 1981.

109. McCallister BD and Brown AL, Jr. A quantitative study of myocardial mitochondria in experimental cardiac hypertrophy. Ann N Y Acad Sci 156: 469-479, 1969.

110. McKean TA. Comparison of respiration in rat, guinea pig and muskrat heart mitochondria. Comp Biochem Physiol B 97: 109-112, 1990.

111. Minarchick VC, Stapleton PA, Fix NR, Leonard SS, Sabolsky EM, and Nurkiewicz TR. Intravenous and gastric cerium dioxide nanoparticle exposure disrupts microvascular smooth muscle signaling. Toxicol Sci 144: 77-89, 2015.

112. Minarchick VC, Stapleton PA, Porter DW, Wolfarth MG, Ciftyurek E, Barger M, Sabolsky EM, and Nurkiewicz TR. Pulmonary cerium dioxide nanoparticle exposure differentially impairs coronary and mesenteric arteriolar reactivity. Cardiovasc Toxicol 13: 323337, 2013.

113. Mishra RK, Devereux RB, Cohen BE, Whooley MA, and Schiller NB. Prediction of heart failure and adverse cardiovascular events in outpatients with coronary artery disease using mitral E/A ratio in conjunction with e-wave deceleration time: the heart and soul study. $J$ Am Soc Echocardiogr 24: 1134-1140, 2011. 
114. Muller W. Subsarcolemmal mitochondria and capillarization of soleus muscle fibers in young rats subjected to an endurance training. A morphometric study of semithin sections. Cell Tissue Res 174: 367-389, 1976.

115. Nelin TD, Joseph AM, Gorr MW, and Wold LE. Direct and indirect effects of particulate matter on the cardiovascular system. Toxicol Lett 208: 293-299, 2012.

116. Nemmar A, Al-Salam S, Dhanasekaran S, Sudhadevi M, and Ali BH. Pulmonary exposure to diesel exhaust particles promotes cerebral microvessel thrombosis: protective effect of a cysteine prodrug l-2-oxothiazolidine-4-carboxylic acid. Toxicology 263: 84-92, 2009.

117. Nemmar A, Vanbilloen H, Hoylaerts MF, Hoet PH, Verbruggen A, and Nemery B. Passage of intratracheally instilled ultrafine particles from the lung into the systemic circulation in hamster. American journal of respiratory and critical care medicine 164: 1665-1668, 2001.

118. Nomura K, Imai H, Koumura T, Kobayashi T, and Nakagawa Y. Mitochondrial phospholipid hydroperoxide glutathione peroxidase inhibits the release of cytochrome $\mathrm{c}$ from mitochondria by suppressing the peroxidation of cardiolipin in hypoglycaemia-induced apoptosis. Biochem J 351: 183-193, 2000.

119. Nurkiewicz TR, Porter DW, Barger M, Millecchia L, Rao KM, Marvar PJ, Hubbs AF, Castranova V, and Boegehold MA. Systemic microvascular dysfunction and inflammation after pulmonary particulate matter exposure. Environ Health Perspect 114: 412-419, 2006. 120. Nurkiewicz TR, Porter DW, Hubbs AF, Stone S, Moseley AM, Cumpston JL, Goodwill AG, Frisbee SJ, Perrotta PL, Brock RW, Frisbee JC, Boegehold MA, Frazer DG, Chen BT, Castranova V, and Committee HEIHR. Pulmonary particulate matter and systemic microvascular dysfunction. Res Rep Health Eff Inst: 3-48, 2011.

121. Oberdorster G, Oberdorster E, and Oberdorster J. Nanotoxicology: an emerging discipline evolving from studies of ultrafine particles. Environ Health Perspect 113: 823-839, 2005. 
122. Oberdorster G, Oldiges H, and Zimmermann B. Lung deposition and clearance of cadmium in rats exposed by inhalation or by intratracheal instillation. Zentralb/ Bakteriol B 170: 35-43, 1980.

123. Oberdorster G, Sharp Z, Atudorei V, Elder A, Gelein R, Kreyling W, and Cox C. Translocation of inhaled ultrafine particles to the brain. Inhal Toxicol 16: 437-445, 2004.

124. Oberdorster G, Sharp Z, Atudorei V, Elder A, Gelein R, Lunts A, Kreyling W, and Cox C. Extrapulmonary translocation of ultrafine carbon particles following whole-body inhalation exposure of rats. J Toxicol Environ Health A 65: 1531-1543, 2002.

\section{Ohtani T, Mohammed SF, Yamamoto K, Dunlay SM, Weston SA, Sakata Y,} Rodeheffer RJ, Roger VL, and Redfield MM. Diastolic stiffness as assessed by diastolic wall strain is associated with adverse remodelling and poor outcomes in heart failure with preserved ejection fraction. Eur Heart J 33: 1742-1749, 2012.

126. Olivet J. Global Markets and Technologies for Carbon Nanotubes. BCC Research, 2015.

\section{Paillard M, Gomez L, Augeul L, Loufouat J, Lesnefsky EJ, and Ovize M.}

Postconditioning inhibits mPTP opening independent of oxidative phosphorylation and membrane potential. J Mol Cell Cardiol 46: 902-909, 2009.

128. Palmer JW, Tandler B, and Hoppel CL. Biochemical differences between subsarcolemmal and interfibrillar mitochondria from rat cardiac muscle: effects of procedural manipulations. Arch Biochem Biophys 236: 691-702, 1985.

129. Palmer JW, Tandler B, and Hoppel CL. Biochemical properties of subsarcolemmal and interfibrillar mitochondria isolated from rat cardiac muscle. J Biol Chem 252: 8731-8739, 1977. 130. Pardo M, Porat Z, Rudich A, Schauer JJ, and Rudich Y. Repeated exposures to roadside particulate matter extracts suppresses pulmonary defense mechanisms, resulting in lipid and protein oxidative damage. Environ Pollut 210: 227-237, 2015. 
131. Peretz A, Peck EC, Bammler TK, Beyer RP, Sullivan JH, Trenga CA, Srinouanprachnah S, Farin FM, and Kaufman JD. Diesel exhaust inhalation and assessment of peripheral blood mononuclear cell gene transcription effects: an exploratory study of healthy human volunteers. Inhal Toxicol 19: 1107-1119, 2007.

132. Perez CM, Hazari MS, and Farraj AK. Role of autonomic reflex arcs in cardiovascular responses to air pollution exposure. Cardiovascular toxicology 15: 69-78, 2015.

133. Perk G, Tunick PA, and Kronzon I. Non-Doppler two-dimensional strain imaging by echocardiography--from technical considerations to clinical applications. J Am Soc Echocardiogr 20: 234-243, 2007.

134. Pfeifer H, Conrad M, Roethlein D, Kyriakopoulos A, Brielmeier M, Bornkamm GW, and Behne D. Identification of a specific sperm nuclei selenoenzyme necessary for protamine thiol cross-linking during sperm maturation. FASEB J 15: 1236-1238, 2001.

135. Pirela SV, Miousse IR, Lu X, Castranova V, Thomas T, Qian Y, Bello D, Kobzik L, Koturbash I, and Demokritou P. Effects of Laser Printer-Emitted Engineered Nanoparticles on Cytotoxicity, Chemokine Expression, Reactive Oxygen Species, DNA Methylation, and DNA Damage: A Comprehensive in Vitro Analysis in Human Small Airway Epithelial Cells, Macrophages, and Lymphoblasts. Environ Health Perspect 124: 210-219, 2016.

136. Poland CA, Duffin R, Kinloch I, Maynard A, Wallace WA, Seaton A, Stone V, Brown S, Macnee W, and Donaldson K. Carbon nanotubes introduced into the abdominal cavity of mice show asbestos-like pathogenicity in a pilot study. Nat Nanotechnol 3: 423-428, 2008.

137. Pope CA, 3rd and Dockery DW. Health effects of fine particulate air pollution: lines that connect. J Air Waste Manag Assoc 56: 709-742, 2006.

138. Pushpa-Rekha TR, Burdsall AL, Oleksa LM, Chisolm GM, and Driscoll DM. Rat phospholipid-hydroperoxide glutathione peroxidase. cDNA cloning and identification of multiple transcription and translation start sites. J Biol Chem 270: 26993-26999, 1995. 
139. Quay JL, Reed W, Samet J, and Devlin RB. Air pollution particles induce IL-6 gene expression in human airway epithelial cells via NF-kappaB activation. Am J Respir Cell Mol Biol 19: 98-106, 1998.

140. Ran Q, Liang H, Gu M, Qi W, Walter CA, Roberts LJ, 2nd, Herman B, Richardson A, and Van Remmen H. Transgenic mice overexpressing glutathione peroxidase 4 are protected against oxidative stress-induced apoptosis. J Biol Chem 279: 55137-55146, 2004.

141. Rao GV, Tinkle S, Weissman DN, Antonini JM, Kashon ML, Salmen R, Battelli LA, Willard PA, Hoover MD, and Hubbs AF. Efficacy of a technique for exposing the mouse lung to particles aspirated from the pharynx. J Toxicol Environ Health A 66: 1441-1452, 2003.

142. Rasola A and Bernardi P. Mitochondrial permeability transition in $\mathrm{Ca}(2+)$-dependent apoptosis and necrosis. Cell Calcium 50: 222-233, 2011.

143. Rodriguez J and Lazebnik Y. Caspase-9 and APAF-1 form an active holoenzyme. Genes Dev 13: 3179-3184, 1999.

144. Rosca MG and Hoppel CL. Mitochondrial dysfunction in heart failure. Heart Fail Rev 18: 607-622, 2013 .

145. Ruckerl R, Phipps RP, Schneider A, Frampton M, Cyrys J, Oberdorster G, Wichmann HE, and Peters A. Ultrafine particles and platelet activation in patients with coronary heart disease--results from a prospective panel study. Part Fibre Toxicol 4: 1, 2007. 146. Sager TM, Kommineni C, and Castranova V. Pulmonary response to intratracheal instillation of ultrafine versus fine titanium dioxide: role of particle surface area. Part Fibre Toxicol 5: 17, 2008.

147. Savi M, Rossi S, Bocchi L, Gennaccaro L, Cacciani F, Perotti A, Amidani D, Alinovi R, Goldoni M, Aliatis I, Lottici PP, Bersani D, Campanini M, Pinelli S, Petyx M, Frati C, Gervasi A, Urbanek K, Quaini F, Buschini A, Stilli D, Rivetti C, Macchi E, Mutti A, Miragoli M, and Zaniboni M. Titanium dioxide nanoparticles promote arrhythmias via a direct interaction with rat cardiac tissue. Part Fibre Toxicol 11: 63, 2014. 
148. Seiler A, Schneider M, Forster H, Roth S, Wirth EK, Culmsee C, Plesnila N, Kremmer E, Radmark O, Wurst W, Bornkamm GW, Schweizer U, and Conrad M.

Glutathione peroxidase 4 senses and translates oxidative stress into 12/15-lipoxygenase dependent- and AIF-mediated cell death. Cell Metab 8: 237-248, 2008.

149. Shakeel M, Jabeen F, Shabbir S, Asghar MS, Khan MS, and Chaudhry AS. Toxicity of Nano-Titanium Dioxide (TiO-NP) Through Various Routes of Exposure: a Review. Biol Trace Elem Res, 2015.

150. Sharma V, Anderson D, and Dhawan A. Zinc oxide nanoparticles induce oxidative DNA damage and ROS-triggered mitochondria mediated apoptosis in human liver cells (HepG2). Apoptosis 17: 852-870, 2012.

151. Shepherd DL, Nichols CE, Croston TL, McLaughlin SL, Petrone AB, Lewis SE, Thapa D, Long DM, Dick GM, and Hollander JM. Early detection of cardiac dysfunction in the type 1 diabetic heart using speckle-tracking based strain imaging. J Mol Cell Cardiol 90: 74-83, 2016.

152. Shimada A, Kawamura N, Okajima M, Kaewamatawong T, Inoue H, and Morita T. Translocation pathway of the intratracheally instilled ultrafine particles from the lung into the blood circulation in the mouse. Toxicol Pathol 34: 949-957, 2006.

153. Shimada T, Horita K, Murakami M, and Ogura R. Morphological studies of different mitochondrial populations in monkey myocardial cells. Cell Tissue Res 238: 577-582, 1984. 154. Shin G, Sugiyama M, Shoji T, Kagiyama A, Sato H, and Ogura R. Detection of mitochondrial membrane damages in myocardial ischemia with ESR spin labeling technique. $J$ Mol Cell Cardiol 21: 1029-1036, 1989.

155. Shukla RK, Kumar A, Gurbani D, Pandey AK, Singh S, and Dhawan A. TiO(2) nanoparticles induce oxidative DNA damage and apoptosis in human liver cells. Nanotoxicology 7: 48-60, 2013. 
156. Simkhovich BZ, Kleinman MT, and Kloner RA. Air pollution and cardiovascular injury epidemiology, toxicology, and mechanisms. J Am Coll Cardiol 52: 719-726, 2008.

157. Skulachev VP. Mitochondrial filaments and clusters as intracellular power-transmitting cables. Trends Biochem Sci 26: 23-29, 2001.

158. Skulachev VP. Uncoupling: new approaches to an old problem of bioenergetics. Biochim Biophys Acta 1363: 100-124, 1998.

159. Sparagna GC, Chicco AJ, Murphy RC, Bristow MR, Johnson CA, Rees ML, Maxey ML, McCune SA, and Moore RL. Loss of cardiac tetralinoleoyl cardiolipin in human and experimental heart failure. J Lipid Res 48: 1559-1570, 2007.

160. St-Pierre J, Buckingham JA, Roebuck SJ, and Brand MD. Topology of superoxide production from different sites in the mitochondrial electron transport chain. J Biol Chem 277: 44784-44790, 2002.

161. Stadtman ER and Oliver CN. Metal-catalyzed oxidation of proteins. Physiological consequences. J Biol Chem 266: 2005-2008, 1991.

162. Stallknecht B, Vinten J, Ploug T, and Galbo H. Increased activities of mitochondrial enzymes in white adipose tissue in trained rats. Am J Physiol 261: E410-414, 1991.

163. Stapleton PA, Abukabda AB, Hardy SL, and Nurkiewicz TR. Xenobiotic pulmonary exposure and systemic cardiovascular response via neurological links. Am J Physiol Heart Circ Physiol 309: H1609-1620, 2015.

164. Stapleton PA, Minarchick VC, Cumpston AM, McKinney W, Chen BT, Sager TM, Frazer DG, Mercer RR, Scabilloni J, Andrew ME, Castranova V, and Nurkiewicz TR. Impairment of coronary arteriolar endothelium-dependent dilation after multi-walled carbon nanotube inhalation: a time-course study. Int J Mol Sci 13: 13781-13803, 2012.

165. Stapleton PA, Minarchick VC, Yi J, Engels K, McBride CR, and Nurkiewicz TR. Maternal engineered nanomaterial exposure and fetal microvascular function: does the Barker hypothesis apply? Am J Obstet Gynecol 209: 227 e221-211, 2013. 
166. Stapleton PA, Nichols CE, Yi J, McBride CR, Minarchick VC, Shepherd DL, Hollander JM, and Nurkiewicz TR. Microvascular and mitochondrial dysfunction in the female F1 generation after gestational TiO2 nanoparticle exposure. Nanotoxicology 9: 941-951, 2015. 167. Starke-Reed PE and Oliver CN. Protein oxidation and proteolysis during aging and oxidative stress. Arch Biochem Biophys 275: 559-567, 1989.

168. Stern ST and McNeil SE. Nanotechnology safety concerns revisited. Toxicol Sci 101: 4$21,2008$.

169. Szweda LI, Uchida K, Tsai L, and Stadtman ER. Inactivation of glucose-6-phosphate dehydrogenase by 4-hydroxy-2-nonenal. Selective modification of an active-site lysine. J Biol Chem 268: 3342-3347, 1993.

170. Tamagawa E, Bai N, Morimoto K, Gray C, Mui T, Yatera K, Zhang X, Xing L, Li Y, Laher I, Sin DD, Man SF, and van Eeden SF. Particulate matter exposure induces persistent lung inflammation and endothelial dysfunction. Am J Physiol Lung Cell Mol Physiol 295: L79-85, 2008.

171. Tandler B and Hoppel CL. Possible division of cardiac mitochondria. Anat Rec 173: 309-323, 1972.

172. Tankersley CG, Champion HC, Takimoto E, Gabrielson K, Bedja D, Misra V, ElHaddad H, Rabold R, and Mitzner W. Exposure to inhaled particulate matter impairs cardiac function in senescent mice. Am J Physiol Regul Integr Comp Physiol 295: R252-263, 2008. 173. Thapa D, Nichols CE, Lewis SE, Shepherd DL, Jagannathan R, Croston TL, Tveter KJ, Holden AA, Baseler WA, and Hollander JM. Transgenic overexpression of mitofilin attenuates diabetes mellitus-associated cardiac and mitochondria dysfunction. J Mol Cell Cardiol 79: 212-223, 2015.

174. Trombly $\mathbf{R}$ and Tappel A. Fractionation and analysis of fluorescent products of lipid peroxidation. Lipids 10: 441-447, 1975. 
175. Troyer D, Cash W, and Leipold H. Skeletal muscle of cattle affected with progressive degenerative myeloencephalopathy. Am J Vet Res 54: 1084-1087, 1993.

176. Upadhyay D, Panduri V, Ghio A, and Kamp DW. Particulate matter induces alveolar epithelial cell DNA damage and apoptosis: role of free radicals and the mitochondria. Am J Respir Cell Mol Biol 29: 180-187, 2003.

177. Urankar RN, Lust RM, Mann E, Katwa P, Wang X, Podila R, Hilderbrand SC, Harrison BS, Chen P, Ke PC, Rao AM, Brown JM, and Wingard CJ. Expansion of cardiac ischemia/reperfusion injury after instillation of three forms of multi-walled carbon nanotubes. Part Fibre Toxicol 9: 38, 2012.

178. Ursini F, Maiorino M, Brigelius-Flohe R, Aumann KD, Roveri A, Schomburg D, and Flohe L. Diversity of glutathione peroxidases. Methods Enzymol 252: 38-53, 1995.

179. van Eeden SF, Tan WC, Suwa T, Mukae H, Terashima T, Fujii T, Qui D, Vincent R, and Hogg JC. Cytokines involved in the systemic inflammatory response induced by exposure to particulate matter air pollutants (PM(10)). American journal of respiratory and critical care medicine 164: 826-830, 2001.

180. Van Hee VC, Adar SD, Szpiro AA, Barr RG, Bluemke DA, Diez Roux AV, Gill EA, Sheppard L, and Kaufman JD. Exposure to traffic and left ventricular mass and function: the Multi-Ethnic Study of Atherosclerosis. Am J Respir Crit Care Med 179: 827-834, 2009.

181. Veronesi B, Oortgiesen M, Carter JD, and Devlin RB. Particulate matter initiates inflammatory cytokine release by activation of capsaicin and acid receptors in a human bronchial epithelial cell line. Toxicol Appl Pharmacol 154: 106-115, 1999.

182. Voigt JU, Exner B, Schmiedehausen K, Huchzermeyer C, Reulbach U, Nixdorff U, Platsch G, Kuwert T, Daniel WG, and Flachskampf FA. Strain-rate imaging during dobutamine stress echocardiography provides objective evidence of inducible ischemia. Circulation 107: 2120-2126, 2003. 
183. Wang C, Hu X, Gao Y, and Ji Y. ZnO Nanoparticles Treatment Induces Apoptosis by Increasing Intracellular ROS Levels in LTEP-a-2 Cells. Biomed Res Int 2015: 423287, 2015. 184. WHO. Ambient (outdoor) air quality and health, edited by Organization WH. Geneva, Switzerland, 2014.

185. Wold LE, Ying Z, Hutchinson KR, Velten M, Gorr MW, Velten C, Youtz DJ, Wang A, Lucchesi PA, Sun Q, and Rajagopalan S. Cardiovascular remodeling in response to long-term exposure to fine particulate matter air pollution. Circ Heart Fail 5: 452-461, 2012.

186. Woolley SM, Meacham SL, Balmert LC, Talbott EO, and Buchanich JM. Comparison of Mortality Disparities in Central Appalachian Coal- and Non-Coal-Mining Counties. J Occup Environ Med, 2015.

187. Wu S, Wang B, Yang D, Wei H, Li H, Pan L, Huang J, Wang X, Qin Y, Zheng C, Shima M, Deng F, and Guo X. Ambient particulate air pollution and circulating antioxidant enzymes: A repeated-measure study in healthy adults in Beijing, China. Environ Pollut 208: 1624, 2016.

188. Xia T, Korge P, Weiss JN, Li N, Venkatesen MI, Sioutas C, and Nel A. Quinones and aromatic chemical compounds in particulate matter induce mitochondrial dysfunction: implications for ultrafine particle toxicity. Environ Health Perspect 112: 1347-1358, 2004. 189. Xia T, Kovochich M, Liong M, Zink Jl, and Nel AE. Cationic polystyrene nanosphere toxicity depends on cell-specific endocytic and mitochondrial injury pathways. ACS Nano 2: 8596, 2008.

190. Xiong Q, Ru Q, Chen L, Yue K, Tian X, Ma B, Liu L, Wu R, Xu C, Pi M, and Li C. Combined effects of fine particulate matter and lipopolysaccharide on apoptotic responses in NR8383 macrophages. J Toxicol Environ Health A 78: 443-452, 2015.

191. Yan YH, Huang CH, Chen WJ, Wu MF, and Cheng TJ. Effects of diesel exhaust particles on left ventricular function in isoproterenol-induced myocardial injury and healthy rats. Inhal Toxicol 20: 199-203, 2008. 
192. Yant LJ, Ran Q, Rao L, Van Remmen H, Shibatani T, Belter JG, Motta L, Richardson A, and Prolla TA. The selenoprotein GPX4 is essential for mouse development and protects from radiation and oxidative damage insults. Free Radic Biol Med 34: 496-502, 2003.

193. Zamzami N, Marchetti P, Castedo M, Hirsch T, Susin SA, Masse B, and Kroemer G. Inhibitors of permeability transition interfere with the disruption of the mitochondrial transmembrane potential during apoptosis. FEBS Lett 384: 53-57, 1996.

194. Zhang Z, Kleinstreuer C, Donohue JF, and Kim CS. Comparison of micro- and nanosize particle depositions in a human upper airway model. Journal of Aerosol Science 36: 211233, 2005.

195. Zhao J, Bowman L, Zhang X, Vallyathan V, Young SH, Castranova V, and Ding M. Titanium dioxide (TiO2) nanoparticles induce JB6 cell apoptosis through activation of the caspase-8/Bid and mitochondrial pathways. J Toxicol Environ Health A 72: 1141-1149, 2009.

196. Zhou L and O'Rourke B. Cardiac mitochondrial network excitability: insights from computational analysis. Am J Physiol Heart Circ Physiol 302: H2178-2189, 2012.

197. Zorov DB, Juhaszova M, and Sollott SJ. Mitochondrial reactive oxygen species (ROS) and ROS-induced ROS release. Physiol Rev 94: 909-950, 2014.

198. Zullig KJ and Hendryx M. A comparative analysis of health-related quality of life for residents of U.S. counties with and without coal mining. Public Health Rep 125: 548-555, 2010. 


\section{Chapter 2:}

\section{Cardiac and Mitochondrial Dysfunction Following Acute Pulmonary Exposure to Mountaintop Removal Mining Particulate Matter}

As Published in the American Journal of Physiology: Heart and Circulatory Physiology; 2015

Cody E. Nichols ${ }^{1,2}$, Danielle L. Shepherd ${ }^{1,2}$, Travis L. Knuckles ${ }^{2,3}$, Dharendra Thapa ${ }^{1,2}$, Janelle C. Stricker ${ }^{2}$, Phoebe A. Stapleton ${ }^{2,4}$, Valerie C. Minarchick ${ }^{2,4}$, Aaron Erdely ${ }^{4,5}$, Patti C. ZeidlerErdely $^{4,5}$, Stephen E. Alway ${ }^{1,2}$, Timothy R. Nurkiewicz ${ }^{2,4}$ and John M. Hollander ${ }^{1,2}$

${ }^{1}$ West Virginia University School of Medicine, Division of Exercise Physiology; ${ }^{2}$ Center for Cardiovascular and Respiratory Sciences; ${ }^{3}$ West Virginia University, School of Public Health, ${ }^{4}$ West Virginia University, Department of Physiology and Pharmacology Morgantown, WV 26506, ${ }^{5}$ National Institute for Occupational Safety and Health, Morgantown, WV 26506

Running Title: Cardiac dysfunction following mining particulate matter exposure

Corresponding Author:

John M. Hollander, Ph.D., F.A.H.A.

West Virginia University School of Medicine

Division of Exercise Physiology

Center for Cardiovascular and Respiratory Sciences

1 Medical Center Drive

Morgantown, WV 26506

Tel: (304) 293-3683

Fax: (304) 293-7105

Email: ihollander@hsc.wvu.edu 


\begin{abstract}
Throughout the United States, air pollution correlates with adverse health outcomes and cardiovascular disease incidence is commonly increased following environmental exposure. In areas surrounding active mountaintop removal mines (MTM) a further increase in cardiovascular morbidity is observed and may be attributed in part to particulate matter (PM) released from the mine. The mitochondrion has been shown to be central in the etiology of many cardiovascular diseases, yet its role in PM related cardiovascular effects are not realized. In this study we sought to elucidate the cardiac processes that are disrupted following exposure to mountaintop removal mining particulate matter $\left(\mathrm{PM}_{\mathrm{MTM}}\right)$. To address this question we exposed male Sprague-Dawley rats to $\mathrm{PM}_{\mathrm{MTM}}$, collected within one mile of an active MTM site, using intratracheal instillation. Twenty-four hours following exposure we evaluated cardiac function, apoptotic indices and mitochondrial function. $\mathrm{PM}_{\mathrm{MTM}}$ exposure, elicited a significant decrease in ejection fraction and fractional shortening compared to controls. Investigation into the cellular impacts of $\mathrm{PM}_{\text {MTM }}$ exposure identified a significant increase in mitochondrial-induced apoptotic signaling as reflected by an increase in TUNEL positive nuclei and increased caspase-3 and -9 activities. Finally, a significant increase in mitochondrial transition pore opening leading to decreased mitochondrial function was identified following exposure. In conclusion, our data suggest that pulmonary exposure to $\mathrm{PM}_{\mathrm{MTM}}$ increases cardiac mitochondrial-associated apoptotic signaling and decreases mitochondrial function concomitant with decreased cardiac function. These results suggest that increased cardiovascular disease incidence in populations surrounding MTM mines may be associated with increased cardiac cell apoptotic signaling and decreased mitochondrial function.
\end{abstract}

Keywords: Mitochondria; Cardiac Function; Particulate Matter; Apoptosis 


\section{NEW AND NOTEWORTHY}

We describe for the first time cardiac and mitochondrial dysfunction following an acute pulmonary exposure to a unique particulate matter which arises from the process of mountaintop removal, common in surface mining operations. Our findings suggest enhanced cardiac risk for populations living in close proximity to mountaintop mining operations. 


\section{INTRODUCTION}

The World Health Organization estimates that 3.7 million premature deaths a year are attributed to ambient air pollution (75). While the lungs are the primary tissue impacted by air pollution exposure, more than $80 \%$ of these deaths are due to cardiovascular disease (75). Throughout the U.S., decreased air quality correlates with adverse health effects including negative cardiovascular end-points $(57,60,61,64)$. While chronic exposure to air pollution is the $13^{\text {th }}$ leading cause of worldwide mortality (76), short term particulate matter (PM) exposure has also been suggested to contribute to tens of thousands of deaths within the U.S. $(27,60)$. Air pollution is a complex mixture of many compounds, including PM, and epidemiological data link PM concentration to adverse cardiovascular effects (84). PM itself is a heterogeneous mixture of particles that vary in size, chemical composition and origin; nevertheless, persistent PM formation creates a near universal inhalation exposure. While PM exposure is widespread, the make-up of this material varies considerably based on origin and geographical region (27). These differing compositions may play a distinct role in adverse cardiovascular end-points associated with a specific geographic locale (22).

The U.S. is among the most active coal producing countries in the world (28) and coal mining is projected to increase over the next 25 years (2). The Appalachian region, which extends from southern New York to Mississippi and Georgia following the Appalachian Mountains, contains more than eight hundred active coal mines, accounting for $30 \%$ of U.S. mining activity (25). Due to its inherent less labor intensive methods, surface mining is beginning to outnumber traditional underground mining two to one (25). One popular, less labor intensive method of surface mining is mountaintop removal mining (MTM), which utilizes explosives to remove the mountaintop, freeing underlying coal seams allowing easier extraction. Economically and ecologically the technique is controversial, but few studies have begun to investigate the human health impacts in areas surrounding MTM sites. The PM generated by 
the MTM process contains toxicants that are environmentally biopersistent (55) suggesting potential for negative health effects.

While the goal of industrial processes is to abate dust generation, fugitive dust from explosive treatment as well as combustion particles from heavy equipment, create a unique PM $\left(\mathrm{PM}_{\mathrm{MTM}}\right)$. Epidemiologically, health effects of coal mining have been outlined $(81,88)$ but, until recently, no comparisons had been drawn between areas surrounding underground and MTM sites. Studies have reported that $\mathrm{PM}_{\mathrm{MTM}}$ causes an increase in chronic cardiovascular disease mortality rates among populations in close proximity to active MTM sites (28). However, the mechanisms underlying this observation is poorly understood. We have previously reported that acute pulmonary exposure to $\mathrm{PM}_{\mathrm{MTM}}$ in rodents is linked to microvascular dysfunction in extrapulmonary tissue (36). However, studies on cardiac tissue have not been undertaken.

The mitochondrion has been implicated in the etiology of many cardiovascular diseases due to the crucial roles it plays within the cardiomyocyte. Among the central roles for the mitochondrion are the production of ATP requisite for cardiac contraction and relaxation as well as its contribution to the signals initiating cellular apoptosis. In vivo and in vitro analyses have revealed an increase in apoptosis in numerous tissues following PM exposure $(3,16,85,86)$. Two pathways reported to activate the apoptotic cascade include the extrinsic pathway via caspase-8 and the intrinsic pathway involving the mitochondrion. In the intrinsic pathway, opening of the mitochondrial permeability transition pore (mPTP) allows uncoupling of the electron transport chain leading to mitochondrial dysfunction and formation of the apoptosome (31). In vitro evidence suggests that both extrinsic and intrinsic pathways are activated following PM exposure (20). Nevertheless, it is unclear whether acute $\mathrm{PM}_{\mathrm{MTM}}$ exposure is associated with mitochondrial dysfunction or enhanced initiation of the apoptotic cascade. 
The goals of the current study were to determine whether acute $\mathrm{PM}_{\mathrm{MTM}}$ exposure is associated with cardiac and mitochondrial dysfunction and to elucidate whether these effects were associated with mitochondrial-associated apoptosis initiation with an emphasis on the cardiomyocyte. Our results suggest that acute $\mathrm{PM}_{\mathrm{MTM}}$ exposure is associated with an increase in mitochondrial-driven apoptotic signaling, which may contribute to cardiac and mitochondrial dysfunction. These findings lend insight into the potential mechanisms underlying acute $\mathrm{PM}_{\mathrm{MTM}}$ exposure effects in the heart. 


\section{MATERIALS AND METHODS}

\section{Experimental Animals}

The animal experiments in this study were approved by the West Virginia University Animal Care and Use Committee and conformed to the most current National Institutes of Health (NIH) Guidelines for the Care and Use of Laboratory Animals manual. Male SpragueDawley rats were housed in the West Virginia University Health Sciences Center animal facility. Rats were given access to a rodent diet and water ad libitum.

\section{PM $_{\text {Mтм }}$ Preparation}

PM was collected on $35 \mathrm{~mm}, 5 \mu \mathrm{m}$ pore size PTFE fiber-backed filters (Whatman, Springfield Mill, UK) for 2-4 weeks at two sites within 1 mile of an active MTM site. Particle storage and extraction from the filters following collection are consistent with previous reports (24). Briefly, filters were stored at room temperature $\left(20-25^{\circ} \mathrm{C}\right)$ and ambient humidity (10-30\%) prior to extraction. PM extraction was accomplished by gentle agitation in ultrapure water for 96 hours. Then, particle suspension aliquots were dried in a Speedvac (Savant; Midland, MI) and total particle weight was determined using a microbalance (Metler-Toledo; Columbus, $\mathrm{OH}$ ).

\section{Intratracheal Instillation}

Intratracheal instillation was performed according to the method of Brain et al. (5) as previously described $(36,45,46,49,50)$. Briefly, following anesthesia with isoflurane, a ball needle attached to a $1-\mathrm{ml}$ tuberculin syringe was inserted under the glottis into the trachea, and $300 \mu \mathrm{l}$ of either vehicle ( $5 \%$ fetal bovine serum in phosphate buffered saline) or vehicle with 300 $\mu \mathrm{g}$ of $\mathrm{PM}_{\mathrm{MTM}}$ was instilled directly into the trachea. We have previously shown that this dose of $\mathrm{PM}_{\text {MTM }}$ partially impaired endothelium dependent microvascular dysfunction (36). The particulate matter characterization and resuspension was carried out as described previously (36). 


\section{Cardiac Contractile Function}

Twenty-four hours following exposure, echocardiography was utilized to assess cardiac contractile function. For echocardiographic assessment, each rat was anesthetized in a knockdown box with inhalant isoflurane at $2.5 \%$ in $100 \%$ oxygen. Following anesthesia, ultrasound images were acquired with a $25 \mathrm{MHz}$ linear array transducer using the Vevo2100 Imaging System (Visual Sonics, Toronto, Canada). M-mode images were acquired by placing the transducer to the left of the sternum and obtaining an image at the mid-papillary muscle level. A gate was placed through the center of the short-axis B-mode image to obtain M-mode recordings of contractile parameters of the myocardium. Images were acquired using the highest possible frame rate (233-401 frames/second). Measurements obtained from left ventricular M-mode images included end-diastolic and end-systolic diameters and volumes, fractional shortening, ejection fraction, stroke volume and cardiac output. All M-mode image measurements were calculated over 3 consecutive cardiac cycles and averaged.

\section{Tissue Preparation and Compartment Isolation}

After cardiac contractile measurements were performed rats were euthanized and hearts excised. Atrial and right ventricular tissues were removed and left ventricular tissue was utilized for the studies. Cytosolic isolation was performed as previously described (77). Subsarcolemmal mitochondria (SSM) and interfibrillar mitochondria (IFM) subpopulations were isolated as previously described following the methods of Palmer et al. (54) with minor modifications by our laboratory $(5,6,14,15,17,18,70,77)$. Mitochondrial pellets were resuspended in KME buffer (100 mM KCl, $50 \mathrm{mM}$ MOPS and $0.5 \mathrm{mM} \mathrm{EGTA} \mathrm{pH} \mathrm{7.4)} \mathrm{and} \mathrm{utilized} \mathrm{for} \mathrm{all} \mathrm{analyses.} \mathrm{Protein}$ concentrations were determined by the Bradford method using bovine serum albumin as a standard (8). 


\section{TUNEL Staining}

Terminal dUTP nick-end labeling (TUNEL) was performed to detect apoptotic nuclei in tissue cross sections as previously described $(32,74)$. Briefly, frozen tissue $(10 \mu \mathrm{m}$ thick) cross sections of left ventricle were mounted on charged microscope slides (Fisher Scientific; Pittsburgh, PA), air dried and incubated overnight at $4^{\circ} \mathrm{C}$ with mouse anti-heavy chain cardiac myosin antibody (product No. ab50967; Abcam; Cambridge, MA). Sections were then incubated with goat anti-mouse Cy5-conjugated secondary antibody (product No. ab6563; Abcam), fixed with $4 \%$ paraformaldehyde, and permeabilized with $0.1 \%$ Triton $\mathrm{X}-100$ in PBS at $4^{\circ} \mathrm{C}$. Sections were incubated with the TUNEL reaction mixture (Roche Diagnostics; Indianapolis, IN) in a humidified chamber in the dark. The exclusion of the TdT enzyme in the TUNEL reaction mixture on one of the tissue sections on each slide was included as a negative control (Figure 1A). Treatment of one tissue section on each slide with DNase I (Life Technologies; Carlsbad, CA) was included as a positive control (Figure 1B). Sections were mounted and stained with a mounting medium containing DAPI (Vectashield; Vector Laboratories; Burlingame, CA) in order to observe nuclei. Slides were then visualized under a Zeiss Axio Imager Z2 (Carl Zeiss Microimaging Inc.; Thornwood, NY). The number of TUNEL and DAPI-positive nuclei were counted and the data were expressed as an apoptotic index, which was calculated as the percentage of TUNEL-positive nuclei relative to the total myonuclei (i.e., DAPI-positive nuclei) pool. The apoptotic index was determined from four non-overlapping regions of each tissue cross section.

\section{Histone Enzyme-Linked Immunosorbent Assay}

Cytoplasmic histone-associated DNA fragments related to apoptosis were quantified utilizing the Cell Death Detection ELISA ${ }^{\text {PLUS }}$ kit (product No. 11774425001; Roche Diagnostics). This photometric enzyme immunoassay which is used for the quantitative determination of 
mono- and oligonucleosomes after cell death, was carried out per the manufacturer's instructions.

\section{Western Blotting}

SDS polyacrylamide gel electrophoresis (SDS-PAGE) was run on $4-12 \%$ gradient gels as previously described $(5,6,17,18,43,70,77)$. Relative amounts of activated caspase-3, -9 and -8 were determined using specific antibodies: anti-caspase-3 rabbit antibody (product No. 3016-100; Biovision; Milpitas, CA), anti-caspase-9 rabbit antibody (product No. 9665; Cell Signaling Technology; Danvers, MA) and anti-caspase-8 goat antibody (product No. Sc6134; Santa Cruz Biotech; Dallas, Texas). Relative amounts of B-cell CLL/lymphoma 2 (Bcl-2), Bcl-2 associated $\mathrm{X}$ protein (Bax), apoptosis protease activating factor 1 (APAF-1), and cytochrome $c$ were determined using specific antibodies: anti-Bcl-2 mouse antibody (product No. sc-7382; Santa Cruz Biotech), anti-Bax rabbit antibody (product No. ab32503; Abcam), anti-APAF-1 rabbit antibody (product No. ab2000; Abcam) and anti-cytochrome c rabbit antibody (product No. 4272; Cell Signaling Technology). Relative amounts of mitochondrial permeability transition pore constituents, adenine nucleotide translocase (ANT), voltage dependent anion channel (VDAC), and cyclophilin D (CypD) were determined using specific antibodies: anti-ANT goat antibody (product No. sc-9300; Santa Cruz Biotech), anti-VDAC rabbit antibody (product No. 4866; Cell Signaling Technology) and anti-CypD rabbit antibody (product No. PA1-028; Affinity Bioreagents; Golden, CO). The secondary antibodies used included: goat anti-mouse lgG horseradish peroxidase (HRP) conjugate (product No. 31430; Pierce Biotechnology; Rockford, IL), goat anti-rabbit IgG HRP conjugate (product No. 10004301; Cayman Chemical) and donkey anti-goat IgG HRP conjugate (product No. sc-2020; Santa Cruz Biotech). Pierce Enhanced Chemiluminescence Western Blotting substrate (Pierce; Rockford, IL) was used to detect signal following the manufacturer's instructions. A G:Box Bioimaging system (Syngene; Frederick, MD) was used to assess autoradiographic signals. Data were captured using GeneSnap/GeneTools 
software (Syngene) and densitometry was analyzed using Image J Software (National Institutes of Health, Bethesda, MD). Controls for protein loading included: anti-GAPDH mouse antibody (product No. ab8245; Abcam) for cytosolic analyses and anti-COXIV rabbit antibody for mitochondrial analyses (product No. ab16056; Abcam).

\section{Caspase Activation}

Caspase activities were assessed as previously described $(77,78)$. Briefly, whole left ventricular tissue was homogenized in the absence of a protease inhibitor cocktail to enable assessment of caspase- 3 , caspase- 8 and caspase- 9 activities. All of the activities were measured in a caspase activation buffer containing 4.8 mmol PIPES, $0.1 \mathrm{mmol}$ EDTA, and 10\% glycerol. For each enzyme activity assay, specific substrates were added: caspase-3, AcDEVD-AFC (Alexis Biochemicals; San Diego, CA); caspase-8, Ac-IETD-AMC (Alexis Biochemicals); and caspase-9, Ac-LEHD-AFC (Alexis Biochemicals). One hundred $\mu \mathrm{g}$ of each sample was loaded with the appropriate substrate and allowed to incubate for 2 hours in the dark at $37^{\circ} \mathrm{C}$. Samples were read fluorometrically using a Flexstation 3 plate reader (Molecular Devices; Sunnyvale, CA). Fluorometric measurements were performed at excitation/emission wavelengths of $400 \mathrm{~nm} / 505 \mathrm{~nm}$ and expressed in relation to protein content.

\section{Immunoprecipitation}

Isolated mitochondrial protein was incubated overnight with a primary anti-Bax rabbit antibody (product No. ab32503; Abcam; Cambridge, MA). Next, Dynabeads Protein G superparamagnetic beads (product No. 10003D; ThermoFisher Scientific; Waltham, MA) were added to the sample mixture and allowed to incubate for 1 hour. After washing the beads, the protein was eluted, heated, and ran through SDS-PAGE as described above. Following SDSPAGE, immunoblotting for relative amounts of B-cell CLL/lymphoma 2 (Bcl-2) and Bcl-2 associated $\mathrm{X}$ protein (Bax) was accomplished as described above. 


\section{Mitochondrial Permeability Transition Pore (mPTP) Opening}

mPTP opening was performed as previously described by measuring mitochondrial swelling, spectrophotometrically $(540 \mathrm{~nm})$, and observing the decrease in light scattering $(1,77)$. Treatment of freshly isolated mitochondrial subpopulations with $100 \mu \mathrm{M}$ tert-butyl hydroperoxide (t-uBOOH), $400 \mu \mathrm{M} \mathrm{Ca}{ }^{2+}$ and $10 \mathrm{mM}$ succinate induced swelling and was followed using a Flexstation 3 plate reader (Molecular Devices; Sunnyvale, CA). As an assay control, $1 \mu \mathrm{M}$ cyclosporin A, a specific MPTP inhibitor, was added to the reaction mixture.

\section{Mitochondria Size and Internal Complexity}

Size and complexity of the mitochondria were analyzed as previously described $(18,19)$ using a FACS Calibur flow cytometer equipped with a 15-MW 488-nm argon laser and 633-nm red diode laser (Becton and Dickinson; San Jose, CA). Each individual parameter (gating, size and complexity) was measured using specific detectors and light sources (laser, photomultiplier tube). The dye MitoTracker Deep Red (product No. M22426, Life Technologies), which passively diffuses into intact mitochondria, was used to selectively stain for mitochondria. Freshly isolated mitochondrial subpopulations were incubated with the dye and 20,000 gated events were analyzed per sample. Gating parameters were established and the forward scatter detector (FSC; $488 \mathrm{~nm}$ argon laser and diode detector) and side scatter detector (SSC; photomultiplier tube and $90^{\circ}$ collection lens) were represented in FSC and SSC density plots. In order to represent size, FSC (logarithmic scale) geometric mean (arbitrary units) was used; and to represent complexity, SSC (logarithmic scale) geometric mean (arbitrary units) was observed. All flow cytometry data collection was supervised by the West Virginia University Flow Cytometry Core Facility. 


\section{Electron microscopy}

A section of left ventricle was cut and fixed in $3 \%$ glutaraldehyde in sodium cacodylate buffer for electron microscopy images. Briefly, sections were post-fixed by incubation with a $1 \% / 0.8 \%$ osmium tetroxide/potassium ferricyanide mixture (Electron Microscopy Science, Hatfield, PA), dehydrated through a graded series of ethanol solutions and acetone then embedded in Epon resin (SPI Supplies, Westchester, PA). Ultrathin sections (95 nm) were cut from the resulting blocks with a Leica EM UC7 ultramicrotome (Leica Biosystems, Buffalo Grove, IL) and then captured on 200 mesh copper electron microscopy grids. The sections were observed at $80 \mathrm{kV}$ with a JEOL JEM-1010 electron microscope (JEOL USA, Inc., Peabody, MA, USA) connected to a AMT XR611S-B (ORCA HR) digital camera driven by Image Capture Engine software (AMT, Woburn, MA) for image acquisition and analysis. All electron microscopy imaging was performed in conjunction with the West Virginia University Pathology Electron Microscopy Core Facility.

\section{Mitochondrial Respiration}

State 3 and state 4 respiration rates were analyzed in freshly isolated mitochondrial subpopulations as previously described $(12,13)$ with modifications by our laboratory $(15,17,19$, 70). Briefly, isolated mitochondrial subpopulations were resuspended in KME buffer and protein content was determined by the Bradford method (8). Mitochondria protein was added to respiration buffer $(80 \mathrm{mM} \mathrm{KCl}, 50 \mathrm{mM}$ MOPS, $1 \mathrm{mmol} / \mathrm{I} \mathrm{EGTA}, 5 \mathrm{mmol} / \mathrm{KH} 2 \mathrm{PO} 4$, and $1 \mathrm{mg} / \mathrm{ml}$ BSA) and placed into a Gilson Chamber (Gilson; Middleton, WI) attached to a Yellow Springs Instruments 5300 biological oxygen monitor (Yellow Springs Instruments, Yellow Springs, OH). Maximal complex I-mediated respiration was initiated by the addition of glutamate $(5 \mathrm{mM})$ and malate $(5 \mathrm{mM})$. Data for state 3 (250 mM ADP) and state 4 (ADP-limited) respiration were expressed as nmol of oxygen consumed $/ \mathrm{min} / \mathrm{mg}$ protein. 


\section{Statistics}

Mean and standard error (SE) were calculated for all data sets. A Student's $t$-test was employed to analyze differences between treatment groups using GraphPad Prism 5 software (GraphPad Software, La Jolla, CA). $P<0.05$ was considered significant. 


\section{RESULTS}

\section{Cardiovascular Function Following PM $_{\text {MTM }}$ Exposure}

While overt cardiac dysfunction is not commonly an endpoint of PM exposure, acute PM exposure has been linked to cardiac stress (60); thus, we began our investigation by evaluating cardiac function using echocardiography. Twenty-four hours following acute PM $_{\text {MTM }}$ exposure, a significant increase in both end-systolic volume and diameter was observed but no significant changes in end-diastolic parameters were noted (Table 1). Acute PM $_{M T M}$ exposure led to decreases in ejection fraction and fractional shortening when compared to control animals (Table 1).

\section{Apoptotic Signaling Following PM $_{M т м}$ Exposure}

Cardiac contractile dysfunction is associated with cell death; therefore, we determined whether acute $\mathrm{PM}_{\mathrm{MTM}}$ exposure triggered apoptotic signaling in the heart. Cardiomyocytes from $\mathrm{PM}_{\mathrm{MTM}}$ exposed animals (Figure 1D) displayed an increase in TUNEL positive nuclei, which fluorescently labels DNA nicks, as compared to control animals (Figure 1C), suggestive of an increase in damage downstream of apoptotic signaling. Summary data for TUNEL positive nuclei in both control and $\mathrm{PM}_{\mathrm{MTM}}$ exposed hearts can be seen in Figure 1E. To confirm apoptotic initiation, we determined cytosolic histone contents following $\mathrm{PM}_{\mathrm{MTM}}$ exposure and found that exposure significantly increased histone concentrations (Figure 1F).

Downstream signals of the apoptotic pathway may be differentially activated depending on the pathway of apoptosis initiated by a given stressor. Among the signaling pathways responsible for the apoptosis cascade are those driven by the extrinsic mechanism (caspase-8) as well as those driven by the intrinsic mechanism via the mitochondrion (caspase- 9 and caspase-3)(56). No increase in the activity of caspase-8 was observed suggesting, that the extracellular pathway of apoptotic induction is not activated following $\mathrm{PM}_{\mathrm{MTM}}$ exposure (Figure 
2A). In contrast, $\mathrm{PM}_{\mathrm{MTM}}$ exposure enhanced the activity of both caspase-9 (Figure 2B) and caspase-3 (Figure 2C). These finding were supported by immunoblotting analysis of relative active caspase concentrations which suggested an increase in caspase-3 (Figure 2F) and caspase-9 (Figure 2E) relative to control with no change in caspase-8 (Figure 2D) following $\mathrm{PM}_{\text {MTM }}$ exposure. These findings indicate that the mitochondrion may play a role in the induction of cardiac apoptotic signals following acute $\mathrm{PM}_{\mathrm{MTM}}$ exposure.

Apoptosome formation requires a number of molecular constituents including APAF-1 and cytochrome $c$ (83). Western blot analyses on the cytosolic fraction of left ventricular tissue from acute $\mathrm{PM}_{\text {MTM }}$ exposed animals revealed a significant increase in APAF-1 content as compared to control exposed animals (Figure 3A). Concurrently, there was an increase in the cytosolic cytochrome $c$ content following acute $\mathrm{PM}_{\text {MTM }}$ exposure (Figure $3 \mathrm{~B}$ ) confirming a role of the mitochondrion in cardiac cell apoptotic signaling. Evaluation of mitochondrial cytochrome $c$ content following acute $\mathrm{PM}_{\mathrm{MTM}}$ exposure revealed a significant decrease in the SSM subpopulation (Figure 3C) without impact on the IFM subpopulation (Figure 3D). Taken together, these findings suggest an enhanced release of cytochrome $c$ from cardiac SSM following acute $\mathrm{PM}_{\mathrm{MTM}}$ exposure which leads to apoptosome formation and mitochondriallydriven apoptotic initiation.

To complement our apoptotic signaling analyses, we examined additional non-specific cellular markers of apoptosis. $\mathrm{BH} 3$ proteins are a class of both pro- and anti-apoptotic proteins found within the cytosol that are differentially expressed following cellular damage and act to either prevent or propagate apoptosis. Examination of the anti-apoptotic protein Bcl-2, revealed a significant decrease following acute $\mathrm{PM}_{\text {MTM }}$ exposure (Figure 4A). In contrast, no significant difference in the relative content of its antagonistic pro-apoptotic Bax protein was noted (Figure 4B). The decrease in $\mathrm{Bcl}-2$ led to a significant increase in the Bax to $\mathrm{Bcl}-2$ ratio (Figure 4C) 
suggesting a pro-apoptotic cellular environment. Bcl-2 and Bax are able to counteract the other's actions by forming dimers, either hetero or homo, to complete their anti- or pro-apoptotic activities. Therefore, it is the dimerization of these proteins that suggests mitochondrial apoptotic signaling. Immunoblotting for Bax following immunoprecipitation with an anti-Bax antibody indicated that there is an increase in Bax:Bax dimerization following exposure (Figure 4E). When investigating the Bax:Bcl-2 dimerization we observed no significant difference in the levels of Bcl-2 following pulldown with Bax in the animals exposed to $\mathrm{PM}_{\mathrm{MTM}}$ (Figure 4D). These results led us to observe an increase in the pro-apoptotic Bax:Bax homodimerization, as compared to the anti-apoptotic Bax:Bcl-2 heterodimerization following exposure to $\mathrm{PM}_{\mathrm{MTM}}$ (Figure 4F). This data further suggests that cardiac mitochondrial apoptotic signaling is increased following pulmonary $\mathrm{PM}_{\mathrm{MTM}}$ exposure.

\section{Mitochondrial Permeability Transition Pore (mPTP) opening propensity}

Mitochondrial initiated apoptotic signaling is associated with the opening of the mPTP (42). We investigated mPTP opening propensity by inducing mitochondrial swelling using an exogenous oxidant $(\mathrm{t}-\mathrm{BuOOH})$. When the mPTP is open, the space that is occupied by the mitochondrial matrix is increased and the time to $\mathrm{V}_{\max }$ represents the rate of pore opening. Relative absorbance plots are presented for mPTP opening in SSM (Figure 5A) and IFM (Figure 5C). Each plot includes control, acute $\mathrm{PM}_{\mathrm{MTM}}$-exposed and an internal control consisting of cyclosporin A treatment, which limits MPTP opening. In general, IFM displayed greater times to $V_{\max }$ as compared to SSM (Figures $5 \mathrm{~B}$ and $5 \mathrm{D}$; white bars), which is in agreement with other reports $(1,77)$. The time to $\mathrm{V}_{\max }$ was significantly decreased in the SSM subpopulation following acute PM $_{\text {MTM }}$ exposure (Figure 5B). In contrast, mPTP opening propensity was not significantly altered in IFM following acute $\mathrm{PM}_{\mathrm{MTM}}$ exposure (Figure 5D). These results suggests that mPTP opening propensity is enhanced following acute $\mathrm{PM}_{\text {MTM }}$ exposure only in the SSM subpopulation and as a result, SSM are more susceptible to oxidant-induced apoptotic stimuli. 


\section{Mitochondrial Permeability Transition Pore (mPTP) opening constituents}

Because of the observed enhanced mPTP opening propensity, we determined whether putative constituents of the pore were affected following acute $\mathrm{PM}_{\text {MTM }}$ exposure. Specifically, we assessed the contents of ANT, VDAC and CypD in both mitochondrial subpopulations. Acute $\mathrm{PM}_{\text {MTM }}$ exposure induced no change in VDAC (Figure 6A and 6B) or ANT (Figure 6C and D6D)

in either mitochondrial subpopulation. In contrast, an increase in the levels of the regulatory subunit CypD was noted, in the SSM (Figure 6E) following acute $\mathrm{PM}_{\text {MTM }}$ exposure with no significant change in the IFM (Figure 6F). These results indicate an increase in the CypD content in the SSM following acute $\mathrm{PM}_{\mathrm{MTM}}$ exposure, which may contribute to the increased pore opening propensity.

\section{Mitochondrial Subpopulation Morphology}

mPTP opening is associated with morphological changes to the mitochondrion (31). To assess the impact of acute $\mathrm{PM}_{\mathrm{MTM}}$ exposure on mitochondrial morphology, we utilized flow cytometry to determine relative size and internal complexity as previously described $(15,17-19$, 77). Using this approach, we have reported that SSM tend to be larger and more complex than IFM $(15,17,18,77)$ and data from the current study are in agreement with these reports (Figures 7A and 7B; white bars). In both the SSM and IFM, there were significant decreases in forward scatter (size) (Figure 7A) and side scatter (internal complexity) (Figure 7B) following acute $\mathrm{PM}_{\mathrm{MTM}}$ exposure. The results were surprising and indicate that both the SSM and IFM were smaller and had decreased internal complexity following acute PM $_{\text {MTM }}$ exposure, suggesting that mitochondrial morphology may be affected in both subpopulations. Qualitative assessment of electron micrographs of left ventricular tissues from control (Figure $7 \mathrm{C}$ ) and exposed (Figure 7D) indicated that mitochondria were smaller following exposure further supporting the data presented in Figure 7A. 


\section{Mitochondrial Respiratory Function}

Mitochondrial dysfunction is frequently concomitant with increased apoptotic signaling; therefore, we determined the respiratory capacity following acute $\mathrm{PM}_{\mathrm{MTM}}$ exposure through evaluation of state 4 and state 3 respiration rates. Representative respiratory plots for the SSM and IFM can be seen in Figures $8 \mathrm{~A}$ and $8 \mathrm{C}$, respectively. We observed a significant decrease in state 3 respiration (active) following acute $\mathrm{PM}_{\mathrm{MTM}}$ exposure in both the SSM (Figure 8B) and IFM (Figure 8D). No significant changes in the state 4 respiration, or resting respiration rate, in either subpopulation were noted following acute $\mathrm{PM}_{\text {MтM }}$ exposure. These findings suggest that acute $\mathrm{PM}_{\mathrm{MTM}}$ exposure elicits disruption to respiratory capacity in both mitochondrial subpopulations. 


\section{DISCUSSION}

Acute and chronic PM inhalation exposure contributes to and exacerbates cardiovascular disease and mortality $(21,27)$. Within the Appalachian region, MTM activity creates a unique exposure, which, combined with mining longevity, may contribute to increased mortality from chronic diseases. While epidemiological data are convincing, the underlying mechanisms responsible for increased morbidity following $\mathrm{PM}_{\mathrm{MTM}}$ exposure are relatively unexplored. Utilizing an acute pulmonary exposure model, we investigated the effects of acute $\mathrm{PM}_{\mathrm{MTM}}$ exposure on cardiovascular function and metabolic disposition. Our data reveal decreases in cardiac pump function concomitant with increased mitochondria-driven apoptotic signaling and decreased mitochondrial respiratory function.

Particle composition varies by region in the U.S. and this variability may underlie health disparities for a given geographical region. Characterization of the particles utilized in this study indicated elements and sizes similar to those resulting from the combination of mineralogical materials as well as engine exhaust emission (36). MTM utilizes blasting, crushing and grinding of materials, which are commonly accomplished and transported by heavy machinery burning off-road diesel fuel. Validation of the PM was accomplished in another study highlighting natural and exhaust emissions, primarily geological, surrounding opencast mines similar to MTM (35). The dominant size range was ultrafine to $0.2 \mu \mathrm{m}$, based on mass measurement, and the principal particle composition was likely crustal with a bulk of particles appearing anthropogenic in origin (79). Previous elemental analyses support the notion that the bulk of the particle was from crustal sources (36). Further confirmation of composition was obtained by comparing PM from MTM sites and non-MTM sites and observing crustal material enriched within the surface mining samples by factors greater than 10 (39). These authors concluded that the PM was similar to coal dust and crustal material with the presence of local combustion sources. The 
authors also suggested that due to the nature of the landscape surrounding the mines (steep valleys with lower wind speeds and less vertical mixing), there would be less PM transport creating an increase in the inhaled deposited lung deposition and greater health effects (40). Whether or not these elements and observations are consistent with our observations remain to be determined in future experiments.

While extrapulmonary toxicological effects are well-documented, the mechanisms of toxicity are still under considerable debate. Three potential hypotheses have been advanced to explain extrapulmonary effects: [1] a systemic inflammatory response that is initiated in the lung; [2] translocation of the PM to extrapulmonary tissue; and [3] neural effects $(9,23)$. Studies in both murine and human models have identified pro-inflammatory markers in the circulation of exposed subjects, providing evidence that a pulmonary insult may stimulate a systemic inflammatory response $(7,33,58,62,63,68,71,73)$ which may contribute to downstream cardiovascular effects $(47,51)$. Data also exists suggesting PM translocation from the lung to the affected tissues $(26,38,52,53,67)$. Pulmonary exposure damages lung epithelium, increasing permeability and enabling PM penetration from the gaseous exchange region leading to escape into the circulation with subsequent impact on extrapulmonary tissues $(48,65)$. Finally, PM exposure may interfere with neuronal signaling and cardiac autonomic dysfunction following exposure $(10,11,59)$. While the hypotheses are scientifically independent, the mechanisms are not mutually exclusive and may overlap, propagating activation of additional mechanisms. Though these mechanisms have not been explored following PM $_{\text {MTM }}$ exposure, acute exposure to other PM has implicated a systemic inflammatory response (44). While this question is not experimentally addressed in this manuscript, it is a crucial concept in fully understanding the interaction between pulmonary damage and extrapulmonary toxicity. 
Acute PM exposure has been shown to contribute to cardiovascular morbidity and mortality. To investigate the cardiac contractile response following acute $\mathrm{PM}_{\mathrm{MTM}}$ exposure, we utilized echocardiography and observed decreases in ejection fraction and fractional shortening, which were associated with increases in both end-systolic volume and diameter. One study investigating the effect of diesel exhaust particle inhalation exposure on cardiac function, reported similar decreases in fractional shortening, yet this functional decrease was due to diastolic effects with an increase in end-diastolic diameter (82). Similarly, decreased fractional shortening following PM exposure was identified in senescent mice (69). Prenatal PM exposure reduced fractional shortening (30) and a chronic model of PM exposure decreased ejection fraction (80), demonstrating the detrimental role PM exposure plays in the progression of heart disease. Following PM exposure, overt cardiac dysfunction is not commonly observed in humans; however, cardiac remodeling occurs indicating cardiac stress (72). Our results suggest conditions of early cardiac stress and alteration which, if maintained, may contribute to the onset and progression of cardiovascular disease.

To identify the cellular mechanisms contributing to cardiac contractile dysfunction following PM exposure, we focused on apoptotic signaling, the role of which has not been widely investigated in PM toxicology. Research into histological changes following oil combustion-derived, fugitive emission PM exposure indicated no change in cardiac cell apoptosis in a chronic model (37). It is unclear why these results differ from those in the current study, but it may be a function of differences in particle composition or a transient increased response which ultimately triggers compensatory mechanisms to attenuate cell death. In addition, the activation of caspase cascades is a critical step in the induction of apoptosis and our study identified increased cardiac caspase activity following PM $_{\mathrm{MTM}}$ exposure. Activation of both caspase-8 and -9 in the lung following PM exposure has been reported (29). In the current study, activation of caspase-3 and -9 suggested a mitochondrial role in apoptotic signaling 
associated with $\mathrm{PM}_{\mathrm{MTM}}$ exposure. Additional studies are needed to determine whether these effects are specific to the cardiomyocyte. Interestingly, differences in absolute changes following PM $_{\text {MTM }}$ exposure were observed between the TUNEL staining and the caspase activity analyses, in which TUNEL staining revealed a greater overall change compared to caspase activation. It should be pointed out that the TUNEL measurements were performed by staining specifically for cardiomyocytes, while the caspase activities were conducted on whole heart tissue, which may have diluted the overall absolute change. Further, TUNEL analyses tend to be more sensitive in terms of absolute detection resolution.

The MPTP is considered a key nodal point in mediating cardiac dysfunction and cellular death. Pore opening enables release of pro-apoptotic proteins including cytochrome c. Our study revealed increased propensity for MPTP opening specifically in the SSM following PM $_{M T M}$ exposure. While the constituents of the MPTP have been debated, CypD has been regarded as the regulatory subunit of the pore and necessary for pore opening (4). Our study revealed no difference in the content of putative pore constituents VDAC and ANT, yet we observed a significant increase in CypD content in the SSM following PM $_{\text {MTM }}$ exposure. These data support a hypothesis of increased pore opening propensity specific for the SSM following $\mathrm{PM}_{\mathrm{MTM}}$ exposure. Differential subpopulation responses to apoptotic stimuli are consistent with other pathological models $(1,77)$.

Many studies indicate that mitochondrial spatial location may be associated with a specific response to pathological stimuli (34). Two spatially-distinct mitochondrial subpopulations have been noted in the myocyte: SSM, which reside below the cell membrane, and IFM, which exist between the myofibrils. In the current study, SSM displayed increased apoptotic propensity following $\mathrm{PM}_{\mathrm{MTM}}$ exposure. In contrast, both mitochondrial subpopulations displayed decreased active respiration rates after $\mathrm{PM}_{\text {MTM }}$ exposure. These findings indicate that 
following $\mathrm{PM}_{\text {MTM }}$ exposure there could potentially be a spatial component to metabolic insult. Further, these data suggest that SSM are impacted to a greater extent by $\mathrm{PM}_{\text {MTM }}$ exposure and, based on their spatial position, we speculate that the primary source of cellular stress comes from outside the sarcolemma. SSM act as a protective barrier to the cell interior, maintaining permissive oxygen levels and the resulting cellular milieu $(41,66)$. We theorize that the impact to SSM supports the hypothesis that a pulmonary particle insult stimulates a systemic response, such as inflammation, which affects the cell at its periphery. It has been indicated that mitochondrial subpopulations can communicate across the cell, providing a platform for mitochondrial synchronization (87). The degree of interaction between these two subpopulations is of debate but one hypothesis indicates that the innermost SSM and the outermost IFM are connected through mitochondrial filaments enabling metabolic coupling (66). If such a scenario were to exist, one could hypothesize that a significant insult at the SSM could stimulate dysfunction to the IFM.

In this study we chose to use an acute exposure to $\mathrm{PM}_{\text {MтM }}$ using intratracheal instillation at a dose that would be similar to an accumulated dose over 1.7 years. This dose was based on ambient recorded concentrations of $8.3 \mu \mathrm{g} / \mathrm{m}^{3}$ and a minute ventilation of $200 \mathrm{ml} / \mathrm{min}$ with an estimated deposition fraction of 0.2 and was chosen because previous effects have been observed (36). Given that our model resembles a young, healthy population, our findings may be of even greater significance to older populations and populations with pre-existing conditions. It should be noted that other methods of pulmonary exposure (e.g. inhalation), as well as a chronic model, may be more translationally relevant. This may be particularly applicable for heart failure which can be influenced by mitochondrial dysfunction through bioenergetic deficit and myocyte apoptosis, both of which contribute to contractile dysfunction and cardiomyocyte loss. Yet because of the limited mass of $\mathrm{PM}_{\text {Мтм }}$ particle collected, more demanding exposure approaches were not possible. Also due to the limited particle mass, elemental analysis was not 
undertaken thus conclusions between elements and their contribution to the reported observations were not drawn. Indeed, future studies should employ inhalation exposure and indepth elemental analysis in order to couple effects with a specific toxicant. Nevertheless, investigations into the acute effects of $\mathrm{PM}_{\mathrm{MTM}}$ exposure are not without value, as they provide insight into the potential toxicological mechanisms elicited by PM $_{\text {MTM }}$ exposure.

Though the current study is aimed at the populations proximal to MTM sites, our findings could provide a broader impact on our understanding of cardiovascular toxicology. The data presented in this manuscript show for the first time that exposure to $\mathrm{PM}_{\mathrm{MTM}}$ induces cardiac dysfunction concomitant with increased mitochondrial associated apoptotic signaling and decreased mitochondrial function. Further, our findings suggest that there is a spatial component to this dysfunction, as evidenced by differential effects to spatially-distinct mitochondrial subpopulations. 


\section{ACKNOWLEDGEMENTS}

We would like to acknowledge Caroll McBride, Dr. Katherine Brundage, Dr. Christopher Cuff, Dr. Amanda Ammer and the West Virginia University Flow Cytometry Core, the West Virginia University Imaging Core, and the West Virginia University Animal Models of Imaging

Core. We would like to further acknowledge Dr. James Coad, Rebecca Radabaugh and the West Virginia University Pathology and Electron Microscopy Core Facility. 


\section{GRANTS}

This work was supported by the National Institute of Diabetes and Digestive and Kidney Diseases Award No. DP2DK083095 (J.M. Hollander), the WVU CTSI (NIH U54GM104942) (J.M. Hollander) and ES015022 (T.R. Nurkiewicz). This work was supported by NSF award Nos. 1003907 and DGE-1144676 (T.R. Nurkiewicz). Cody Nichols is a recipient of an Integrative Graduate Education and Research Traineeship Program (DGE-1144676) and also a recipient of an American Heart Association Predoctoral Fellowship (AHA 13PRE16850066). Danielle Shepherd is a recipient of an NIH Predoctoral Fellowship (T32HL090610) and also an American Heart Association Predoctoral Fellowship (14PRE19890020). Phoebe Stapleton is a recipient of a Post-doctoral fellowship (NIH F32 ES023435) and an NIH Career Development award (NIH K99 ES024783). Valerie Minarchick is also a recipient of an Integrative Graduate Education and Research Traineeship Program (DGE-1144676). Core facilities were supported by NIH P30RR031155, NIH P20 RR016440, NIH P30 GM103488 and NIH S10 RR026378. 


\section{AUTHOR CONTRIBUTIONS}

C.E.N, D.L.S., T.L.K., D.T., J.C.S., P.A.S., V.C.M. researched data. C.E.N., D.L.S., J.M.H. performed statistical analyses. C.E.N. wrote the manuscript. C.E.N., D.L.S., T.L.K., P.A.S., A.E., P.C.Z., S.E.A., T.R.N, J.M.H. reviewed/edited manuscript. C.E.N, A.E, P.C.Z., S.E.A., T.R.N., J.M.H. contributed to discussion. 


\section{DISCLAIMER}

The findings and conclusions in this report are those of the author(s) and do not necessarily represent the views of the National Institute for Occupational Safety and Health. 


\section{REFERENCES}

1. Adhihetty PJ, Ljubicic V, Menzies KJ, and Hood DA. Differential susceptibility of subsarcolemmal and intermyofibrillar mitochondria to apoptotic stimuli. Am J Physiol Cell Physiol 289: C994-C1001, 2005.

2. Administration UEl. Annual Energy Outlook 2010. Washington DC: EIA, 2010.

3. Astort F, Sittner M, Ferraro SA, Orona NS, Maglione GA, De la Hoz A, and Tasat DR. Pulmonary inflammation and cell death in mice after acute exposure to air particulate matter from an industrial region of Buenos Aires. Arch Environ Contam Toxicol 67: 87-96, 2014.

4. Baines CP, Kaiser RA, Purcell NH, Blair NS, Osinska H, Hambleton MA, Brunskill EW, Sayen MR, Gottlieb RA, Dorn GW, Robbins J, and Molkentin JD. Loss of cyclophilin D reveals a critical role for mitochondrial permeability transition in cell death. Nature 434: 658-662, 2005.

5. Baseler WA, Dabkowski ER, Jagannathan R, Thapa D, Nichols CE, Shepherd DL, Croston TL, Powell M, Razunguzwa TT, Lewis SE, Schnell DM, and Hollander JM. Reversal of mitochondrial proteomic loss in Type 1 diabetic heart with overexpression of phospholipid hydroperoxide glutathione peroxidase. Am J Physiol Regul Integr Comp Physiol 304: R553-565, 2013.

6. Baseler WA, Dabkowski ER, Williamson CL, Croston TL, Thapa D, Powell MJ, Razunguzwa TT, and Hollander JM. Proteomic alterations of distinct mitochondrial subpopulations in the type 1 diabetic heart: contribution of protein import dysfunction. $A m J$ Physiol Regul Integr Comp Physiol 300: R186-200, 2011.

7. Becher R, Bucht A, Ovrevik J, Hongslo JK, Dahlman HJ, Samuelsen JT, and Schwarze PE. Involvement of NADPH oxidase and iNOS in rodent pulmonary cytokine responses to urban air and mineral particles. Inhal Toxicol 19: 645-655, 2007.

8. Bradford MM. A rapid and sensitive method for the quantitation of microgram quantities of protein utilizing the principle of protein-dye binding. Anal Biochem 72: 248-254, 1976. 
9. Brook RD, Rajagopalan S, Pope CA, 3rd, Brook JR, Bhatnagar A, Diez-Roux AV, Holguin F, Hong Y, Luepker RV, Mittleman MA, Peters A, Siscovick D, Smith SC, Jr., Whitsel L, Kaufman JD, American Heart Association Council on E, Prevention CotKiCD, Council on Nutrition PA, and Metabolism. Particulate matter air pollution and cardiovascular disease: An update to the scientific statement from the American Heart Association. Circulation 121: 2331-2378, 2010.

10. Carll AP, Haykal-Coates N, Winsett DW, Hazari MS, Ledbetter AD, Richards JH, Cascio WE, Costa DL, and Farraj AK. Cardiomyopathy confers susceptibility to particulate matter-induced oxidative stress, vagal dominance, arrhythmia and pulmonary inflammation in heart failure-prone rats. Inhal Toxicol 27: 100-112, 2015.

11. Carll AP, Hazari MS, Perez CM, Krantz QT, King CJ, Haykal-Coates N, Cascio WE, Costa DL, and Farraj AK. An autonomic link between inhaled diesel exhaust and impaired cardiac performance: insight from treadmill and dobutamine challenges in heart failure-prone rats. Toxicological sciences : an official journal of the Society of Toxicology 135: 425-436, 2013.

12. Chance B and Williams GR. Respiratory enzymes in oxidative phosphorylation. I. Kinetics of oxygen utilization. J Biol Chem 217: 383-393, 1955.

13. Chance B and Williams GR. Respiratory enzymes in oxidative phosphorylation. VI. The effects of adenosine diphosphate on azide-treated mitochondria. J Biol Chem 221: 477-489, 1956.

14. Croston TL, Shepherd DL, Thapa D, Nichols CE, Lewis SE, Dabkowski ER, Jagannathan R, Baseler WA, and Hollander JM. Evaluation of the cardiolipin biosynthetic pathway and its interactions in the diabetic heart. Life sciences 93: 313-322, 2013.

15. Croston TL, Thapa D, Holden AA, Tveter KJ, Lewis SE, Shepherd DL, Nichols CE, Long DM, Olfert IM, Jagannathan R, and Hollander JM. Functional deficiencies of subsarcolemmal mitochondria in the type 2 diabetic human heart. Am J Physiol Heart Circ Physiol 307: H54-65, 2014. 
16. Cui Y, Xie X, Jia F, He J, Li Z, Fu M, Hao H, Liu Y, Liu JZ, Cowan PJ, Zhu H, Sun Q, and Liu Z. Ambient fine particulate matter induces apoptosis of endothelial progenitor cells through reactive oxygen species formation. Cell Physiol Biochem 35: 353-363, 2015.

17. Dabkowski ER, Baseler WA, Williamson CL, Powell M, Razunguzwa TT, Frisbee JC, and Hollander JM. Mitochondrial dysfunction in the type 2 diabetic heart is associated with alterations in spatially distinct mitochondrial proteomes. Am J Physiol Heart Circ Physiol 299: H529-540, 2010.

18. Dabkowski ER, Williamson CL, Bukowski VC, Chapman RS, Leonard SS, Peer CJ, Callery PS, and Hollander JM. Diabetic cardiomyopathy-associated dysfunction in spatially distinct mitochondrial subpopulations. Am J Physiol Heart Circ Physiol 296: H359-369, 2009.

19. Dabkowski ER, Williamson CL, and Hollander JM. Mitochondria-specific transgenic overexpression of phospholipid hydroperoxide glutathione peroxidase (GPx4) attenuates ischemia/reperfusion-associated cardiac dysfunction. Free Radic Biol Med 45: 855-865, 2008.

20. Deng X, Zhang F, Wang L, Rui W, Long F, Zhao Y, Chen D, and Ding W. Airborne fine particulate matter induces multiple cell death pathways in human lung epithelial cells. Apoptosis 19: 1099-1112, 2014.

21. Dockery DW, Pope CA, 3rd, Xu X, Spengler JD, Ware JH, Fay ME, Ferris BG, Jr., and Speizer FE. An association between air pollution and mortality in six U.S. cities. $N$ Engl $J$ Med 329: 1753-1759, 1993.

22. Dominici F, McDermott A, Zeger SL, and Samet JM. National maps of the effects of particulate matter on mortality: exploring geographical variation. Environmental health perspectives 111: 39-44, 2003.

23. Donaldson $\mathbf{K}$ and Stone $\mathbf{V}$. Current hypotheses on the mechanisms of toxicity of ultrafine particles. Ann Ist Super Sanita 39: 405-410, 2003.

24. Dye JA, Lehmann JR, McGee JK, Winsett DW, Ledbetter AD, Everitt Jl, Ghio AJ, and Costa DL. Acute pulmonary toxicity of particulate matter filter extracts in rats: coherence 
with epidemiologic studies in Utah Valley residents. Environmental health perspectives 109 Suppl 3: 395-403, 2001.

25. EIA. US. Annual coal report 2013, edited by Administration USEI. Washington, DC, 2015.

26. Elder A and Oberdorster G. Translocation and effects of ultrafine particles outside of the lung. Clin Occup Environ Med 5: 785-796, 2006.

27. EPA. US. Air Quality Criteria for Particulate Matter (Final Report, Oct 2004). edited by Agency USEP. Washington, DC, 2004.

28. Esch L and Hendryx M. Chronic cardiovascular disease mortality in mountaintop mining areas of central Appalachian states. $J$ Rural Health 27: 350-357, 2011.

29. Farina F, Sancini G, Mantecca P, Gallinotti D, Camatini M, and Palestini P. The acute toxic effects of particulate matter in mouse lung are related to size and season of collection. Toxicol Lett 202: 209-217, 2011.

30. Gorr MW, Velten M, Nelin TD, Youtz DJ, Sun Q, and Wold LE. Early life exposure to air pollution induces adult cardiac dysfunction. Am J Physiol Heart Circ Physiol 307: H13531360, 2014.

31. Halestrap AP. What is the mitochondrial permeability transition pore? Journal of molecular and cellular cardiology 46: 821-831, 2009.

32. Hao Y, Jackson JR, Wang Y, Edens N, Pereira SL, and Alway SE. beta-Hydroxybeta-methylbutyrate reduces myonuclear apoptosis during recovery from hind limb suspensioninduced muscle fiber atrophy in aged rats. Am J Physiol Regul Integr Comp Physiol 301: R701715, 2011.

33. Hartz AM, Bauer B, Block ML, Hong JS, and Miller DS. Diesel exhaust particles induce oxidative stress, proinflammatory signaling, and P-glycoprotein up-regulation at the blood-brain barrier. FASEB J 22: 2723-2733, 2008. 
34. Hollander JM, Thapa D, and Shepherd DL. Physiological and structural differences in spatially distinct subpopulations of cardiac mitochondria: influence of cardiac pathologies. Am $J$ Physiol Heart Circ Physiol 307: H1-14, 2014.

35. Jones $\mathbf{T}$, Blackmore $\mathbf{P}$, Leach $\mathbf{M}$, Berube $\mathrm{K}$, Sexton $\mathrm{K}$, and Richards $\mathbf{R}$. Characterisation of airborne particles collected within and proximal to an opencast coalmine: South Wales, U.K. Environ Monit Assess 75: 293-312, 2002.

36. Knuckles TL, Stapleton PA, Minarchick VC, Esch L, McCawley M, Hendryx M, and Nurkiewicz TR. Air pollution particulate matter collected from an Appalachian mountaintop mining site induces microvascular dysfunction. Microcirculation 20: 158-169, 2013.

37. Kodavanti UP, Moyer CF, Ledbetter AD, Schladweiler MC, Costa DL, Hauser R, Christiani DC, and Nyska A. Inhaled environmental combustion particles cause myocardial injury in the Wistar Kyoto rat. Toxicological sciences : an official journal of the Society of Toxicology 71: 237-245, 2003.

38. Kreyling WG, Semmler-Behnke M, and Moller W. Ultrafine particle-lung interactions: does size matter? J Aerosol Med 19: 74-83, 2006.

39. Kurth L, Kolker A, Engle M, Geboy N, Hendryx M, Orem W, McCawley M, Crosby L, Tatu C, Varonka M, and DeVera C. Atmospheric particulate matter in proximity to mountaintop coal mines: sources and potential environmental and human health impacts. Environ Geochem Health, 2014.

40. Kurth LM, McCawley M, Hendryx M, and Lusk S. Atmospheric particulate matter size distribution and concentration in West Virginia coal mining and non-mining areas. $J$ Expo Sci Environ Epidemiol 24: 405-411, 2014.

41. Kuznetsov AV, Troppmair J, Sucher R, Hermann M, Saks V, and Margreiter R. Mitochondrial subpopulations and heterogeneity revealed by confocal imaging: possible physiological role? Biochimica et biophysica acta 1757: 686-691, 2006. 
42. Kwong JQ and Molkentin JD. Physiological and pathological roles of the mitochondrial permeability transition pore in the heart. Cell Metab 21: 206-214, 2015.

43. Laemmli UK. Cleavage of structural proteins during the assembly of the head of bacteriophage T4. Nature 227: 680-685, 1970.

44. Langrish JP, Bosson J, Unosson J, Muala A, Newby DE, Mills NL, Blomberg A, and Sandstrom T. Cardiovascular effects of particulate air pollution exposure: time course and underlying mechanisms. J Intern Med 272: 224-239, 2012.

45. Minarchick VC, Stapleton PA, Fix NR, Leonard SS, Sabolsky EM, and Nurkiewicz TR. Intravenous and Gastric Cerium Dioxide Nanoparticle Exposure Disrupts Microvascular Smooth Muscle Signaling. Toxicological sciences : an official journal of the Society of Toxicology, 2014.

46. Minarchick VC, Stapleton PA, Porter DW, Wolfarth MG, Ciftyurek E, Barger M, Sabolsky EM, and Nurkiewicz TR. Pulmonary cerium dioxide nanoparticle exposure differentially impairs coronary and mesenteric arteriolar reactivity. Cardiovascular toxicology 13: 323-337, 2013.

47. Nelin TD, Joseph AM, Gorr MW, and Wold LE. Direct and indirect effects of particulate matter on the cardiovascular system. Toxicol Lett 208: 293-299, 2012.

48. Nemmar A, Vanbilloen H, Hoylaerts MF, Hoet PH, Verbruggen A, and Nemery B. Passage of intratracheally instilled ultrafine particles from the lung into the systemic circulation in hamster. American journal of respiratory and critical care medicine 164: 1665-1668, 2001.

49. Nurkiewicz TR, Porter DW, Barger M, Castranova V, and Boegehold MA. Particulate matter exposure impairs systemic microvascular endothelium-dependent dilation. Environmental health perspectives 112: 1299-1306, 2004.

50. Nurkiewicz TR, Porter DW, Barger M, Millecchia L, Rao KM, Marvar PJ, Hubbs AF, Castranova V, and Boegehold MA. Systemic microvascular dysfunction and inflammation 
after pulmonary particulate matter exposure. Environmental health perspectives 114: 412-419, 2006.

51. Nurkiewicz TR, Porter DW, Hubbs AF, Stone S, Moseley AM, Cumpston JL, Goodwill AG, Frisbee SJ, Perrotta PL, Brock RW, Frisbee JC, Boegehold MA, Frazer DG, Chen BT, Castranova V, and Committee HEIHR. Pulmonary particulate matter and systemic microvascular dysfunction. Res Rep Health Eff Inst: 3-48, 2011.

52. Oberdorster G, Sharp Z, Atudorei V, Elder A, Gelein R, Kreyling W, and Cox C. Translocation of inhaled ultrafine particles to the brain. Inhal Toxicol 16: 437-445, 2004.

53. Oberdorster G, Sharp Z, Atudorei V, Elder A, Gelein R, Lunts A, Kreyling W, and Cox C. Extrapulmonary translocation of ultrafine carbon particles following whole-body inhalation exposure of rats. J Toxicol Environ Health A 65: 1531-1543, 2002.

54. Palmer JW, Tandler B, and Hoppel CL. Biochemical properties of subsarcolemmal and interfibrillar mitochondria isolated from rat cardiac muscle. J Biol Chem 252: 8731-8739, 1977.

55. Palmer MA, Bernhardt ES, Schlesinger WH, Eshleman KN, Foufoula-Georgiou E, Hendryx MS, Lemly AD, Likens GE, Loucks OL, Power ME, White PS, and Wilcock PR. Science and regulation. Mountaintop mining consequences. Science 327: 148-149, 2010.

56. Parrish AB, Freel CD, and Kornbluth S. Cellular mechanisms controlling caspase activation and function. Cold Spring Harbor perspectives in biology 5, 2013.

57. Peng RD, Dominici F, Pastor-Barriuso R, Zeger SL, and Samet JM. Seasonal analyses of air pollution and mortality in 100 US cities. Am J Epidemiol 161: 585-594, 2005.

58. Peretz A, Peck EC, Bammler TK, Beyer RP, Sullivan JH, Trenga CA, Srinouanprachnah S, Farin FM, and Kaufman JD. Diesel exhaust inhalation and assessment of peripheral blood mononuclear cell gene transcription effects: an exploratory study of healthy human volunteers. Inhal Toxicol 19: 1107-1119, 2007.

59. Perez CM, Hazari MS, and Farraj AK. Role of autonomic reflex arcs in cardiovascular responses to air pollution exposure. Cardiovascular toxicology 15: 69-78, 2015. 
60. Pope CA, 3rd and Dockery DW. Health effects of fine particulate air pollution: lines that connect. J Air Waste Manag Assoc 56: 709-742, 2006.

61. Pope CA, 3rd, Thun MJ, Namboodiri MM, Dockery DW, Evans JS, Speizer FE, and Heath CW, Jr. Particulate air pollution as a predictor of mortality in a prospective study of U.S. adults. American journal of respiratory and critical care medicine 151: 669-674, 1995.

62. Quay JL, Reed W, Samet J, and Devlin RB. Air pollution particles induce IL-6 gene expression in human airway epithelial cells via NF-kappaB activation. Am J Respir Cell Mol Biol 19: 98-106, 1998.

63. Ruckerl R, Phipps RP, Schneider A, Frampton M, Cyrys J, Oberdorster G, Wichmann HE, and Peters A. Ultrafine particles and platelet activation in patients with coronary heart disease--results from a prospective panel study. Part Fibre Toxicol 4: 1, 2007.

64. Samet JM, Dominici F, Curriero FC, Coursac I, and Zeger SL. Fine particulate air pollution and mortality in 20 U.S. cities, 1987-1994. N Engl J Med 343: 1742-1749, 2000.

65. Shimada A, Kawamura N, Okajima M, Kaewamatawong T, Inoue H, and Morita T. Translocation pathway of the intratracheally instilled ultrafine particles from the lung into the blood circulation in the mouse. Toxicol Pathol 34: 949-957, 2006.

66. Skulachev VP. Mitochondrial filaments and clusters as intracellular power-transmitting cables. Trends Biochem Sci 26: 23-29, 2001.

67. Stapleton PA, Minarchick VC, Cumpston AM, McKinney W, Chen BT, Sager TM, Frazer DG, Mercer RR, Scabilloni J, Andrew ME, Castranova V, and Nurkiewicz TR. Impairment of coronary arteriolar endothelium-dependent dilation after multi-walled carbon nanotube inhalation: a time-course study. International journal of molecular sciences 13: 1378113803, 2012.

68. Tamagawa E, Bai N, Morimoto K, Gray C, Mui T, Yatera K, Zhang X, Xing L, Li Y, Laher I, Sin DD, Man SF, and van Eeden SF. Particulate matter exposure induces persistent 
lung inflammation and endothelial dysfunction. Am J Physiol Lung Cell Mol Physiol 295: L79-85, 2008.

69. Tankersley CG, Champion HC, Takimoto E, Gabrielson K, Bedja D, Misra V, ElHaddad H, Rabold R, and Mitzner W. Exposure to inhaled particulate matter impairs cardiac function in senescent mice. Am J Physiol Regul Integr Comp Physiol 295: R252-263, 2008.

70. Thapa D, Nichols CE, Lewis SE, Shepherd DL, Jagannathan R, Croston TL, Tveter KJ, Holden AA, Baseler WA, and Hollander JM. Transgenic overexpression of mitofilin attenuates diabetes mellitus-associated cardiac and mitochondria dysfunction. Journal of molecular and cellular cardiology 79: 212-223, 2015.

71. van Eeden SF, Tan WC, Suwa T, Mukae H, Terashima T, Fujii T, Qui D, Vincent R, and Hogg JC. Cytokines involved in the systemic inflammatory response induced by exposure to particulate matter air pollutants $(\mathrm{PM}(10))$. American journal of respiratory and critical care medicine 164: 826-830, 2001.

72. Van Hee VC, Adar SD, Szpiro AA, Barr RG, Bluemke DA, Diez Roux AV, Gill EA,

Sheppard L, and Kaufman JD. Exposure to traffic and left ventricular mass and function: the Multi-Ethnic Study of Atherosclerosis. American journal of respiratory and critical care medicine 179: 827-834, 2009.

73. Veronesi B, Oortgiesen M, Carter JD, and Devlin RB. Particulate matter initiates inflammatory cytokine release by activation of capsaicin and acid receptors in a human bronchial epithelial cell line. Toxicol Appl Pharmacol 154: 106-115, 1999.

74. Wang Y, Hao Y, and Alway SE. Suppression of GSK-3beta activation by M-cadherin protects myoblasts against mitochondria-associated apoptosis during myogenic differentiation. $J$ Cell Sci 124: 3835-3847, 2011.

75. WHO. Ambient (outdoor) air quality and health, edited by Organization WH. Geneva, Switzerland, 2014. 
76. WHO. World Health Report 2002, edited by Organization WH. Geneva, Switzerland, 2002.

77. Williamson CL, Dabkowski ER, Baseler WA, Croston TL, Alway SE, and Hollander

JM. Enhanced apoptotic propensity in diabetic cardiac mitochondria: influence of subcellular spatial location. Am J Physiol Heart Circ Physiol 298: H633-642, 2010.

78. Williamson CL, Dabkowski ER, Dillmann WH, and Hollander JM. Mitochondria protection from hypoxia/reoxygenation injury with mitochondria heat shock protein 70 overexpression. Am J Physiol Heart Circ Physiol 294: H249-256, 2008.

79. Wilson WE and Suh HH. Fine particles and coarse particles: concentration relationships relevant to epidemiologic studies. J Air Waste Manag Assoc 47: 1238-1249, 1997.

80. Wold LE, Ying Z, Hutchinson KR, Velten M, Gorr MW, Velten C, Youtz DJ, Wang A, Lucchesi PA, Sun Q, and Rajagopalan S. Cardiovascular remodeling in response to long-term exposure to fine particulate matter air pollution. Circulation Heart failure 5: 452-461, 2012.

81. Woolley SM, Meacham SL, Balmert LC, Talbott EO, and Buchanich JM. Comparison of Mortality Disparities in Central Appalachian Coal- and Non-Coal-Mining Counties. J Occup Environ Med, 2015.

82. Yan $\mathbf{Y H}$, Huang $\mathbf{C H}$, Chen WJ, Wu MF, and Cheng TJ. Effects of diesel exhaust particles on left ventricular function in isoproterenol-induced myocardial injury and healthy rats. Inhal Toxicol 20: 199-203, 2008.

83. Yuan S and Akey CW. Apoptosome structure, assembly, and procaspase activation. Structure 21: 501-515, 2013.

84. Zanobetti A and Schwartz J. The effect of fine and coarse particulate air pollution on mortality: a national analysis. Environmental health perspectives 117: 898-903, 2009.

85. Zhang J, Ghio AJ, Chang W, Kamdar O, Rosen GD, and Upadhyay D. Bim mediates mitochondria-regulated particulate matter-induced apoptosis in alveolar epithelial cells. FEBS Lett 581: 4148-4152, 2007. 
86. Zhou B, Liang G, Qin H, Peng X, Huang J, Li Q, Qing L, Zhang L, Chen L, Ye L, Niu P, and Zou Y. p53-dependent apoptosis induced in human bronchial epithelial (16-HBE) cells by PM2.5 sampled from air in Guangzhou, China. Toxicol Mech Methods 24: 552-559, 2014.

87. Zhou L and O'Rourke B. Cardiac mitochondrial network excitability: insights from computational analysis. Am J Physiol Heart Circ Physiol 302: H2178-2189, 2012.

88. Zullig KJ and Hendryx M. A comparative analysis of health-related quality of life for residents of U.S. counties with and without coal mining. Public Health Rep 125: 548-555, 2010. 
Table 2.1

\begin{tabular}{lcc}
\hline Parameter & $\begin{array}{c}\text { Control } \\
\text { Average } \pm \text { SEM }\end{array}$ & $\begin{array}{c}\text { Exposed } \\
\text { Average } \pm S E M\end{array}$ \\
\hline Heart Weight (mg) & $743.00 \pm 39.39$ & $837.00 \pm 51.00$ \\
Body Weight (g) & $299.63 \pm 8.94$ & $288.5 \pm 1.50$ \\
Heart Weight:Body Weight & $2.51 \pm 0.18$ & $2.90 \pm 0.19$ \\
Heart Rate (BPM) & $416.60 \pm 10.38$ & $403.54 \pm 10.05$ \\
Diameter;s (mm) & $2.29 \pm 0.09$ & $2.71 \pm 0.18 *$ \\
Diameter;d (mm) & $5.62 \pm 0.08$ & $5.84 \pm 0.18$ \\
Volume;s $(\mu \mathrm{L})$ & $18.66 \pm 1.97$ & $29.46 \pm 5.08 *$ \\
Volume;d $(\mu \mathrm{L})$ & $155.39 \pm 5.22$ & $171.61 \pm 12.12$ \\
Stroke Volume $(\mu \mathrm{L})$ & $136.73 \pm 5.54$ & $142.15 \pm 8.84$ \\
Ejection Fraction $(\%)$ & $87.88 \pm 1.25$ & $83.53 \pm 1.98 *$ \\
Fractional Shortening $(\%)$ & $59.16 \pm 1.76$ & $53.89 \pm 2.09 *$ \\
Cardiac Output $(\mathrm{mL} / \mathrm{min})$ & $57.15 \pm 3.16$ & $57.33 \pm 3.79$ \\
\hline
\end{tabular}


Table 2.1. M-Mode Echocardiographic Measurements. Values are means \pm SE; $n=10$ for each group. ${ }^{*} P<0.05$ for Control vs. Exposed. 
Figure 2.1

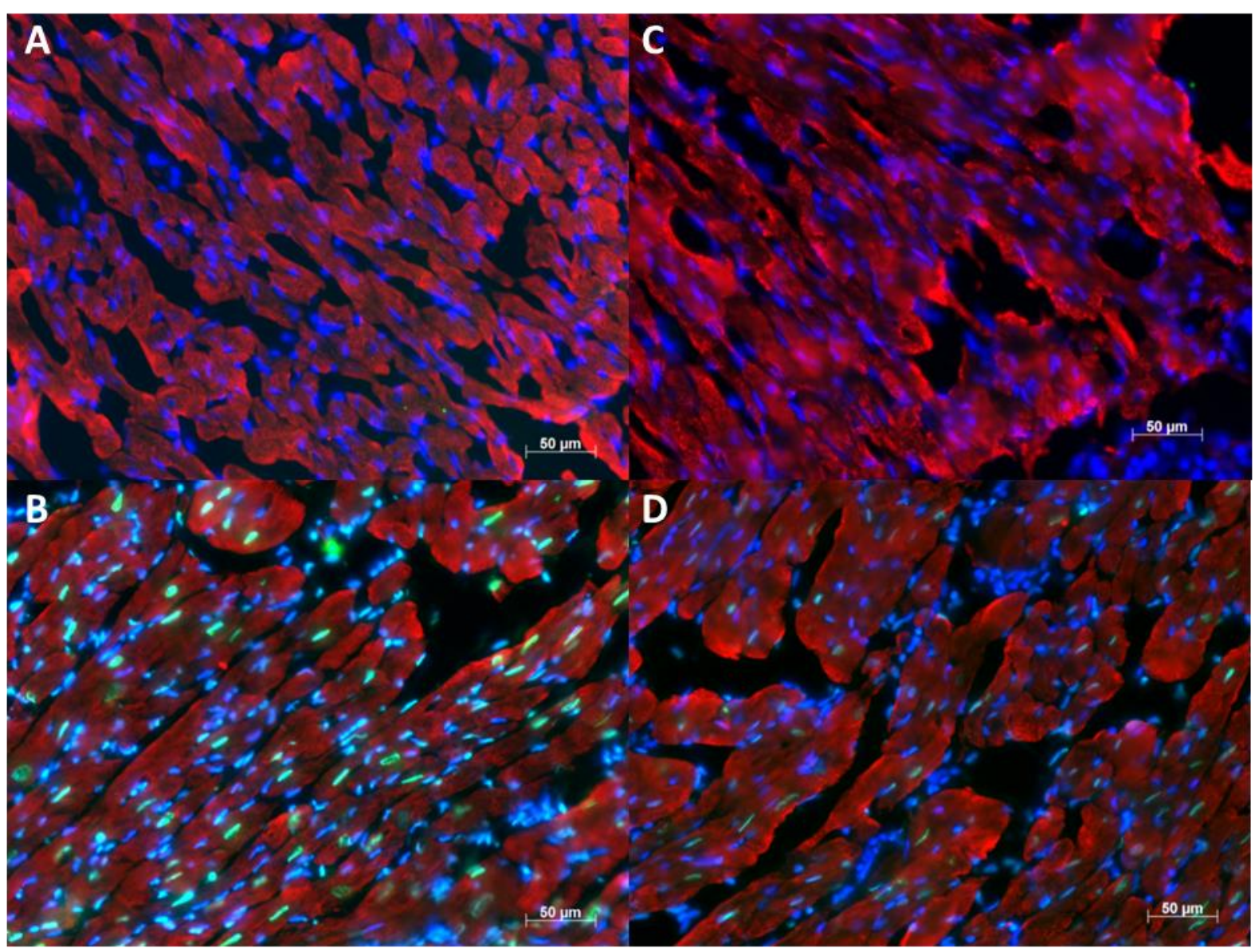

E

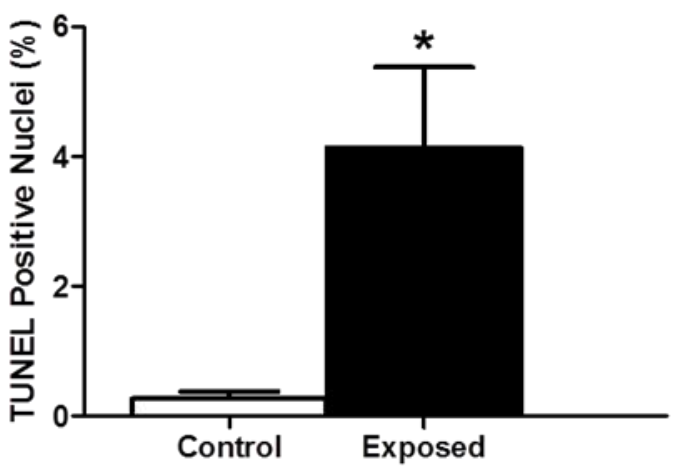

F

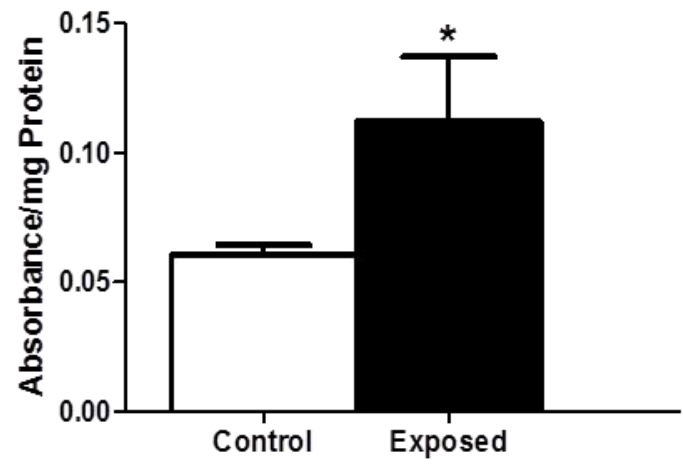


Figure 2.1. Cardiac Apoptotic Index Following $\mathbf{P M}_{\mathrm{MTM}}$ Exposure. Representative fluorescent images of cardiac tissue with exclusion of TdT enzyme (A) Negative control; (B) positive control with inclusion of DNase I; (C) control with vehicle instillation; and (D) exposed with $\mathrm{PM}_{\mathrm{MTM}}$ instillation. DAPI stained nuclei are indicated in blue while TUNEL positive nuclei are shown in green and red indicates heavy chain cardiac myosin. Scale bar: $50 \mu \mathrm{m}$. (E) Apoptotic index was calculated as the percentage of total cardiomyocyte nuclei that were TUNEL positive nuclei. Values are mean $\pm \mathrm{SE} ; n=3$ for each group. (F) Relative cytosolic histone concentrations determined by ELISA on left ventricular tissue from control and $\mathrm{PM}_{\mathrm{MTM}}$ exposed animals. Values are mean \pm SE; $n=5$ for each group. ${ }^{*} P<0.05$ for Control vs. Exposed. 
Figure 2.2

A

Caspase -8

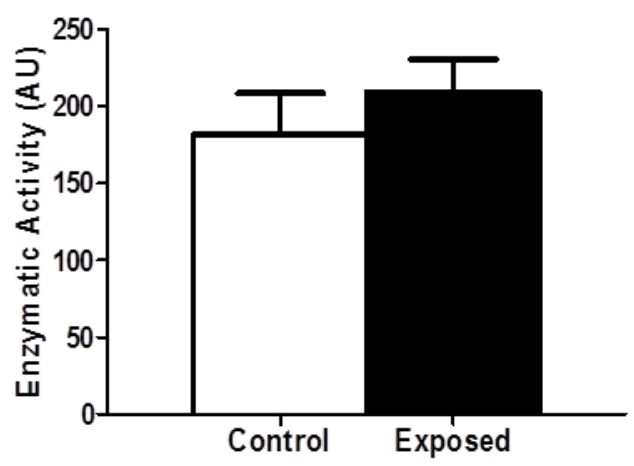

B

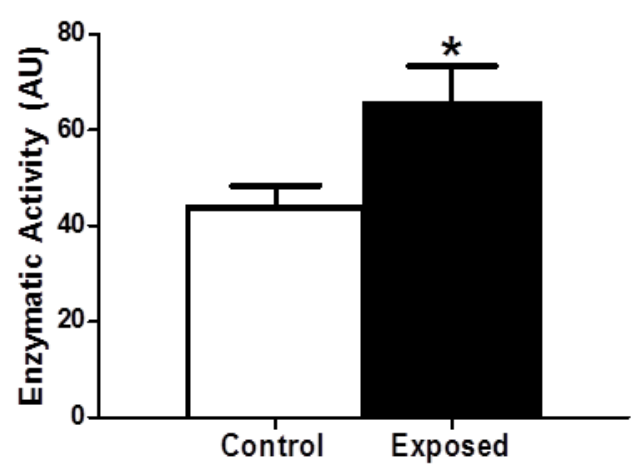

C Caspase-3

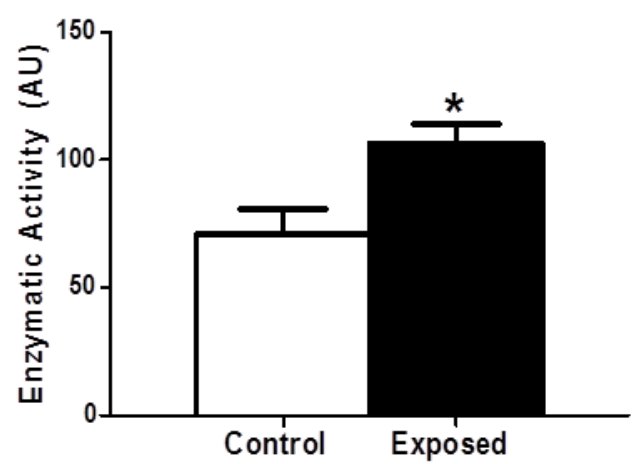

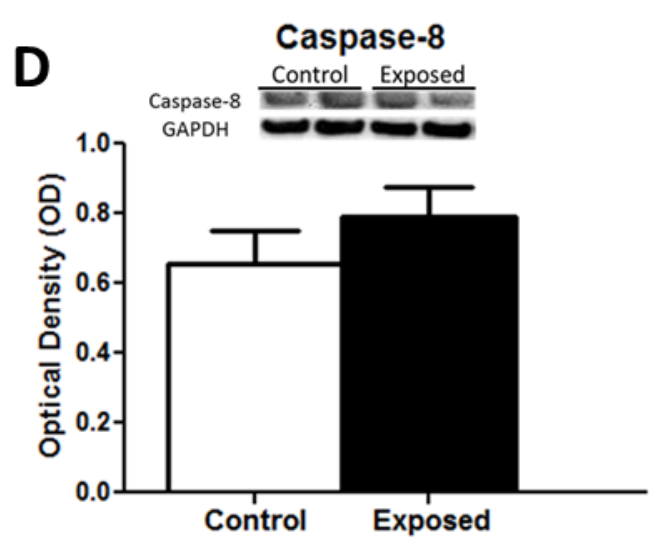

E
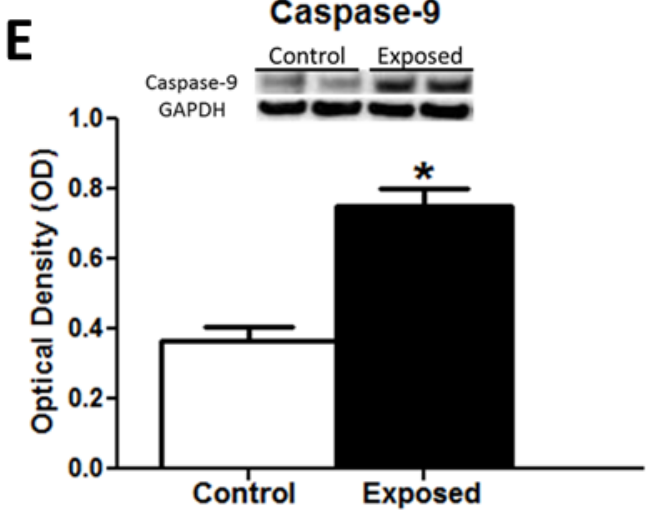

F

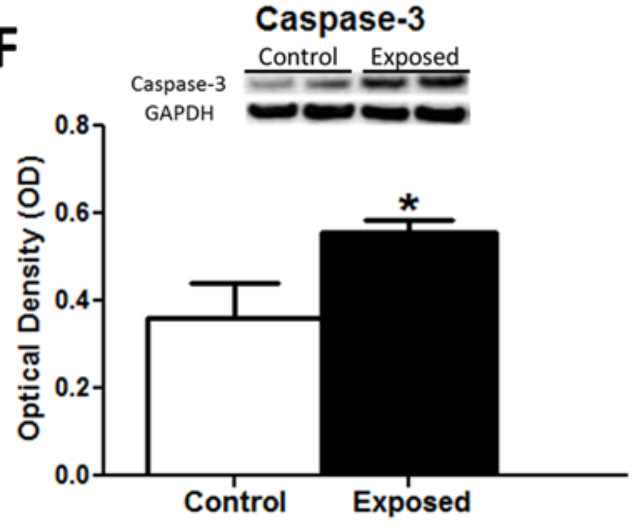


Figure 2.2. Cardiac Caspase Activities and Content Following РМ $_{\text {MTM Exposure. }}$ Fluorometric analysis of enzymatic activities of $(\mathbf{A})$ caspase-8; $(\mathbf{B})$ caspase-9; and (C) caspase3 from the cytosol of rat left ventricles exposed by instillation to either vehicle control or $\mathrm{PM}_{\mathrm{MTM}}$. Data are expressed as arbitrary units (AU). Relative protein contents of activated caspases from cytosolic fractions from left ventricles of rats exposed by instillation to either vehicle control or $\mathrm{PM}_{\text {MTM. }}$. Representative Western blots (top) and densitometric analyses (bottom) for total protein content of (D) caspase-8; (E) caspase-9; and (F) caspase-3. All Western blots are expressed per GAPDH levels. Values are means \pm SE; $n=6$ for each group. ${ }^{\star} P<0.05$ for Control vs. Exposed. 
Figure 2.3

A

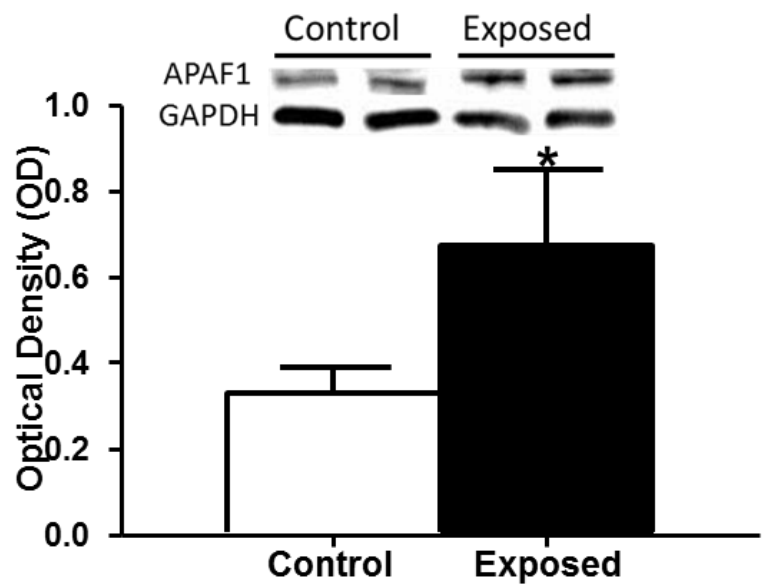

C

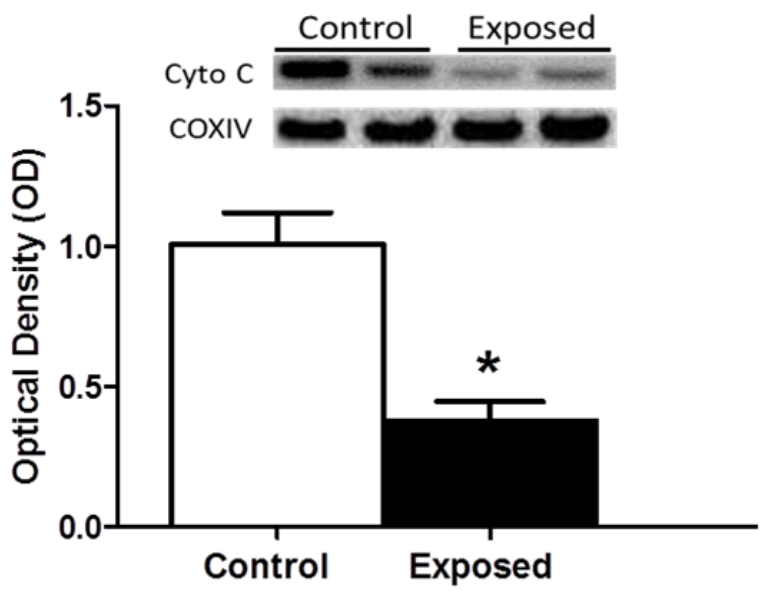

B Cytosolic

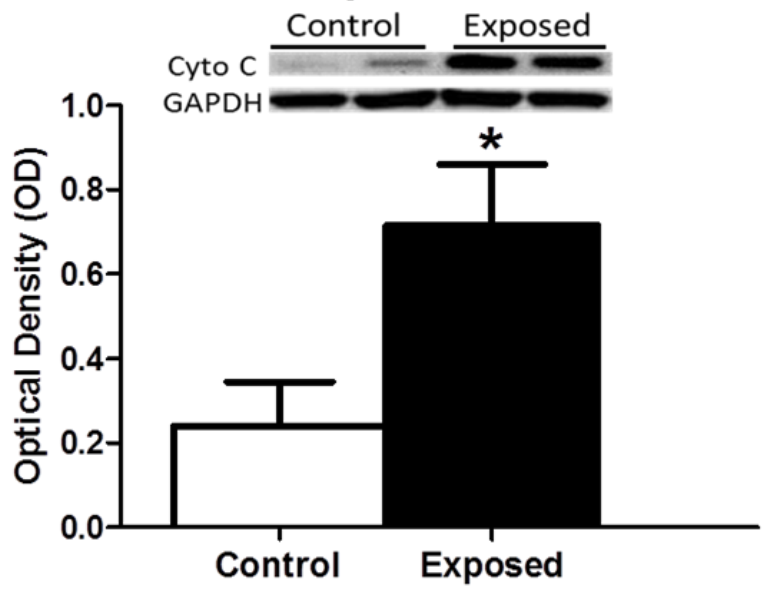

D

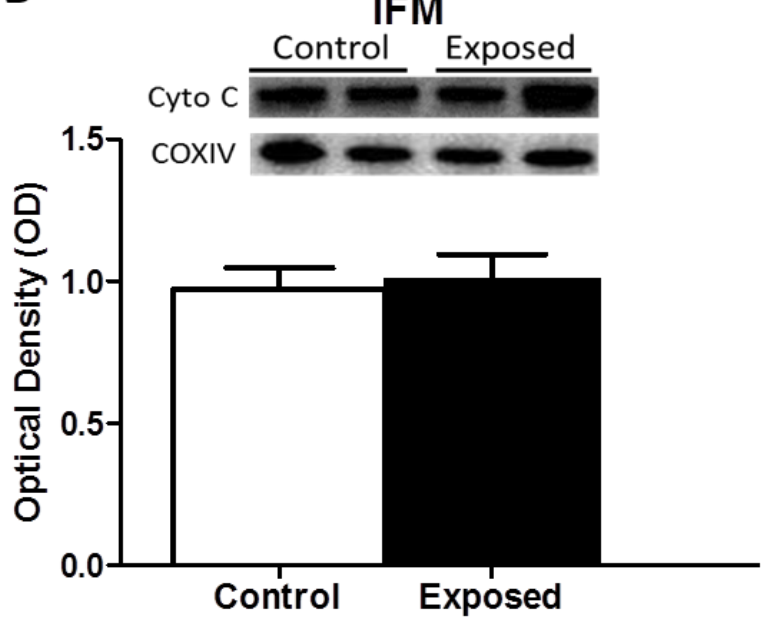


Figure 2.3. Apoptosome Constituent Contents. Relative protein contents of apoptosome constituents from cytosol and isolated mitochondrial subpopulations from left ventricles of rats exposed by instillation to either vehicle control or $\mathrm{PM}_{\mathrm{MTM}}$. Representative Western blots (top) and densitometric analyses (bottom) for total protein content of (A) cytosolic apoptosis protease activating factor 1 (APAF1); (B) cytosolic cytochrome $c$ (Cyto C); (C) cytochrome $c$ in the SSM; and (D) cytochrome $c$ in the IFM. Cytosolic proteins (A and B) were expressed per GAPDH levels, while mitochondrial analyses (C and D) were expressed per COX IV levels. Values are means $\pm \mathrm{SE} ; n=8$ for each group. ${ }^{*} P<0.05$ for Control vs. Exposed. 
Figure 2.4

A

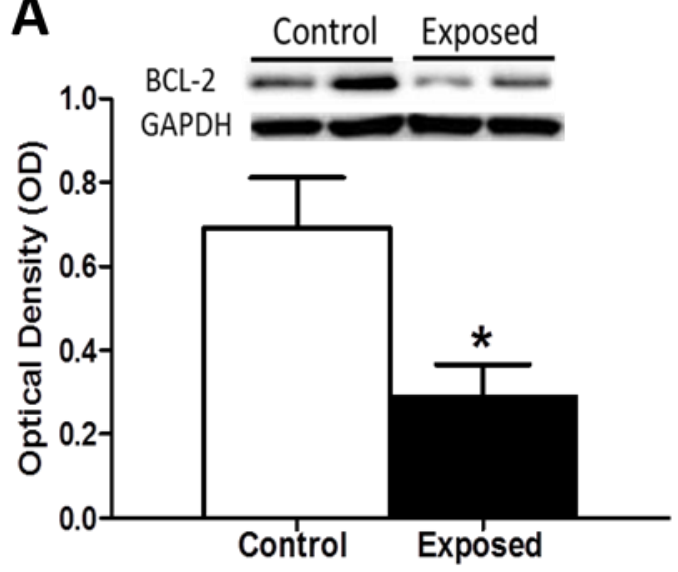

B

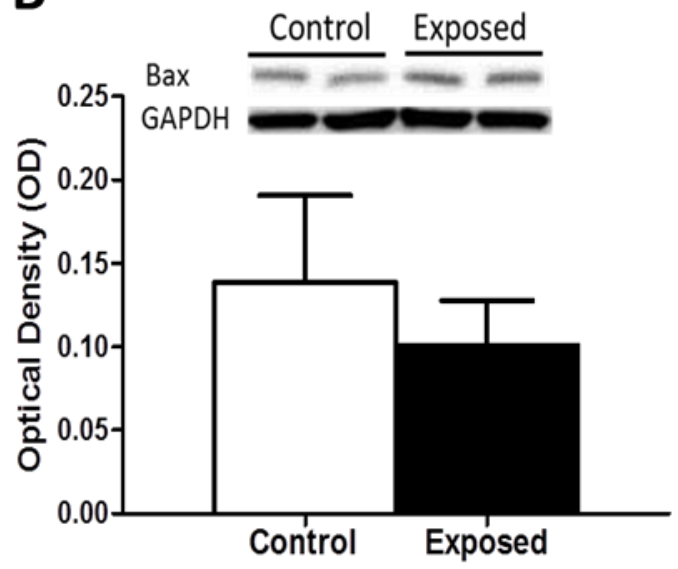

C

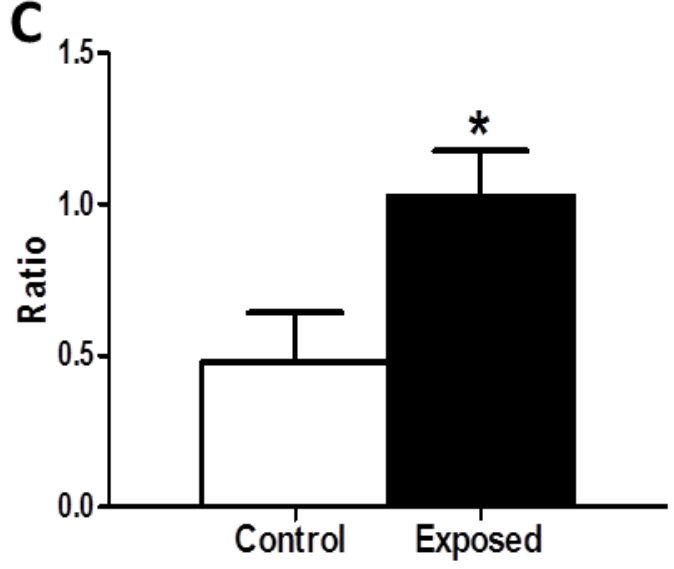

D

IP:Bax

WB:BCL-2

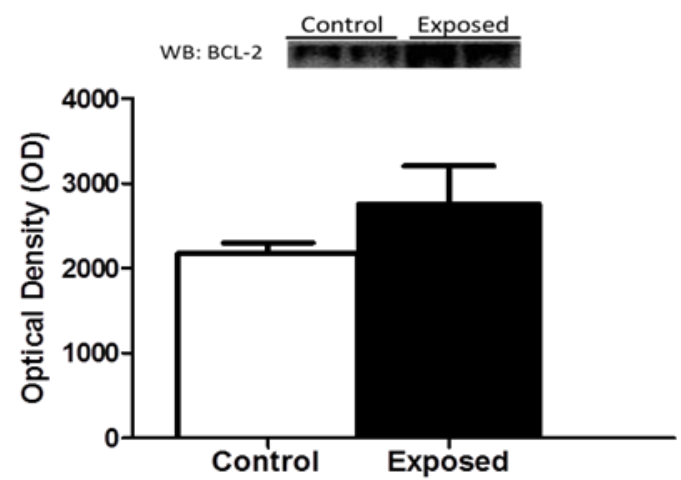

E

IP:Bax

WB:Bax

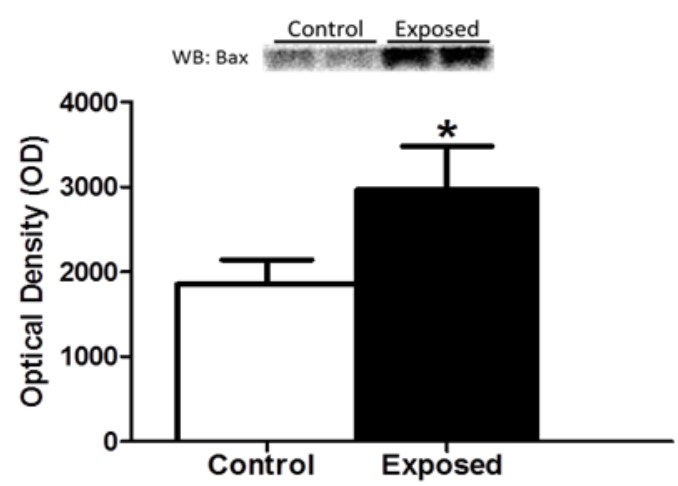

F

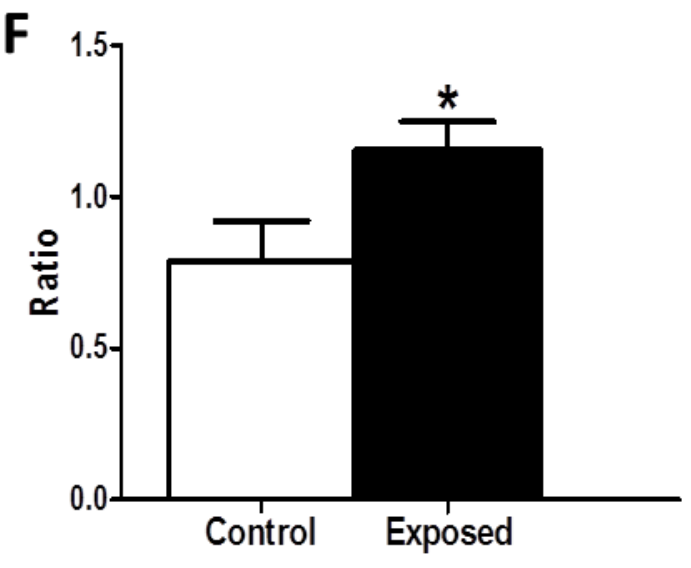


Figure 2.4. BAX and Bcl-2 Protein Contents. Relative protein contents of total-cell markers of apoptosis from left ventricles of rats exposed by instillation to either vehicle control or $\mathrm{PM}_{\mathrm{MTM}}$. Representative Immunoblots (top) and densitometric analyses (bottom) for cytosolic (A) Bcl-2associated X protein (BAX) and (B) B-cell lymphoma 2 (Bcl-2). (C) Ratio of densitometric analysis of Bax to Bcl-2. Western blots are expressed per GAPDH levels. Immunoblots from coimmunoprecipitation with Bax suggesting the formation of hetero- or homo-dimers with (D) Bcl-2 or (E) Bax. Ratio of densitometric analysis of Bax dimers with Bax to Bcl-2 (F). Values are means \pm SE; $n=8$ for each group, ${ }^{*} P<0.05$ for Control vs. Exposed. 
Figure 2.5
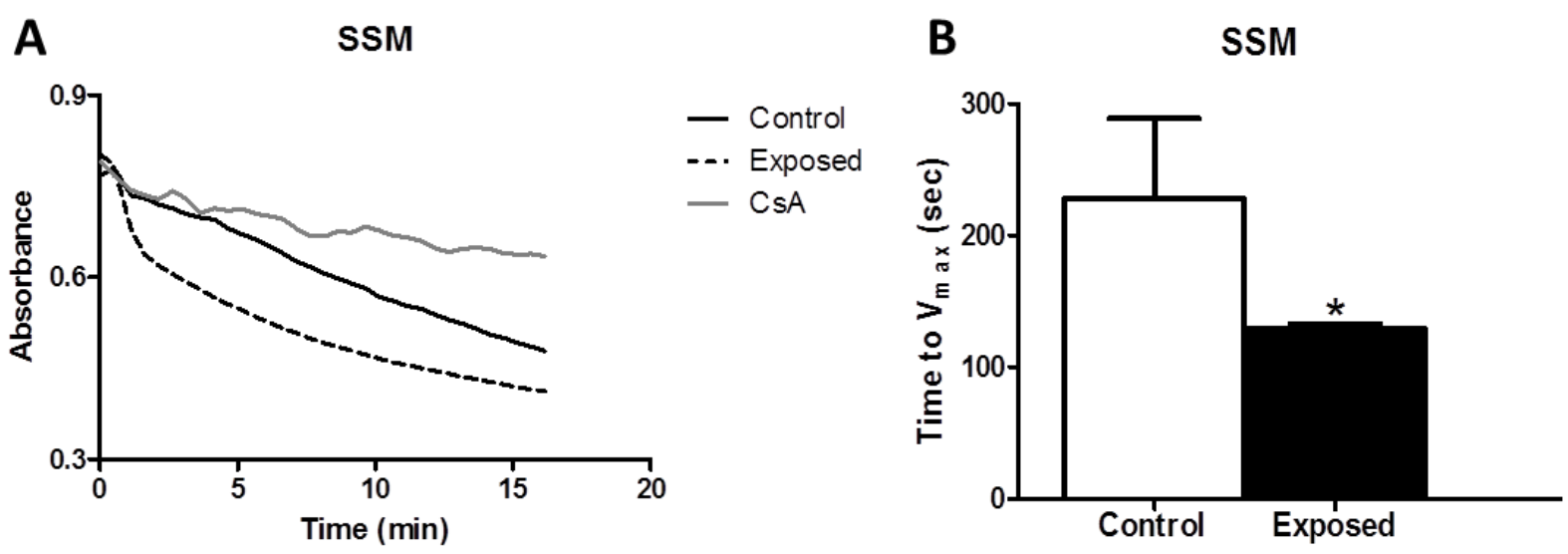

C

IFM
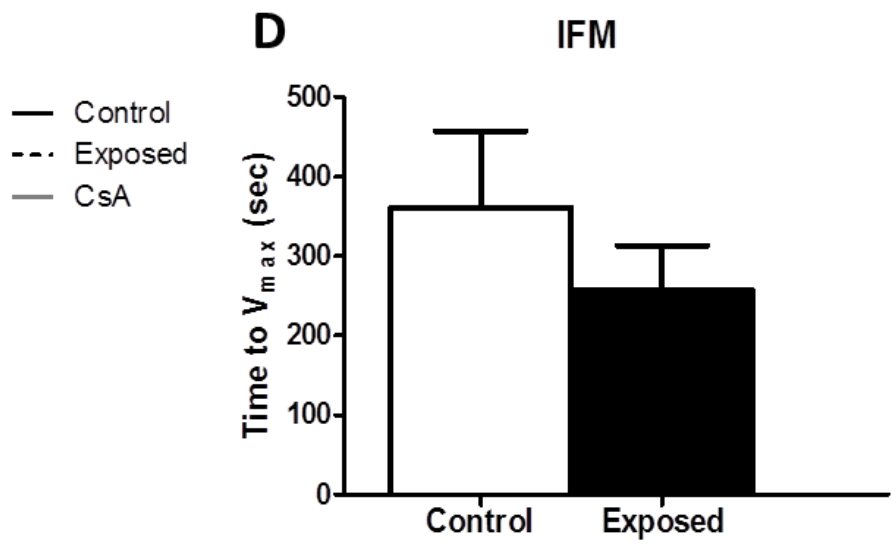
Figure 2.5. mPTP Opening Propensity. Mitochondrial permeability transition pore (mPTP) opening propensity from left ventricles of rats exposed by instillation to either vehicle control or $\mathrm{PM}_{\mathrm{MTM}}$. Spectrophotometric analysis of MPTP opening propensity using the exogenous oxidant $\mathrm{t}-\mathrm{BuOOH}$ to induce mitochondrial swelling. Time to $\mathrm{V}_{\max }$ was assessed over a 15 minute time period. Representative absorbance plots for (A) SSM and (C) IFM. Solid lines represent control, dashed lines represent exposed and dotted lines represents the internal control, cyclosporine A (CsA) treatment. $V_{\max }$ data graphed for (B) SSM and (D) IFM. Values are means \pm SE; $n=6$ for each group. ${ }^{*} P<0.05$ for Control vs. Exposed. 
Figure 2.6

A

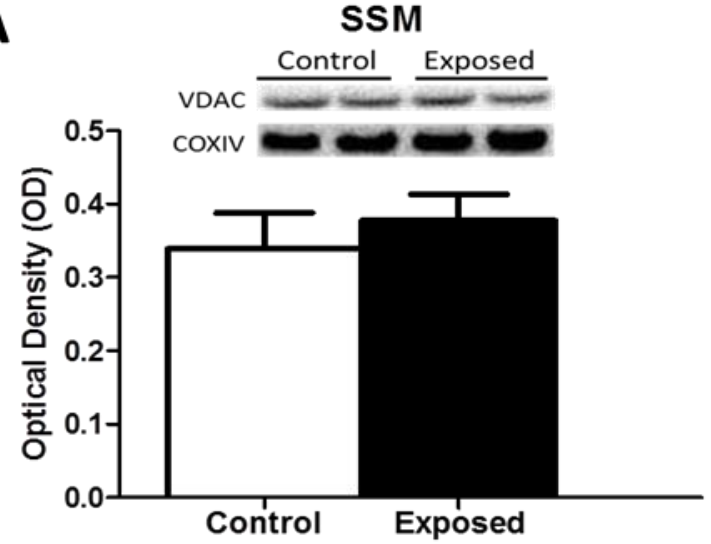

C

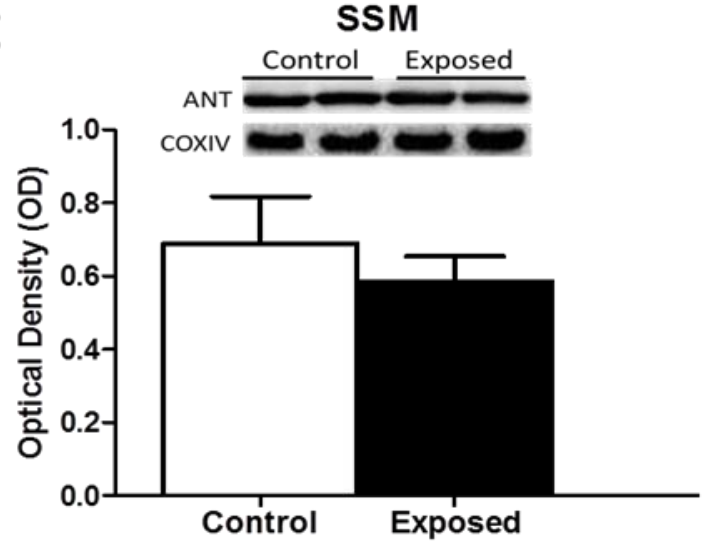

E

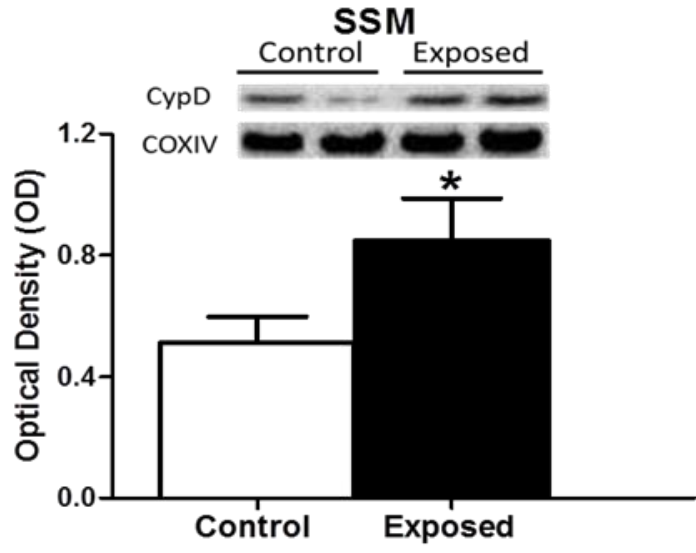

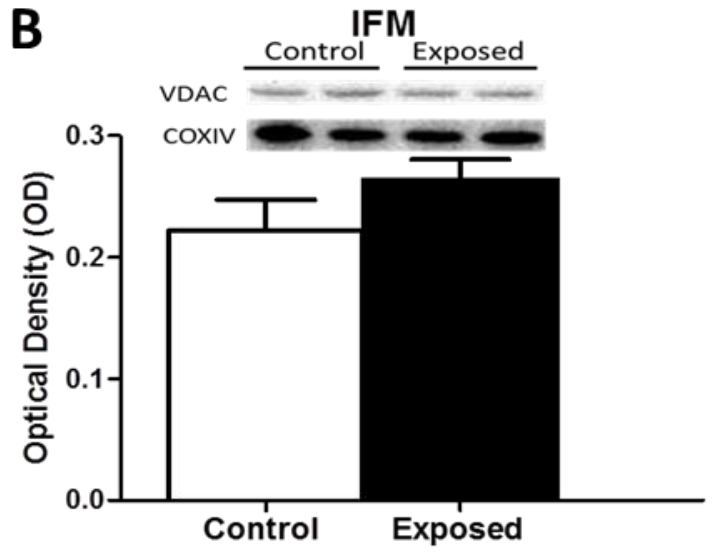

D

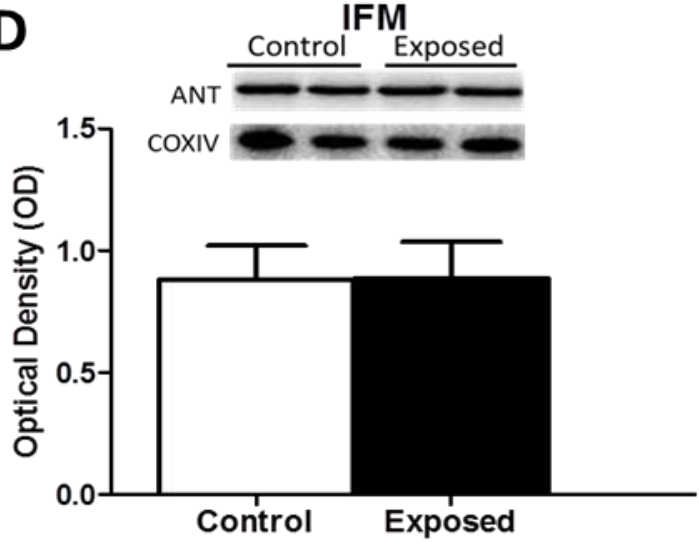

F

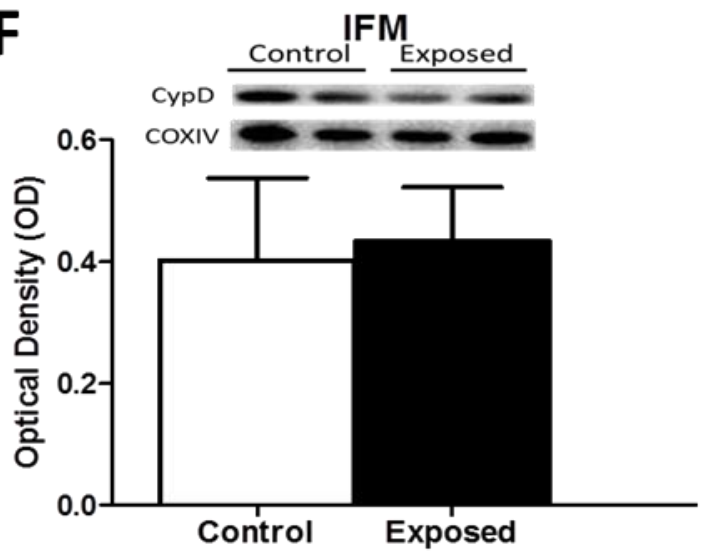


Figure 2.6. mPTP Components. Relative protein content assessed by Western blotting of putative members of the mitochondrial permeability transition pore (mPTP) from left ventricles of rats exposed by instillation to either vehicle control or $\mathrm{PM}_{\mathrm{MTM}}$. Representative Western blots (top) and densitometric analyses (bottom) for (A) total voltage dependent anion channel (VDAC) in SSM and (B) in IFM; adenine nucleotide translocase in SSM (C) and IFM (D); cyclophilin D in SSM (E) and IFM (F). All Western blots are expressed per COX IV levels. Values are means \pm SE; $n=8$ for each group. ${ }^{*} P<0.05$ for Control vs. Exposed. 
Figure 2.7
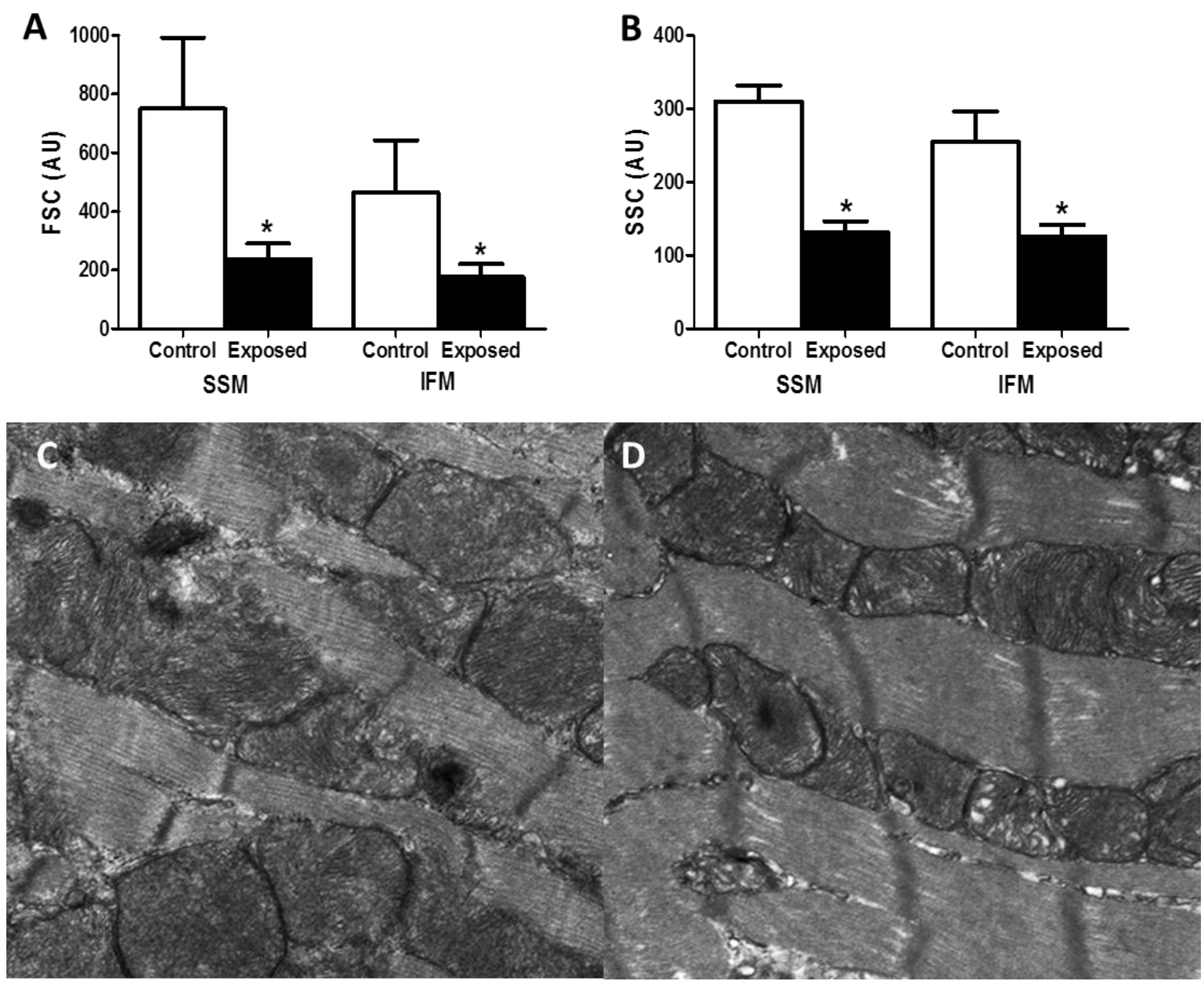
Figure 2.7. Mitochondrial Morphological Assessment. Relative size and internal complexity were analyzed using mitotracker deep red 633 and flow cytometry. (A) Analysis of cardiac SSM and IFM size (FSC) in control and exposed mitochondria subpopulations. (B) Analysis of cardiac SSM and IFM internal complexity (SSC) in control and exposed mitochondrial subpopulations. Representative electron micrographs of left ventricle tissue from control (C) and PM $_{\text {MTM }}$ exposed (D). Values for both FSC and SSC are expressed as arbitrary units (AU) \pm SE; $n=8$ for each group. ${ }^{\star} P<0.05$ for Control vs. Exposed. 
Figure 2.8
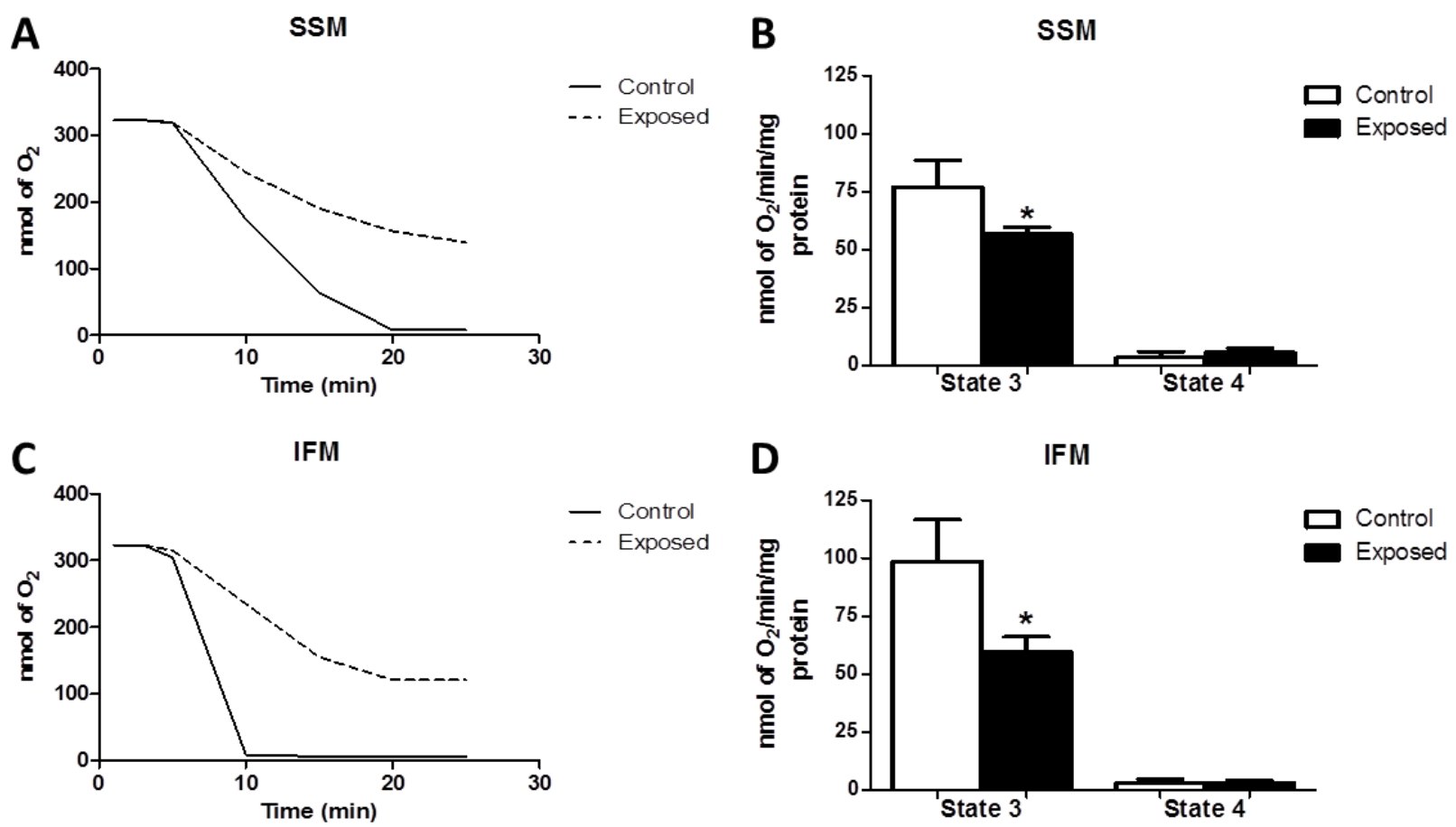
Figure 2.8. Mitochondrial Respiratory Capacity. Representative polarographic traces of oxygen consumption following addition of glutamate and malate to (A) SSM and (C) IFM. Solid line traces represent mitochondria from control and dashed line traces represent mitochondria from $\mathrm{PM}_{\mathrm{MTM}}$ exposed. Summary analyses of state 3 and state 4 respiration rates from trace measurements of (B) SSM and (D) IFM. Respiration rates are expressed in $\mathrm{nmol} \cdot \mathrm{min}^{-1} \cdot \mathrm{mg}$ protein $^{-1}$.Values are means \pm SE; $n=6$ for each group. ${ }^{*} P<0.05$ for Control vs. Exposed. 


\section{Chapter 3:}

\section{Differential Cardiac Mitochondrial Dose Responses Following Pulmonary Exposure to Multi-Walled Carbon Nanotubes}

Cody E. Nichols ${ }^{1}$, Aaron Erdely ${ }^{2}$, Danielle L. Shepherd ${ }^{1}$, Lindsey Bishop ${ }^{2}$, Dharendra Thapa ${ }^{1}$, Rebecca Salmen², Michael L. Kashon², Timothy R. Nurkiewicz ${ }^{3}$, John M. Hollander ${ }^{1}$

${ }^{1}$ West Virginia University School of Medicine, Division of Exercise Physiology; ${ }^{2}$ National Institute for Occupational Safety and Health, ${ }^{3}$ West Virginia University Department of Physiology and Pharmacology, Morgantown, WV 26506

Running Title: Cardiac and mitochondrial dysfunction following multi-walled carbon nanotube

$$
\text { exposure }
$$

Corresponding Author:

John M. Hollander, Ph.D., F.A.H.A.

West Virginia University School of Medicine

Division of Exercise Physiology

Center for Cardiovascular and Respiratory Sciences

1 Medical Center Drive

Morgantown, WV 26506

Tel: (304) 293-3683

Fax: (304) 293-7105

Email: jhollander@hsc.wvu.edu 


\begin{abstract}
While carbon-based nanomaterial use continues to grow, the health effects of inhalation exposures are not fully realized. Following nanomaterial pulmonary exposure, extrapulmonary effects are recognized but cardiac effects are not well defined. Further, the in vivo mechanisms describing the subcellular impacts of exposure, especially within the cardiomyocyte, are undetermined. The current study investigated the impact of pulmonary exposure to multi-walled carbon nanotubes (MWCNT) on cardiac and mitochondrial function. Male C57BL/6 mice were exposed using pharyngeal aspiration to either $40 \mu \mathrm{g}$ of MWCNT; $10 \mu \mathrm{g}$ of MWCNT; or sham, dispersion media. Four or 24 hours after exposure, conventional and speckle tracking-based echocardiography were utilized to assess cardiac function. Cardiac mitochondrial subpopulations were then isolated and run through polarographic assessments for mitochondrial oxygen consumption, and mitochondrial hydrogen peroxide $\left(\mathrm{H}_{2} \mathrm{O}_{2}\right)$ production was measured using the fluorescent dye Amplex red. Differential strain analyses were identified between the doses suggesting MWCNT exposure dose dictates response. Yet both doses of MWCNT decreased active respiration rates in mitochondrial subpopulations at four hr compared to controls $(\mathrm{P}<0.05)$, but only the dysfunction associated with the $10 \mu \mathrm{g}$ dose persisted at $24 \mathrm{hr}$ $(\mathrm{P}<0.05)$. Increased production of $\mathrm{H}_{2} \mathrm{O}_{2}$ was observed $24 \mathrm{~h}$ after exposure to $40 \mu \mathrm{g}$ MWCNT as compared to shams $(\mathrm{P}<0.05)$. Increased myoglobin in the $40 \mu \mathrm{g}$ MWCNT exposure $(\mathrm{P}<0.05)$ may act as a compensatory mechanism to rectify mitochondrial dysfunction but contribute to reactive oxygen species production. In conclusion, cardiac disruptions and mitochondrial dysfunction was observed following acute pulmonary exposure to MWCNT.
\end{abstract}

Keywords: Mitochondria; Cardiac Function; Nanomaterials; Reactive Oxygen Species; MultiWalled Carbon Nanotubes 


\section{INTRODUCTION}

While nanotechnology is continually growing into a billion dollar industry, carbon-based nanomaterials are already being utilized for a wide variety of applications ranging from industrial to biomedical. Multi-walled carbon nanotubes (MWCNT) are described as many hollow cylinders of carbon atoms stacked inside one another. The global market for MWCNT continues to grow as the number of applications continually increases; and with the increasing market, industrial production and widespread distribution into consumer products raises considerable concern for the human health effects of exposure to MWCNT.

The unique physicochemical properties that make MWCNT revolutionary in consumer products are the same properties that may elicit toxic effects when exposure occurs. To date, no human end-points following exposure have been realized thus extrapolation from rodent toxicological studies is relied on to drive regulatory decisions. Yet even within rodent models, the cardiac impacts following exposure to MWCNT have not been fully realized. Systemic effects such as immunosuppression, systemic inflammation and changes in extrapulmonary tissue molecular signaling following exposure manifest $(18,19,27,28,34)$. Within the cardiovascular system, reduced vascular responsiveness (38) and increased susceptibility to ischemia/reperfusion injury following MWCNT exposure have been identified (42). Yet the effects of MWCNT pulmonary exposure on cardiac function and molecular endpoints within the heart have not been elucidated.

Investigating possible cardiotoxic effects is best accomplished through in vivo assessments do to the complexity of the cardiovascular system which integrates global pump function, neurohormonal status, vascular properties and systemic hemodynamics. In recent years, echocardiography has emerged as the standard cardiac imaging technique even in small animal models, yet conventional echocardiographic measures lack the sensitivity to capture 
subtle changes in left ventricular performance. Speckle tracking-based strain analyses are able to provide integrated and detailed information regarding both regional and global LV function, with much greater sensitivity and specificity than conventional measures (24). Utilizing these analyses, speckle-tracking based strain echocardiographic analysis has efficiently detected subtle changes in cardiac performance and identified early differences in response to cardiac therapies in the left ventricle both globally and regionally $(5,37)$.

To date, speckle-tracking based echocardiography has not been used to investigate cardiac function following an inhalation exposure to ENMs. Further, the subcellular mechanisms that can contribute to cardiac dysfunction and the subclinical indices that may be impacted have not been characterized. In single-walled carbon nanotube pulmonary exposure aortic protein and mitochondrial DNA were damaged by ROS highlighting cardiovascular oxidative milieu disruption effecting subcellular organelles (25). But the disruptions of subcellular cardiac mechanisms following a pulmonary exposure to MWCNT have not been well characterized.

The mitochondrion has been implicated in the etiology of many cardiovascular diseases due to the many crucial roles it plays within the cardiomyocyte. Among the central roles for the mitochondrion are the production of ATP requisite for cardiac contraction and relaxation as well as its production of reactive oxygen species that can be used for signaling or produce damage to cellular materials. In vitro analyses have observed an increase in ROS production from mitochondrial sources and increased mitochondrial ROS damage following exposure to CNT (21). Yet, in vivo cardiac mitochondrial analysis of exposure impacts have not been recognized.

To safely integrate nanomaterials into our lives we need to fully realize the health impacts of these materials. Thus, the goal of the current studies was to examine the impact of acute pulmonary exposure to MWCNT on the heart and identify mechanisms contributing to 
cardiac functional disturbances. To test this question we will use a well characterized MWCNT and state-of-the-art echocardiographic techniques coupled with in-depth mitochondrial functional analyses to characterize the functional impacts of these particles. In this study we identify subclinical cardiac functional aberrations accompanied by increased mitochondrial ROS production and damage that may arise from mechanisms arising from decreased mitochondrial function following acute MWCNT pulmonary exposure. 


\section{MATERIALS AND METHODS}

\section{Experimental animals}

The animal experiments in this study were approved by the West Virginia University Animal Care and Use Committee and conformed to the most current National Institutes of Health (NIH) Guidelines for the Care and Use of Laboratory Animals manual. Male C57BL/6J mice from Jackson Laboratory (Bar Harbor, ME) were housed in the AAALAC-approved NIOSH Animal Facility were provided food and tap water ad libitum in ventilated cages in a controlled humidity and temperature environment with a $12 \mathrm{hr}$ light/dark cycle. Animal care and use procedures were conducted in accordance with the "PHS Policy on Humane Care and Use of Laboratory Animals" and the "Guide for the Care and Use of Laboratory Animals" (NIH publication 86-23, 1996). These procedures were approved by the National Institute for Occupational Safety and Health Institutional Animal Care and Use Committee.

\section{Pharyngeal Aspiration}

Pharyngeal aspiration was performed according to the method of Rao et al. (33) as previously described $(20,46)$. Mice were anesthetized with isoflurane in a bell jar, placed on a slant board, and the tongue was gently held in full extension while a $50-\mu$ suspension of particles was pipetted onto the base of the tongue. Tongue restraint was maintained until the complete suspension was respired. Less than a minute after exposure, all mice awoke from anesthesia without visible sequela. Mice were exposed to either 10 or $40 \mu \mathrm{g}$ of MWCNT resuspended in a physiologic dosing media (DM) for the vehicle that consisted of mouse serum albumin $(0.6 \mathrm{mg} / \mathrm{ml})$ and 1,2-dipalmitoyl-sn-glycero-3-phosphocholine $(10 \mu \mathrm{g} / \mathrm{ml})$ in PBS, with 5 minutes of both external and pulse internal sonication to ensure dispersion. Controls were instilled with the same volume of dosing media. Previously these doses have shown correlation to workplace exposures and partially impairment of endothelium dependent microvascular dysfunction $(2,17)$. 


\section{Echocardiography}

Echocardiographic assessments were carried out as previously described (36). Briefly, each mouse was anesthetized with inhalant isoflurane then maintained at $1 \%$ isoflurane or lower in order to sustain a physiologically relevant heart rate range for the duration of the experiment, effectively minimizing consequences of anesthesia. Brightness and motion mode imaging was accomplished using a $32-55 \mathrm{MHz}$ linear array transducer using the highest possible frame rate (233-401 frames/second) on the Vevo2100 Imaging System (Visual Sonics, Toronto, Canada). All images were acquired by one individual.

Conventional echocardiographic assessment was completed on grayscale M-mode parasternal short-axis images at the mid-papillary level of the LV. All M-mode image measurements were calculated over 3 consecutive cardiac cycles and then averaged. Speckletracking based strain assessments were performed by tracing the walls of the endocardium and epicardium on B-mode video loops and analyzed throughout the 3 cardiac cycles using Visual Sonics VevoStrain software (Toronto, Canada) employing a speckle-tracking algorithm. The software then generates time-to-peak analysis for curvilinear data as output for strain and strain rate. The same trained investigator using the Vevo2100 Imaging analysis software (Visual Sonics, Toronto, Canada) completed all analyses.

\section{Tissue Preparation and Compartment Isolation}

Following cardiac contractile measurements mice were euthanized and hearts excised. Atrial tissue was removed and left and right ventricular tissue utilized for the studies. Cytosolic isolation was performed as previously described (44). SSM and IFM subpopulations were isolated as previously described following the methods of Palmer et al. (31) with minor modifications by our laboratory $(3,4,11-14,40,44)$. Mitochondrial pellets were resuspended in 
KME buffer (100 mM KCL, $50 \mathrm{mM}$ MOPS and $0.5 \mathrm{mM}$ EGTA pH 7.4) for all mitochondrial analyses. Protein concentrations were determined by the Bradford method using bovine serum albumin as a standard (6).

\section{Western Blotting}

SDS polyacrylamide gel electrophoresis (SDS-PAGE) was run on $4-12 \%$ gradient gels as previously described $(3,4,13,14,23,40,44)$. Relative amounts of myoglobin were determined using a specific antibody: anti-myoglobin rabbit antibody (Product No. ab77232; Abcam, Cambridge, MA). Anti-GAPDH mouse (Product No. ab8245; Abcam, Cambridge, MA) was utilized to control for protein loading in cytosolic analyses. The secondary antibody used include: goat anti-mouse IgG horseradish peroxidase (HRP) conjugate (Product No. 31430; Pierce Biotechnology) and goat anti-rabbit IgG HRP conjugate (Product No. 10004301; Cayman Chemical). Pierce Enhanced Chemiluminescence Western Blotting substrate (Pierce, Rockford, IL) was used to detect signal following the manufacturer's instructions. A G:Box Bioimaging System (Syngene, Frederick, MD) was used to assess autoradiographic signals. Data were captured and analyzed using GeneSnap/GeneTools software (Syngene).

\section{Mitochondrial Respiration}

State 3 and state 4 respiration rates were analyzed in freshly isolated mitochondrial subpopulations as previously described $(7,8)$ with modifications by our laboratory $(12,13,15$, 40). Briefly, isolated mitochondrial subpopulations were resuspended in KME buffer and protein content determined by the Bradford method (6). Mitochondria protein was added to respiration buffer (80 mmol/I KCl, $50 \mathrm{mmol} / \mathrm{l} \mathrm{MOPS,} 1 \mathrm{mmol} / \mathrm{I} \mathrm{EGTA,} 5 \mathrm{mmol} / \mathrm{KH} 2 \mathrm{PO} 4$, and $1 \mathrm{mg} / \mathrm{ml} \mathrm{BSA}$ ) and placed into a respiration chamber connected to an oxygen probe (OX1LP-1mL Dissolved Oxygen Package, Qubit System, Kingston, ON, Canada). Maximal complex I-mediated respiration was initiated by the addition of glutamate $(5 \mathrm{mM})$ and malate $(5 \mathrm{mM})$. Data for state 3 
(250 mM ADP) and state 4 (ADP-limited) respiration were expressed as nmol of oxygen consumed $/ \mathrm{min} / \mathrm{mg}$ protein.

\section{Mitochondrial Hydrogen Peroxide Production}

Cardiac mitochondrial hydrogen peroxide production was analyzed following MWCNT pulmonary exposure utilizing the fluorescent dye Amplex Red. The Amplex Red reagent reacts with hydrogen peroxide in a 1:1 stoichiometry to produce the red-fluorescent oxidation product, resorufin. Experiments were carried out following manufacturer's instructions with minor modifications. Briefly, isolated mitochondria were incubated with reaction buffer and amplex red dye was added before fueling mitochondria with glutamate, malate and ADP. Changes in fluorescence over time were read on a Molecular Devices Flex Station 3 fluorescent plate reader (Molecular Devices, Sunnyvale, CA) and normalized per milligram of protein.

\section{Mitochondrial Electron Transport Chain Complex Activities}

ETC complex I, III, IV and ATP synthase activities were measured in isolated mitochondria spectrophotometrically as previously described $(12,41)$. Briefly, complex I activity was determined by measuring the oxidation of $\mathrm{NADH}$. Complex III activity was determined by measuring the reduction of cytochrome $\mathrm{c}$ in the presence of reduced decylubiquinone. Complex IV activity was determined by measuring the oxidation of cytochrome c. ATP synthase activity was measured as oligomycin-sensitive ATPase activity using an assay coupled with pyruvate kinase, which converts ADP to ATP and produces pyruvate from phosphoenolpyruvate. ETC activities were normalized to citrate synthase activity per protein content utilizing a Citrate Synthase Assay Kit (ScienCell Research Laboratories; Carlsbad, CA) per manufacturer's instructions. Protein content was determined by the Bradford method as described above. 


\section{Lipid Peroxidation Products}

Lipid peroxidation was assessed through the measurement of stable, oxidized end products of polyunsaturated fatty acids and esters: malondialdehyde (MDA) and 4hydroxyalkenal $(4-\mathrm{HAE})$ as previously described $(3,15)$. Briefly, one molecule of either MDA or 4-HAE reacts with two molecules of $\mathrm{N}$-methyl-2-phenylindole (Oxford Biomedical Research Company, Oxford, MI) to yield a stable chromophore whose absorbance was measured on a Molecular Devices Flex Station 3 spectrophotometric plate reader (Molecular Devices, Sunnyvale, CA). Protein content was assessed by the Bradford method, as above, and values were normalized per milligram of protein.

\section{Statistics}

Mean and standard error (SE) were calculated for all data sets. A One-Way Analysis of Variance (ANOVA) was employed with a Bonferroni post-Hoc test to analyze differences between treatment groups using GraphPad Prism 5 (GraphPad Software, La Jolla, CA). $P<$ 0.05 was considered significant. 


\section{RESULTS}

\section{Conventional Echocardiographic Measurements following MWCNT Exposure}

Cardiovascular function following carbon nanotube pulmonary exposure has been identified but focused on the vascular impacts of exposure with little focus on cardiac functional impacts. When considering cardiac function, especially systolic function, it is important to initially investigate and examine the potential of overt cardiac dysfunction. Using conventional echocardiographic measurements we are able to investigate the in vivo function of the heart following acute MWCNT exposure. Throughout our study across both time points and doses we observed no significant change in any of the conventional measures of echocardiography as measured by M-Mode echocardiography (Table 1).

Technological progression has enhanced our ability to measure subclinical discrepancies in cardiac function through the use of speckle-tracking echocardiography. Initially, we do not see a change in any strain parameter four hours after exposure (Figure 1A-D). We begin to see dose impacting the cardiac strain analyses 24 hours after exposure and identified that systolic strain was decreased following a $40 \mu \mathrm{g}$ exposure with no change in the $10 \mu \mathrm{g}$ exposed animals as compared to dispersion media (Figure 1E). Inversely, we identified increased radial strain rate in the $10 \mu \mathrm{g}$ exposed animals with no significant difference in the 40 $\mu \mathrm{g}$ exposed animals compared to dispersion media (Figure 1F). Continuing our thorough analysis, we identified a significant increase in the circumferential strain in the $40 \mu \mathrm{g}$ exposure yet no change in the $10 \mu \mathrm{g}$ exposed animals as compared to dispersion media (Figure 1G). Finally, we observed an increase in the circumferential strain rate following exposure to $10 \mu \mathrm{g}$ of MWCNT yet no significant change following a $40 \mu \mathrm{g}$ exposure as compared to dispersion media (Figure $1 \mathrm{H}$ ). This data illustrates that the strain profiles were differentially impacted by dose throughout our study suggesting that MWCNT exposure dose impacts cardiac function. Further, 
this dose response may not follow a typical dose response relationship with the dose eliciting differential responses.

\section{Spatially-Distinct Mitochondrial Respiratory Function}

Due to the heavy energy input needed throughout the cardiac contractile cycle we investigated the mitochondrial respiratory function following exposure to MWCNT. Mitochondrial analyses within the cardiomyocyte are further complicated by the presence of two biochemically and spatially distinct mitochondrial subpopulations: the subsarcolemmal mitochondria (SSM) found beneath the sarcolemma and the interfibrillar mitochondria (IFM) that reside within the contractile apparatus. In the SSM, we observed a decrease in the maximal respiratory rate (State 3) of both the $10 \mu \mathrm{g}$ and $40 \mu \mathrm{g}$ MWCNT exposed animals at four hours (Figure 2A). Yet at 24 hours we did not observe a change in mitochondrial state 3 respiratory rate in either group compared to control (Figure 2B). In the basal mitochondrial respiratory rate (state 4) we detected no functional change at 4 hours in the SSM (Figure 2E), but at 24 hours we observed a significant increase in the state 4 respiratory rate of the $40 \mu \mathrm{g}$ MWCNT exposure only (Figure 2F). Similarly in the IFM we observed a significant decrease in the state 3 respiratory rate at four hours in both the $10 \mu \mathrm{g}$ and $40 \mu \mathrm{g}$ MWCNT exposure (Figure 2C). This respiratory dysfunction was attenuated within 24 hours of exposure as there is no change in state 3 respiration at 24 hours in the $40 \mu \mathrm{g}$ dose, but the decreased respiration persisted in the $10 \mu \mathrm{g}$ exposure (Figure 2D). Yet within the IFM, state 4 respiratory rates are not significantly changed at either four hours (Figure $2 \mathrm{G}$ ) or 24 hours (Figure $2 \mathrm{H}$ ) post-exposure. This data suggests that cardiac mitochondrial function is impacted four hours following MWCNT exposure but the dysfunction is adaptively eliminated by 24 hours following exposure. 


\section{Mitochondrial Electron Transport Chain Activities}

Within in the inner membrane of the mitochondrion sits the electron transport chain which is responsible for building a gradient that will drive ATP synthesis. By fueling each complex with its specific substrates we can isolate and identify the activity of the individual complex to distinguish dysfunctional enzymes within the greater enzyme chain. Following exposure to MWCNT, the activities of complexes I, III and IV were not impacted by MWCNT exposure (Table 2). Yet, Complex V (ATP Synthase) activity was significantly decreased four hours following exposure to high dose MWCNT pulmonary exposure (Table 2). At 24 hours following exposure all ETC complexes were returned to control levels (Table 3 ). This supports that mitochondrial respiratory dysfunction is observed following MWCNT exposure.

\section{Mitochondrial Hydrogen Peroxide Production}

Reactive oxygen species production is difficult due to their short half-life, yet by utilizing a fluorescent dye that is irreversibly activated by reactive oxygen species we can measure ROS production by the mitochondria. Four hours after MWCNT exposure we see no change in mitochondrial ROS production in either the SSM (Figure 4A) or the IFM (Figure 4B). Mitochondrial ROS production within the SSM 24 hours after exposure was not altered with either dose of MWCNT (Figure 4C). Yet, within the IFM we see a significant increase in ROS production at 24 hours but only following a high dose exposure to MWCNT (Figure 4D). This data suggests that increased mitochondrial ROS production arises 24 hours after MWCNT but is dose dependent.

\section{Mitochondrial Lipid Peroxidation}

Due to the mitochondrion's propensity for ROS production, we investigated the ROS damage by-products malondialdehyde (MDA) and 4-hydroxyalkenal (4-HAE) to address if increased ROS production leads to increased damage within the mitochondrion. Doing so, we 
identified no change in lipid peroxidation of either the SSM or IFM four hours following either dose of pulmonary MWCNT exposure (Figure 4A and B). Twenty-four hours following exposure there was a significant increase in the lipid damage by high dose MWCNT exposure in the IFM (Figure 4D), but no change in the SSM (Figure 4C). Taken together, this data suggests that ROS production within the IFM may contribute to increased lipid damage following high dose MWCNT exposure.

\section{Myoglobin Content}

Myoglobin, an oxygen-binding hemeprotein, supports ATP generation to preserve the function of energy-demanding tissues, such as the heart. Following exposure to MWCNT, after four hours no changes in cytosolic myoglobin content were detected in either group (Figure 5A). Yet, 24 hours following exposure a significant increase in cytosolic myoglobin content was observed in the high dose MWCNT exposed animals with no change detected in the low dose group (Figure 5B). This data suggests that an increase in myoglobin may attenuate mitochondrial dysfunction, yet lead to increased mitochondrial ROS production and damage. 


\section{DISCUSSION}

With literature to support negative pulmonary impacts of MWCNT exposure fulfilling the realization of extrapulmonary effects lags behind the commercial incorporation especially in terms of cardiac impacts. The current study highlights the impact of MWCNT pulmonary exposure on cardiac and mitochondrial function. Utilizing a readily available and utilized MWCNT we help to build a foundational study highlighting subclinical cardiac disturbances accompanied by mitochondrial respiratory dysfunction and ROS production. Our data reveals irregular cardiac and mitochondrial dose response following MWCNT emphasizing that dose not only dictates toxicological threshold but also response.

Cardiovascular function has been suggested to be disrupted by MWCNT but to date no study has investigated cardiac functional disruption following a pulmonary exposure. In this study we utilize both conventional and speckle tracking-based echocardiography to thoroughly investigate changes in systolic function post-exposure. In both human and rodent models speckle tracking-based echocardiography has shown earlier and more sensitive prediction of cardiac dysfunction $(5,10,37)$. In this study we show that 24 hour post exposure a high dose of MWCNT stimulates changes in systolic strain while a low dose induces change in strain rate. Normal left ventricular function involves patterns of myocardial deformation which can be measured through speckle tracking-based echocardiography as a sensitive marker of cardiac phenotyping (35). In this study we focused on the peak radial thickening and circumferential shortening of the myocardial fibers during systole and the rate of that fiber deformation index. The decreased peak strain values observed at 24 hours post high dose exposure suggest both decreased thickening and shortening of the fiber therefore decreased systolic function. Yet with the low dose of MWCNT exposure we observed a significant increase in the strain rate in both the radial and circumferential axes suggesting that the peak deformation isn't disrupted but the rate at which the deformation develops is increased following exposure. This suggests a 
metabolic disruption following low dose exposure to MWCNT. While overt systolic dysfunction was not observed at either dose of MWCNT exposure through M Mode imaging this data suggests that continued exposure and persistent strain dysfunction could precede systolic dysfunction.

The mitochondrion plays a large role in maintaining the homeostatic environment within the cardiomyocyte through ATP generation necessary for cellular function and the production of ROS as signal molecules or agents of injury. After identifying disturbed cardiac function we wanted to investigate the function of mitochondrial subpopulations following exposure to MWCNT. Interestingly, we observed a decrease in the maximal respiratory rate of both the SSM and IFM of low and high dose exposed animals at 4 hours post-exposure, yet no change in this same respiratory rate at 24 hours. This data suggests that a strong initial provocation stimulates mitochondrial dysfunction with either that stimulus dissipating or a compensatory mechanism correcting the observed dysfunction by 24 hours post exposure. The theory of a compensatory mechanism activation may be supported by the increased basal respiratory rate of the SSM from high dose exposed animals 24 hours after exposure.

When pulmonary function isn't limited, intracellular diffusion of oxygen to the mitochondria is limiting to the production of ATP. Evidence suggested that MWCNT exposure is capable of decreasing pulmonary function therefore oxygen deliver to tissue may be limiting and the need for intracellular transportation of oxygen is increased following exposure (43). The function of myoglobin was suggested in 1939 as a molecule for oxygen storage, oxygen transportation and an intracellular catalyst (26). Myoglobin is capable of storing and transporting oxygen to the interior of the cell where respiring mitochondria are located (39). Work in muscle fibers showed that the maintenance of oxygen consumption was dependent on the presence of myoglobin (9). Pharmacological inhibition of myoglobin showed that myoglobin-oxygen binding 
regulated oxidative phosphorylation $(16,45)$. The active site of myoglobin contains an iron atom which allows the protein to transport oxygen, yet also opens the molecule to ROS damage and production. When the iron within myoglobin is oxidized, the active site can then interact with protein radicals capable of generating more ROS as well as initiating lipid peroxidation (1). Taken together, the increased myoglobin content observed 24 hours following high dose exposure to MWCNT may be a compensatory mechanism that unfortunately rebounds leading to an increase in ROS production and damage by the mitochondria.

While the increase in myoglobin and the potential ROS production by the protein doesn't directly necessitate increased mitochondrial ROS production, it is well understood that increased ROS production and damage can lead to further ROS production and damage. Thus, mitochondrial ROS production and damage may stimulate myoglobin ROS production and damage, or the reciprocal may occur, propagating ROS production and damage. When kidney mitochondria were incubated with isolated myoglobin an increase in lipid peroxidation endproducts were detected suggesting increased myoglobin may direct increased ROS production (32).

Previously our lab has identified cardiac mitochondrial dysfunction following pulmonary particulate exposure. In these studies we identified differential mitochondrial impacts between exposure to particulates of various sizes and chemical composition. Within these studies, we identified decreased mitochondrial respiratory rates of both cardiac mitochondrial subpopulations following an exposure to a regional specific particulate matter. These subpopulations are unique because not only are they spatially distinct but also biochemically. The subsarcolemmal mitochondria (SSM) sit below the sarcolemma, are larger more variable in size, and may be more resistant to ROS mediated dysfunction. In contrast, the interfibrillar mitochondria (IFM) sit within the contractile apparatus, are smaller and more compact and have 
a higher respiratory rate compared to the SSM. The particulate matter previously investigated was a composite particle collected within the Appalachian region and particle size and chemical composition was not uniform. This study highlighted mitochondrial dysfunction at 24 hours postexposure, but in the current study we identify mitochondrial dysfunction much earlier with the dysfunction being resolved within 24 hours of exposure. Taking into account the data discussed within this manuscript suggests that MWCNT can induce mitochondrial dysfunction earlier. Thus, MWCNT may have greater potential for toxicity than particulate matter. Further, while they are less than $100 \mathrm{~nm}$ in one dimension they can be micrometers in length suggesting that while they are nanomaterials they may also elicit responses similar to larger materials. Further investigation into the intermediates differentially impacted through a pulmonary exposure that elicit extrapulmonary effects can help to elucidate some of the mechanisms contributing to the cardiac and mitochondrial outcomes.

While extrapulmonary toxicological effects are well-documented, the mechanisms of toxicity are still under considerable debate and systemic spillover of intermediates from the lung is highlighted following exposure. Studies in both murine and human models have identified proinflammatory markers in the circulation of exposed subjects, providing evidence that a pulmonary impact stimulates a pulmonary response large enough to spillover to the systemic circulation (22) which may contribute to downstream cardiovascular effects $(29,30)$. Further, by treating naïve vasculature to serum collected from MWCNT exposed animals Aragon et al. identified the impact of circulating factors in mediating extrapulmonary impacts following exposure (2). Interestingly, this study also identified that the effects of MWCNT-induced serum were not linearly associated with lung burden suggesting the induction of different biological responses at different doses. While our study does not experimentally address the mediation of pulmonary impacts to extrapulmonary effects, it is important to realize these mechanisms to fully appreciate MWCNT induced toxicity. 
With respect to the exposure, while this dose has been previously utilized in numerous studies to define potential impacts of MWCNT, at a typical occupational exposure of approximately $10 \mathrm{ug} / \mathrm{m}^{3}$, seen in U.S facilities, it would require a 5 day/week exposure for 19 years in humans to reach the lung burden in the lowest dose (17). These doses were chosen to identify potential impacts as no study has identified cardiac and mitochondrial impacts in vivo following exposure to MWCNT. Moving forward, the confirmation of the observed effects in a sub-chronic inhalation model would be of value. Yet investigation into the effects of acute exposure on cardiac tissue is not without merit due to the tissue's essential function. Acute inhalation exposure has been shown to expeditiously induce cardiac dysfunction and disrupt subcellular process such as mitochondrial function. While most of these effects have been identified in particulate matter exposures, the vast majority of literature suggests that nanomaterials are more toxic than their larger counterparts, with nanomaterial size, shape and chemical composition also confounding the extrapolation of extrapulmonary impacts. Thus, the observed effects add to our limited, current understanding of cardiac mechanisms disrupted by acute nanomaterial exposure.

The exposure concentration used within this study is relevant to an occupational study but due to the rise of nanomaterial incorporation into consumer products and the limited pulmonary removal this dose may become relevant to a larger population. The data presented in this paper shows for the first time that cardiac function is impacted by acute exposure to MWCNT concomitant with increased mitochondrial ROS production and damage but preceded by decreased mitochondrial function. Within the disrupted cellular mechanisms, our study suggests that there is a spatial component to the dysfunction as shown by differential effects in mitochondrial subpopulations and we suggest that this could allude to a spatial component to the toxicological trigger. 


\section{REFERENCES}

1. Alayash Al, Patel RP, and Cashon RE. Redox reactions of hemoglobin and myoglobin: biological and toxicological implications. Antioxid Redox Signal 3: 313-327, 2001.

2. Aragon M, Erdely A, Bishop L, Salmen R, Weaver J, Liu J, Hall P, Eye T, Kodali V, Zeidler-Erdely P, Stafflinger JE, Ottens AK, and Campen MJ. MMP-9-Dependent Serum-Borne Bioactivity Caused by Multi-walled Carbon Nanotube Exposure Induces Vascular Dysfunction Via the CD36 Scavenger Receptor. Toxicol Sci, 2016.

3. Baseler WA, Dabkowski ER, Jagannathan R, Thapa D, Nichols CE, Shepherd DL, Croston TL, Powell M, Razunguzwa TT, Lewis SE, Schnell DM, and Hollander JM. Reversal of mitochondrial proteomic loss in Type 1 diabetic heart with overexpression of phospholipid hydroperoxide glutathione peroxidase. Am J Physiol Regul Integr Comp Physiol 304: R553-565, 2013.

4. Baseler WA, Dabkowski ER, Williamson CL, Croston TL, Thapa D, Powell MJ, Razunguzwa TT, and Hollander JM. Proteomic alterations of distinct mitochondrial subpopulations in the type 1 diabetic heart: contribution of protein import dysfunction. Am J Physiol Regul Integr Comp Physiol 300: R186200, 2011.

5. Bauer M, Cheng S, Jain M, Ngoy S, Theodoropoulos C, Trujillo A, Lin FC, and Liao R. Echocardiographic speckle-tracking based strain imaging for rapid cardiovascular phenotyping in mice. Circ Res 108: 908-916, 2011.

6. Bradford MM. A rapid and sensitive method for the quantitation of microgram quantities of protein utilizing the principle of protein-dye binding. Anal Biochem 72: 248-254, 1976.

7. Chance B and Williams GR. Respiratory enzymes in oxidative phosphorylation. I. Kinetics of oxygen utilization. J Biol Chem 217: 383-393, 1955.

8. Chance B and Williams GR. Respiratory enzymes in oxidative phosphorylation. VI. The effects of adenosine diphosphate on azide-treated mitochondria. J Biol Chem 221: 477-489, 1956. 
9. Cole RP. Skeletal muscle function in hypoxia: effect of alteration of intracellular myoglobin. Respir Physiol 53: 1-14, 1983.

10. Cottrell C and Kirkpatrick JN. Echocardiographic strain imaging and its use in the clinical setting. Expert Rev Cardiovasc Ther 8: 93-102, 2010.

11. Croston TL, Shepherd DL, Thapa D, Nichols CE, Lewis SE, Dabkowski ER, Jagannathan R, Baseler WA, and Hollander JM. Evaluation of the cardiolipin biosynthetic pathway and its interactions in the diabetic heart. Life sciences 93: 313-322, 2013.

12. Croston TL, Thapa D, Holden AA, Tveter KJ, Lewis SE, Shepherd DL, Nichols CE, Long DM, Olfert IM, Jagannathan R, and Hollander JM. Functional deficiencies of subsarcolemmal mitochondria in the type 2 diabetic human heart. Am J Physiol Heart Circ Physiol 307: H54-65, 2014.

13. Dabkowski ER, Baseler WA, Williamson CL, Powell M, Razunguzwa TT, Frisbee JC, and Hollander JM. Mitochondrial dysfunction in the type 2 diabetic heart is associated with alterations in spatially distinct mitochondrial proteomes. Am J Physiol Heart Circ Physiol 299: H529-540, 2010.

14. Dabkowski ER, Williamson CL, Bukowski VC, Chapman RS, Leonard SS, Peer CJ, Callery PS, and Hollander JM. Diabetic cardiomyopathy-associated dysfunction in spatially distinct mitochondrial subpopulations. Am J Physiol Heart Circ Physiol 296: H359-369, 2009.

15. Dabkowski ER, Williamson CL, and Hollander JM. Mitochondria-specific transgenic overexpression of phospholipid hydroperoxide glutathione peroxidase (GPx4) attenuates ischemia/reperfusion-associated cardiac dysfunction. Free Radic Biol Med 45: 855-865, 2008.

16. Doeller JE and Wittenberg BA. Myoglobin function and energy metabolism of isolated cardiac myocytes: effect of sodium nitrite. Am J Physiol 261: H53-62, 1991.

17. Erdely A, Dahm M, Chen BT, Zeidler-Erdely PC, Fernback JE, Birch ME, Evans DE, Kashon ML, Deddens JA, Hulderman T, Bilgesu SA, Battelli L, Schwegler-Berry D, Leonard HD, McKinney W, Frazer 
DG, Antonini JM, Porter DW, Castranova V, and Schubauer-Berigan MK. Carbon nanotube dosimetry: from workplace exposure assessment to inhalation toxicology. Part Fibre Toxicol 10: 53, 2013.

18. Erdely A, Hulderman T, Salmen R, Liston A, Zeidler-Erdely PC, Schwegler-Berry D, Castranova V, Koyama S, Kim YA, Endo M, and Simeonova PP. Cross-talk between lung and systemic circulation during carbon nanotube respiratory exposure. Potential biomarkers. Nano Lett 9: 36-43, 2009.

19. Erdely A, Liston A, Salmen-Muniz R, Hulderman T, Young SH, Zeidler-Erdely PC, Castranova V, and Simeonova PP. Identification of systemic markers from a pulmonary carbon nanotube exposure. J Occup Environ Med 53: S80-86, 2011.

20. Erdely A, Salmen-Muniz R, Liston A, Hulderman T, Zeidler-Erdely PC, Antonini JM, and Simeonova PP. Relationship between pulmonary and systemic markers of exposure to multiple types of welding particulate matter. Toxicology 287: 153-159, 2011.

21. He X, Young SH, Schwegler-Berry D, Chisholm WP, Fernback JE, and Ma Q. Multiwalled carbon nanotubes induce a fibrogenic response by stimulating reactive oxygen species production, activating NF-kappaB signaling, and promoting fibroblast-to-myofibroblast transformation. Chem Res Toxicol 24: 2237-2248, 2011.

22. Inoue K, Takano H, Koike E, Yanagisawa R, Sakurai M, Tasaka S, Ishizaka A, and Shimada A. Effects of pulmonary exposure to carbon nanotubes on lung and systemic inflammation with coagulatory disturbance induced by lipopolysaccharide in mice. Exp Biol Med (Maywood) 233: 15831590, 2008.

23. Laemmli UK. Cleavage of structural proteins during the assembly of the head of bacteriophage T4. Nature 227: 680-685, 1970.

24. Leitman M, Lysyansky P, Sidenko S, Shir V, Peleg E, Binenbaum M, Kaluski E, Krakover R, and Vered Z. Two-dimensional strain-a novel software for real-time quantitative echocardiographic assessment of myocardial function. J Am Soc Echocardiogr 17: 1021-1029, 2004. 
25. Li Z, Hulderman T, Salmen R, Chapman R, Leonard SS, Young SH, Shvedova A, Luster MI, and Simeonova PP. Cardiovascular effects of pulmonary exposure to single-wall carbon nanotubes. Environ Health Perspect 115: 377-382, 2007.

26. Millikan GA. Muscle hemoglobin. Physiol Rev 19: 503-523, 1939.

27. Mitchell LA, Gao J, Wal RV, Gigliotti A, Burchiel SW, and McDonald JD. Pulmonary and systemic immune response to inhaled multiwalled carbon nanotubes. Toxicol Sci 100: 203-214, 2007.

28. Mitchell LA, Lauer FT, Burchiel SW, and McDonald JD. Mechanisms for how inhaled multiwalled carbon nanotubes suppress systemic immune function in mice. Nat Nanotechnol 4: 451-456, 2009.

29. Nelin TD, Joseph AM, Gorr MW, and Wold LE. Direct and indirect effects of particulate matter on the cardiovascular system. Toxicol Lett 208: 293-299, 2012.

30. Nurkiewicz TR, Porter DW, Hubbs AF, Stone S, Moseley AM, Cumpston JL, Goodwill AG, Frisbee SJ, Perrotta PL, Brock RW, Frisbee JC, Boegehold MA, Frazer DG, Chen BT, Castranova V, and Committee HEIHR. Pulmonary particulate matter and systemic microvascular dysfunction. Res Rep Health Eff Inst: 3-48, 2011.

31. Palmer JW, Tandler B, and Hoppel CL. Biochemical properties of subsarcolemmal and interfibrillar mitochondria isolated from rat cardiac muscle. J Biol Chem 252: 8731-8739, 1977.

32. Plotnikov EY, Chupyrkina AA, Pevzner IB, Isaev NK, and Zorov DB. Myoglobin causes oxidative stress, increase of NO production and dysfunction of kidney's mitochondria. Biochim Biophys Acta 1792: 796-803, 2009.

33. Rao GV, Tinkle S, Weissman DN, Antonini JM, Kashon ML, Salmen R, Battelli LA, Willard PA, Hoover MD, and Hubbs AF. Efficacy of a technique for exposing the mouse lung to particles aspirated from the pharynx. J Toxicol Environ Health A 66: 1441-1452, 2003.

34. Reddy AR, Krishna DR, Reddy YN, and Himabindu V. Translocation and extra pulmonary toxicities of multi wall carbon nanotubes in rats. Toxicol Mech Methods 20: 267-272, 2010. 
35. Sengupta PP, Krishnamoorthy VK, Korinek J, Narula J, Vannan MA, Lester SJ, Tajik JA, Seward JB, Khandheria BK, and Belohlavek M. Left ventricular form and function revisited: applied translational science to cardiovascular ultrasound imaging. J Am Soc Echocardiogr 20: 539-551, 2007.

36. Shepherd DL, Nichols CE, Croston TL, McLaughlin SL, Petrone AB, Lewis SE, Thapa D, Long DM, Dick GM, and Hollander JM. Early detection of cardiac dysfunction in the type 1 diabetic heart using speckle-tracking based strain imaging. J Mol Cell Cardiol 90: 74-83, 2015.

37. Shepherd DL, Nichols CE, Croston TL, McLaughlin SL, Petrone AB, Lewis SE, Thapa D, Long DM, Dick GM, and Hollander JM. Early detection of cardiac dysfunction in the type 1 diabetic heart using speckle-tracking based strain imaging. J Mol Cell Cardiol 90: 74-83, 2016.

38. Stapleton PA, Minarchick VC, Cumpston AM, McKinney W, Chen BT, Sager TM, Frazer DG, Mercer RR, Scabilloni J, Andrew ME, Castranova V, and Nurkiewicz TR. Impairment of coronary arteriolar endothelium-dependent dilation after multi-walled carbon nanotube inhalation: a time-course study. Int J Mol Sci 13: 13781-13803, 2012.

39. Takahashi E, Endoh H, and Doi K. Visualization of myoglobin-facilitated mitochondrial $\mathrm{O}(2)$ delivery in a single isolated cardiomyocyte. Biophys J 78: 3252-3259, 2000.

40. Thapa D, Nichols CE, Lewis SE, Shepherd DL, Jagannathan R, Croston TL, Tveter KJ, Holden AA, Baseler WA, and Hollander JM. Transgenic overexpression of mitofilin attenuates diabetes mellitusassociated cardiac and mitochondria dysfunction. Journal of molecular and cellular cardiology 79: 212223, 2015.

41. Thapa D, Nichols CE, Lewis SE, Shepherd DL, Jagannathan R, Croston TL, Tveter KJ, Holden AA, Baseler WA, and Hollander JM. Transgenic overexpression of mitofilin attenuates diabetes mellitusassociated cardiac and mitochondria dysfunction. J Mol Cell Cardiol 79: 212-223, 2015. 
42. Urankar RN, Lust RM, Mann E, Katwa P, Wang X, Podila R, Hilderbrand SC, Harrison BS, Chen P, Ke PC, Rao AM, Brown JM, and Wingard CJ. Expansion of cardiac ischemia/reperfusion injury after instillation of three forms of multi-walled carbon nanotubes. Part Fibre Toxicol 9: 38, 2012.

43. Wang X, Katwa P, Podila R, Chen P, Ke PC, Rao AM, Walters DM, Wingard CJ, and Brown JM. Multi-walled carbon nanotube instillation impairs pulmonary function in C57BL/6 mice. Part Fibre Toxicol 8: 24, 2011.

44. Williamson CL, Dabkowski ER, Baseler WA, Croston TL, Alway SE, and Hollander JM. Enhanced apoptotic propensity in diabetic cardiac mitochondria: influence of subcellular spatial location. Am J Physiol Heart Circ Physiol 298: H633-642, 2010.

45. Wittenberg BA and Wittenberg JB. Myoglobin-mediated oxygen delivery to mitochondria of isolated cardiac myocytes. Proc Natl Acad Sci U S A 84: 7503-7507, 1987.

46. Zeidler-Erdely PC, Meighan TG, Erdely A, Battelli LA, Kashon ML, Keane M, and Antonini JM. Lung tumor promotion by chromium-containing welding particulate matter in a mouse model. Part Fibre Toxicol 10: 45, 2013. 
Table 3.1

\begin{tabular}{|c|c|c|c|c|c|c|}
\hline & \multicolumn{3}{|c|}{4 Hour } & \multicolumn{3}{|c|}{24 Hour } \\
\hline & $\mathrm{DM}$ & $10 \mu \mathrm{g}$ & $40 \mu \mathrm{g}$ & $\mathrm{DM}$ & $10 \mu \mathrm{g}$ & $40 \mu \mathrm{g}$ \\
\hline & Average \pm SE & Average $\pm S E$ & Average $\pm S E$ & Average $\pm S E$ & Average $\pm S E$ & Average $\pm S E$ \\
\hline Heart Rate (BPM) & $563.04 \pm 14.22$ & $533.91 \pm 14.79$ & $534.45 \pm 15.4$ & $647.4 \pm 8.54$ & $611.98 \pm 17.44$ & $570.54 \pm 22.09$ \\
\hline LVIDs (mm) & $1.15 \pm 0.1$ & $1.04 \pm 0.04$ & $1.09 \pm 0.05$ & $1.06 \pm 0.1$ & $0.99 \pm 0.09$ & $1.03 \pm 0.08$ \\
\hline LVIDd (mm) & $2.71 \pm 0.12$ & $2.43 \pm 0.07$ & $2.69 \pm 0.09$ & $2.52 \pm 0.12$ & $2.31 \pm 0.1$ & $2.49 \pm 0.09$ \\
\hline ESV $(\mu L)$ & $3.51 \pm 0.67$ & $2.22 \pm 0.25$ & $2.71 \pm 0.29$ & $2.07 \pm 0.45$ & $2.46 \pm 0.89$ & $2.5 \pm 0.48$ \\
\hline EDV $(\mu \mathrm{L})$ & $28.11 \pm 3.08$ & $21.12 \pm 1.49$ & $27.21 \pm 2.27$ & $23.76 \pm 2.86$ & $19.04 \pm 2.49$ & $22.84 \pm 2.19$ \\
\hline Stroke Volume $(\mu \mathrm{L})$ & $23.11 \pm 2.37$ & $19.19 \pm 1.28$ & $24.49 \pm 2.02$ & $20.86 \pm 2.29$ & $16.58 \pm 1.68$ & $20.34 \pm 1.75$ \\
\hline Ejection Fraction (\%) & $88.29 \pm 1.75$ & $91.18 \pm 1.09$ & $90.09 \pm 0.69$ & $88.86 \pm 1.79$ & $88.78 \pm 1.77$ & $89.89 \pm 1.17$ \\
\hline Fractional Shortening (\%) & $54.29 \pm 3$ & $61.46 \pm 1.92$ & $59.51 \pm 1.08$ & $58.52 \pm 2.56$ & $57.71 \pm 2.18$ & $59.33 \pm 1.79$ \\
\hline Cardiac Output (mL/min) & $11.27 \pm 0.49$ & $9.69 \pm 0.67$ & $11.79 \pm 0.64$ & $11.62 \pm 0.99$ & $10.16 \pm 1.08$ & $10.69 \pm 0.74$ \\
\hline
\end{tabular}


Table 3.1. M-Mode Echocardiographic Measurements. Values are means \pm SEM; $n=8$ for each group. 
Table 3.2

\begin{tabular}{|c|c|c|c|c|}
\hline 4 Hour & $\begin{array}{c}\text { Complex I } \\
\text { Average } \pm \text { SE }\end{array}$ & $\begin{array}{l}\text { Complex III } \\
\text { Average } \pm \text { SE }\end{array}$ & $\begin{array}{c}\text { Complex IV } \\
\text { Average } \pm \text { SE }\end{array}$ & $\begin{array}{c}\text { Complex V } \\
\text { Average } \pm \text { SE }\end{array}$ \\
\hline DM SSM & $224.3323 \pm 69.61$ & $186.6086 \pm 103.58$ & $296.0724 \pm 66.79$ & $1206.028 \pm 249.78$ \\
\hline $10 \mu \mathrm{g} \mathrm{SSM}$ & $142.1319 \pm 30.35$ & $41.16203 \pm 8.66$ & $147.2433 \pm 31.29$ & $821.7974 \pm 114.11$ \\
\hline $40 \mu \mathrm{g} \mathrm{SSM}$ & $145.4745 \pm 28.52$ & $34.52176 \pm 4.8$ & $84.38369 \pm 40.39$ & $801.3384 \pm 161.95^{\star}$ \\
\hline DM IFM & $265.2446 \pm 34.23$ & $48.40687 \pm 9.94$ & $138.3053 \pm 9.23$ & $1584.467 \pm 341.78$ \\
\hline $10 \mu \mathrm{g}$ IFM & $193.2203 \pm 19.73$ & $34.22708 \pm 2.84$ & $179.318 \pm 21.59$ & $1248.098 \pm 146.71$ \\
\hline $40 \mu \mathrm{g} \mathrm{IFM}$ & $210.422 \pm 24.86$ & $33.87782 \pm 2.99$ & $199.1806 \pm 21.15$ & $917.9645 \pm 131.59^{*}$ \\
\hline
\end{tabular}


Table 3.2. Mitochondrial Electron Transport Chain Assessment Four Hours Following MWCNT Exposure. Mitochondrial electron transport chain (ETC) complex activities were examined in SSM and IFM four hours following exposure to Dispersion Media, $10 \mu \mathrm{g}$ MWCNT or $40 \mu \mathrm{g}$ MWCNT. ETC complex I, III, IV and V activities were assessed spectrophotometrically by measuring the oxidation of $\mathrm{NADH}$ (complex I), reduction of cytochrome c (complex III), oxidation of cytochrome c (complex IV) and an assay coupled with pyruvate kinase (complex V). Enzymatic activities for complexes I, III and IV are expressed as activity per minute per citrate synthase activity per milligram of protein and complex $\mathrm{V}$ is expressed as nmol of $\mathrm{NADH}$ per minute per citrate synthase activity per milligram of protein. Values are expressed as means \pm SEM; $n=8$ per each group. SSM: subsarcolemmal mitochondria, IFM: interfibrillar mitochondria. 
Table 3.3

\begin{tabular}{lcccc}
\hline 24 Hour & $\begin{array}{c}\text { Complex I } \\
\text { Average } \pm \text { SE }\end{array}$ & $\begin{array}{c}\text { Complex III } \\
\text { Average } \pm \text { SE }\end{array}$ & $\begin{array}{c}\text { Complex IV } \\
\text { Average } \pm \text { SE }\end{array}$ & $\begin{array}{c}\text { Complex V } \\
\text { Average } \pm \text { SE }\end{array}$ \\
\hline DM SSM & $140.8833 \pm 16.9$ & $33.62504 \pm 1.97$ & $154.9319 \pm 38.13$ & $1015.66 \pm 88.91$ \\
$10 \mu \mathrm{g} \mathrm{SSM}$ & $179.2188 \pm 56.99$ & $173.7949 \pm 74.88$ & $184.1054 \pm 78$ & $1070.021 \pm 111.38$ \\
$40 \mu \mathrm{g} \mathrm{SSM}$ & $257.1428 \pm 65.31$ & $64.02517 \pm 17.47$ & $289.2751 \pm 52.88$ & $1067.541 \pm 214.39$ \\
DM IFM & $229.1245 \pm 47.57$ & $36.52219 \pm 2.92$ & $210.751 \pm 29.23$ & $1239.028 \pm 283.13$ \\
$10 \mu \mathrm{g} \mathrm{IFM}$ & $233.1429 \pm 24.98$ & $93.77521 \pm 30.58$ & $179.9017 \pm 28.12$ & $965.7913 \pm 92.09$ \\
$40 \mu \mathrm{g} \mathrm{IFM}$ & $156.4285 \pm 17.08$ & $60.94515 \pm 15.49$ & $182.9402 \pm 18.11$ & $1078.95 \pm 88.52$ \\
\hline
\end{tabular}


Table 3.3. Mitochondrial Electron Transport Chain Assessment 24 Hours Following MWCNT Exposure. Mitochondrial electron transport chain (ETC) complex activities were examined in SSM and IFM 24 hours following exposure to dispersion media (DM), $10 \mu \mathrm{g}$ MWCNT or $40 \mu \mathrm{g}$ MWCNT. ETC complex I, III, IV and V activities were assessed spectrophotometrically by measuring the oxidation of $\mathrm{NADH}$ (complex I), reduction of cytochrome c (complex III), oxidation of cytochrome c (complex IV) and an assay coupled with pyruvate kinase (complex V). Enzymatic activities for complexes I, III and IV are expressed as activity per minute per citrate synthase activity per milligram of protein and complex $\mathrm{V}$ is expressed as nmol of NADH per minute per citrate synthase activity per milligram of protein. Values are expressed as means \pm SEM; $n=8$ per each group. SSM: subsarcolemmal mitochondria, IFM: interfibrillar mitochondria. 
Figure 3.1
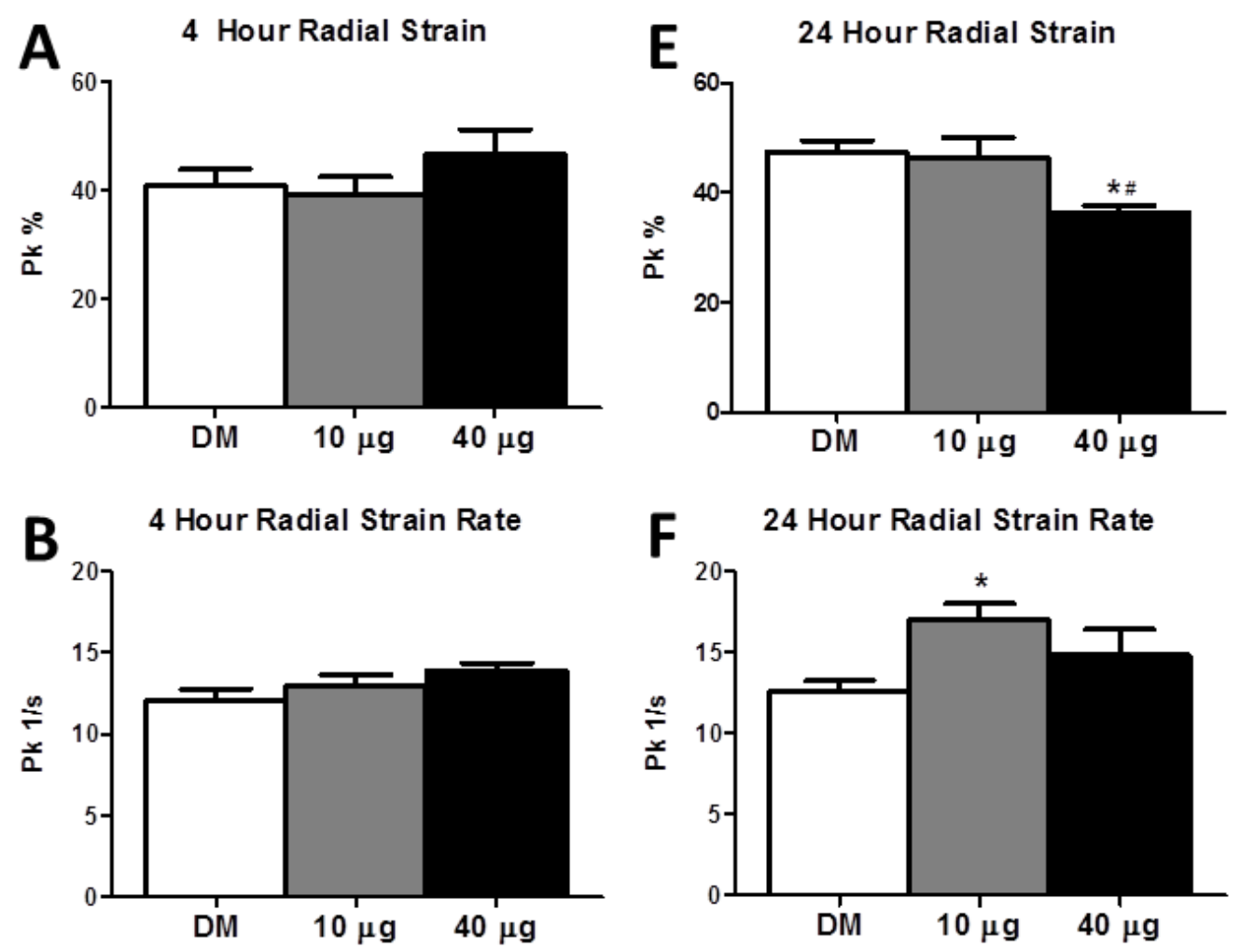

C 4 Hour Circumferential Strain

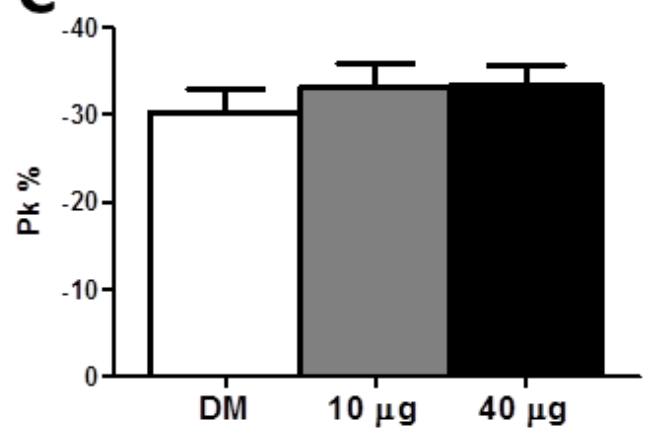

G 24 Hour Circumferential Strain

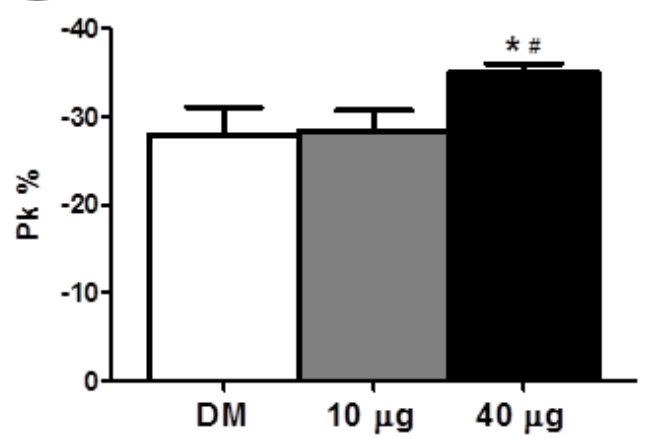

D 4 Hour Circumferential Strain Rate

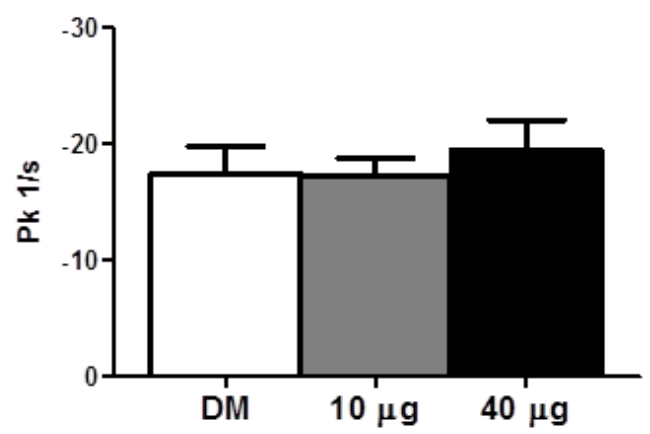

H 24 Hour Circumferential Strain Rate

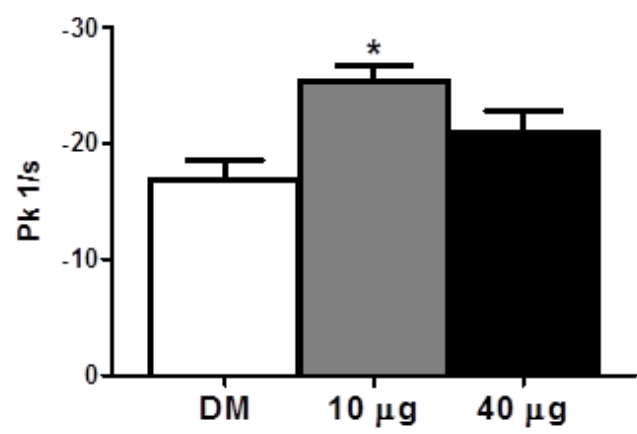


Figure 3.1. Speckle-Tracking Based Strain Analyses. Systolic circumferential and radial strain and strain rate were analyzed in DM, $10 \mu \mathrm{g}$ MWCNT and $40 \mu \mathrm{g}$ MWCNT exposed mice. Systolic radial strain (A) and strain rate (B) at four hours following exposure to MWCNT. Circumferential strain (C) and strain rate (D) at four hours following exposure to MWCNT. Systolic radial strain $(E)$ and strain rate $(F)$ at 24 hours following exposure to MWCNT. Circumferential strain $(G)$ and strain rate $(H)$ at 24 hours following exposure to MWCNT. Values are means \pm SEM; $n=8$ for each group. ${ }^{*} P<0.05$ for Control vs. MWCNT Exposed. ${ }^{\#}<0.05$ for $10 \mu \mathrm{g}$ MWCNT exposed vs. $40 \mu \mathrm{g}$ MWCNT exposed. 
Figure 3.2
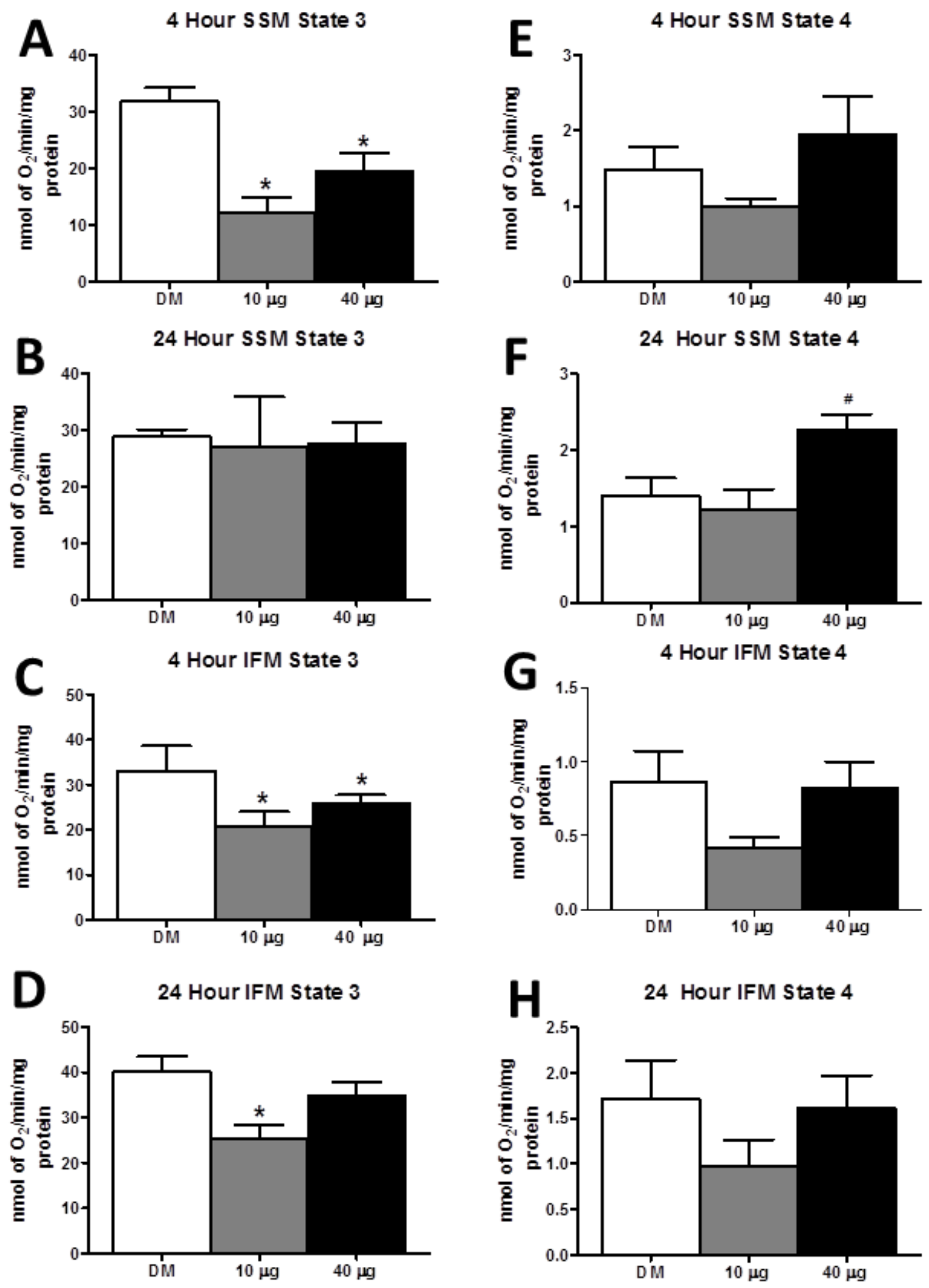
Figure 3.2. Mitochondrial Respiratory Capacity. Respiratory analyses of state 3 and state 4 respiratory rates in mitochondrial subpopulations following exposure to DM, $10 \mu \mathrm{g}$ MWCNT or $40 \mu \mathrm{g}$ MWCNT. Four hours following exposure, state $3(\mathrm{~A})$ and state $4(\mathrm{E})$ respiratory rates in SSM. State $3(\mathrm{~B})$ and State $4(\mathrm{~F})$ respiratory rates 24 hours following exposure in the SSM. Four hours following exposure, state $3(\mathrm{C})$ and state $4(\mathrm{G})$ respiratory rates in IFM. State $3(\mathrm{D})$ and State $4(\mathrm{H})$ respiratory rates 24 hours following exposure in the IFM. State 3 and state 4 respiration rates were determined in the presence of the substrates glutamate-malate, and state 3 respiration was examined upon addition of ADP. Respiration rates are expressed in $\mathrm{nmol} \cdot \mathrm{min}^{-1} \cdot \mathrm{mg}$ protein ${ }^{-1}$.Values are means \pm SEM; $n=8$ for each group. ${ }^{*} P<0.05$ for Control vs. Exposed. SSM: subsarcolemmal mitochondria, IFM: interfibrillar mitochondria. 
Figure 3.3

A C 4 Hour SSM Hydrogen Peroxide Production

24 Hour SSM Hydrogen Peroxide Production

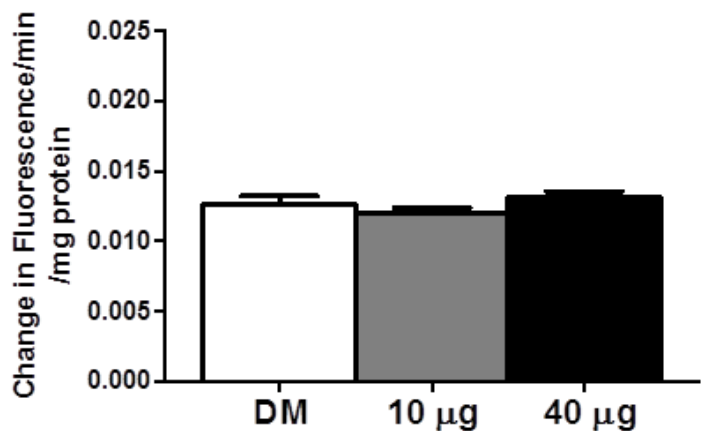

B

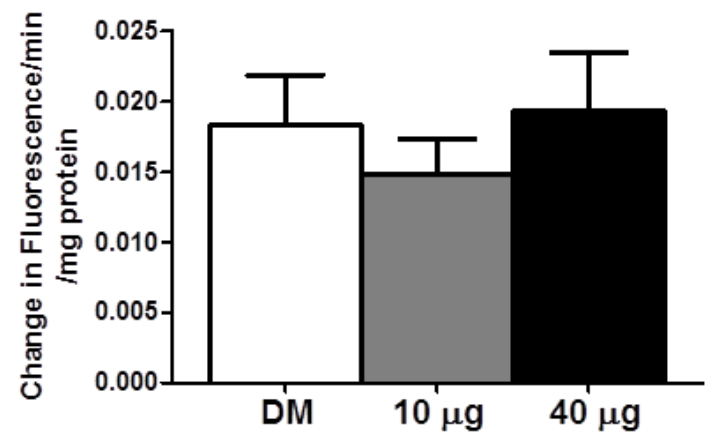

4 Hour IFM Hydrogen Peroxide Production

D

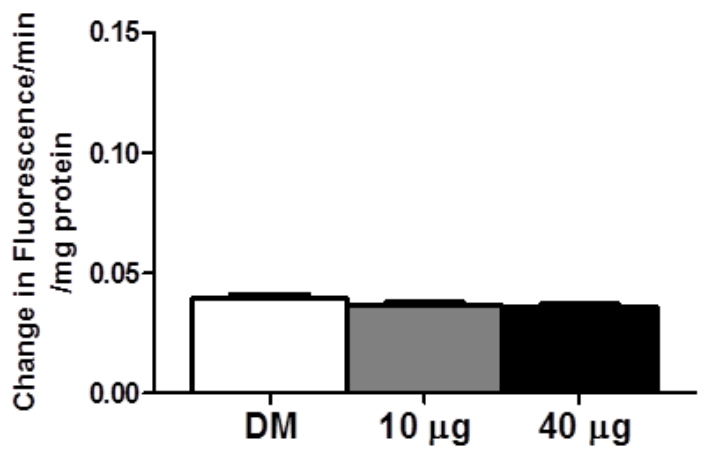

24 Hour IFM Hydrogen Peroxide Production

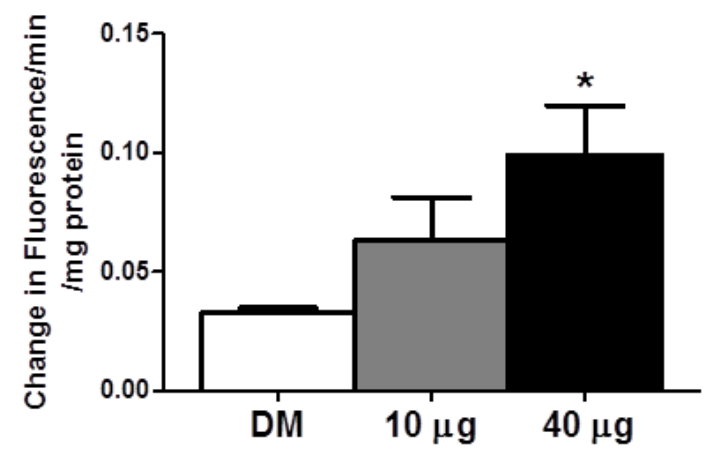


Figure 3.3. Mitochondrial Reactive Oxygen Species Production. Summary data of hydrogen peroxide production in the SSM over time four hours (A) and 24 hours (B) following exposure to either dispersion media (DM), $10 \mu \mathrm{g}$ MWCNT or $40 \mu \mathrm{g}$ MWCNT utilizing a fluorescent dye activated by hydrogen peroxide. Hydrogen peroxide production in the IFM four (C) and 24 (D) hours following exposure to MWCNT. Summary data of hydrogen peroxide production expressed as change in fluorescence $\mathrm{min}^{-1} \cdot \mathrm{mg}$ protein $^{-1}$. Values are expressed as means \pm SEM. $n=8$ per each group. ${ }^{*} \mathrm{P}<0.05$ for Control vs. Exposed. SSM: subsarcolemmal mitochondria, IFM: interfibrillar mitochondria. 
Figure 3.4

A 4 Hour SSM Lipid Peroxidation

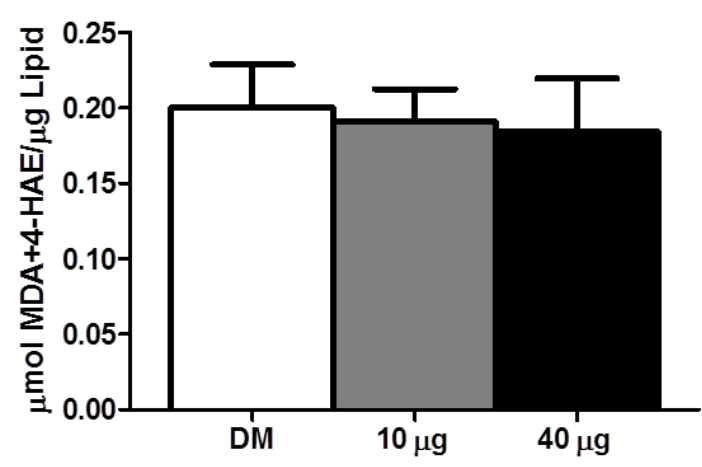

B 4 Hour IFM Lipid Peroxidation

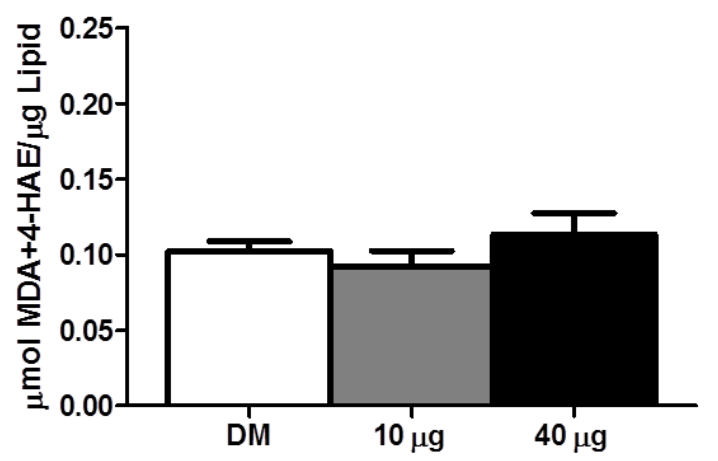

C 24 Hour SSM Lipid Peroxidation

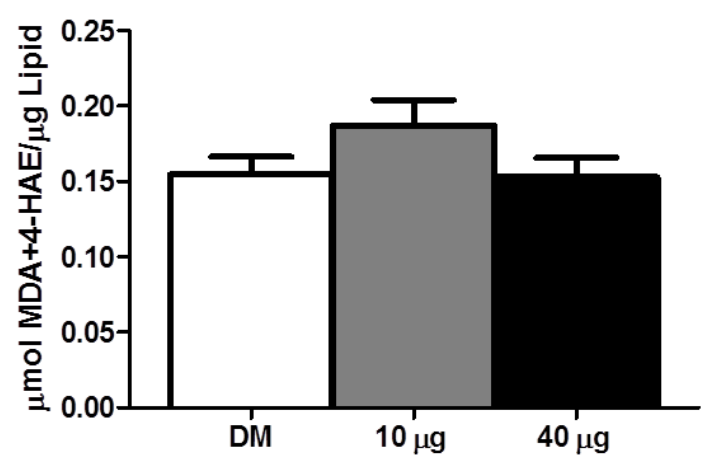

D 24 Hour IFM Lipid Peroxidation

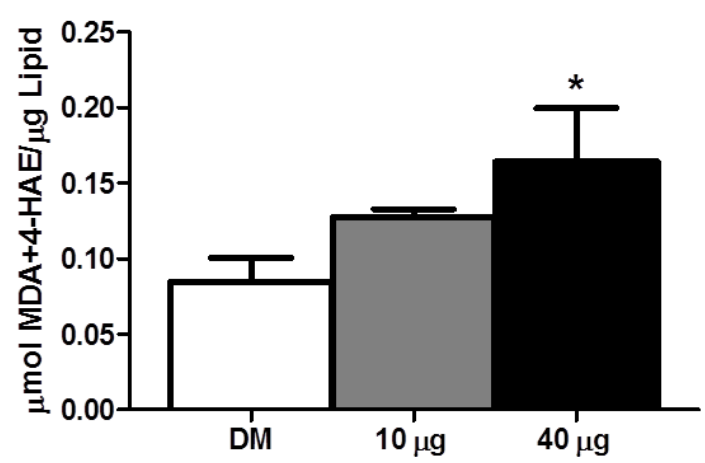


Figure 3.4. Lipid peroxidation by-products. Oxidative damage to lipids was assessed in SSM from animals exposed to dispersion media, $10 \mu \mathrm{g}$ MWCNT or $40 \mu \mathrm{g}$ MWCNT four (A) and 24 (B) hours following exposure. This colorimetric assay measured lipid peroxidation byproducts malondialdehyde (MDA) and 4-hydroxyalkenal (4-HAE) MWCNT exposure impacts at four (A) and 24 (D) hours in the IFM. Results were compared against a standard curve of known 4-HAE and MDA concentrations. Values are expressed as means \pm SE. $n=8$ per each group. ${ }^{*} \mathrm{P}<0.05$ for Control vs. Exposed. SSM: subsarcolemmal mitochondria, IFM: interfibrillar mitochondria. 
Figure 3.5

A 4 Hour Myoglobin Content

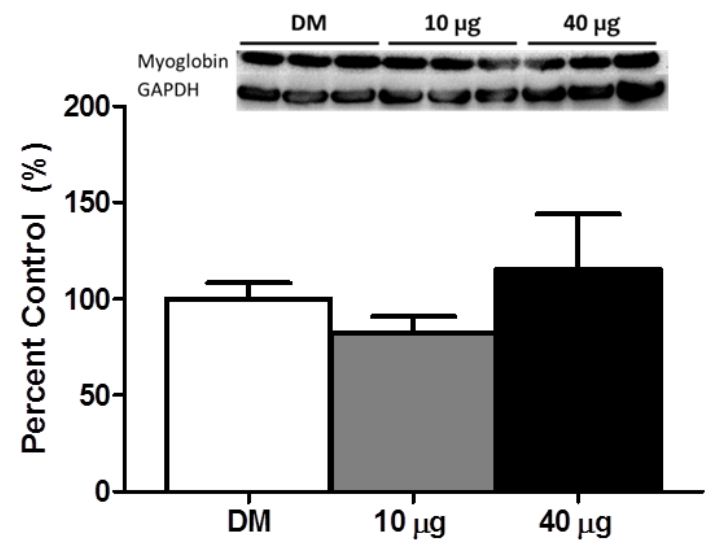

B 24 Hour Myoglobin Content

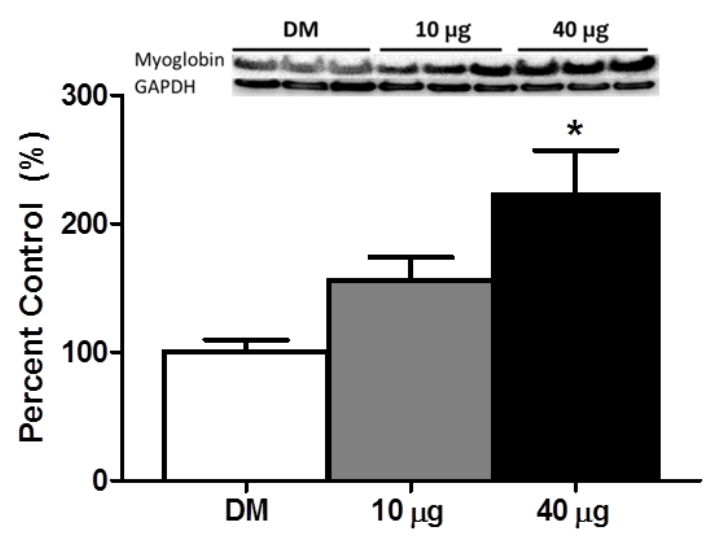


Figure 3.5. Cytosolic Myoglobin Content. Relative protein content of myoglobin from cytosol from mice exposed to dispersion media, $10 \mu \mathrm{g}$ MWCNT or $40 \mu \mathrm{g}$ MWCNT four (A) and 24 (B) hours following exposure. Representative Western blots (top) and densitometric analyses (bottom) for protein content. Cytosolic proteins (A and B) were expressed per GAPDH levels. Values are means $\pm \mathrm{SEM} ; n=6$ for each group. ${ }^{*} P<0.05$ for Control vs. Exposed. 


\section{Chapter 4:}

\section{Reactive Oxygen Species Damage Drives Cardiac and Mitochondrial Dysfunction Following Acute Nano-Titanium Dioxide Inhalation Exposure}

Cody E. Nichols ${ }^{1,2}$, Danielle L. Shepherd ${ }^{1,2}$, Dharendra Thapa ${ }^{1,2}$, Jinghai $\mathrm{Yi}^{2,3}$, Erinne R. Dabkowski, Timothy R. Nurkiewicz ${ }^{2,3}$ and John M. Hollander ${ }^{1,2}$

${ }^{1}$ West Virginia University School of Medicine, Division of Exercise Physiology; ${ }^{2}$ Center for Cardiovascular and Respiratory Sciences; ${ }^{3}$ West Virginia University, Department of Physiology and Pharmacology Morgantown, WV 26506,

Running Title: Cardiac and mitochondrial dysfunction following nano-titanium dioxide exposure

Corresponding Author:

John M. Hollander, Ph.D., F.A.H.A.

West Virginia University School of Medicine

Division of Exercise Physiology

Center for Cardiovascular and Respiratory Sciences

1 Medical Center Drive

Morgantown, WV 26506

Tel: (304) 293-3683

Fax: (304) 293-7105

Email: jhollander@hsc.wvu.edu 


\begin{abstract}
While nanotechnology offers innovation in products from cosmetics to drug delivery, leading to increased engineered nanomaterial (ENM) exposure; unfortunately, health impacts of ENM are not fully realized. Titanium dioxide $\left(\mathrm{TiO}_{2}\right)$ is one of the most widely produced ENM due to its variety of uses. Extrapulmonary effects following a pulmonary exposure have been identified with studies highlighting the cardiovascular effects, yet no study has identified cardiac effects. The goal of this study was to determine the impact of nano- $\mathrm{TiO}_{2}$ on cardiac function and attempt to maintain cardiac metabolism by exposure. To address this question, control FVB mice and mice overexpressing the mitochondrial antioxidant phospholipid hydroperoxide glutathione peroxidase (mPHGPx) were exposed to a commercially available nano- $\mathrm{TiO}_{2}$ and evaluated 24 hours following exposure. Utilizing state-of-the-art echocardiographic techniques, diastolic dysfunction was observed following exposure with an E/A ratio greater than 2 and increased radial strain during diastole $(P<0.05)$, indicative of restrictive filling of the left ventricle. To investigate the cellular mechanisms associated with the observed cardiac dysfunction, we investigated mitochondrial function following exposure to nano- $\mathrm{TiO}_{2}$. We observed a significant increase in ROS production $(\mathrm{P}<0.05)$ and decreased mitochondrial respiratory function $(P<0.05)$. By utilizing our novel transgenic mPHGPx mouse we were able to attenuate mitochondrial ROS production and dysfunction, along with cardiac diastolic dysfunction observed with nano- $\mathrm{TiO}_{2}$ exposure. In summary, nano- $\mathrm{TiO}_{2}$ inhalation exposure is associated with cardiac diastolic dysfunction and mitochondrial functional alterations, which are rectified by the overexpression of a mitochondrial antioxidant, suggesting ROS in the development of the dysfunction.
\end{abstract}

Keywords: Mitochondria; Cardiac Function; Titanium Dioxide; Nanomaterials; Reactive Oxygen Species; Antioxidant 


\section{INTRODUCTION}

Due to the wide range of end-uses and potential product and application incorporation, the nanotechnology industry is predicted to reach $\$ 64.2$ billion by 2019 (26). Yet with the exponential growth of the industry, thorough toxicological evaluation is not able to progress at the same pace as industrial growth; thus, neither intentional nor unintentional human health impacts following nanomaterial exposure are fully realized. Nanotechnology is the control of matter at the nanoscale, which encompasses sizes ranging from 1-100 nm. Manipulating matter at this scale can instill new properties and functions into the resulting material that allow for better, new, and/or unique uses for that material. Yet within the context of exposure, these materials may interact with membranes or proteins in a novel manner eliciting unexpected toxicological responses. One classic example of increased toxicity at the nanoscale is titanium dioxide $\left(\mathrm{TiO}_{2}\right)$.

$\mathrm{TiO}_{2}$ is one of the most broadly applied ENM, commonly used as a pigment and photocatalyst added to paint, food and sunscreen to enhance the appearance of the product. Exposure to $\mathrm{TiO}_{2}$ has been shown to induce negative cardiac effects centered on the dysregulation of the oxidative milieu $(36,37)$. Functionally, acute pulmonary nano- $\mathrm{TiO}_{2}$ exposure induced diastolic dysfunction in rats (23), yet the direct role of oxidative stress on the dysfunction is unknown. Long-term gastric exposure to nano- $\mathrm{TiO}_{2}$ has shown to increase reactive oxygen species (ROS) concomitant with a decreased antioxidant capacity within the heart (10). In vitro analyses have implicated mitochondrial ROS production as central to the pathways of toxicity following nano- $\mathrm{TiO}_{2}$ exposure (19). However, the role of the mitochondrion in the cardiovascular response to acute $\mathrm{TiO}_{2}$ exposure in vivo is not fully understood.

The mitochondrion has been implicated in the etiology of many cardiovascular diseases due to the crucial roles it plays within the cardiomyocyte. Among the central roles for cardiac 
mitochondria is the production of ATP requisite for contraction and relaxation as well as its contribution to cellular oxidative milieu. Within the cell, the mitochondrion is the leading producer of ROS, and ROS damage can obstruct the function of proteins, lipids and DNA. By proximity, the macromolecules within the mitochondria are most at-risk for ROS damage; appropriately, the mitochondria have their own antioxidant enzymes to protect their molecules.

Relative to its highly aerobic nature, the myocardium's antioxidant defense is modest, which can leave the organ at risk for ROS mediated functional impairment. To aid in the protection, ROS within the mitochondria are regulated by mitochondrial antioxidant enzymes including mitochondrial phospholipid hydroperoxide glutathione peroxidase (mPHGPx; GPx4) $(1,21)$. GPx4 primarily exists in two regionally specific forms: the long form with a mitochondrial targeting sequence that exists in the mitochondria (mPHGPx) and the short form which does not contain the mitochondrial targeting sequence found outside of the mitochondrion (20). This mitochondrial antioxidant is particularly interesting because it is a lipophilic enzyme capable of reducing peroxidized acyl groups in phospholipids (42), fatty acids hydroperoxides (35) and cholesterol peroxides (41) in biological membranes and is the primary antioxidant defense against oxidation of mitochondrial biomembranes.

Mitochondrial membrane integrity and function is crucial in the preservation of protein components and mitochondrial respiratory function. Mitochondrial membranes and electron transport chain enzymes can be damaged by highly reactive products derived from peroxidized lipids such as malondialdehyde (MDA) and 4-hydroxyalkenal (HAE) $(2,15)$. Our previous studies have shown that genetic overexpression of mPHGPx can protect mitochondrial and cardiac function in the face of diabetes and ischemia/reperfusion injury $(3,14,18)$. In vitro nanotoxicity studies have suggested that exposure decreases antioxidant content including 
GPx4 (30), but in vivo analyses and the effects of genetic overexpression of GPx4 following exposure have not been conducted.

Taken together, we sought to identify the impact of ENM inhalation on cardiac function and further investigate, then mitigate, exposure effects on cardiac metabolism. We hypothesized that nano- $\mathrm{TiO}_{2}$ exposure induces cardiac dysfunction arising from disturbed metabolic function. In order to test this hypothesis, we will utilize a novel transgenic animal overexpressing the mitochondrial form of GPx4 (mPHGPx) as a way to eliminate the influence of cytosolic peroxide scavenging and highlights the protective role of GPx4 on cardiac metabolic function following exposure. Our results indicate that mitochondria-specific overexpression of mPHGPx provides protection to both cardiac contractile and mitochondrial function following nano- $\mathrm{TiO}_{2}$ inhalation exposure. 


\section{MATERIALS AND METHODS}

\section{Experimental Animals}

The animal experiments in this study were approved by the West Virginia University Animal Care and Use Committee and conformed to the most current National Institutes of Health (NIH) Guidelines for the Care and Use of Laboratory Animals manual. Male FVB mice were housed in the West Virginia University Health Sciences Center animal facility and given access to a rodent diet and water ad libitum. To verify genetic overexpression, DNA from 3week-old mice was isolated from tail clips and screened using a real-time PCR (RT-PCR) approach as previously described (3). Briefly, we probed for GPx4 using a custom-designed fluorometric probe (Applied Biosystems, Foster City, CA) and RT-PCR on an Applied Biosystems 7900HT Fast Real-Time PCR system (Applied Biosystems).

\section{Engineered Nanomaterial Inhalation Exposure}

Nano- $\mathrm{TiO}_{2}$ P25 powder was obtained from Evonik (Aeroxide $\mathrm{TiO}_{2}$, Parsippany, NJ). Previously, this powder was identified to be a mixture composed of anatase $(80 \%)$ and rutile (20\%) $\mathrm{TiO}_{2}$, with a primary particle size of $21 \mathrm{~nm}$ and a surface area of $48.08 \mathrm{~m}^{2} / \mathrm{g}$. The nano$\mathrm{TiO}_{2}$ was prepared with care prior to aerosolization by drying, sieving and storing the powder.

The nanoparticle aerosol generator was developed, designed and tested specifically for rodent nanoparticle inhalation exposures (US patent application \# US13/317,472) as previously described (44). The test atmospheres were monitored in real time with the ELPI (Dekati, Tampere, Finland) and adjusted manually throughout the exposure duration to assure a consistent and known exposure for each animal group (Figure 1B). ELPI showed that the count median aerodynamic diameter of the particles was $131.6 \mathrm{~nm}$ (Figure 1A). 
Once a steady-state aerosol concentration was achieved, exposure duration was adjusted to achieve an estimated deposition of $11.58 \pm 0.27 \mu \mathrm{g}$. Total deposition was based on mouse methodology previously described and normalized to minute ventilation using the following equation: $D=F \times V \times C \times T$, where $F$ is the deposition fraction (10\%), $V$ is the minute ventilation based on body weight, $\mathrm{C}$ equals the mass concentration $\left(\mathrm{mg} / \mathrm{m}^{3}\right)$ and $\mathrm{T}$ equals the exposure duration (minutes).

\section{Echocardiography}

Echocardiographic assessments were carried out as previously described (38). Briefly, each mouse was anesthetized with inhalant isoflurane then maintained at $1 \%$ isoflurane or lower in order to sustain a physiologically relevant heart rate range for the duration of the experiment, effectively minimizing consequences of anesthesia. Brightness and motion mode imaging was accomplished using a $32-55 \mathrm{MHz}$ linear array transducer using the highest possible frame rate (233-401 frames/second) on the Vevo2100 Imaging System (Visual Sonics, Toronto, Canada). All images were acquired by one individual.

Conventional echocardiographic assessment was completed on grayscale M-mode parasternal short-axis images at the mid-papillary level of the LV. All M-mode image measurements were calculated over 3 consecutive cardiac cycles and then averaged. To assess diastolic function, LV filling was evaluated using mitral valve Doppler echocardiography and measured over 3 cardiac cycles.

Speckle-tracking based strain assessments were performed by tracing the walls of the endocardium and epicardium on B-mode video loops and analyzed throughout the 3 cardiac cycles using Visual Sonics VevoStrain software (Toronto, Canada) employing a speckle-tracking 
algorithm. The software then generates time-to-peak analysis for curvilinear data as output for strain and strain rate. The same trained investigator using the Vevo2100 Imaging analysis software (Visual Sonics, Toronto, Canada) completed all analyses.

\section{Tissue Preparation and Compartment Isolation}

After cardiac contractile measurements were performed mice were euthanized, hearts excised and cardiac mitochondria isolated via differential centrifugation. Subsarcolemmal mitochondria (SSM) and interfibrillar mitochondria (IFM) subpopulations were isolated as previously described following the methods of Palmer et al. (32) with minor modifications by our laboratory $(3,4,11,13,40)$. Mitochondrial pellets were resuspended in KME buffer (100 mM $\mathrm{KCl}, 50 \mathrm{mM}$ MOPS and $0.5 \mathrm{mM}$ EGTA $\mathrm{pH}$ 7.4) and utilized for all analyses. Protein concentrations were determined by the Bradford method using bovine serum albumin as a standard (6).

\section{Mitochondrial Respiration}

State 3 and state 4 respiration rates were analyzed in freshly isolated mitochondrial subpopulations as previously described $(7,8)$ with modifications by our laboratory $(12-14,40)$. Briefly, isolated mitochondrial subpopulations were resuspended in KME buffer and protein content was determined by the Bradford method. Mitochondria protein was added to respiration buffer ( $80 \mathrm{mM} \mathrm{KCl}, 50 \mathrm{mM}$ MOPS, $1 \mathrm{mmol} / \mathrm{I} \mathrm{EGTA}, 5 \mathrm{mmol} / / \mathrm{KH}_{2} \mathrm{PO}_{4}$, and $1 \mathrm{mg} / \mathrm{ml} \mathrm{BSA}$ ) and placed into a respiration chamber connected to an oxygen probe (OX1LP-1mL Dissolved Oxygen Package, Qubit System, Kingston, ON, Canada). Maximal complex I-mediated respiration was initiated by the addition of glutamate $(5 \mathrm{mM})$ and malate $(5 \mathrm{mM})$. Data for state 3 (250 mM ADP) and state 4 (ADP-limited) respiration were expressed as nmol of oxygen consumed $/ \mathrm{min} / \mathrm{mg}$ protein. 


\section{ATP Synthase Enzymatic Activity}

ATP synthase activities were measured in isolated mitochondria spectrophotometrically as previously described $(11,40)$. Protein content was determined by the Bradford method as described above, and activity values were expressed as nmol of NADH oxidized/min/mg protein.

\section{Mitochondrial Hydrogen Peroxide Production}

Cardiac mitochondrial hydrogen peroxide production was analyzed following nano- $\mathrm{TiO}_{2}$ inhalation exposure utilizing the fluorescent dye Amplex Red. The Amplex Red reagent reacts with hydrogen peroxide in a 1:1 stoichiometry to produce the red-fluorescent oxidation product, resorufin. Experiments were carried out following manufacturer's instructions with minor modifications. Briefly, isolated mitochondria were incubated with reaction buffer and amplex red dye was added before fueling mitochondria with glutamate, malate and ADP. Changes in fluorescence over time were read on a Molecular Devices Flex Station 3 fluorescent plate reader (Molecular Devices, Sunnyvale, CA) and normalized per milligram of protein.

\section{Lipid Peroxidation Products}

Lipid peroxidation was assessed through the measurement of stable, oxidized end products of polyunsaturated fatty acids and esters: malondialdehyde (MDA) and 4hydroxyalkenal $(4-\mathrm{HAE})$ as previously described $(3,14)$. Briefly, one molecule of either MDA or 4-HAE reacts with two molecules of N-methyl-2-phenylindole (Oxford Biomedical Research Company, Oxford, MI) to yield a stable chromophore whose absorbance was measured on a Molecular Devices Flex Station 3 spectrophotometric plate reader (Molecular Devices, Sunnyvale, CA). Protein content was assessed by the Bradford method, as above, and values were normalized per milligram of protein. 


\section{Western Blotting}

SDS polyacrylamide gel electrophoresis (SDS-PAGE) was run on $4-12 \%$ gradient gels as previously described $(3,4,13,24)$. Relative amounts of Glutathione Peroxidase 1 (GPx1), Glutathione Peroxidase 4 (GPx4), Superoxide Dismutase 1 (SOD1), and Superoxide Dismutase 2 (SOD2) were determined using specific antibodies: anti-GPx1 (Prod. No. ab22604; Abcam), anti-GPx4 (Prod. No. 10005258; Cayman Chemical), anti-SOD1 (Prod. No. ab16831; Abcam) and anti-SOD2 (Prod. No. ab13533; Abcam). The secondary antibodies used included: goat anti-mouse IgG horseradish peroxidase (HRP) conjugate (product No. 31430; Pierce Biotechnology; Rockford, IL) and goat anti-rabbit IgG HRP conjugate (product No. 10004301; Cayman Chemical). Pierce Enhanced Chemiluminescence Western Blotting substrate (Pierce; Rockford, IL) was used to detect signal following the manufacturer's instructions. A G:Box Bioimaging system (Syngene; Frederick, MD) was used to assess autoradiographic signals. Data were captured using GeneSnap/GeneTools software (Syngene) and densitometry was analyzed using Image J Software (National Institutes of Health, Bethesda, MD). Anti-COXIV rabbit antibody was used as a loading control for mitochondrial protein (product No. \#4844; Cell Signaling Technology).

\section{Glutathione Peroxidase Activity}

Total glutathione peroxidase activity was measured spectrophotometrically through the change in absorbance of NADPH utilizing a commercially available assay (Cayman Chemical, Prod. No. 703102). In this model, GPx activity is rate limiting allowing us to consider the change in absorbance as the enzyme activity. The assay was carried out as per manufacturer's instructions. 


\section{Statistics}

Mean and standard error (SE) were calculated for all data sets. A One-Way Analysis of Variance (ANOVA) was employed with a Bonferroni post-Hoc test to analyze differences between treatment groups using GraphPad Prism 5 (GraphPad Software, La Jolla, CA). $P<$ 0.05 was considered significant. 


\section{RESULTS}

\section{Cardiac Function Following $\mathrm{Nano}_{-} \mathrm{TiO}_{2}$ Inhalation Exposure}

While nanomaterial inhalation has implicated cardiovascular dysfunction following exposure, cardiac functional measures have been limited. In this study we utilized conventional, pulsed wave Doppler flow and speckle-tracking based strain measures of echocardiography to thoroughly and sensitively measure cardiac function in vivo following nano- $\mathrm{TiO}_{2}$ inhalation. Within our study, diametric and spatial parameters identified by M-Mode echocardiography were not significantly changed with mPHGPx overexpression or following nano- $\mathrm{TiO}_{2}$ inhalation when compared to control (Table 1). This data suggests that no overt systolic dysfunction is observed with acute nano- $\mathrm{TiO}_{2}$ exposure.

One common diastolic measure utilizes pulsed wave Doppler flow through the mitral valve. In this measure, the individual contribution of the passive left ventricle suction during early diastole (E wave) and the active contraction of the left atria during late diastole (A Wave) in the refilling of the ventricle can be identified to examine diastolic function through the ratio of $\mathrm{E}$ to $\mathrm{A}$. Following exposure to nano- $\mathrm{TiO}_{2}$, there was a significant increase in the velocity of the $\mathrm{E}$ wave (Figure 2E), yet no change in the A wave velocity was observed (Figure 2F). This change in $E$ without an accompanying change in A led to an increase in the $E / A$ Ratio (Figure 2G) over 2 following exposure to nano- $\mathrm{TiO}_{2}$ and is indicative of restrictive filling of the left ventricle during diastole. Deceleration of the mitral valve following exposure was increased (Figure $2 \mathrm{H}$ ) and prompts investigation into the effects of nano- $\mathrm{TiO}_{2}$ on the deceleration time of the mitral valve filling velocity. Deceleration time of early mitral flow, a marker of stiffness routinely measured during the quantitation of diastolic function, was shortened following exposure to nano- $\mathrm{TiO}_{2}$ further supporting that the heart is stiffer following exposure to nanomaterials (Figure 2I). To complete our analyses of diastolic function following nano- $\mathrm{TiO}_{2}$ exposure, we normalized deceleration time to the early filling velocity $(E)$. In humans, this measure has been shown to 
augment the prognostic power of mitral valve tissue Doppler flow indices and predicts heart failure hospitalization (27). Following nano- $\mathrm{TiO}_{2}$ exposure the normalization of deceleration time to early filling velocity decreased supporting the conclusion that ENM exposure induces diastolic dysfunction (Figure 2J). Finally, the diastolic dysfunction observed with nano- $\mathrm{TiO}_{2}$ exposure was attenuated with overexpression of mPHGPx (Figure 2E-J).

To reinforce the PW-Doppler flow data, we investigated the strain on the heart during diastole utilizing speckle-tracking based strain echocardiography. Following an acute inhalation exposure to nano- $\mathrm{TiO}_{2}$, there was a significant increase in the radial strain and strain rate throughout the wall of the left ventricle (Figure $3 A$ and $B$ ). The increased strain and strain rate further suggest restrictive filling of the left ventricle throughout diastole. Following work that identified the ratio of the $\mathrm{E}$ wave velocity to radial strain rate most closely correlates to the cardiac catheterization pressures, we investigated this index following nanomaterial exposure. Our previous data was corroborated as the ratio of E/SR was significantly increased following exposure (Figure 3C). Overexpression of mPHGPx attenuated the increased speckle-tracking based strain measures following nano- $\mathrm{TiO}_{2}$ exposure (Figure $3 \mathrm{~A}-\mathrm{C}$ ). This data suggests that following nanomaterial exposure, the heart has to work harder during diastole to refill and maintain cardiac systolic function; however, by reducing the impact of ROS through the overexpression of mPHGPx, we can attenuate the observed diastolic dysfunction.

\section{Spatially-Distinct Mitochondrial Function}

Diastole itself is an energy intensive process, and the mitochondria provide the energy necessary for both contraction and relaxation. Mitochondrial respiratory capacity can be evaluated by identifying the state 3 and state 4 respiratory rates. Within the cardiomyocyte, there are two spatially and biochemically distinct subpopulations of mitochondria: the subsarcolemmal (SSM) which are located below the sarcolemma and the interfibrillar (IFM) 
which reside within the contractile apparatus. Following inhalation exposure, there was no significant change in either respiratory rate in the SSM (Figure 4A). In contrast, , nanomaterial exposure decreased the state 3 respiratory rate in IFM suggesting decreased function of the organelle (Figure 4B). To support the respiratory data we used a spectrophotometric assay to identify the activity of ATP synthase following nano- $\mathrm{TiO}_{2}$ exposure. Following pulmonary nanomaterial exposure, no changes were noted in the ATP synthase activity in the SSM (Figure 4C), however, in the IFM there was a significant decrease in the ATP synthase activity (Figure 4D). mPHGPx overexpression rescued the state 3 mitochondrial respiratory rate (Figure 4B) and the ATP synthase activity (Figure 4D) of the IFM to control levels. This data suggests that decreased mitochondrial function accompanies cardiac diastolic dysfunction following nano- $\mathrm{TiO}_{2}$ exposure. Also, this data demonstrates that the decreased mitochondrial function observed following nano- $\mathrm{TIO}_{2}$ exposure is localized to the IFM and treatment with an antioxidant attenuates the damage.

\section{Mitochondrial Lipid Peroxidation}

ROS damage, especially lipid peroxidation, can influence the macromolecule's function thus influencing an organelle's function. We investigated the ROS damage by-products malondialdehyde (MDA) and 4-hydroxyalkenal (4-HAE) to address the impact ROS have on the molecules within the mitochondrion. Doing so, we identified that there was a significant increase in lipid damaged by nano- $\mathrm{TiO}_{2}$ inhalation in the IFM, which was mitigated with overexpression of mPHGPx (Figure 5B). Again, there was no change in lipid peroxidation within any of the groups compared to the control in the SSM (Figure 5A). Taken together, this data suggests that ROS damage within the IFM may contribute to the observed mitochondrial dysfunction following nano- $\mathrm{TiO}_{2}$ exposure. 


\section{Mitochondrial Hydrogen Peroxide Production}

SSM isolated from animals exposed to nano- $\mathrm{TiO}_{2}$ showed no increase in ROS production (Figure 5C and E). In contrast, there was a significant increase in the hydrogen peroxide production in IFM following exposure to nano- $\mathrm{TiO}_{2}($ Figure 5D and $\mathrm{F})$. Overexpression of $\mathrm{mPHGPx}$ was able to attenuate the increased ROS production in the IFM following exposure (Figure 5D and F). Thus, these data suggest that increased mitochondrial ROS damage in the IFM following nano- $\mathrm{TiO}_{2}$ exposure may arise from increased mitochondrial ROS production. The ability of the mPHGPx overexpression to attenuate ROS production suggests that ROS play a central role in the mitochondrial dysfunction that occurs following nano- $\mathrm{TiO}_{2}$ exposure.

\section{Antioxidant Capacity}

In our study, we observed no change in any of the mitochondrial antioxidant enzymes following exposure to nano- $\mathrm{TiO}_{2}$ in either SSM or IFM (Figure 6A and B). With genetic overexpression of mPHGPx, we observed a significant increase in the protein concentration of GPx4 in both SSM and IFM (Figure 6A and B). In addition, by utilizing spectrophotometry and substrates specific to glutathione peroxidase, we confirmed increased glutathione peroxidase activity of both SSM and IFM in animals overexpressing mPHGPx (Figure 6C and D). This data confirms overexpression of mPHGPx was accomplished and that nano- $\mathrm{TiO}_{2}$ did not affect the antioxidant capacity of the mitochondria. 


\section{DISCUSSION}

Nanomaterial commercial incorporation continues to rise, but the impact of these materials on human health is not fully understood. Inhalation of nano- $\mathrm{TiO}_{2}$ has been shown to impact cardiovascular function and ROS production within the heart, yet the influence of the mitochondria on both cardiovascular function and ROS production following acute inhalation exposure is unexplored. Utilizing our nanomaterial inhalation exposure chamber and a novel transgenic mouse line overexpressing the antioxidant enzyme mPHGPx, we examined the role of ROS damage in the cardiac mitochondrial dysfunction and diastolic dysfunction observed with nano- $\mathrm{TiO}_{2}$ exposure. Our data revealed that acute nano- $\mathrm{TiO}_{2}$ inhalation induces diastolic dysfunction associated with increased mitochondrial ROS production and metabolic dysfunction that can be attenuated with overexpression of mPHGPx.

Within this study, we highlight the diastolic dysfunction that occurs after inhalation exposure to nano- $\mathrm{TiO}_{2}$. While we are not the first to highlight that diastolic function is altered with exposure to nanomaterials, though we are the first to incorporate speckle tracking based strain echocardiography to identify this adverse outcome. Previously, Kan et al. identified decreased diastolic dysfunction following inhalation exposure to nano- $\mathrm{TiO}_{2}$ utilizing pressurevolume loops (22). This supports our data and the use of speckle-tracking based strain echocardiography as we see a similar end-point. Our lab and others have described the benefit of this technique in the early identification of cardiac functional defects that precede overt systolic dysfunction in disease models in both rodent and human analyses $(5,25,38)$. Because this tool is commonly used to identify dysfunction earlier, the dysfunction identified in our acute model may precede overt dysfunction that may occur in a chronic exposure model.

Diastolic dysfunction is clinically characterized by a decreased rate of $L V$ relaxation and commonly precedes systolic dysfunction found in many cardiac disorders, such as heart failure. 
By comparing non-invasive speckle-tracking based echocardiographic and invasive cardiac catheterization indices in humans, Chen et al. was able to isolate the combination of noninvasive parameters that best correlate with diastolic function (9). While they suggested SR by itself was indicative of $L V$ relaxation, the authors continued that the use of the ratio of $E$ velocity to SR correlated well with Left ventricular end-diastolic pressure. Our data indicates that following nano- $\mathrm{TiO}_{2}$ exposure there was an increase in both strain rate and the ratio of $\mathrm{E} / \mathrm{SR}$ in the exposed animals. This data supports the use of non-invasive speckle-tracking based strain echocardiography to identify diastolic dysfunction following nano- $\mathrm{TiO}_{2}$ exposure.

Within the cardiomyocyte, resetting of the cell during diastole to prepare for contraction is an energy intensive process. Mitochondrial dysfunction has been shown to lead to diastolic dysfunction in a diabetic model (16), but cardiac mitochondrial dysfunction following nano- $\mathrm{TiO}_{2}$ exposure has not been investigated. Cardiac mitochondrial function following in vivo nanomaterial exposure is not intensely investigated, but studies have emphasized decreased mitochondrial function arises following exposure (39). In vitro analyses in a variety of cell types support the suggestion that decreased mitochondrial function results from exposure to engineered nanomaterials $(28,43)$. Thus this manuscript highlights that the mitochondria may be central in the extrapulmonary impacts following a nanomaterial inhalation exposure.

Previously our lab has identified cardiac mitochondrial dysfunction following exposure to a regionally specific particulate matter (29). Further, we identified decreased mitochondrial respiratory rates of both mitochondrial subpopulations that exist in the cardiomyocyte. These subpopulations are unique both spatially and biochemically. The SSM sit below the sarcolemma, are larger more variable in size. In contrast, the IFM sit within the contractile apparatus, are smaller and more compact and have a higher respiratory rate compared to the SSM. The particulate matter previously investigated was a composite regionally-specific particle 
collected with non-uniform particle size and chemical composition. We then utilized the ENM MWCNT and compared the effects observed between the composite PM and this uniform ENM. While the time frames were different, within both of these studies we observed decreased mitochondrial function. The current studies identifies that the mitochondrial dysfunction occurring after nanomaterial inhalation is limited to the IFM. Taken together, these studies may suggest that nanomaterial or the ultrafine fraction of particulate matter may decrease IFM function, while the larger particle size induces SSM dysfunction. Taking into account these three data sets, especially the MWCNT, we could assume that this hypothesis is not true, but while MWCNT are less than $100 \mathrm{~nm}$ in one dimension, they can be up to microns in length. Thus the larger portion of the particle can induce SSM dysfunction while the nano-size particles induce IFM dysfunction. This hypothesis would be supported by differentially impacted intermediate mediators following exposure to the particles of different sizes.

In the mitochondria, mPHGPx exists within the inner membrane space primarily at contact points between the inner and outer mitochondrial membranes. This is important to point out because it suggests that this antioxidant is especially critical in protecting the lipids and proteins within these mitochondrial membranes, such as the electron transport chain complex enzymes. ROS, due to their short half-life, mostly impact the compartment in which they were produced. In the electron-rich environment near the inner mitochondrial membrane the probability of ROS formation is increased. Thus, overexpression of a mitochondrial antioxidant targeted to the inner mitochondrial membrane is likely to prevent mitochondrial dysfunction as shown by the data within this manuscript. Throughout this study we showed that overexpression of mPHGPx was able to attenuate cardiac and mitochondrial dysfunction following nano- $\mathrm{TiO}_{2}$ exposure. This data also further suggests ROS as a central component to the cardiac toxicity of nano- $\mathrm{TiO}_{2}$. 
With respect to the exposure, we have previously reported that this dose is equivalent to a worker working in the production facility exposed to the current NIOSH recommended exposure limit of $300 \mu \mathrm{g} / \mathrm{m}^{3}$ for 40 hours a week for 26 days. This dose has been used within other animal models and shown to elicit microvascular dysfunction and systemic oxidative stress (31). The utilization of our novel inhalation facility creates an extremely translationally relevant exposure model, yet the confirmation of the observed effects in a chronic model would be of value. Investigation into the effects of acute exposure on cardiac tissue is not without merit due to the tissues essential function. Acute inhalation exposure has been shown to expeditiously induce cardiac dysfunction and disrupt subcellular processes such as oxidative milieu and mitochondrial function $(17,34)$. While most of these effects have been identified in particulate matter exposures, the vast majority of literature suggests that nanomaterials are more toxic than their larger counterparts (33). Thus, the effects observed in this manuscript add to our limited, current understanding of cardiac mechanisms following nanomaterial exposure.

The exposure concentration used within this study is relevant to an occupational setting, but due to the rise of nanomaterial incorporation into consumer products and limited pulmonary elimination, this dose may become relevant to a larger population. The data presented in this manuscript shows for the first time that ROS production and damage drives mitochondrial dysfunction, leading to cardiac dysfunction following an acute exposure to nano- $\mathrm{TiO}_{2}$. To elucidate the importance of ROS in this mechanism we utilized a genetic overexpression of mPHGPx, which attenuated mitochondrial ROS damage and restored mitochondrial and cardiac function, highlighting ROS as the driving mechanism of toxicity. Within the disrupted cellular mechanisms, our study suggests that there is a spatial component to the dysfunction as shown by differential effects in mitochondrial subpopulations. We propose that this could allude to a spatial component to the toxicological trigger. Even though this study is specific to nano- $\mathrm{TiO}_{2}$, 
the nature of this particle could suggest the extrapolation of the observed effects to nanomaterials in general.

\section{Conclusions}

Throughout this article we have outlined the impact of nano- $\mathrm{TiO}_{2}$ on cardiac diastolic function and the mitochondrial impacts that may contribute to this dysfunction. Utilizing a novel transgenic animal overexpressing the antioxidant mPHGPx, we support our hypothesis that the cardiac and mitochondrial dysfunction observed following nano- $\mathrm{TiO}_{2}$ exposure is due to an increase in mitochondrial ROS production and damage. Our transgenic animal identifies that by enhancing the antioxidant capacity we can reduce the cardiac and mitochondrial dysfunction observed following nano- $\mathrm{TiO}_{2}$ exposure. 


\section{REFERENCES}

1. Arai M, Imai H, Koumura T, Yoshida M, Emoto K, Umeda M, Chiba N, and Nakagawa Y. Mitochondrial phospholipid hydroperoxide glutathione peroxidase plays a major role in preventing oxidative injury to cells. J Biol Chem 274: 4924-4933, 1999.

2. Ayala A, Munoz MF, and Arguelles S. Lipid peroxidation: production, metabolism, and signaling mechanisms of malondialdehyde and 4-hydroxy-2-nonenal. Oxid Med Cell Longev 2014: 360438, 2014.

3. Baseler WA, Dabkowski ER, Jagannathan R, Thapa D, Nichols CE, Shepherd DL, Croston TL, Powell M, Razunguzwa TT, Lewis SE, Schnell DM, and Hollander JM. Reversal of mitochondrial proteomic loss in Type 1 diabetic heart with overexpression of phospholipid hydroperoxide glutathione peroxidase. Am J Physiol Regul Integr Comp Physiol 304: R553-565, 2013.

4. Baseler WA, Dabkowski ER, Williamson CL, Croston TL, Thapa D, Powell MJ, Razunguzwa TT, and Hollander JM. Proteomic alterations of distinct mitochondrial subpopulations in the type 1 diabetic heart: contribution of protein import dysfunction. $A m J$ Physiol Regul Integr Comp Physiol 300: R186-200, 2011.

5. Bauer M, Cheng S, Jain M, Ngoy S, Theodoropoulos C, Trujillo A, Lin FC, and Liao R. Echocardiographic speckle-tracking based strain imaging for rapid cardiovascular phenotyping in mice. Circ Res 108: 908-916, 2011.

6. Bradford MM. A rapid and sensitive method for the quantitation of microgram quantities of protein utilizing the principle of protein-dye binding. Anal Biochem 72: 248-254, 1976.

7. Chance B and Williams GR. Respiratory enzymes in oxidative phosphorylation. I. Kinetics of oxygen utilization. J Biol Chem 217: 383-393, 1955. 
8. Chance B and Williams GR. Respiratory enzymes in oxidative phosphorylation. VI. The effects of adenosine diphosphate on azide-treated mitochondria. J Biol Chem 221: 477-489, 1956.

9. Chen S, Yuan J, Qiao S, Duan F, Zhang J, and Wang H. Evaluation of left ventricular diastolic function by global strain rate imaging in patients with obstructive hypertrophic cardiomyopathy: a simultaneous speckle tracking echocardiography and cardiac catheterization study. Echocardiography 31: 615-622, 2014.

10. Chen Z, Wang Y, Zhuo L, Chen S, Zhao L, Luan X, Wang H, and Jia G. Effect of titanium dioxide nanoparticles on the cardiovascular system after oral administration. Toxicol Lett 239: 123-130, 2015.

11. Croston TL, Shepherd DL, Thapa D, Nichols CE, Lewis SE, Dabkowski ER, Jagannathan R, Baseler WA, and Hollander JM. Evaluation of the cardiolipin biosynthetic pathway and its interactions in the diabetic heart. Life Sci 93: 313-322, 2013.

12. Croston TL, Thapa D, Holden AA, Tveter KJ, Lewis SE, Shepherd DL, Nichols CE, Long DM, Olfert IM, Jagannathan R, and Hollander JM. Functional deficiencies of subsarcolemmal mitochondria in the type 2 diabetic human heart. Am J Physiol Heart Circ Physiol 307: H54-65, 2014.

13. Dabkowski ER, Baseler WA, Williamson CL, Powell M, Razunguzwa TT, Frisbee JC, and Hollander JM. Mitochondrial dysfunction in the type 2 diabetic heart is associated with alterations in spatially distinct mitochondrial proteomes. Am J Physiol Heart Circ Physiol 299: H529-540, 2010.

14. Dabkowski ER, Williamson CL, and Hollander JM. Mitochondria-specific transgenic overexpression of phospholipid hydroperoxide glutathione peroxidase (GPx4) attenuates ischemia/reperfusion-associated cardiac dysfunction. Free Radic Biol Med 45: 855-865, 2008.

15. Esterbauer H, Schaur RJ, and Zollner H. Chemistry and biochemistry of 4hydroxynonenal, malonaldehyde and related aldehydes. Free Radic Biol Med 11: 81-128, 1991. 
16. Flarsheim CE, Grupp IL, and Matlib MA. Mitochondrial dysfunction accompanies diastolic dysfunction in diabetic rat heart. Am J Physiol 271: H192-202, 1996.

17. Fu PP, Xia Q, Hwang HM, Ray PC, and Yu H. Mechanisms of nanotoxicity: generation of reactive oxygen species. J Food Drug Anal 22: 64-75, 2014.

18. Hollander JM, Lin KM, Scott BT, and Dillmann WH. Overexpression of PHGPx and HSP60/10 protects against ischemia/reoxygenation injury. Free Radic Biol Med 35: 742-751, 2003.

19. Huerta-Garcia E, Perez-Arizti JA, Marquez-Ramirez SG, Delgado-Buenrostro NL, Chirino YI, Iglesias GG, and Lopez-Marure R. Titanium dioxide nanoparticles induce strong oxidative stress and mitochondrial damage in glial cells. Free Radic Biol Med 73: 84-94, 2014.

20. Imai H and Nakagawa Y. Biological significance of phospholipid hydroperoxide glutathione peroxidase (PHGPx, GPx4) in mammalian cells. Free Radic Biol Med 34: 145-169, 2003.

21. Ji LL, Leeuwenburgh C, Leichtweis S, Gore M, Fiebig R, Hollander J, and Bejma J. Oxidative stress and aging. Role of exercise and its influences on antioxidant systems. Ann N Y Acad Sci 854: 102-117, 1998.

22. Kan H, Wu Z, Lin YC, Chen TH, Cumpston JL, Kashon ML, Leonard S, Munson AE, and Castranova V. The role of nodose ganglia in the regulation of cardiovascular function following pulmonary exposure to ultrafine titanium dioxide. Nanotoxicology 8: 447-454, 2014.

23. Kan H, Wu Z, Young SH, Chen TH, Cumpston JL, Chen F, Kashon ML, and Castranova V. Pulmonary exposure of rats to ultrafine titanium dioxide enhances cardiac protein phosphorylation and substance P synthesis in nodose ganglia. Nanotoxicology 6: 736$745,2012$.

24. Laemmli UK. Cleavage of structural proteins during the assembly of the head of bacteriophage T4. Nature 227: 680-685, 1970. 
25. Liang HY, Cauduro S, Pellikka P, Wang J, Urheim S, Yang EH, Rihal C, Belohlavek M, Khandheria B, Miller FA, and Abraham TP. Usefulness of two-dimensional speckle strain for evaluation of left ventricular diastolic deformation in patients with coronary artery disease. Am J Cardiol 98: 1581-1586, 2006.

26. McWilliams A. Nanotechnology: A Realistic Market Assessment. Wellesley, MA: BBC Research, 2014.

27. Mishra RK, Devereux RB, Cohen BE, Whooley MA, and Schiller NB. Prediction of heart failure and adverse cardiovascular events in outpatients with coronary artery disease using mitral E/A ratio in conjunction with e-wave deceleration time: the heart and soul study. $J$ Am Soc Echocardiogr 24: 1134-1140, 2011.

28. Moschini E, Gualtieri M, Colombo M, Fascio U, Camatini M, and Mantecca P. The modality of cell-particle interactions drives the toxicity of nanosized $\mathrm{CuO}$ and $\mathrm{TiO}(2)$ in human alveolar epithelial cells. Toxicol Lett 222: 102-116, 2013.

29. Nichols CE, Shepherd DL, Knuckles TL, Thapa D, Stricker JC, Stapleton PA, Minarchick VC, Erdely A, Zeidler-Erdely PC, Alway SE, Nurkiewicz TR, and Hollander JM. Cardiac and mitochondrial dysfunction following acute pulmonary exposure to mountaintop removal mining particulate matter. Am J Physiol Heart Circ Physiol 309: H2017-2030, 2015.

30. Niska K, Santos-Martinez MJ, Radomski MW, and Inkielewicz-Stepniak I. CuO nanoparticles induce apoptosis by impairing the antioxidant defense and detoxification systems in the mouse hippocampal HT22 cell line: protective effect of crocetin. Toxicol In Vitro 29: 663$671,2015$.

31. Nurkiewicz TR, Porter DW, Hubbs AF, Stone S, Chen BT, Frazer DG, Boegehold MA, and Castranova V. Pulmonary nanoparticle exposure disrupts systemic microvascular nitric oxide signaling. Toxicol Sci 110: 191-203, 2009.

32. Palmer JW, Tandler B, and Hoppel CL. Biochemical properties of subsarcolemmal and interfibrillar mitochondria isolated from rat cardiac muscle. J Biol Chem 252: 8731-8739, 1977. 
33. Roduner E. Size matters: why nanomaterials are different. Chem Soc Rev 35: 583-592, 2006.

34. Sarkar A, Ghosh M, and Sil PC. Nanotoxicity: oxidative stress mediated toxicity of metal and metal oxide nanoparticles. J Nanosci Nanotechnol 14: 730-743, 2014.

35. Schnurr K, Belkner J, Ursini F, Schewe T, and Kuhn H. The selenoenzyme phospholipid hydroperoxide glutathione peroxidase controls the activity of the 15-lipoxygenase with complex substrates and preserves the specificity of the oxygenation products. J Biol Chem 271: 4653-4658, 1996.

36. Sha B, Gao W, Wang S, Li W, Liang X, Xu F, and Lu TJ. Nano-titanium dioxide induced cardiac injury in rat under oxidative stress. Food Chem Toxicol 58: 280-288, 2013.

37. Sheng L, Wang X, Sang X, Ze Y, Zhao X, Liu D, Gui S, Sun Q, Cheng J, Cheng Z, Hu R, Wang L, and Hong F. Cardiac oxidative damage in mice following exposure to nanoparticulate titanium dioxide. J Biomed Mater Res A 101: 3238-3246, 2013.

38. Shepherd DL, Nichols CE, Croston TL, McLaughlin SL, Petrone AB, Lewis SE, Thapa D, Long DM, Dick GM, and Hollander JM. Early detection of cardiac dysfunction in the type 1 diabetic heart using speckle-tracking based strain imaging. J Mol Cell Cardiol 90: 74-83, 2015.

39. Stapleton PA, Nichols CE, Yi J, McBride CR, Minarchick VC, Shepherd DL, Hollander JM, and Nurkiewicz TR. Microvascular and mitochondrial dysfunction in the female F1 generation after gestational TiO2 nanoparticle exposure. Nanotoxicology 9: 941-951, 2015.

40. Thapa D, Nichols CE, Lewis SE, Shepherd DL, Jagannathan R, Croston TL, Tveter KJ, Holden AA, Baseler WA, and Hollander JM. Transgenic overexpression of mitofilin attenuates diabetes mellitus-associated cardiac and mitochondria dysfunction. $J$ Mol Cell Cardiol 79: 212-223, 2015. 
41. Thomas JP, Maiorino M, Ursini F, and Girotti AW. Protective action of phospholipid hydroperoxide glutathione peroxidase against membrane-damaging lipid peroxidation. In situ reduction of phospholipid and cholesterol hydroperoxides. J Biol Chem 265: 454-461, 1990.

42. Ursini F, Maiorino M, and Gregolin C. The selenoenzyme phospholipid hydroperoxide glutathione peroxidase. Biochim Biophys Acta 839: 62-70, 1985.

43. Xia T, Korge P, Weiss JN, Li N, Venkatesen MI, Sioutas C, and Nel A. Quinones and aromatic chemical compounds in particulate matter induce mitochondrial dysfunction: implications for ultrafine particle toxicity. Environ Health Perspect 112: 1347-1358, 2004.

44. Yi J, Chen BT, Schwegler-Berry D, Frazer D, Castranova V, McBride C, Knuckles TL, Stapleton PA, Minarchick VC, and Nurkiewicz TR. Whole-body nanoparticle aerosol inhalation exposures. J Vis Exp: e50263, 2013. 
Table 4.1

\begin{tabular}{llrccc}
\hline & & $\begin{array}{c}\text { Control } \\
\text { Average } \pm \text { SEM }\end{array}$ & $\begin{array}{c}\text { Exposed } \\
\text { Average } \pm \text { SEM }\end{array}$ & $\begin{array}{c}\text { mPHGPx } \\
\text { Average } \pm \text { SEM }\end{array}$ & $\begin{array}{c}\text { mPHGPx Exposed } \\
\text { Average } \pm \text { SEM }\end{array}$ \\
\hline Heart Rate & BPM & $505.43 \pm 6.35$ & $502.36 \pm 24.21$ & $480.57 \pm 16.07$ & $506.97 \pm 14.63$ \\
Cardiac Output & $\mathrm{mL} / \mathrm{min}$ & $12.63 \pm 1.10$ & $12.79 \pm 1.39$ & $14.53 \pm 1.66$ & $15.73 \pm 0.77$ \\
LVIDd & $\mathrm{mm}$ & $2.86 \pm 0.11$ & $3.02 \pm 0.21$ & $3.16 \pm 0.16$ & $3.35 \pm 0.11$ \\
LVIDs & $\mathrm{mm}$ & $1.54 \pm 0.09$ & $1.64 \pm 0.15$ & $1.83 \pm 0.11$ & $1.97 \pm 0.08$ \\
Ejection Fraction & $\%$ & $79.13 \pm 1.66$ & $78.22 \pm 2.69$ & $74.65 \pm 1.32$ & $73.16 \pm 1.03$ \\
Fractional Shortening & $\%$ & $46.39 \pm 1.61$ & $46.17 \pm 2.64$ & $42.35 \pm 1.07$ & $41.19 \pm 0.83$ \\
Stroke Volume & $\mathrm{uL}$ & $24.89 \pm 2.06$ & $28.93 \pm 4.58$ & $30.49 \pm 3.60$ & $33.77 \pm 2.55$ \\
EDV & $\mathrm{uL}$ & $31.68 \pm 3.07$ & $37.47 \pm 5.98$ & $41.11 \pm 5.06$ & $46.29 \pm 3.65$ \\
ESV & $\mathrm{uL}$ & $6.78 \pm 1.11$ & $8.54 \pm 1.76$ & $10.63 \pm 1.55$ & $12.52 \pm 1.21$ \\
\hline
\end{tabular}


Table 4.1. M-Mode Echocardiographic Measurements. Values are means \pm SE; $n=8$ for each group. 
Figure 4.1
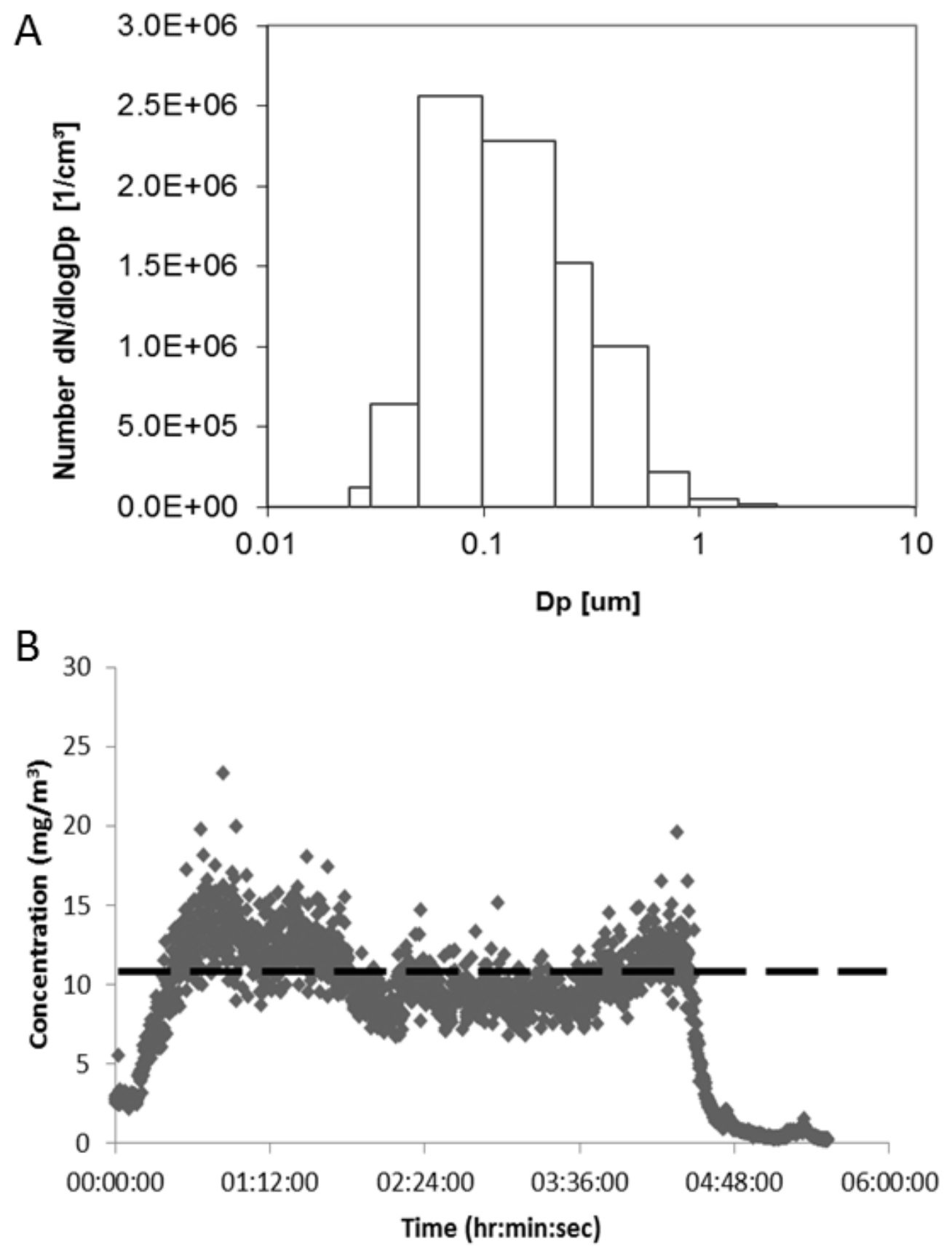
Figure 4.1. Nanomaterial Inhalation Characterization. (A) Electrical Low Pressure Impactor (ELPI) count median aerodynamic diameter $D_{p}=131.6 \mathrm{~nm}$. (B) Titanium Dioxide aerosol mass concentration throughout the inhalation exposure measured with ELPI. Dashed black line is the average exposure concentration. 
Figure 4.2
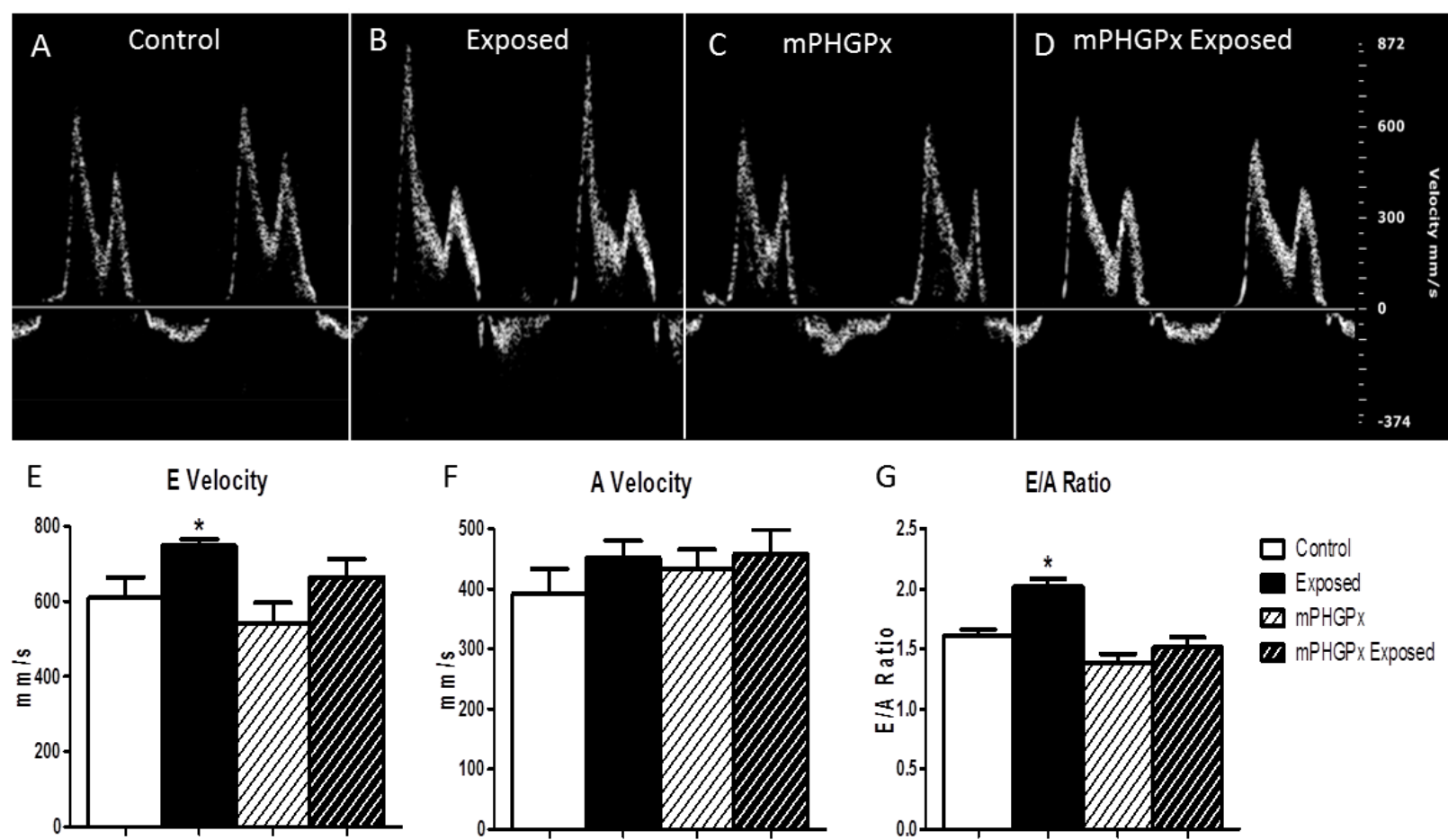

F A Velocity

G

EIA Ratio
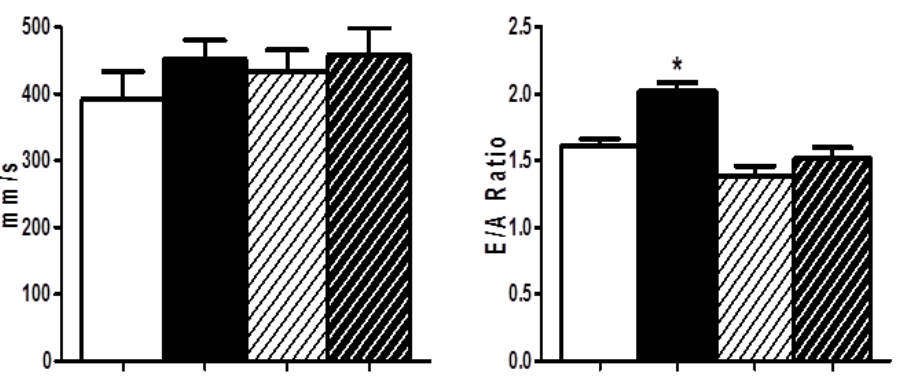

$\square$ Control

Exposed

(27 mPHGPx

II mPHGPx Exposed
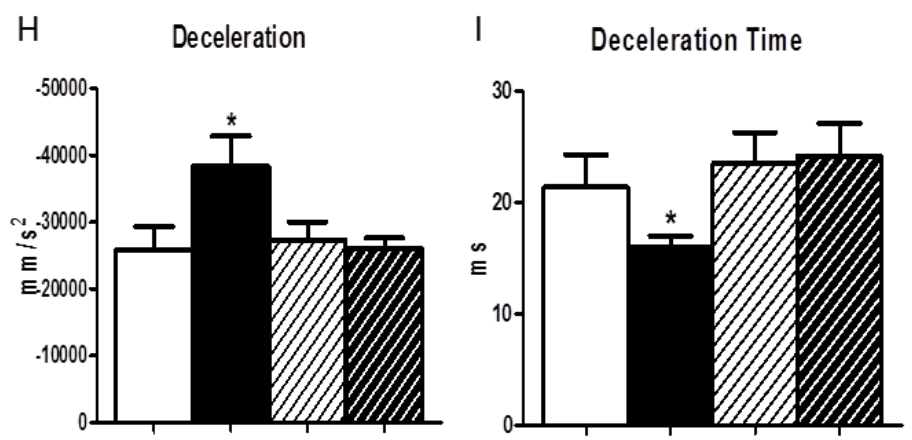

J Deceleration Time/E Velocity

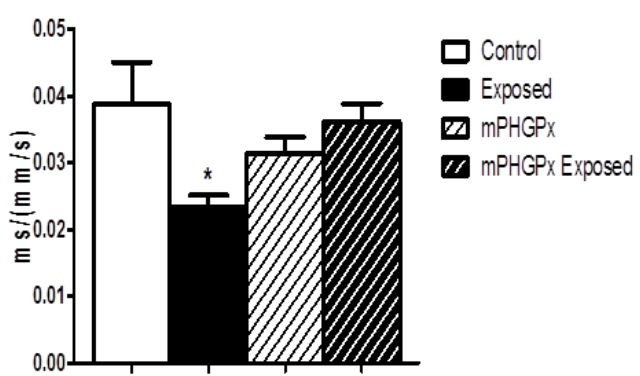


Figure 4.2. Mitral Valve Pulsed-Wave Doppler Flow. Representative images from pulsedwave Doppler flow through the mitral valve analyses in control (A), nano- $\mathrm{TiO}_{2}$ exposed (B), mPHGPx (C) and mPHGPx nano- $\mathrm{TiO}_{2}$ exposed (D). Summary data for early mitral valve filling velocity ( $E$ wave) $(E)$ and late mitral valve filling velocity (A wave) $(F)$ in control, exposed, mPHGPx control and mPHGPx exposed. Ratiometric analysis of E wave velocity to A Wave velocity in control, exposed, mPHGPx control and mPHGPx exposed (G). Deceleration of early mitral valve filling velocity ( $E$ wave) in control, exposed, mPHGPx control and mPHGPx exposed $(H)$. Deceleration time of early mitral valve filling velocity (E wave) in control, exposed, mPHGPx control and mPHGPx exposed (I). Normalization of deceleration time of early mitral valve filling velocity to the early filling velocity in control, exposed, mPHGPx control and mPHGPx exposed (J). Values are means \pm SE; $n=8$ for each group. ${ }^{\star} P<0.05$ for Control vs. Exposed. 
Figure 4.3

A

Radial Strain

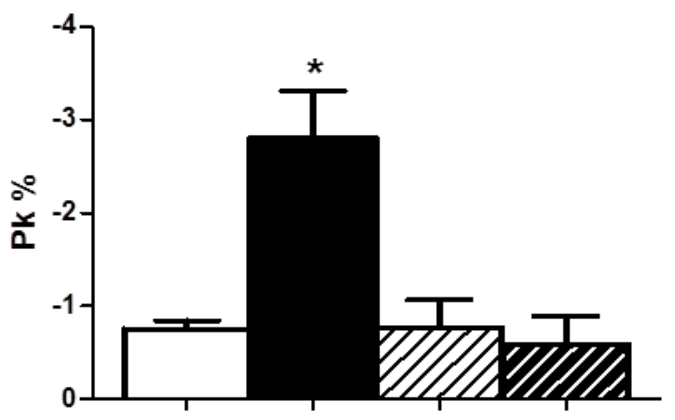

B

Radial Strain Rate

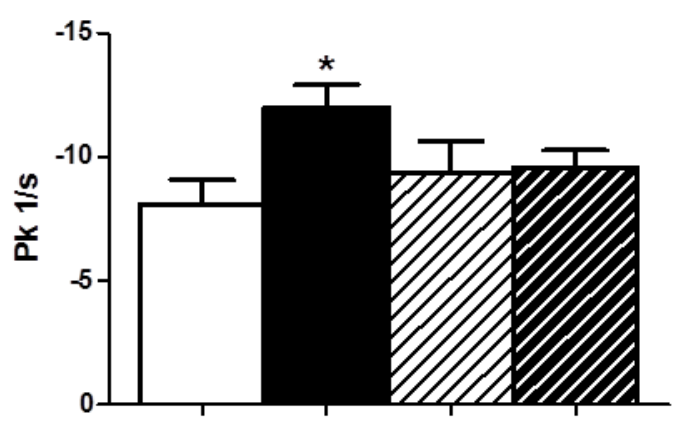

$\square$ Control

- Control Exposed

ש7 $\mathrm{mPHGPx}$

II mPHGPx Exposed

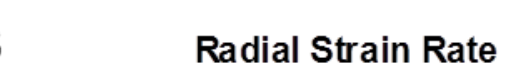

C

E/SR Ratio

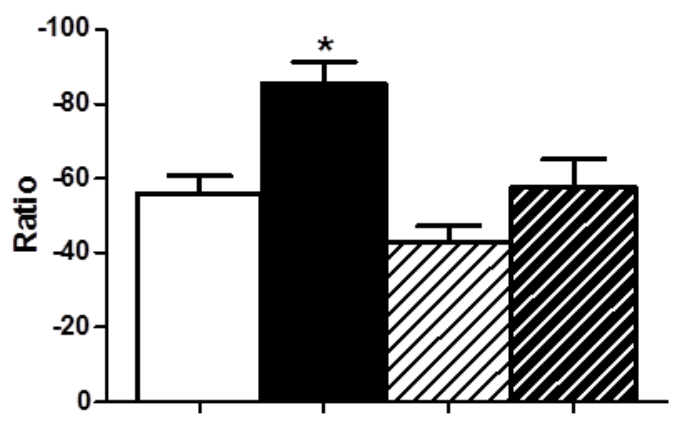

$\square$ Control

- Control Exposed

ש $\mathrm{mPHGPx}$

II mPHGPx Exposed

$\square$ Control

Control Exposed

D $\mathrm{mPHGPx}$

II. mPHGPx Exposed 
Figure 4.3. Diastolic Speckle-Tracking Based Strain Analyses. Diastolic radial strain was analyzed in control, nano-TiO2 exposed, mPHGPx, and nano-TiO2 mPHGPx exposed mice (A). Diastolic radial strain rate analyzed in control, nano-TiO2 exposed, mPHGPx, and nano-TiO2 mPHGPx exposed mice (B). Analysis of the ratio of early mitral valve filling velocity $(\mathrm{E})$ to radial strain rate analyzed in control, exposed, mPHGPx, and mPHGPx exposed mice (C). Values are means \pm SE; $n=8$ for each group. ${ }^{*} P<0.05$ for Control vs. Exposed. 
Figure 4.4
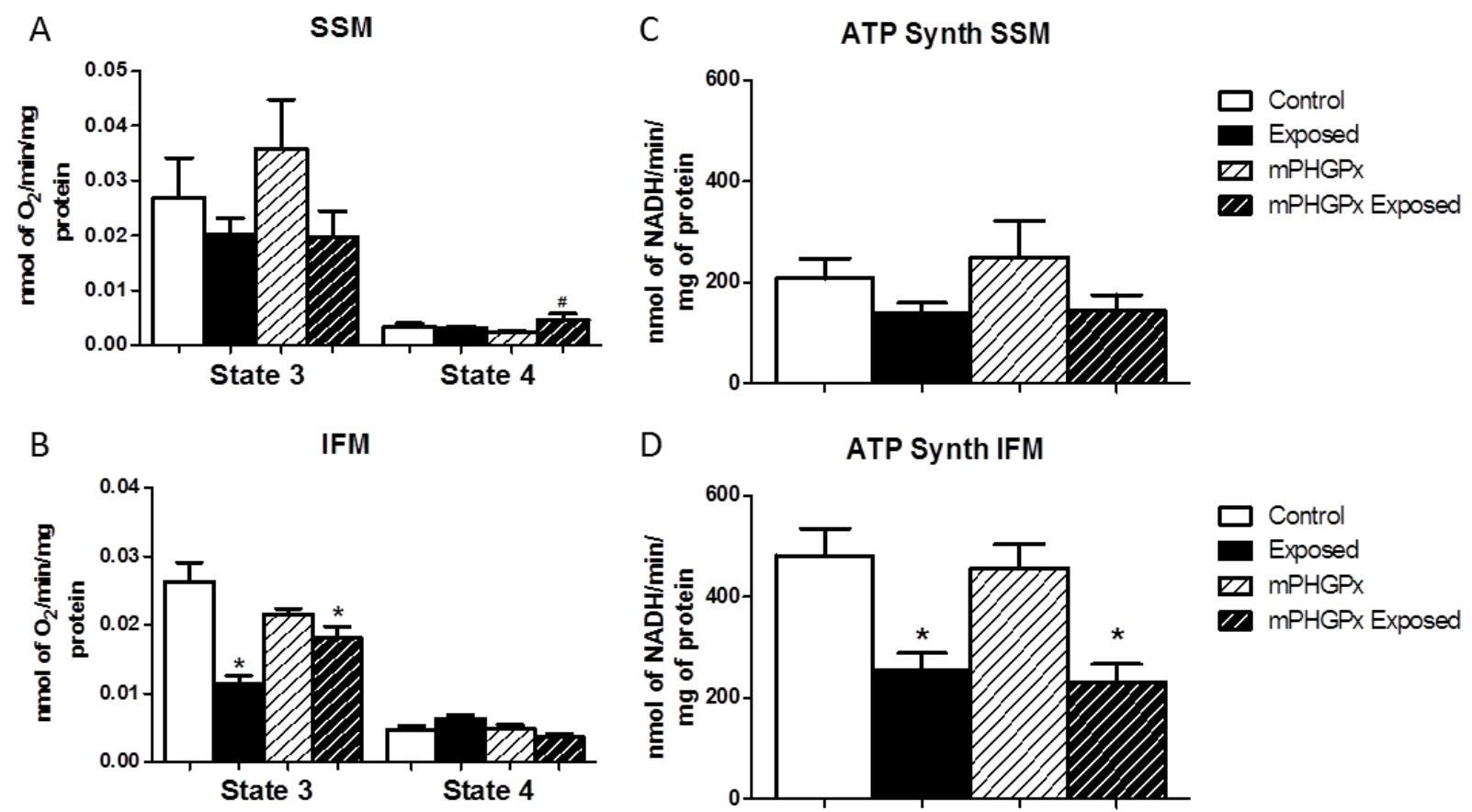
Figure 4.4. Mitochondrial Respiratory Capacity and ATP Synthase Function. Summary analyses of state 3 and state 4 respiration rates from trace measurements of SSM (A) and IFM (B) in control, nano- $\mathrm{TiO}_{2}$ exposed, mPHGPx and mPHGPx nano-TiO ${ }_{2}$ exposed. ATP Synthase activities were assessed spectrophotometrically by measuring the oxidation of NADH coupled with pyruvate kinase in SSM (C) and IFM (D) in control, exposed, mPHGPx and mPHGPx exposed. Respiration rates are expressed in $\mathrm{nmol}$ of oxygen $\cdot \mathrm{min}^{-1} \cdot \mathrm{mg} \mathrm{protein}^{-1}$. ATP Synthase is expressed as nmol of $\mathrm{NADH} \mathrm{min}^{-1} \cdot \mathrm{mg}_{\text {protein }}{ }^{-1}$. Values are means $\pm \mathrm{SE} ; n=6$ for each group. ${ }^{*} P<0.05$ for Control vs. Exposed. SSM: subsarcolemmal mitochondria, IFM: interfibrillar mitochondria. 


\section{Figure 4.5}
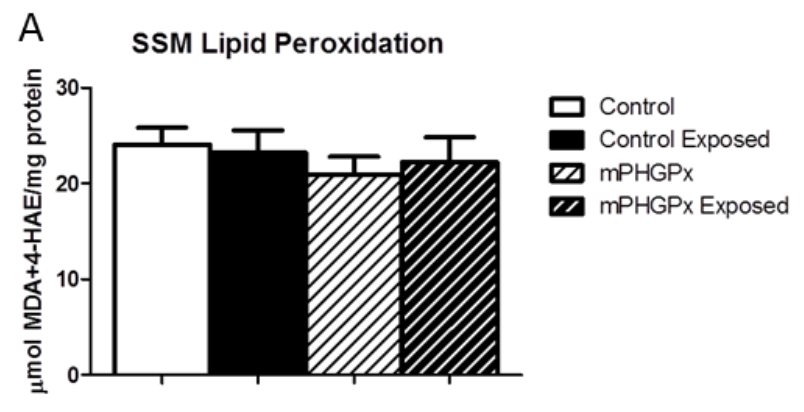

B IFM Lipid Peroxidation

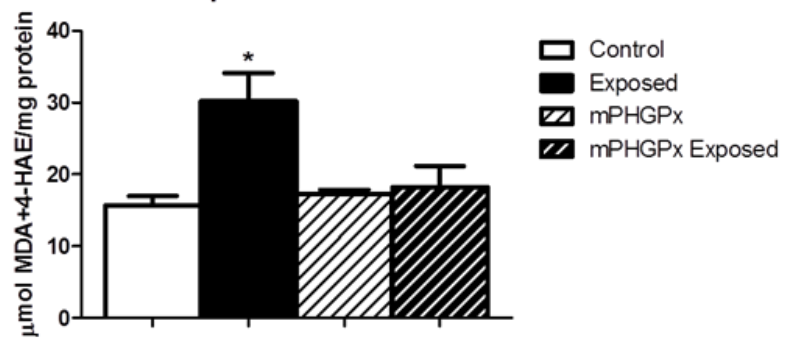

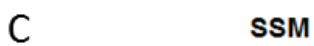
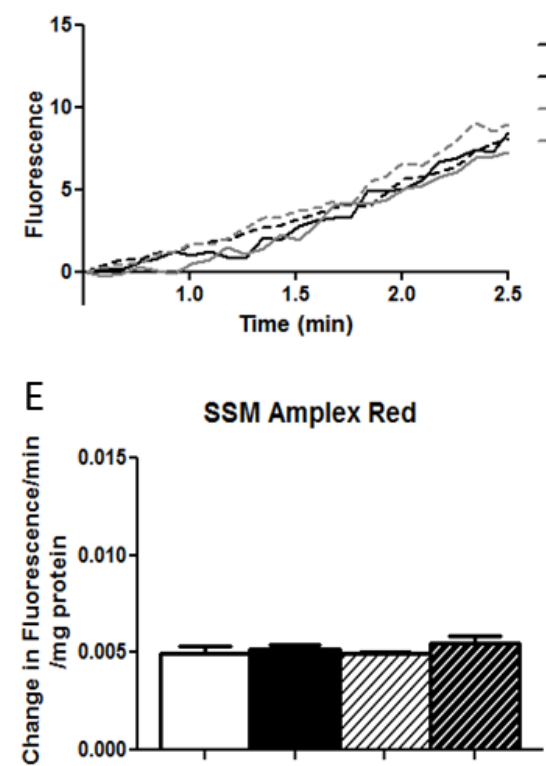

- Contro

- Control Exposed

- Transgenic

-. Transgenic Exposed
D

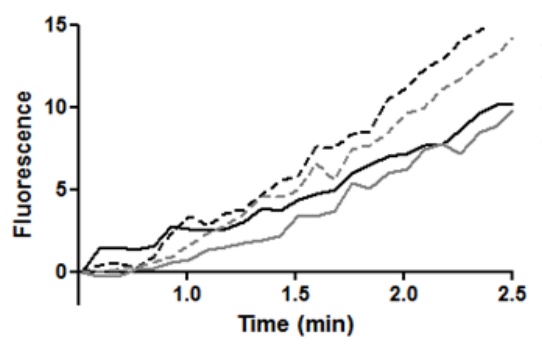

- Control

- Control Exposed

- mPHGPX

-- mPHGPx Exposed

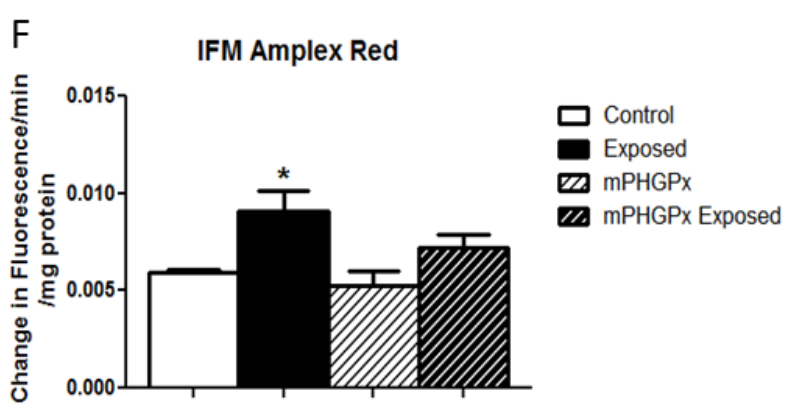


Figure 4.5. Mitochondrial Reactive Oxygen Species Production and Lipid peroxidation by-products. Oxidative damage to lipids was assessed in control, exposed, mPHGPx control and mPHGPx exposed SSM (A) and IFM (B) subpopulations by measuring lipid peroxidation by-products malondialdehyde (MDA) and 4-hydroxyalkenal (4-HAE) using a colorimetric assay. Results were compared against a standard curve of known 4-HAE and MDA concentrations. Representative plot of hydrogen peroxide production over time in SSM (C) and IFM (D) utilizing a fluorescent dye activated by hydrogen peroxide. Solid lines represent control exposure and dashed lines represent nano-TiO2 exposure. Black lines represent control mice, while grey lines represent mPHGPx mice. Summary data of hydrogen peroxide production expressed as change in fluorescence $\mathrm{min}^{-1} \cdot \mathrm{mg}$ protein ${ }^{-1}$ for SSM (E) and IFM (F). Values are expressed as means \pm SE. $n=8$ per each group. ${ }^{*} \mathrm{P}<0.05$ for Control vs. Exposed. SSM: subsarcolemmal mitochondria, IFM: interfibrillar mitochondria. 


\section{Figure 4.6}

A

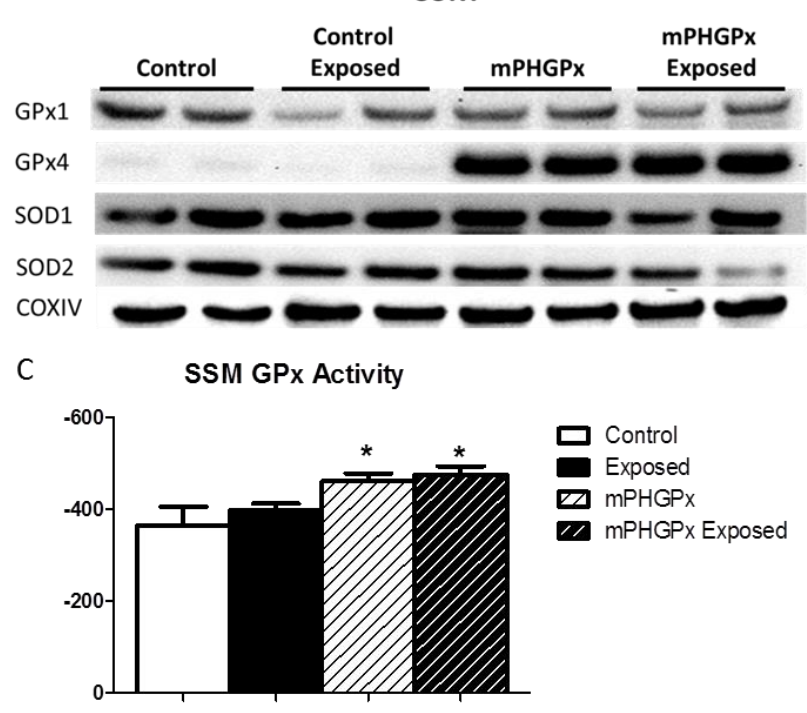

B

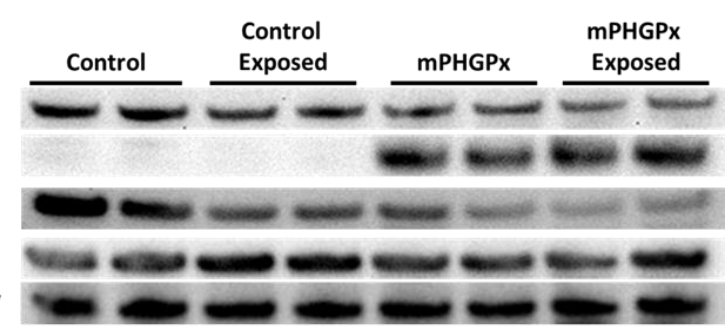

D

IFM GPx Activity

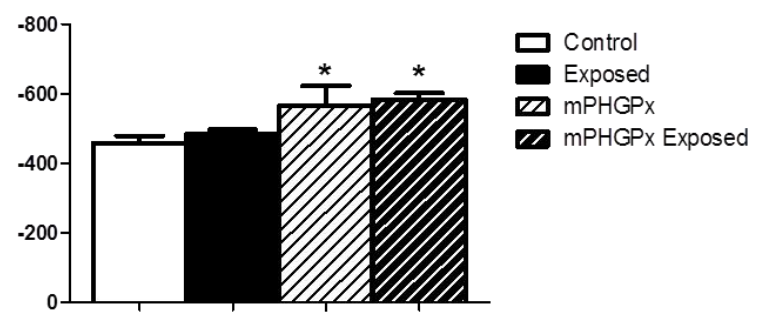


Figure 4.6. Mitochondrial Antioxidant Capacity. Relative protein content assessed by Western blotting of mitochondrial antioxidant enzymes. Representative Western blots for glutathione peroxidase 1 (GPx1), glutathione peroxidase 4 (GPx4), superoxide dismutase 1 (SOD1) and superoxide dismutase 2 (SOD2) in SSM (A) and IFM (B). All Western blots were normalized to cytochrome c oxidase (COXIV) for analysis. $n=6$ for each group. Total mitochondrial glutathione activity was assessed utilizing spectrophotometry in SSM (C) and IFM (D). ${ }^{\star} P<0.05$ for Control vs. Exposed. SSM: subsarcolemmal mitochondria, IFM: interfibrillar mitochondria. 


\section{GENERAL DISCUSSION}

The overall objective of this dissertation was to determine the impacts of an acute xenobiotic pulmonary exposure on cardiac and mitochondrial function. Specifically, we wanted to [1] to elucidate the impact a regionally-specific particulate matter pulmonary exposure has on cardiac apoptosis and mitochondrial dysfunction [2] to investigate the influence of a pulmonary exposure to carbon-based engineered nanomaterials on mitochondrial oxidative stress and [3] to evaluate the impact ROS damage plays in cardiac and mitochondrial dysfunction following a pulmonary exposure to an ENM using a mitochondrial antioxidant (mitochondrial phospholipid hydroperoxide glutathione peroxidase; mPHGPx). Our long-term goal is to better understand the impacts of xenobiotic exposure in order to understand how they may contribute to cardiovascular disorders. The central hypothesis of this dissertation was that acute pulmonary exposure to particulates of varying size and chemical composition differentially elicits increased cardiac oxidative stress triggering apoptosis and eliciting cardiac mitochondrial dysfunction, which is subject to spatial influence, contributing to cardiac dysfunction following exposure. My rationale for the proposed research was based on the finding that particulate matter increases cardiac susceptibility and increased mortality from chronic cardiovascular disease. Also, this research was based on the findings that mitochondria may be targets of engineered nanomaterial exposure. I anticipated being able to determine the mechanisms impacting cardiac and mitochondrial function following acute xenobiotic exposure to particles of different size and chemical composition. The outcomes provided insight into the role of ROS in mitochondrial

mechanisms impacting the cardiovascular system following an acute pulmonary xenobiotic exposure.

Adverse cardiovascular outcomes of acute pulmonary xenobiotic exposure have been identified but the mechanisms contributing to these outcomes are not well defined. Short-term exposure to ambient PM has been associated with increased acute cardiovascular mortality in 
humans (7). Animal models support the cardiovascular disruption and deliver potential mechanisms contributing to the increased mortality (6). Importantly, particulate chemical composition varies regionally due to variations in particle sources (17), and this composition may play a role in the different health outcomes that are observed following exposure (82). Particle size also varies significantly within a translational, composite particle such as PM: ranging from large micron-sized particles $\left(\mathrm{PM}_{10}\right.$ and $\left.\mathrm{PM}_{2.5}\right)$ to smaller nano-sized particles (UFP). Previous studies have shown that smaller PM particles have greater cardiovascular effects when compared to larger particles $(6,47,63)$. While these UFP are similar in size to ENMs they not only differ in intention but also in composition. ENMs are materials created intentionally through precise procedures with relatively uniform size and composition; while, UFP are mostly by-products of combustion and heterogeneous in size and chemical composition. Thus, particle size and chemical composition may be able to induce differential toxic endpoints.

Adverse cardiovascular events have been identified in a number of particle exposures (7). The mechanisms proposed to induce these adverse outcomes vary between exposures, but ROS production and damage are commonly implicated in xenobiotic toxicity (49). Within the cell, reactive oxygen species are predominantly derived as a by-product of oxidative phosphorylation within the mitochondria. Studies indicate the mitochondrion may be implicated in the toxicity associated with xenobiotic exposure: highlighting mitochondrial dysfunction, increased ROS production, and mitochondrial apoptotic signaling following exposure (90). Mitochondria have been identified as central in the etiology of cardiac pathology, but their impact in the cardiovascular dysfunction observed following xenobiotic exposure has not been investigated. Cardiac mitochondrial studies are further complicated by the presence of two spatially and biochemically distinct subpopulations of mitochondria. These mitochondrial subpopulations differentially respond to physiological and pathological stimuli. The studies 
within this dissertation suggest that cardiac mitochondrial subpopulations may be differentially affected following xenobiotic exposure.

To begin to investigate the impact of particle size and composition on cardiac and mitochondrial function, I first began by investigating the endpoints of exposure to PM from ambient air pollution surrounding active MTM sites. Utilizing conventional echocardiography following exposure to $\mathrm{PM}_{\mathrm{MTM}}$ there was a significant decrease in the end-systolic volume and diameter but no change in the end-diastolic volume or diameter leading to a significant decrease in fractional shortening and ejection fraction. This data suggests that the cardiac function was decreased following exposure to $\mathrm{PM}_{\mathrm{MTM}}$. Concomitant with the decreased function was an increase in cardiac apoptosis with mitochondrial apoptotic signaling increased. The mitochondrial signaling was supported by an increased mPTP opening propensity. While the apoptotic propensity was highest in the SSM, both the SSM and IFM exhibited decreased maximal respiratory rates following exposure suggesting mitochondrial dysfunction induced by $\mathrm{PM}_{\text {MTM}}$. Taken together, this data illustrates that acute pulmonary exposure to $\mathrm{PM}_{\mathrm{MTM}}$ induces cardiac contractile dysfunction and mitochondrial dysfunction, most pronounced in the SSM.

We next sought to understand the impact of acute pulmonary ENM exposure on cardiac and mitochondrial function utilizing MWCNT. Further, we applied two different MWCNT doses and time points to identify the effect of dose and time on cardiac and mitochondrial endpoints. Following exposure we identified subclinical cardiac disturbances as measured by the novel speckle-tracking based echocardiography. Yet the responses observed 24 hours post-exposure were not dose dependent. Mitochondrial impacts were observed four hours following exposure exhibiting decreased maximal mitochondrial respiration in both the SSM and IFM. Twenty-four hours following exposure the observed decrease in mitochondrial respiratory rate was restored to control levels except in the IFM of animals exposed to the lower MWCNT dose. Finally, we investigated ROS production and damage following MWCNT exposure, and identified increased 
ROS production and damage in the IFM 24 hours following exposure. This study suggests that carbon-based ENM exposure induced mitochondrial dysfunction and ROS production, with the IFM most impacted.

ROS is commonly implicated in studies of both xenobiotic exposure and the mitochondrion independently, thus we wanted to investigate the role of mitochondrial ROS in the extrapulmonary toxicity of ENM exposure. In order to accomplish this goal, we utilized a novel transgenic animal, developed within our laboratory, overexpressing the mitochondrial antioxidant mPHGPx and WVU's unique nanomaterial inhalation chamber to expose these animals to the relatively inert ENM, nano-titanium dioxide. Following nano- $\mathrm{TiO}_{2}$ exposure, we observed diastolic dysfunction as indicated by an increase in pulsed-wave Doppler flow indices as well as increased cardiac strain as measured by speckle-tracking based echocardiography. Yet, the diastolic dysfunction observed with exposure was attenuated with overexpression of mPHGPx. We then assessed mitochondrial dysfunction and observed a decrease in the maximal respiratory rate of the IFM following nano- $\mathrm{TiO}_{2}$ exposure, and that was attenuated with overexpression of mPHGPx. Finally, we investigated mitochondrial ROS production and damage following nano-TiO2 exposure and recognized a significant increase in both production and damage in the IFM. Both indices were attenuated with overexpression of mPHGPx; supporting that mPHGPx can protect the heart from xenobiotic indiced damage. This data indicates that acute pulmonary exposure to nano- $\mathrm{TiO}_{2}$ induces diastolic dysfunction concomitant with mitochondrial ROS production and dysfunction in the IFM.

Taken together, this data suggests that xenobiotic particle size and/or chemical composition can impact the extrapulmonary outcomes of an acute pulmonary exposure. Throughout this dissertation we have utilized particles with varying sizes. In the ambient PM $\left(\mathrm{PM}_{\mathrm{MTM}}\right)$ the particle is translational, as it was taken from areas surrounding active MTM mines. Yet this means that the exposure particle is a composite particle encompassing a range of 
sizes. The heterogeneity of the particle makes discussions on the specific particle characteristics responsible for extrapulmonary toxicity difficult. Yet when we compare this heterogenous particle with our homogenous ENMs we can then begin to theorize on the impact size plays. We see differential cardiac and mitochondrial effects between all of the examined particles. In the ambient $\mathrm{PM}_{\mathrm{MTM}}$ our impacts were observed in the SSM and the IFM, yet many indices pointed to a more significant SSM effect. In the MWCNT again both the SSM and IFM were functionally impaired but ROS generation and damage was highlighted in the IFM alone. Finally, nano- $\mathrm{TiO}_{2}$ exposure only impacted the IFM function and oxidative potential. Considering size alone, this data would suggest that larger particles induces pulmonary and extrapulmonary mechanisms that contibute to functional dysfunction in the SSM, yet smaller, nano-sized materials stimulate mechanisms contributing to IFM dysfunction.

This theory stems from the fact that there is a fraction of the PM used within this dissertation that is within the same size fraction as ENMs. Thus the IFM dysfunction induced by $\mathrm{PM}_{\text {MTM }}$ exposure would arise from the mechanisms stimulated by this UFP fraction and the SSM dysfunction is induced by the remaining larger fractions. Taking into account the SSM dysfunction observed with MWCNT exposure challenges this theory, but while MWCNTs fit the definition of nanomaterial, as the width of the tubes is less than $100 \mathrm{~nm}$, the tubes are microns in length and agglomerate. Thus again in this exposure the particle size may stimulate mechanisms leading to both SSM and IFM dysfunction, yet because the MWCNT are of nanosize, IFM effects were predominant. Finally, the nano- $\mathrm{TiO}_{2}$ is the most straightforward as its primary particle size is a nanoparticle in every dimension and best fits the definition. The data from our exposure supports that the nano-size is able to induce IFM dysfunction as this was the only subpopulation impacted by nano- $\mathrm{TiO}_{2}$ exposure. This data suggests that particle size can differentially impact toxicological impact, but further suggests that size alone doesn't dictate effect. 
When considering nanomaterial size and physiochemical properties many studies utilize surface area to compare the biological impacts of ENM exposure. It has been suggested that normalization to surface area is a better predictor of bioactivity than mass or size $(54,67)$. As we observed in Figure 1.1A the surface area of nano-sized particles in the same particle mass is significantly higher than in micron sized particles. The PM studied within this dissertation contains a mixture of micron and nano-sized particles, and without thorough particle characterization the exact surface area isn't known. We can estimate that the surface area is lower in reference to our other particles, and other studies utilizing ambient PM have recorded the surface area of their material. Depending on the filter that was used, one study from Portland, Oregon reported the surface area of their material between 0.82 and $2.4 \mathrm{~m}^{2} / \mathrm{g}(71)$. Estimating the surface area of CNT is also difficult and depends on the number of walls within the particle. A theoretical estimation of CNT surface area identified a very broad range, from 50 to $1315 \mathrm{~m}^{2} / \mathrm{g}$, again depending on the number of walls $(61)$. Finally, with a primary particle size of $21 \mathrm{~nm}$ nano- $\mathrm{TiO}_{2}$ has a surface area of $48.08 \mathrm{~m}^{2} / \mathrm{g}(52,76)$. Considering our data in this context, the lower surface area particle primarily impacted the SSM and the higher surface area particles significantly effected the IFM. And while the theory is not complete simply considering surface area, combining surface area and size helps to delineate the particle characteristics that impact mitochondrial subpopulation response. Thus, this evidence builds on the theory that the particle's physical properties dictate toxicological impact but suggests that size and surface area need to be considered.

Of course size and surface area are not the only difference between the particles, as the chemical composition varies throughout the particle utilized in this dissertation. The ambient $\mathrm{PM}_{\text {MTM }}$ used in Chapter 2 had a heterogenous chemical composition which was high in carbon, silicon and sulfate with traces of metals such as aluminum and iron (37). Previoulsy we have discussed the sizes within ambient PM and related the UFP fraction to ENMs, yet it is important 
to point out the significant differences in composition between these particles. Ambient UFP are heterogenous in size, aggregation state and chemical composition. These particles are generally from combustion sources and include a solid core of either inorganic material or soot surrounded by a layer of absorbed or condensed semi-volatile organic chemicals (66). In contrast, the ENMs utilized within these studies were homogenous. The MWCNTs used were greater than 99 percent carbon and the greatest deviance within the $\mathrm{TiO}_{2}$ was the mineral form ( $80 \%$ anatase and $20 \%$ rutile). The easiest comparison is between the $\mathrm{PM}_{\text {MTM }}$ and MWCNT as they are both comprised mainly of carbon. Interestingly, exposure to these carbon-based materials induced both SSM and IFM functional deficiencies suggesting that exposure to particles high in carbon may induce cardiac mitochondrial dysfunction. Both PM (41) and CNT (85) have been shown to induce mitochondrial dysfunction thus our results are in accordance with previous examination. Previous study has suggested that carbon nanomaterials and titanium dioxide can induce similar endpoints through different mechanisms (33). The data within this dissertation agrees with this study as we observed similar mitochondrial endpoints in both the MWCNT and nano- $\mathrm{TiO}_{2}$ exposure. Combined, these studies make it difficult to speak to the influence of chemical composition on the observed mitochondrial toxicological impacts as they are similar and in accordance with literature but spatially divergent.

As with most acute exposures we observed significant impacts but it is difficult to determine the longevity of these impacts and their impacts on chronic disease. The $\mathrm{PM}_{\text {MTM }}$ dose used is similar to a 1.7 year exposure but given in a matter of seconds. Also, both doses of MWCNT would require exposure over years to reach the exposures utilized in these studies. MWCNT occupational exposures at typical $10 \mu \mathrm{g} / \mathrm{m}^{3}$ would require 19 years of exposure in humans to achieve the pulmonary deposition of even the lowest MWCNT dose (22). The nano$\mathrm{TiO}_{2}$ dose was utilized as previous studies have identifued cardiovascular impacts and is an occupationally relevant dose similar to a human working eight hours per day at the National 
Institute for Occupational Safety and Health current recommended exposure limit for nano- $\mathrm{TiO}_{2}$ $\left(0.3 \mathrm{mg} / \mathrm{m}^{3}\right)$ for approximately one week. Yet with our increasing understanding of nanomaterial impacts this dose could still be considered high. This dosen't decrease the importance of these studies as acute exposures still occur and acute PM effects are well established $(7,64)$. We do need to consider the possibility that the observed effects are due to a bolus effect and with chronic exposures we may see different effects or adaptations rectifying the acute effects that are observed in our studies.

Throughout the time course in the MWCNT exposure we observed a significant increase in the myoglobin concentration and suggested that this could be an adaptation to protect the mitochondria from dysfunction. Myoglobin is increased in response to hypoxia (25) and the combination of work and hypoxia may further stimulate an increase in myoglobin $(35,88)$. Previously exposure to CNT stimulated hypoxia and mitochondrial dysfunction not only suggesting nanomaterials can induce hypoxia but that mitochondrial dysfunction and hypoxia are associated following particulate exposure (85). Intracellular hypoxia can arise from insufficient oxygen delivery occurring either by decreased pulmonary oxygen loading or decreased deliver to the tissue. Pulmonary dysfunction following chronic MWCNT exposure has been identified (86) but in an acute model is highly unlikely. However, impaired coronary microvascular function following MWCNT exposure may suggest decreased delivery of blood and oxygen to the tissue may occur within 24 hours post-exposure and persists through 168 hours (75). While we did not experimentally investigate hypoxia in this MWCNT exposure model taken together these studies suggest acute hypoxia may follow exposure and could induce the observed mitochondrial effects. Further, because we observed similar mitochondrial impacts in following nano- $\mathrm{TiO}_{2}$ exposure, it is interesting to discuss that similar coronary microvascular impacts have been identified following $\mathrm{TiO}_{2}$ exposure (40). Thus, this could suggest that nanomaterials can induce acute cardiac hypoxia as a shared exposure impact. 
Pulmonary impacts leading to extrapulmonary effects are identified but subcellular mechanisms that induce cardiac dysfunction are not well characterized. Throughout this dissertation we highlight cardiac and mitochondrial dysfunction. In pathological models mitochondrial dysfunction precedes muscle dysfunction suggesting that the mitochondrial dysfunction elicits tissue dysfunction $(21,44)$. In our studies, mitochondrial dysfunction is concomitant with cardiac dysfunction making discussion of the relationship between cause and consequence difficult. As previously stated cardiac dysfunction can shadow mitochondrial dysfunction. The mitochondria are essential, yet complex, organelles that not only provide the cell with ATP but also synthesize key molecules, buffer calcium gradients and are a source of free radicals. Sub-organelle dysfunction initiation is difficult to assess in vivo, but in vitro analyses have suggested increased ROS production precedes mitochondrial dysfunction (10, 77). ROS is commonly increased in exposure models $(8,43)$ and could suggest that systemic ROS contributes to increased mitochondrial ROS production leading to mitochondrial dysfunction. Inversely, one study suggests that mitochondrial dysfunction can precede ROS production in pulmonary tissue suggesting in our study mitochondrial dysfunction may initiate ROS production (50). Our time course study of the impacts of MWCNT suggests mitochondrial dysfunction precedes ROS production, but within the other particle exposures we cannot speak to which is the subcellular stimulus and which is the response. Yet considering our data, we suggest that xenobiotic exposure induces mitochondrial dysfunction leading to increased ROS production.

Combining our data and previous literature it is most likely that mitochondrial dysfunction contributes to cardiac dysfunction, but it could also be suggested that cardiac dysfunction could contribute to mitochondrial dysfunction. The mitochondrion is a complex organelle and receives significant input from the nucleus and cytoplasm. Especially within the cardiomyocyte, the exchange of ions, such as calcium, is important for the function of the cell but mitochondrial ion 
handling can impact the organelle's function and apoptotic propensity (55). The cardiovascular system is a highly integrated system regulating and assimilating global pump function, neurohormonal status, vascular properties and systemic hemodynamics. Alteration in any of these components elicits a response in the others to maintain output; in fact, this occurs so predictably that computational models have been developed and curated to estimate cardiovascular adaptations (36). Thus, as seen in hypertension, when blood pressure increases, vascular properties are supplemented to compensate for the pressure and global pump function is altered by increasing pumping strength to overcome the vascular pressure and maintain tissue oxygen delivery. Further, hypertension has been shown to stimulate cardiac mitochondrial dysfunction and ROS production (18, 31). As previously discussed, vascular impairment has been characterized following $\operatorname{ENM}(40,75)$ and PM $(53)$ exposure; thus, cardiac adaptations could arise as compensatory mechanisms to overcome vascular impairments. These adaptations may result in the induction of mitochondrial dysfunction from cardiovascular disruptions. Yet, in Chapter 3 following MWCNT exposure, we observed cardiac dysfunction follows mitochondrial dysfunction; thus, this data supports that mitochondrial dysfunction contributes to cardiac dysfunction. Yet without different time points we cannot confirm this timecourse in other exposure models.

Mitochondrial defects, systemic inflammation, and oxidative stress are central to most noncommunicable diseases such as cancer, atherosclerosis, neurodegenerative diseases, heart and lung disturbances, diabetes, and autoimmune diseases (2, 21, 38, 45, 56-58). During xenobiotic exposures oxidative stress and systemic inflammation are identified $(29,62,80)$, and throughout this dissertation we suggest that mitochondrial defects are also present following exposure. Thus, it is of utility to compare the mitochondrial impacts observed in our study to the mitochondrial effects during pathology. In Chapter 1, we discussed in detail the differential impacts of pathological stimuli on mitochondrial subpopulations, but some of the discussed 
effects are more applicable to the effects observed. Like the studies in this dissertation, some pathologies impact both subpopulations but the effects are most prevalent in one subpopulation. Ischemia/reperfusion injury leads to increased mitochondrial ROS, apoptosis initiation, and mitochondrial dysfunction $(5,74)$, but when we distill out the phases of this injury we see differential effects. During ischemia alone the SSM are predominantly affected $(9,73)$, and, taken together, these studies may relate to the results observed following PM $_{\text {MTM }}$ exposure. Initially the impacts are observed in both SSM and IFM but apoptotic propensity is most impacted at the SSM. This may suggest changes in oxygen concentration stimulate the more preferentially SSM phenomenon as larger changes in oxygen tension are more likely to be experienced by the SSM as compared to IFM (32). Further, this could be applied to the SSM changes observed following MWCNT exposure, and builds on the importance of changes in oxygen tension following xenobiotic exposure.

Conversely, oxygen tension in the center of the cell is much less than at the cell periphery (79), and hypertrophic conditions stimulated by pressure overload more negatively impact the IFM (70). This data may support the studies included within this dissertation that utilize ENMs as they most impacted the IFM, and would suggest decreased oxygen tension following ENM exposure. Further, the increased myoglobin content following MWCNT exposure could support this theory as decreased oxygen tension stimulates myoglobin production (23). However, without the scientific evidence to directly implicate oxygen tension it is unrealistic to assign causality. To date, there are no studies manipulating oxygen tension and investigating the impacts on mitochondrial subpopulations, but a three-dimensional computational cardiomyocyte model that integrates electrophysiology, metabolism, and mechanics with subcellular structure and further includes intracellular oxygen diffusion in order to determine whether mitochondrial localization or intrinsic properties cause functional variations. Utilizing this model the authors suggested that under limited oxygen supply, oxygen is mostly exhausted in 
SSM, leaving the core region in an anoxic condition leading to a decrease in inner membrane potential in the IFM (30). Acute changes in oxygen tension can decrease mitochondrial respiration by up to $50 \%$ and as a compensatory mechanism stimulate hydrogen peroxide production (16). This could support that decreased oxygen tension can differentially impact the IFM and elicit the results observed following exposure to the ENMs, MWCNT and nano- $\mathrm{TiO}_{2}$.

Interestingly, cardiovascular complications and heart disease are the leading cause of morbidity and mortality in patients with diabetes mellitus, and mitochondrial dysfunction is central to the pathogenesis of these complications (24). Diabetes mellitus is characterized by either a lack of insulin (Type 1) or resistance to insulin (Type 2), and there are differential mitochondrial subpopulation impacts during these disease states. During type 1 diabetes the IFM are preferentially impacted: exhibiting increased ROS production (13), increased apoptotic propensity (87) and dysregulated proteomics (3). While in type 2 diabetes the SSM are preferentially affected: exhibiting increased ROS production and dysregulated proteomics (12). Interestingly, the effects observed in a mouse model of type 2 diabetes directly correlate to the effects observed in the human suggesting that mouse models are sufficient predictors of human mitochondrial function (11). Even though both pathologies impart similar deleterious effects on the mitochondria, the resulting milieus are different. These differential effects suggest that different stimuli can elicit similar mitochondrial end-points. Also, this highlights that disparities in the developed stress elicits differential subcellular locale influences, including the mitochondria contained within.

Systemic effects following a pulmonary exposure have been identified and linked to extrapulmonary impacts. Yet these systemic effects can vary between exposures and may include inflammation (20), particle translocation (19) and circulating bioactive factors (1). Within our exposures we did not experimentally investigate the systemic stimuli leading to extrapulmonary effects, but evidence most supports inflammation to lead to these impacts (39, 
48). Especially in an acute setting, the quick response of inflammation to xenobiotic particulates suggests inflammation can play a role in the exposures observed throughout this dissertation. Therefore exposing an animal with suppressed inflammation to xenobiotic particulates would elicit an attenuated response as this is carrying the signals from the lung to the systemic circulation. Yet recent evidence supports that circulating bioactive factors can impact the cardiovascular system even in naïve tissue (1). When the authors knocked out matrix metalloproteinase- 9 the cardiovascular effects of these factors were attenuated suggesting decreased production of bioactive factors and significantly implicating these factors in the initiation of cardiovascular effects (1). Yet systemic effects may not directly dictate end point, as MWCNTs with different physiochemical properties induce similar systemic effects but different tissue responses (65). Thus, it is interesting to identify the differential systemic stressors in each particle exposure in order to better understand the differential cardiac and mitochondrial impacts observed, but may not definitively transcribe into other exposure models.

Because we are investigating extrapulmonary impacts of a pulmonary exposure we can safely assume that signals are being generated at the lungs and transmitted to extrapulmonary tissue. Pulmonary effects such as increased alveolar permeability and inflammation are well characterized, but very rarely is decreased pulmonary function identified in translationally relevant models of xenobiotic exposure. Yet, cardiovascular effects are commonly identified (7) suggesting either systemic effects are more specific to the cardiovascular system or the cardiovascular system is more sensitive to these stressors. In fact, one study comparing pulmonary and cardiac effects concluded that the heart is more susceptible to the oxidative effects induced by xenobiotic exposure (15). Further these authors suggest that the oxidative damage mediated by hydrogen peroxide may be involved in the cardiac toxicity related to PM exposure (15). Highly metabolic demanding tissues as a whole may be preferential targets of 
xenobiotic toxicity and further suggest the disruption of the oxidative milieu as central to the etiology of dysfunction (68).

Throughout this dissertation we highlight that the cardiac mitochondria are impacted following xenobiotic exposure, but the direct mechanisms leading to these effects are transiently discussed. As previously discussed, systemic inflammation most likely champions extrapulmonary effects and a common mechanism utilized by inflammatory cells is ROS. Systemic ROS after xenobiotic exposure follows systemic inflammatory increases and as previously discussed cardiac tissue may be more sensitive to ROS damage (15). Increased ROS damage within the heart helps to explain cardiac functional deficiencies as proteins damaged within the contractile apparatus cannot function as well (4). But differential ROS damage within cardiac mitochondrial subpopulations can begin to explain the differential responses observed following xenobiotic exposure. Due to the location of the SSM, beneath the sarcolemma, and the dysfunction observed following exposure this could support that the initial insult is carried out through inflammation and moves from outside of the cell into the interior. Taken together with the observation that the SSM may have a higher antioxidant profile (32) this could support that ROS damage moving through the cell can lead to dysfunction in both subpopulations with a larger insult or only the IFM when the ROS damage can be handled by the antioxidants within the SSM. Thus the ROS signal created within the lung can permeate to the heart and induce mitochondrial dysfunction but may more frequently lead to IFM dysfunction.

Within the mitochondria there are sub-organelle locales that may also be differentially impacted by ROS. Due to the unstable, radical nature of ROS, the molecules have a short halflife and the sites of origin are most susceptible to damage by these molecules. ROS are most produced as by-products of electron exchange by NADH dehydrogenase (complex 1) and cytochrome c reductase (complex 3 ) within the IMM of the mitochondrion $(78,81)$. Thus the IMM 
and the proteins and lipids that reside within the membrane are most susceptible to ROS damage. This situation suggests that protecting the IMM may be critical in maintaining mitochondrial dysfunction during increased ROS production. MPHGPx is a unique antioxidant as it can reduce free ROS species and their lipid peroxidation by-products. Also it is located within the IMS and capable of preserving the integrity of the membrane by protecting against ROS-mediated dysfunction $(3,14,51)$. Following ENM exposure, we suggested that mPHGPx was able to protect the mitochondria from dysfunction; implicating ROS in the induction of dysfunction and reiterating the protective capabilities of mPHGPx. Ultimately, mPHGPx was also able to restore cardiac function supporting the importance of not only mPHGPx but also protecting the IMM from ROS damage.

Finally, as cardiac function is the functional implication indicated in each study discussion into the relative impacts is critical in this dissertation. The most straightforward impacts are observed in the $\mathrm{PM}_{\mathrm{MTM}}$ exposure: decreased end-systolic volumetric and diametric parameters leading to decreased ejection fraction and fractional shortening. Yet no changes in cardiac output were observed illustrating increased cardiac stress but ultimately maintaining cardiac function. This is relevant to other animal studies $(26,89)$ and indicative of human PM exposures, in which cardiac remodeling without cardiac dysfunction is detected indicative of increased stress (83). With the recent advent of nanotechnology there are no human studies identifying ENM induced cardiac functional deficiencies. Functional analyses following animal exposures to MWCNT and nano- $\mathrm{TiO}_{2}$ are limited but suggest disturbances $(34,91)$. Following nano- $\mathrm{TiO}_{2}$ exposure our results emulate these studies identifying diastolic dysfunction, but in our study we utilized speckle-tracking based echocardiography as a sensitive marker of cardiac function. This data suggested the heart may be stiffer following exposure. Taken together with the mitochondrial dysfunction observed, this supports that the resetting of the contractile apparatus and calcium currents during diastole is an energy intensive process. Thus 
mitochondrial dysfunction correlates with both systolic and diastolic function. Speckle-tracking echocardiography is already being utilized clinically to subtly detect cardiac functional abnormalities earlier in diabetes (72), myocardial ischemia (84), and non-ischemic cardiomyopathies (42) and prediction of patient outcomes with heart failure (28). Thus, utilizing this technique may allow clinicians to detect cardiac abnormalities associated with exposure to ENMs and include exposure as a risk factor for cardiovascular dysfunction.

While speckle-tracking based strain analyses are already clinically used as an early predictor of cardiac abnormalities, the mechanical and biochemical mechanisms that contribute to changes in strain have not been investigated. As discussed in chapter 1 , strain is a complicated measure that, while we use it to discuss cardiac function, is most tightly correlated with cardiomyocyte contractility and relaxation. Relating to both contractility and relaxation are the proteins of the contractile apparatus. Posttranslational modifications induced by ROS damage to the contractile apparatus can impair the function of the cardiomyocyte implicating ROS to induce changes in strain values $(27,46)$. Yet also, of mention in relation to the function of the contractile apparatus and thus the cardiomyocyte is calcium regulation. While calcium currents are most regulated by the sarcoplasmic reticulum, the mitochondrion also plays a large role in calcium handling. Calcium within the mitochondria is a mediator of metabolic and pathological processes (69), but calcium handling also differs between mitochondrial subpopulations and suggests that the IFM are more sensitive to changes in calcium $(59,60)$. Thus changes in calcium may be able to regulate mitochondrial function and impact cardiomyocyte contractility. Also taken together, with the data in this dissertation, implicates cardiac calcium dysregulation following xenobiotic exposure suggesting that ENM exposure especially induces calcium dysregulation leading to impaired contractility, as indicated by changes in the speckle-tracking based strain profile, and mitochondrial dysfunction most pronounced in the IFM. 
The overall summary of this dissertation identifies cardiac and mitochondrial dysfunction following acute pulmonary xenobiotic exposure. Examining cardiac function following exposure to ambient PM taken from areas surrounding active MTM sites ( $\left(\mathrm{PM}_{\mathrm{MTM}}\right)$ suggested decreased cardiac function indicated by decreased ejection fraction and fractional shortening. Investigating the mechanisms that could induce this result, we identified increased cardiomyocyte apoptosis from a mitochondrial source. The mitochondrial apoptotic signaling was suggested to be most pronounced in the SSM with increased apoptotic propensity suggested by increased opening of the mPTP in this subpopulation. Yet mitochondrial respiratory function was decreased in both the SSM and IFM, suggesting that $\mathrm{PM}_{\text {MTM }}$ exposure stimulates mitochondrial impacts with the SSM being unequally impacted. Yet due to the heterogeneous nature of the ambient particle we wanted to use a homogenous material to distill the effect of size on cardiac and mitochondrial impacts. Utilizing a well-characterized MWCNT, we identified that exposure induces notable impacts. These cardiac aberrations were concomitant with increased mitochondrial ROS production and damage in the IFM, and these mitochondrial effects followed mitochondrial dysfunction acutely observed post-MWCNT exposure in both the SSM and IFM. This data suggests that ENMs induce mitochondrial effects, most pronounced in the IFM, which may lead to decreased cardiac function. We then wanted to investigate the role of ROS in the induction of mitochondrial and cardiac dysfunction following ENM exposure. In order to accomplish this we used the mitochondrial antioxidant mPHGPx and the abundant ENM, nano- $\mathrm{TiO}_{2}$. Following exposure we identified cardiac diastolic dysfunction concomitant with increased mitochondrial ROS production and damage in the IFM. This increased ROS damage led to decreased IFM respiratory function. By overexpressing a mitochondrial antioxidant we could attenuate the ROS production and damage to the IFM. Attenuating ROS damage alleviated the identified IFM dysfunction and further diminished the diastolic dysfunction created by nano- $\mathrm{TiO}_{2}$ exposure. This suggests that ROS plays a significant role in the cardiac and mitochondrial dysfunction observed following ENM exposure. Taken together these studies identify that cardiac 
dysfunction is initiated by acute pulmonary exposure to xenobiotic particles, and particle size and surface area may regulate toxic endpoint. Further, this dysfunction may arise from increased mitochondrial ROS leading to mitochondrial dysfunction that may have a spatial aspect. 


\section{REFERENCES}

1. Aragon M, Erdely A, Bishop L, Salmen R, Weaver J, Liu J, Hall P, Eye T, Kodali V, Zeidler-Erdely P, Stafflinger JE, Ottens AK, and Campen MJ. MMP-9-Dependent SerumBorne Bioactivity Caused by Multiwalled Carbon Nanotube Exposure Induces Vascular Dysfunction via the CD36 Scavenger Receptor. Toxicol Sci, 2016.

2. Arduino DM, Esteves AR, and Cardoso SM. Mitochondria drive autophagy pathology via microtubule disassembly: a new hypothesis for Parkinson disease. Autophagy 9: 112-114, 2013.

3. Baseler WA, Dabkowski ER, Jagannathan R, Thapa D, Nichols CE, Shepherd DL, Croston TL, Powell M, Razunguzwa TT, Lewis SE, Schnell DM, and Hollander JM. Reversal of mitochondrial proteomic loss in Type 1 diabetic heart with overexpression of phospholipid hydroperoxide glutathione peroxidase. Am J Physiol Regul Integr Comp Physiol 304: R553-565, 2013.

4. Bayeva $\mathbf{M}$ and Ardehali $\mathbf{H}$. Mitochondrial dysfunction and oxidative damage to sarcomeric proteins. Curr Hypertens Rep 12: 426-432, 2010.

5. Borutaite $\mathbf{V}$ and Brown GC. Mitochondria in apoptosis of ischemic heart. FEBS Lett 541: 1-5, 2003.

6. Brook RD, Franklin B, Cascio W, Hong Y, Howard G, Lipsett M, Luepker R, Mittleman M, Samet J, Smith SC, Jr., Tager I, Expert Panel on P, and Prevention Science of the American Heart A. Air pollution and cardiovascular disease: a statement for healthcare professionals from the Expert Panel on Population and Prevention Science of the American Heart Association. Circulation 109: 2655-2671, 2004.

7. Brook RD, Rajagopalan S, Pope CA, 3rd, Brook JR, Bhatnagar A, Diez-Roux AV, Holguin F, Hong Y, Luepker RV, Mittleman MA, Peters A, Siscovick D, Smith SC, Jr., Whitsel L, Kaufman JD, American Heart Association Council on E, Prevention CotKiCD, Council on Nutrition PA, and Metabolism. Particulate matter air pollution and cardiovascular 
disease: An update to the scientific statement from the American Heart Association. Circulation 121: 2331-2378, 2010.

8. Cassee FR, Mills NL, and Newby DE. Cardiovascular effects of inhaled ultrafine and nano-sized particles. Hoboken, N.J.: Wiley, 2011.

9. Chen Q, Moghaddas S, Hoppel CL, and Lesnefsky EJ. Ischemic defects in the electron transport chain increase the production of reactive oxygen species from isolated rat heart mitochondria. Am J Physiol Cell Physiol 294: C460-466, 2008.

10. Cheng WY, Tong H, Miller EW, Chang CJ, Remington J, Zucker RM, Bromberg PA, Samet JM, and Hofer TP. An integrated imaging approach to the study of oxidative stress generation by mitochondrial dysfunction in living cells. Environ Health Perspect 118: 902-908, 2010.

11. Croston TL, Thapa D, Holden AA, Tveter KJ, Lewis SE, Shepherd DL, Nichols CE, Long DM, Olfert IM, Jagannathan R, and Hollander JM. Functional deficiencies of subsarcolemmal mitochondria in the type 2 diabetic human heart. Am J Physiol Heart Circ Physiol 307: H54-65, 2014.

12. Dabkowski ER, Baseler WA, Williamson CL, Powell M, Razunguzwa TT, Frisbee JC, and Hollander JM. Mitochondrial dysfunction in the type 2 diabetic heart is associated with alterations in spatially distinct mitochondrial proteomes. Am J Physiol Heart Circ Physiol 299: H529-540, 2010.

13. Dabkowski ER, Williamson CL, Bukowski VC, Chapman RS, Leonard SS, Peer CJ, Callery PS, and Hollander JM. Diabetic cardiomyopathy-associated dysfunction in spatially distinct mitochondrial subpopulations. Am J Physiol Heart Circ Physiol 296: H359-369, 2009.

14. Dabkowski ER, Williamson CL, and Hollander JM. Mitochondria-specific transgenic overexpression of phospholipid hydroperoxide glutathione peroxidase (GPx4) attenuates ischemia/reperfusion-associated cardiac dysfunction. Free Radic Biol Med 45: 855-865, 2008. 
15. Damiani RM, Piva MO, Petry MR, Saldiva PHN, de Oliveira ATD, and Rhoden CR. Is cardiac tissue more susceptible than lung to oxidative effects induced by chronic nasotropic instillation of residual oil fly ash (ROFA)? Toxicol Mech Method 22: 533-539, 2012.

16. Di Maria CA, Bogoyevitch MA, McKitrick DJ, Arnolda LF, Hool LC, and Arthur PG. Changes in oxygen tension affect cardiac mitochondrial respiration rate via changes in the rate of mitochondrial hydrogen peroxide production. J Mol Cell Cardiol 47: 49-56, 2009.

17. Dockery DW and Pope CA, 3rd. Acute respiratory effects of particulate air pollution. Annu Rev Public Health 15: 107-132, 1994.

18. Eirin A, Lerman A, and Lerman LO. Mitochondrial injury and dysfunction in hypertension-induced cardiac damage. Eur Heart J 35: 3258-3266, 2014.

19. Elder A and Oberdorster G. Translocation and effects of ultrafine particles outside of the lung. Clin Occup Environ Med 5: 785-796, 2006.

20. Elder AC, Gelein R, Azadniv M, Frampton M, Finkelstein J, and Oberdorster G. Systemic effects of inhaled ultrafine particles in two compromised, aged rat strains. Inhal Toxicol 16: 461-471, 2004.

21. Enache I, Charles AL, Bouitbir J, Favret F, Zoll J, Metzger D, Oswald-Mammosser M, Geny B, and Charloux A. Skeletal muscle mitochondrial dysfunction precedes right ventricular impairment in experimental pulmonary hypertension. Mol Cell Biochem 373: 161170, 2013.

22. Erdely A, Dahm M, Chen BT, Zeidler-Erdely PC, Fernback JE, Birch ME, Evans DE, Kashon ML, Deddens JA, Hulderman T, Bilgesu SA, Battelli L, Schwegler-Berry D, Leonard HD, McKinney W, Frazer DG, Antonini JM, Porter DW, Castranova V, and Schubauer-Berigan MK. Carbon nanotube dosimetry: from workplace exposure assessment to inhalation toxicology. Part Fibre Toxicol 10: 53, 2013. 
23. Fraser J, de Mello LV, Ward D, Rees HH, Williams DR, Fang Y, Brass A, Gracey AY, and Cossins AR. Hypoxia-inducible myoglobin expression in nonmuscle tissues. Proc Natl Acad Sci U S A 103: 2977-2981, 2006.

24. Garcia MJ, McNamara PM, Gordon T, and Kannel WB. Morbidity and mortality in diabetics in the Framingham population. Sixteen year follow-up study. Diabetes 23: 105-111, 1974.

25. Garry DJ, Ordway GA, Lorenz JN, Radford NB, Chin ER, Grange RW, Bassel-Duby R, and Williams RS. Mice without myoglobin. Nature 395: 905-908, 1998.

26. Gorr MW, Velten M, Nelin TD, Youtz DJ, Sun Q, and Wold LE. Early life exposure to air pollution induces adult cardiac dysfunction. Am J Physiol Heart Circ Physiol 307: H13531360, 2014.

27. Hamdani N, Kooij V, van Dijk S, Merkus D, Paulus WJ, Remedios CD, Duncker DJ, Stienen GJ, and van der Velden J. Sarcomeric dysfunction in heart failure. Cardiovasc Res 77: 649-658, 2008.

28. Hare JL, Brown JK, and Marwick TH. Association of myocardial strain with left ventricular geometry and progression of hypertensive heart disease. Am J Cardiol 102: 87-91, 2008.

29. Hartz AM, Bauer B, Block ML, Hong JS, and Miller DS. Diesel exhaust particles induce oxidative stress, proinflammatory signaling, and P-glycoprotein up-regulation at the blood-brain barrier. FASEB J 22: 2723-2733, 2008.

30. Hatano A, Okada J, Washio T, Hisada T, and Sugiura S. Distinct functional roles of cardiac mitochondrial subpopulations revealed by a 3D simulation model. Biophys $J$ 108: 27322739, 2015.

31. Hickey AJ, Chai CC, Choong SY, de Freitas Costa S, Skea GL, Phillips AR, and Cooper GJ. Impaired ATP turnover and ADP supply depress cardiac mitochondrial respiration 
and elevate superoxide in nonfailing spontaneously hypertensive rat hearts. Am J Physiol Cell Physiol 297: C766-774, 2009.

32. Hollander JM, Thapa D, and Shepherd DL. Physiological and structural differences in spatially distinct subpopulations of cardiac mitochondria: influence of cardiac pathologies. Am J Physiol Heart Circ Physiol 307: H1-14, 2014.

33. Hussain S, Thomassen LC, Ferecatu I, Borot MC, Andreau K, Martens JA, Fleury J, Baeza-Squiban A, Marano F, and Boland S. Carbon black and titanium dioxide nanoparticles elicit distinct apoptotic pathways in bronchial epithelial cells. Part Fibre Toxicol 7: 10, 2010.

34. Kan H, Wu Z, Lin YC, Chen TH, Cumpston JL, Kashon ML, Leonard S, Munson AE, and Castranova V. The role of nodose ganglia in the regulation of cardiovascular function following pulmonary exposure to ultrafine titanium dioxide. Nanotoxicology 8: 447-454, 2014.

35. Kanatous SB, Mammen PP, Rosenberg PB, Martin CM, White MD, Dimaio JM, Huang G, Muallem S, and Garry DJ. Hypoxia reprograms calcium signaling and regulates myoglobin expression. Am J Physiol Cell Physiol 296: C393-402, 2009.

36. Kim YT, Lee JS, Youn $\mathbf{C H}$, Choi JS, and Shim EB. An integrative model of the cardiovascular system coupling heart cellular mechanics with arterial network hemodynamics. $J$ Korean Med Sci 28: 1161-1168, 2013.

37. Knuckles TL, Stapleton PA, Minarchick VC, Esch L, McCawley M, Hendryx M, and Nurkiewicz TR. Air pollution particulate matter collected from an Appalachian mountaintop mining site induces microvascular dysfunction. Microcirculation 20: 158-169, 2013.

38. Kumar H, Lim HW, More SV, Kim BW, Koppula S, Kim IS, and Choi DK. The role of free radicals in the aging brain and Parkinson's Disease: convergence and parallelism. Int $\mathrm{J}$ Mol Sci 13: 10478-10504, 2012.

39. Langrish JP, Bosson J, Unosson J, Muala A, Newby DE, Mills NL, Blomberg A, and Sandstrom T. Cardiovascular effects of particulate air pollution exposure: time course and underlying mechanisms. J Intern Med 272: 224-239, 2012. 
40. LeBlanc AJ, Moseley AM, Chen BT, Frazer D, Castranova V, and Nurkiewicz TR. Nanoparticle inhalation impairs coronary microvascular reactivity via a local reactive oxygen species-dependent mechanism. Cardiovasc Toxicol 10: 27-36, 2010.

41. Li R, Kou X, Geng H, Xie J, Yang Z, Zhang Y, Cai Z, and Dong C. Effect of ambient $\mathrm{PM}(2.5)$ on lung mitochondrial damage and fusion/fission gene expression in rats. Chem Res Toxicol 28: 408-418, 2015.

42. Liang HY, Cauduro S, Pellikka P, Wang J, Urheim S, Yang EH, Rihal C, Belohlavek M, Khandheria B, Miller FA, and Abraham TP. Usefulness of two-dimensional speckle strain for evaluation of left ventricular diastolic deformation in patients with coronary artery disease. Am J Cardiol 98: 1581-1586, 2006.

43. Lim HB, Ichinose T, Miyabara Y, Takano H, Kumagai Y, Shimojyo N, Devalia JL, and Sagai M. Involvement of superoxide and nitric oxide on airway inflammation and hyperresponsiveness induced by diesel exhaust particles in mice. Free Radic Biol Med 25: 635644, 1998.

44. Lucas DT, Aryal P, Szweda LI, Koch WJ, and Leinwand LA. Alterations in mitochondrial function in a mouse model of hypertrophic cardiomyopathy. Am J Physiol Heart Circ Physiol 284: H575-583, 2003.

45. Medina-Gomez G. Mitochondria and endocrine function of adipose tissue. Best Pract Res Clin Endocrinol Metab 26: 791-804, 2012.

46. Messer AE, Jacques AM, and Marston SB. Troponin phosphorylation and regulatory function in human heart muscle: dephosphorylation of Ser23/24 on troponin I could account for the contractile defect in end-stage heart failure. J Mol Cell Cardiol 42: 247-259, 2007.

47. Miller KA, Siscovick DS, Sheppard L, Shepherd K, Sullivan JH, Anderson GL, and Kaufman JD. Long-term exposure to air pollution and incidence of cardiovascular events in women. N Engl J Med 356: 447-458, 2007. 
48. Miller MR, Shaw CA, and Langrish JP. From particles to patients: oxidative stress and the cardiovascular effects of air pollution. Future Cardiol 8: 577-602, 2012.

49. Moller P, Danielsen PH, Karottki DG, Jantzen K, Roursgaard M, Klingberg H, Jensen DM, Christophersen DV, Hemmingsen JG, Cao Y, and Loft S. Oxidative stress and inflammation generated DNA damage by exposure to air pollution particles. Mutat Res Rev Mutat Res 762: 133-166, 2014.

50. Nicolescu AC, Ji Y, Comeau JL, Hill BC, Takahashi T, Brien JF, Racz WJ, and Massey TE. Direct mitochondrial dysfunction precedes reactive oxygen species production in amiodarone-induced toxicity in human peripheral lung epithelial HPL1A cells. Toxicol Appl Pharmacol 227: 370-379, 2008.

51. Nomura K, Imai H, Koumura T, Kobayashi T, and Nakagawa Y. Mitochondrial phospholipid hydroperoxide glutathione peroxidase inhibits the release of cytochrome c from mitochondria by suppressing the peroxidation of cardiolipin in hypoglycaemia-induced apoptosis. Biochem J 351: 183-193, 2000.

52. Nurkiewicz TR, Porter DW, Hubbs AF, Cumpston JL, Chen BT, Frazer DG, and Castranova V. Nanoparticle inhalation augments particle-dependent systemic microvascular dysfunction. Part Fibre Toxicol 5: 1, 2008.

53. Nurkiewicz TR, Porter DW, Hubbs AF, Stone S, Moseley AM, Cumpston JL, Goodwill AG, Frisbee SJ, Perrotta PL, Brock RW, Frisbee JC, Boegehold MA, Frazer DG, Chen BT, Castranova V, and Committee HEIHR. Pulmonary particulate matter and systemic microvascular dysfunction. Res Rep Health Eff Inst: 3-48, 2011.

54. Oberdorster G, Ferin J, and Lehnert BE. Correlation between Particle-Size, in-Vivo Particle Persistence, and Lung Injury. Environmental Health Perspectives 102: 173-179, 1994.

55. Orrenius S, Gogvadze V, and Zhivotovsky B. Calcium and mitochondria in the regulation of cell death. Biochem Biophys Res Commun 460: 72-81, 2015. 
56. Osellame LD, Blacker TS, and Duchen MR. Cellular and molecular mechanisms of mitochondrial function. Best Pract Res Clin Endocrinol Metab 26: 711-723, 2012.

57. Ouyang J, Wu M, Huang C, Cao L, and Li G. Overexpression of oxidored-nitro domain containing protein 1 inhibits human nasopharyngeal carcinoma and cervical cancer cell proliferation and induces apoptosis: Involvement of mitochondrial apoptotic pathways. Oncol Rep 29: 79-86, 2013.

58. Pagano G, Castello G, and Pallardo FV. Sjogren's syndrome-associated oxidative stress and mitochondrial dysfunction: prospects for chemoprevention trials. Free Radic Res 47: 71-73, 2013.

59. Palmer JW, Tandler B, and Hoppel CL. Heterogeneous response of subsarcolemmal heart mitochondria to calcium. Am J Physiol 250: H741-748, 1986.

60. Papanicolaou KN, Ngoh GA, Dabkowski ER, O'Connell KA, Ribeiro RF, Jr., Stanley WC, and Walsh K. Cardiomyocyte deletion of mitofusin-1 leads to mitochondrial fragmentation and improves tolerance to ROS-induced mitochondrial dysfunction and cell death. Am J Physiol Heart Circ Physiol 302: H167-179, 2012.

61. Peigney A, Laurent C, Flahaut E, Bacsa RR, and Rousset A. Specific surface area of carbon nanotubes and bundles of carbon nanotubes. Carbon 39: 507-514, 2001.

62. Peretz A, Peck EC, Bammler TK, Beyer RP, Sullivan JH, Trenga CA, Srinouanprachnah S, Farin FM, and Kaufman JD. Diesel exhaust inhalation and assessment of peripheral blood mononuclear cell gene transcription effects: an exploratory study of healthy human volunteers. Inhal Toxicol 19: 1107-1119, 2007.

63. Pope CA, 3rd, Burnett RT, Thurston GD, Thun MJ, Calle EE, Krewski D, and Godleski JJ. Cardiovascular mortality and long-term exposure to particulate air pollution: epidemiological evidence of general pathophysiological pathways of disease. Circulation 109: 71-77, 2004. 
64. Pope CA, 3rd, Thun MJ, Namboodiri MM, Dockery DW, Evans JS, Speizer FE, and Heath CW, Jr. Particulate air pollution as a predictor of mortality in a prospective study of U.S. adults. Am J Respir Crit Care Med 151: 669-674, 1995.

65. Poulsen SS, Saber AT, Williams A, Andersen O, Kobler C, Atluri R, Pozzebon ME, Mucelli SP, Simion M, Rickerby D, Mortensen A, Jackson P, Kyjovska ZO, Molhave K, Jacobsen NR, Jensen KA, Yauk CL, Wallin H, Halappanavar S, and Vogel U. MWCNTs of different physicochemical properties cause similar inflammatory responses, but differences in transcriptional and histological markers of fibrosis in mouse lungs. Toxicol Appl Pharmacol 284: 16-32, 2015.

66. Quinton LJ, Nelson S, Zhang P, Boe DM, Happel KI, Pan W, and Bagby GJ. Selective transport of cytokine-induced neutrophil chemoattractant from the lung to the blood facilitates pulmonary neutrophil recruitment. Am J Physiol Lung Cell Mol Physiol 286: L465-472, 2004.

67. Sager TM and Castranova V. Surface area of particle administered versus mass in determining the pulmonary toxicity of ultrafine and fine carbon black: comparison to ultrafine titanium dioxide. Particle and Fibre Toxicology 6, 2009.

68. Sardao VA, Pereira SL, and Oliveira PJ. Drug-induced mitochondrial dysfunction in cardiac and skeletal muscle injury. Expert Opin Drug Saf 7: 129-146, 2008.

69. Scheffler IE. Mitochondria. Hoboken, N.J.: Wiley-Liss, 2008.

70. Schwarzer M, Schrepper A, Amorim PA, Osterholt M, and Doenst T. Pressure overload differentially affects respiratory capacity in interfibrillar and subsarcolemmal mitochondria. Am J Physiol Heart Circ Physiol 304: H529-537, 2013.

71. Sheffield AE and Pankow JF. Specific surface area of urban atmospheric particulate matter in portland, Oregon. Environ Sci Technol 28: 1759-1766, 1994.

72. Shepherd DL, Nichols CE, Croston TL, McLaughlin SL, Petrone AB, Lewis SE, Thapa D, Long DM, Dick GM, and Hollander JM. Early detection of cardiac dysfunction in the 
type 1 diabetic heart using speckle-tracking based strain imaging. J Mol Cell Cardiol 90: 74-83, 2016.

73. Shin G, Sugiyama M, Shoji T, Kagiyama A, Sato H, and Ogura R. Detection of mitochondrial membrane damages in myocardial ischemia with ESR spin labeling technique. $J$ Mol Cell Cardiol 21: 1029-1036, 1989.

74. Solaini G and Harris DA. Biochemical dysfunction in heart mitochondria exposed to ischaemia and reperfusion. Biochem J 390: 377-394, 2005.

75. Stapleton PA, Minarchick VC, Cumpston AM, McKinney W, Chen BT, Sager TM, Frazer DG, Mercer RR, Scabilloni J, Andrew ME, Castranova V, and Nurkiewicz TR. Impairment of coronary arteriolar endothelium-dependent dilation after multi-walled carbon nanotube inhalation: a time-course study. Int J Mol Sci 13: 13781-13803, 2012.

76. Stapleton PA, Nichols CE, Yi J, McBride CR, Minarchick VC, Shepherd DL, Hollander JM, and Nurkiewicz TR. Microvascular and mitochondrial dysfunction in the female F1 generation after gestational TiO2 nanoparticle exposure. Nanotoxicology 9: 941-951, 2015.

77. Suematsu N, Tsutsui H, Wen J, Kang D, Ikeuchi M, Ide T, Hayashidani S, Shiomi T, Kubota T, Hamasaki N, and Takeshita A. Oxidative stress mediates tumor necrosis factoralpha-induced mitochondrial DNA damage and dysfunction in cardiac myocytes. Circulation 107: 1418-1423, 2003.

78. Sugioka K, Nakano M, Totsune-Nakano H, Minakami H, Tero-Kubota S, and Ikegami Y. Mechanism of $\mathrm{O} 2-$ generation in reduction and oxidation cycle of ubiquinones in a model of mitochondrial electron transport systems. Biochim Biophys Acta 936: 377-385, 1988.

79. Takahashi E, Sato K, Endoh H, Xu ZL, and Doi K. Direct observation of radial intracellular PO2 gradients in a single cardiomyocyte of the rat. Am J Physiol 275: H225-233, 1998.

80. Tamagawa E, Bai N, Morimoto K, Gray C, Mui T, Yatera K, Zhang X, Xing L, Li Y, Laher I, Sin DD, Man SF, and van Eeden SF. Particulate matter exposure induces persistent 
lung inflammation and endothelial dysfunction. Am J Physiol Lung Cell Mol Physiol 295: L79-85, 2008.

81. Turrens JF and Boveris A. Generation of superoxide anion by the NADH dehydrogenase of bovine heart mitochondria. Biochem J 191: 421-427, 1980.

82. Valavanidis A, Fiotakis K, and Vlachogianni T. Airborne particulate matter and human health: toxicological assessment and importance of size and composition of particles for oxidative damage and carcinogenic mechanisms. J Environ Sci Health C Environ Carcinog Ecotoxicol Rev 26: 339-362, 2008.

83. Van Hee VC, Adar SD, Szpiro AA, Barr RG, Bluemke DA, Diez Roux AV, Gill EA, Sheppard L, and Kaufman JD. Exposure to traffic and left ventricular mass and function: the Multi-Ethnic Study of Atherosclerosis. Am J Respir Crit Care Med 179: 827-834, 2009.

84. Voigt JU, Exner B, Schmiedehausen K, Huchzermeyer C, Reulbach U, Nixdorff U, Platsch G, Kuwert T, Daniel WG, and Flachskampf FA. Strain-rate imaging during dobutamine stress echocardiography provides objective evidence of inducible ischemia. Circulation 107: 2120-2126, 2003.

85. Wang LR, Xue X, Hu XM, Wei MY, Zhang CQ, Ge GL, and Liang XJ. Structuredependent mitochondrial dysfunction and hypoxia induced with single-walled carbon nanotubes. Small 10: 2859-2869, 2014.

86. Wang X, Katwa P, Podila R, Chen P, Ke PC, Rao AM, Walters DM, Wingard CJ, and Brown JM. Multi-walled carbon nanotube instillation impairs pulmonary function in C57BL/6 mice. Part Fibre Toxicol 8: 24, 2011.

87. Williamson CL, Dabkowski ER, Baseler WA, Croston TL, Alway SE, and Hollander JM. Enhanced apoptotic propensity in diabetic cardiac mitochondria: influence of subcellular spatial location. Am J Physiol Heart Circ Physiol 298: H633-642, 2010. 
88. Wittenberg BA. Both hypoxia and work are required to enhance expression of myoglobin in skeletal muscle. Focus on "Hypoxia reprograms calcium signaling and regulates myoglobin expression". Am J Physiol Cell Physiol 296: C390-392, 2009.

89. Wold LE, Ying Z, Hutchinson KR, Velten M, Gorr MW, Velten C, Youtz DJ, Wang A, Lucchesi PA, Sun Q, and Rajagopalan S. Cardiovascular remodeling in response to long-term exposure to fine particulate matter air pollution. Circ Heart Fail 5: 452-461, 2012.

90. Xia T, Kovochich M, and Nel AE. Impairment of mitochondrial function by particulate matter (PM) and their toxic components: implications for PM-induced cardiovascular and lung disease. Front Biosci 12: 1238-1246, 2007.

91. Zheng W, McKinney W, Kashon M, Salmen R, Castranova V, and Kan H. The influence of inhaled multi-walled carbon nanotubes on the autonomic nervous system. Part Fibre Toxicol 13: 8, 2016. 


\section{CURRICULUM VITAE}

\section{Cody E. Nichols}

\section{OFFICE ADDRESS}

RESIDENT ADDRESS

Division of Exercise Physiology and

928 C Stewart Street

Center for Cardiovascular and

Morgantown WV 26505

Respiratory Sciences

Tel: (304) 488-9390

West Virginia School of Medicine

P.O. Box 9227

Morgantown, WV 26506

Tel: (304) 293-7311

Fax: (304) 293-7105

Email: cenichols@hsc.wvu.edu

\section{EDUCATION}

May 2016

Biomedical Sciences, Division of Exercise Physiology

West Virginia University School of Medicine

Dissertation: Cardiac and Mitochondrial Impacts of Acute

Pulmonary Xenobiotic Exposure.

May 2010

Bachelor of Science, Biology

Department of Biology

West Virginia Wesleyan College 


\section{HONORS AND FELLOWSHIPS}

2016

2015

2015

2014

2014

2014

2013

WVU Exercise Physiology Outstanding Graduate Student

Award

Cardiovascular Toxicology Specialty Section Outstanding Graduate Student Abstract

West Virginia University School of Medicine Biomedical Sciences Travel Award

Allegheny-Erie Society of Toxicology Annual Meeting Best Graduate Student Poster Presentation

Allegheny-Erie Regional Chapter Student Travel Award

West Virginia University School of Medicine Biomedical

Sciences Travel Award

American Association for the Advancement of

Science/Science Program for Excellence in Science Scholarship 
National Science Foundation's Research and Education in Nanotoxicology Interdisciplinary Graduate Education and Research Traineeship Fellow

2012

West Virginia University School of Medicine

Biomedical Sciences Travel Award

2012

Allegheny-Erie Chapter Society of Toxicology Best

Methodology for poster presentation at Annual Meeting

2012

$\mathrm{NIH}$ Predoctoral Training Grant in Cardiovascular and Pulmonary Disease (T32) - Offered

2009

Beta Beta Beta National Biological Honor Society Induction

2006

Boy Scouts of America Eagle Scout Rank

PROFESSIONAL SOCIETIES
2014-Present
Society of Toxicology
2012-2013
American Physiological Society
2012-Present
American Heart Association 
2012-Present

2011-Present

2013-Present
Allegheny-Erie Society of Toxicology

Cardiovascular and Respiratory Sciences Center at West Virginia University

Cell Biology Training Program, West Virginia University

\section{SPECIALIZED TRAINING}

2011

Workshop on Surgical Techniques in the Laboratory

Mouse. The Jackson Laboratory. Bar Harbor, Maine.

\section{LEADERSHIP POSITIONS}

2014-2016

Allegheny-Erie Society of Toxicology Student Representative

2014-2016

Society of Toxicology Graduate Student Leadership

Committee

2014-2015

West Virginia University's Health Sciences Center Graduate Student Organization President Emeritus

2013-2014

West Virginia University's Health Sciences Center Graduate Student Organization President. 


\section{GRANTS}

American Heart Association Predoctoral Fellowship

Role: Principal Investigator

Funded: July 2013 - June 2015

National Science Foundation's Research and Education in Nanotoxicology Interdisciplinary Graduate Education and Research Traineeship Fellow

Role: Predoctoral Fellow

Funded: August 2012 - June 2013

Environmental Protection Agency Science To Achieve Results (STAR) Fellowship Program

Role: Principal Investigator

Score: "Very Good"

NIH Predoctoral Training Grant in Cardiovascular and Pulmonary Disease (T32)

Role: Predoctoral Fellow

Funded: Admitted but Declined Offer 


\section{PRESENTATIONS}

Oral

Nichols C.E., Erdely A., Shepherd D.L., Thapa D., Salmen R., McLoughlin C., Sager T., Roberts J.R., Hollander J.M. Carbon-based nanomaterials impact cardiac mitochondrial function following pulmonary exposure. Van Liere Convocation, West Virginia University. February 2014.

Nichols C. E., Baseler W.A., Thapa D., LaFata G.L., Croston T.L., Shepherd D.L., Lewis S.L., Knuckles T.L., McCawley M., Hendryx M., Nurkiewicz T.R., Hollander J.M. Effect of mountain-top mining particulate exposure on function and apoptotic propensity of distinct subcellular species of mitochondria. AESOT 2012.

Video

Nichols C. E., Dymacek J., Pisane K., Shamitko-Klingensmith N. Does size matter? Connecting materials and biological researchers to understand how nanomaterials interact with life. NSF IGERT Video Competition 2013. 


\section{PUBLICATIONS}

\section{Articles}

Nichols C.E., Shepherd D.L., Knuckles T.L., Thapa D., Stricker J.C., Stapleton P.A., Minarchick V.C., Erdely A., Zeidler-Erdely P.C., Alway S.E., Nurkiewicz T.R. and. Hollander J.M. Cardiac and Mitochondrial Dysfunction Following Acute Pulmonary Exposure to Mountaintop Removal Mining Particulate Matter Am J Physiol Heart Circ Physiol. 2015 Oct 23:ajpheart.00353.2015. doi: 10.1152/ajpheart.00353.2015.

O'Connell G.C., Nichols C.E., Guo G., Croston T.L., Thapa D., Hollander J.M., and Pistilli E.E. IL-15Ra deficiency in skeletal muscle alters respiratory function and the proteome of mitochondrial subpopulations independent of changes to the mitochondrial genome. Mitochondrion. 2015 Nov;25:87-97. doi: 10.1016/j.mito.2015.10.004.

Shepherd D.L., Nichols C.E., Croston T.L., Thapa D., Baseler W.A., Lewis S.E., Hollander J.M. Longitudinal assessment of type I diabetes mellitus using conventional echocardiography and speckle-tracking based strain imaging. J Mol Cell Cardiol. 2016 Jan;90:74-83. doi: 10.1016/j.yjmcc.2015.12.001. Epub 2015 Dec 3. 
Jagannathan R., Thapa D., Nichols C., Shepherd D., Baseler W., Croston T., Lewis S., Hollander J. Translational Regulation of the Mitochondrial Genome Following Redistribution of Mitochondrial MicroRNA (MitomiR) in the Diabetic Heart. Circ Cardiovasc Genet. 2015 Sep 16 pii: CIRCGENETICS.115.001067.

Thapa D., Nichols C.E., Lewis S.E., Shepherd D.L., Jagannathan R., Croston T.L., Tveter K.J., Holden A.A., Baseler W.A., Hollander J.M. Transgenic overexpression of mitofilin attenuates diabetes mellitus-associated cardiac and mitochondria dysfunction. J Mol Cell Cardiol 2015 Feb;79:212-23. doi: 10.1016/j.yjmcc.2014.11.008. Epub 2014 Nov 22.

Stapleton P.A., Nichols C.E., Yi J., McBride C.R., Minarchick V.C., Shepherd D.L., Hollander J.M., Nurkiewicz T.R. Microvascular and Mitochondrial Dysfunction in the FemaleF1 Generation after Gestational $\mathrm{TiO} 2$ Nanoparticle Exposure. Nanotoxicology. 2015 Nov;9(8):941-51. doi: 10.3109/17435390.2014.984251. Epub 2015 Sep 4. 
Croston T.L., Holden A.A., Tveter K.J., Thapa D., Lewis S.E., Shepherd D.L., Nichols C.E., Long D.M., Olfert I.M., Jagannathan R., Hollander J.M. Functional Deficiencies of Subsarcolemmal Mitochondria in the Type 2 Diabetic Human Heart. Am J Physiol Heart Circ Physiol 2014 Jul 1;307(1):H54-65.

Croston T.L., Shepherd D.L., Jagannathan R., Thapa D., Nichols C.E., Dabkowski E.R., Lewis S.E., Hollander J.M. Evaluation of the cardiolipin biosynthetic pathway and its interactions in the diabetic heart. Life Sci 2013 Sep;93(8):313-22.

Chen F., Hadfield J.M., Berzingi C., Hollander J.M., Miller D.B., Nichols C.E., Finkel M.S. N-acetylcysteine Reverses Cardiac Myocyte Dysfunction in a Rodent Model of Behavioral Stress. J Appl Physiol. 2013 Aug;115(4):514-24.

Baseler W.A., Dabkowski E.R., Jagannathan R., Thapa D., Nichols C.E., Shepherd D.L., Croston T.L., Powell M., Razunguzwa T.T., Lewis S.E., Schnell D.M., Hollander J.H. Reversal of Mitochondrial Proteomic Loss in Type 1 Diabetic Heart with Overexpression of Phospholipid Hydroperoxide Glutathione Peroxidase. Am J Physiol Regul Integr Comp Physiol 2013 Apr;304(7):R553-65. 


\section{Abstracts}

Nichols C.E., Hollander J.M., Engels K., McBride C.R., Yi J., Shepherd D.L., Abukabda A.B., Stapleton P.A., Nurkiewicz T.R. Maternal Engineered Nanomaterial Inhalation During Gestation Alters the Fetal Transcriptome. Society of Toxicology March 2016.

Nichols C.E., Thapa D., Shepherd D.L., Knuckles T.L., Erdely A., Zeidler-Erdely P.C., Nurkiewicz T.R., Hollander J.M. Mitochondrial microRNA Dysregulation Contributes to Acute Cardiac Dysfunction following Pulmonary Mountaintop Mining Particulate Matter Exposure. Toxicologist 2015 144(1):343

Erdely A., Antonini J.M., Tugendreich S., Shah S., Nichols C.E., Hollander J.M., Salmen R., Liston A., Eye T., Simeonova P.P., Kashon M.L., Li S., Stone S., Chen B.T., Frazer D.G. and ZeidlerErdely P.C.. Temporal Evaluation of Multicompartment Molecular Signaling following an Inhalation Exposure to Metal-Rich Particulate Matter. SOT 2015. Abstract 1584

Shepherd D.L., Croston T.L., Holden A.A., Tveter K.J., Thapa D., Nichols C.E., Long D.M., Olfert I.M., Hollander J.M. Hyperglycemia and Hemoglobin A1c: Can They Serve as Clinical Predictors of Cardiac Mitochondrial Dysfunction in the Type 2 Diabetic Patient? Appalachian Regional Cell Conference, Marshall University. November 2014. 
Zambito J.L., Nichols C.E., Barnes K.M., Spooner H.S. and Hollander J.M Influence of Weight Loss on Skeletal Muscle Mitochondrial Function in the Mature Horse. Equine Veterinary Journal June 2014 46:S46 (30)

Shepherd D.L., Croston T.L., Holden A.A., Tveter K.J., Thapa D., Nichols C.E., Long D.M., Olfert I.M., Hollander J.M. Mitochondrial Dysfunction in the Type II Diabetic Patient: A different viewpoint. American Association of Pharmaceutical Scientists, West Virginia University. May 2014.

Nichols C.E., Erdely A., Shepherd D.L., Thapa D., Salmen R., McLoughlin C., Sager T., Roberts J.R., Hollander J.M. Pulmonary Exposure to Carbon-Based Nanomaterials induces Spatially-distinct Cardiac Mitochondrial Dysfunction. AESOT. May 2014.

Shepherd D.L., Croston T.L., Holden A.A., Tveter K.J., Thapa D., Nichols C.E., Long D.M., Olfert I.M., Hollander J.M. The Type 2 Diabetic Patient and Cardiac Mitochondrial Dysfunction: A new perspective. FASEB J. 2014 28:688.10. 
Nichols C.E., Erdely A., Shepherd D.L., Thapa D., Salmen R., McLoughlin C., Sager T., Roberts J.R., Hollander J.M. Spatially-distinct cardiac mitochondrial dysfunction following pulmonary exposure to various carbon-based nanomaterials. Toxicologist 2014 138(1):127.

Nurkiewicz T.R., Stapleton P.A., Nichols C.E., Yi J., Minarchick V.C., Hollander J.M. Gestational nanomaterial exposure: what does the future hold? Toxicologist 2014 138(1):440

Zambito J.L., Spooner H.S., Nichols C.E., Hoffman R.M., Hollander J.M., Barnes K.M. Influence of Weight Loss on Skeletal Muscle Mitochondrial Function and Metabolism in the Mature Horse. American Society of Animal Science March 2014.

Nichols C.E., Erdely A., Shepherd D.L., Thapa D., Salmen R., McLoughlin C., Sager T., Roberts J.R., Hollander J.M. Carbon-based nanomaterials impact cardiac mitochondrial function following pulmonary exposure. Van Liere Convocation, West Virginia University. February 2014. 
Shepherd D.L., Croston T.L., Holden A.A., Tveter K.J., Thapa D., Nichols C.E., Long D.M., Olfert I.M., Hollander J.M. Cardiac Mitochondrial Dysfunction in the Type 2 Diabetic Patient: A new perspective. Van Liere Convocation, West Virginia University. February 2014.

Thapa D., Nichols C.E., Shepherd D.L., Hollander J.M. Overexpression of mitofilin restores cardiac contractile function during a type 1 diabetic insult. Van Liere Convocation, West Virginia University. February 2014.

Shepherd D.L., Croston T.L., Holden A.A., Tveter K.J., Thapa D., Nichols C.E., Hollander J.M. Human and Mouse Type 2 Diabetes Mellitus and the Mitochondrial Proteome: The beginning to therapeutic possibilities. American Association of Pharmaceutical Scientists, Duquesne University. November 2013.

Nichols C.E., Shepherd D.L., Croston T.L., Thapa D., Lewis S.E., Jagannathan R., Yi J., Nurkiewicz T.R., Hollander J.M. Acute Nanoparticle Inhalation Provokes Diastolic Stress and Cardiac Mitochondrial Dysfunction. Appalachian Regional Cell Conference, West Virginia University in Charleston, WV. October 2013. 
Shepherd D.L., Croston T.L., Holden A.A., Tveter K.J., Thapa D., Nichols C.E., Hollander J.M. Human and Mouse Cardiac Dysfunction during Type 2 Diabetes Mellitus: Effects on the mitochondrial proteome. Appalachian Regional Cell Conference, West Virginia University in Charleston, WV. October 2013.

Thapa D., Croston T.L., Shepherd D.L., Nichols C.E., Lewis S.E., Jagannathan R., Hollander J.M. Role of mitofilin in mitochondrial structure and function during a type 1 diabetic insult. Appalachian Regional Cell Conference, West Virginia University in Charleston, WV. October 2013.

Zambito J.L., Nichols C.E., Spooner H.S., Barnes K.M., Hollander J.M. Novel evaluation of equine and murine skeletal muscle mitochondrial function: electron transport chain complex activity and oxygen consumption. Journal of Equine Veterinary Science May 2013 33:5 (326-327)

Shepherd D.L., Croston T.L., Lewis S.E., Nichols C.E., Thapa D., Jagannathan R., Hollander J.M. Hsp27 Phosphorylation and Mitochondrial Translocation: What's the type 1 diabetic story? American Association of Pharmaceutical Scientists, West Virginia University. May 2013. 
Nichols C.E., Shepherd D.L., Croston T.L., Thapa D., Lewis S.E., Jagannathan R., Yi J., Nurkiewicz T.R., Hollander J.M. Nano-Titanium Dioxide Inhalation Exposure induces Cardiac and Spatially-Distinct Mitochondrial Dysfunction. Van Liere Convocation, West Virginia University. March 2013.

Shepherd D.L., Croston T.L., Lewis S.E., Nichols C.E., Thapa D., Jagannathan R., Hollander J.M. Mitochondrial Translocation and Phosphorylation: What's the Hsp27 connection? Van Liere Convocation, West Virginia University. March 2013.

Nichols C.E., Shepherd D.L., Croston T.L., Thapa D., Lewis S.E., Jagannathan R., Yi J., Nurkiewicz T.R., Hollander J.M. Acute Inhalation Exposure of Nano-Titanium Dioxide induces Cardiac and Mitochondrial Dysfunction in Mice. FASEB J. 2013 27:890.9.

Shepherd D.L., Croston T.L., Lewis S.E., Nichols C.E., Thapa D., Jagannathan R., Hollander J.M. Heat Shock Protein 27 (hsp27) Translocation to the Mitochondria is Associated with Protection Against Diabetic Cardiomyopathy. FASEB J. 2013 27:1209.3. 
Jagannathan R., Thapa D., Baseler W.A., Shepherd D.L., Croston T.L., Nichols C.E., Lewis S.E., Hollander J.M. Translational regulation of the mitochondrial genome following redistribution of mitochondrial microRNA (MitomiR) in the diabetic heart. FASEB J. 2013 27:701.10.

Lewis S.E., Dabkowski E.R., Baseler W.A., Shepherd D.L., Croston T.L., Thapa D., Nichols C.E., Hollander J.M. Impact of mitochondria phospholipid hydroperoxide glutathione peroxidase (mPHGPx) overexpression on the type 1 diabetic heart. FASEB J. $201327: 1209.2$.

Thapa D., Jagannathan R., Croston T.L., Baseler W.A., Nichols C.E., Shepherd D.L., Lewis S.E., Hollander J.M. Interaction of mitofilin with respiratory complexes in mitochondrial subpopulations. FASEB J. 2013 27:1126.6.

Croston T.L., Holden A.A., Tveter K., Lewis S.E., Thapa D., Shepherd D.L., Nichols C.E., Jagannathan R., Hollander J.M. Diabetic mouse hearts: a good predictor for the human population? FASEB J. 2013 27:701.9. 
Nichols C.E., Shepherd D.L., Croston T.L., Thapa D., Lewis S.E., Jagannathan R., Yi J., Nurkiewicz T.R., Hollander J.M. Reactive oxygen species induce spatially-distinct mitochondrial dysfunction and diastolic cardiac dysfunction in mice following inhalation exposure to nano-titanium dioxide. AESOT 2013.

Nichols C. E., Dymacek J., Pisane K., Shamitko-Klingensmith N. Does size matter? Connecting materials and biological researchers to understand how nanomaterials interact with life. NSF IGERT Video Competition 2013.

Shepherd D.L., Croston T.L., Lewis S.E., Nichols C.E., Thapa D., Jagannathan R., Hollander J.M. Mitochondrial Translocation and Phosphorylation: What's the Hsp27 connection? Van Liere Convocation, West Virginia University. 2013.

Shepherd D.L., Croston T.L., Lewis S.E., Nichols C.E., Thapa D., Jagannathan R., Hollander J.M. Hsp27 Phosphorylation and Mitochondrial Translocation: What's the type 1 diabetic story? American Association of Pharmaceutical Scientists, West Virginia University. May 2013. 
Nichols C. E., Baseler W.A., Thapa D., LaFata G.L., Croston T.L., Shepherd D.L., Lewis S.L., Knuckles T.L., McCawley M., Hendryx M., Nurkiewicz T.R., Hollander J.M. Effect of mountain-top mining particulate exposure on function and apoptotic propensity of distinct subcellular species of mitochondria. AESOT 2012.

Nichols C. E., Shepherd D.L., Croston T.L., Thapa D, Lewis S.L., Yi J., McBride C., Nurkiewicz T.R., Hollander J.M. Acute inhalation exposure of titanium dioxide nanoparticles induces diastolic dysfunction and mitochondrial dysfunction in mice. AESOT. 2012

Nichols C. E., Baseler W.A., Thapa D., LaFata G.L., Croston T.L., Shepherd D.L., Lewis S.L., Knuckles T.L., McCawley M., Hendryx M., Nurkiewicz T.R., Hollander J.M. Mountain-top mining particulate matter exposure increases markers of mitochondriallydriven apoptosis in rat cardiac tissue. FASEB J. 20127175

Nichols C. E., Baseler W.A., Thapa D., LaFata G.L., Croston T.L., Shepherd D.L., Lewis S.L., Knuckles T.L., McCawley M., Hendryx M., Nurkiewicz T.R., Hollander J.M. Effect of mountain-top mining particulate exposure on mitochondria function and apoptotic propensity. Van Liere Convocation, West Virginia University. 2012 
Shepherd D.L., Croston T.L., Nichols C.E., Baseler W.A., Thapa D., Hollander J.M. Conventional echocardiography and speckle-tracking based strain imaging of the type I diabetic heart. Van Liere Convocation, West Virginia University. 2012

Baseler W.A., Dabkowski E.R., Jagannathan R., Thapa D., Nichols C.E., Shepherd D.L., Croston T.L., Schnell D.M., Hollander J.M. Overexpression of phospholipid hydroperoxide glutathione peroxidase (MPHGPx) attenuates cardiac mitochondrial proteomic loss and reverses protein import detriments observed with type 1 diabetes mellitus. FASEB J. 20126561

Thapa D., Baseler W.A., Jagannathan R., Dabkowski E.R., Croston T.L., Nichols C.E., Shepherd D.L., Lewis S.E., Hollander J.M. miRNA-141 is a potential regulator of the mitochondrial phosphate carrier (slc25a3) in the type 1 diabetic heart. FASEB J. 2012 6563

Croston T.L., Shepherd D.L, Baseler W.A., Dabkowski E.R., Thapa D., Nichols C.E., Jagannathan R., Lewis S.E., Hollander J.M. Examination of cardiolipin biosynthesis in the diabetic heart FASEB J. 2012 26:Ib746. 
Fancher I.S., Baseler W.A., Croston T.L., Thapa D., Shepherd D.L., Nichols C.E., Jagannathan R., Asano S., Lewis S.E., Dick G.M., Hollander J.M. Differential expression of mitoKATP subunits in cardiac mitochondrial subpopulations and the influence of Type I diabetes mellitus. FASEB J. 2012

LaFata G.L., Nichols C. E., Baseler W.A., Thapa D., Knuckles T.L., Nurkiewicz T.R., Hollander J.M. Coal dust exposure increases markers of mitochondrially-driven apoptosis in rat cardiac tissue. WV-INBRE Symposium 2011

Audet G.N., Nichols C.E., Butcher J.T., Frisbee J.C., Olfert I.M. Aging disrupts the balance between positive and negative angiogenic factors in skeletal muscle. FASEB J. 2011 25:Ib557

Stricker J.C., Nichols C.E., Katz A., Fancher I.S., Cuppett T.C., Miletti K., Vasisko C., Dabkowski E.R., Baseler W.A., Hollander J.M., Morissette M.R. Characterization of regression of exercise-induced cardiac hypertrophy. FASEB J 2010 24:Ib593

Nichols C. E., Baseler W.A., Dabkowski E.R., Hollander J.M., Morissette M. R. Characterization of Reverse Remodeling in Physiologic Hypertrophy of the Heart. WVINBRE Symposium 2009 
Nichols C.E., Jackson J.R., Regal S.M., Alway S.E. The effects of an antioxidant cocktail on apoptotic signaling in the soleus muscles of aged hindlimb suspended rats. FASEB J 2009 23:617.6

Nichols C. E., Jackson J. R., Regal S., Ryan M.J., Hao Y., Alway S. E. The Effects of an Antioxidant Cocktail on Apoptotic Signaling in the Soleus muscles of Aged Hindlimb Suspended Rats. WV-INBRE Symposium 2008 


\section{REFERENCES}

1. John Hollander - Mentor, Associate Professor, Director of Graduate Studies, Vice Chair for Research, Division of Exercise Physiology, West Virginia University.

ihollander@hsc.wvu.edu

P.O. Box 92271 Medical Center Drive Morgantown, WV 26506

2. Tim Nurkiewicz - Assistant Professor, Department of Physiology and Pharmacology

tnurkiewicz@hsc.wvu.edu

P.O. Box 92291 Medical Center Drive Morgantown, WV 26506

3. Fred Minnear - Professor of Emeritus (retired June 2015) Formerly Professor of Physiology and Pharmacology, Assistant Vice President for Graduate Education, and Director of Program in Clinical Research, Mentoring, and Career Development for the West Virginia Clinical and Translational Science Institute

fminnear@hsc.wvu.edu

678 Southview St. Morgantown, WV 26505 